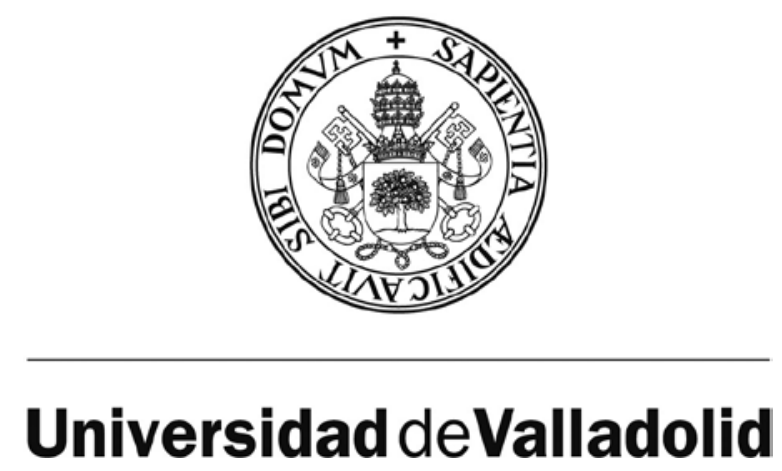

ESCUELA TÉCNICA SUPERIOR DE INGENIRÍAS AGRARÍAS

INGENIERÍA AGROFORESTAL

TESIS DOCTORAL:

\title{
EXTRUDED FLOURS: APPLICATIONS AND NEW FUNCTIONALITY
}

Presentada por Mario Martínez Martínez para optar al grado de Doctor por la Universidad de Valladolid

Dirigida por:

Manuel Gómez Pallarés 


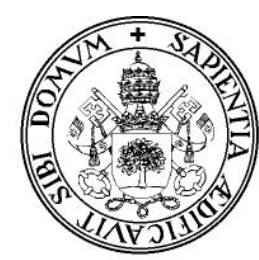

\section{Universidad deValladolid}

D. Manuel Gómez Pallarés, Catedrático de la Universidad de Valladolid

HACEN CONSTAR QUE:

el trabajo de investigación titulado "Extruded flours: applications and new functionality" que presenta D. Mario Martínez Martínez para optar al grado de Doctor por la Universidad de Valladolid, ha sido realizada bajo su dirección en La Escuela Técnica Superior de Ingenierías Agrarias de Palencia y que reúne las condiciones para ser defendida por su autor y optar al grado Doctor Internacional.

Palencia, noviembre de 2015

Fdo: Manuel Gómez Pallarés 


\section{Resumen}

El trigo, el arroz y el maíz, y especialmente su parte almidonosa, son una parte importante de la dieta humana. El almidón puede ser degradado a glucosa, la cual es una fuente de energía importante para el cuerpo humano. Además, el almidón de estas harinas interesa por su efecto sobre las propiedades físicas de muchos de nuestros alimentos. Sin embargo, la innovación continua en materiales alimenticios y sus nuevos requisitos de calidad están forzando a adaptar aquellas materias primas a las necesidades emergentes en términos de funcionalidad y nutrición. Ésta modificación llevada a cabo mediante tratamientos hidrotérmicos están ganando protagonismo, debido, entre otras cosas, a la ausencia de ingredientes químicos o artificiales. Entre estos tratamientos, la extrusión es una de las alternativas más versátiles para lograr la gelatinización del almidón industrialmente.

El primer objetivo de ésta tesis doctoral consistió en el estudio de la influencia de diferentes condiciones de extrusión (temperatura del extrusor, velocidad de alimentación y cantidad de agua añadida) sobre las propiedades fisicoquímicas y digestivas de harinas con gluten (trigo) y sin gluten (arroz). Un incremento en la intensidad de la extrusión provocó una mayor cantidad de almidón gelatinizado. Éste almidón gelatinizado tuvo una gran capacidad de absorción de agua, incrementando significativamente las propiedades de hidratación de las harinas (llegando incluso a multiplicar por 5 y por 9 la capacidad de absorción de agua y el poder de hinchamiento, respectivamente). Ésta capacidad de hidratación conduce a un alto poder espesante en frío, lo cual puede ser muy interesante para algunas aplicaciones alimenticias. Además, se incrementó la susceptibilidad a la hidrólisis, indicando que estas harinas podrían ser buenas materias primas para la industria almidonera en la producción de glucosa y maltosa. Sin embargo, ésta ata susceptibilidad también afectó negativamente las propiedades de digestión del almidón, disminuyendo la cantidad de almidón resistente (RS) a medida que se incrementaba la intensidad de la extrusión tanto en las harinas extruidas de trigo como de arroz.

Las diferentes propiedades fisicoquímicas de las harinas extruidas fueron explotadas para estudiar su en productos intermedios durante el procesado, tales como batidos para posterior rebozado, cuyos parámetros más cruciales son su viscosidad y las propiedades reológicas. La sustitución de harina de trigo nativa por harina de trigo extrusionada extrusionada incrementó el índice de consistencia y la pseudoplasticidad de los batidos, indicando un importante incremento de la viscosidad aparente de los batidos. Aquellos cambios fueron atribuidos a la disminución del contenido en agua, a consecuencia de la alta capacidad de absorción de agua del almidón gelatinizado, así como al desplegamiento proteico en las harinas extruidas. Los resultados sugirieron que un 15\% de sustitución de harina de trigo por harina de trigo sometida a diferentes tratamientos de extrusión ofrecería batidos con diferentes viscosidades y propiedades viscoelásticas incrementando así la variedad de batidos para posterior rebozado disponible en el mercado.

\footnotetext{
Mario Martínez Martínez

Extruded flours: Applications and new functionality
} 
Algunas harinas nativas y extruidas pueden incluso necesitar de una suplementación adicional con otros ingredientes y aditivos para su uso en ciertos productos. De éste modo, harinas de trigo nativas y extruidas fueron combinadas con agares (Gracilaria and Gelidium) y carragenatos (k-carragenato y i-carragenato), los hidrocoloides marinos más comúnmente usados en la industria alimentaria, para modificar las propiedades de sus pastas y geles. Las propiedades de viscosidad en ciclos de calentamiento/enfriamiento de las combinaciones con harina nativa mostraron que cualquiera de los hidrocoloides produjo un incremento del pico de viscosidad (especialmente agar de Gelidium), pero solamente los agares disminuyeron el inicio de la temperatura de pastosidad e incrementaron la caída de viscosidad (Breakdown), indicando por lo tanto un mecanismo de acción diferente entre los diferentes hidrocoloides. En general, los carragenatos, además de producir pastas más rígidas y estables, dieron lugar a geles más duros y claros en comparación con aquellos hechos con agar, tanto en sus combinaciones con harina nativa o extrusionada. Por su parte, pastas hechas con combinaciones de harinas extrusionadas y agar mostraron una mayor tixotropía, la cual podría ser beneficiosa en la fabricación de salsas.

El efecto de la adición de harina sometida a diferentes condiciones de extrusión sobre la calidad de panes con y sin gluten también fue estudiado. En panes de trigo, los resultados sugirieron que es posible obtener una masa y unos panes adecuados usando masas con un 5\% de harina de trigo extruida. La adición de un 5\% de ésta harina permite incrementar la cantidad de agua en la formulación, incrementando paralelamente ésta cantidad con las intensidad de la extrusión de esas harinas. De éste modo se incrementó el rendimiento productivo. En panes sin gluten, la sustitución de un 10\% de harina de arroz por harina de arroz extruida también incrementó el rendimiento productivo. Sin embargo, su adición también redujo el volumen específico de los panes y su dureza. No obstante, estos efectos fueron minimizados usando una harina gruesa, lo que también redujo el endurecimiento del pan. En otro estudio para retrasar el endurecimiento de panes sin gluten, la adición de lipasa y harina extrusionada incrementó el volumen del pan y redujo la dureza inicial y el endurecimiento del pan.

Con el objetivo de explotar la alta susceptibilidad de las harinas extruidas a la catálisis enzimática, se estudió la influencia de una amilolisis con $\alpha$-amilasa y glucoamilasa sobre harinas de trigo nativas y extruidas. Se lograron unos incrementos de un 300\% y un $500 \%$ respectivamente del contenido en glucosa y maltosa en harinas extruidas comparadas con sus equivalentes nativos. Así, los resultados sugirieron que las harinas extruidas son buenos sustratos para la flora fermentativa y los principales reactantes que participan en las reacciones de Maillard y las reacciones térmicas de caramelización.

Desde un punto de vista nutricional, aquella alta susceptibilidad a la hidrólisis enzimática también incrementa la acción de la $\alpha$-amilasa pancreática, empeorando las propiedades digestivas de esas harinas. De éste modo, se estudiaron las enzimas branching enzyme (B) y $\alpha$-amilasa maltogénica (MA) con el fin de atenuar las propiedades de digestión del 
almidón de las harinas de maíz extruidas. El tratamiento enzimático en sí mismo afectó a la formación de estructuras supramoleculares resistentes, incrementando: 1) las cadenas largas de amilosa susceptibles de retrogradar; 2) el nivel de ordenamiento molecular de pequeño orden, típico de un ordenamiento conformacional de las cadenas laterales de amilosa o amilopectina; 3) y los complejos amilo-lipídicos. En concreto, la combinación de B y MA sobre las harinas extruidas incrementó: 1) el número de ramificaciones y la relación cadenas cortas/cadenas largas en la amilopectina, asociadas con almidón lentamente digestible; 2) y la cantidad de panosa y isomaltosa, catalogados como prebióticos. 


\section{Abstract}

Among cereals, wheat, rice and maize, and especially their starchy fraction, are an important part of the human diet. Starch can be degraded to glucose, which provides the body with an important source of energy. In addition, starch from these flours is important because of its effect on the physical properties of many of our foods. However, continuous innovation in foodstuff and their higher quality requirements force to adapt those commodities to the emerging needs in terms of functionality and nutrition. The modification of the functionality of starchy ingredients by hydrothermal treatments is becoming of great interest, among other things due to absence of artificial ingredients and chemicals. Among those treatments, extrusion is one of the most versatile alternatives to industrially achieved starch gelatinization.

The first objective of this doctoral thesis consisted on the study of the influence of the different extrusion conditions (barrel temperature, feed rate and fed moisture content) on the physicochemical and digestive properties of gluten-containing (wheat) and gluten-free (rice) flours. An increase in the extrusion severity caused a higher amount of gelatinized starch. This gelatinised starch had a great water absorption capacity, enhancing significantly the hydration properties of flours (5-fold water binding capacity and 9-fold swelling compared with untreated wheat flour). This hydration ability leads to higher viscosity in cold solution, which might be very interesting for some food applications. Added to that, the susceptibility to enzymatic hydrolysis increased, which could indicate that these flours can be good raw materials for the starch conversion industry for the production of maltose or glucose. Nevertheless, this high susceptibility also affected negatively the starch digestion properties, decreasing the amount of resistant starch (RS) as the extrusion severity increased in both rice and wheat extruded flours.

The different physicochemical properties of extruded flours were exploited to study the effect of their incorporation in intermediate products during processing, such as batters for coating, whose most crucial parameters is their viscosity and rheological properties. Extruded flour substitution increased the consistency coefficient and pseudoplasticity of batters, indicating an important increase of the apparent viscosity of the batters. Those changes were attributed to the diminution of the water content as a consequence of the high water absorption capacity of gelatinised starch and of unfolded proteins of extruded flour. Results suggested that a $15 \%$ of wheat flour replacement by wheat flour subjected to different extrusion treatments would offer batters with different viscosities and viscoelastic properties increasing the range of batters coatings available in the market.

Sometimes native or extruded flours can need further supplementation with other ingredients or additives, for their use in certain products. In this way, extruded and native wheat flours were combined with agars (Gracilaria and Gelidium) and carrageenans (kcarrageenan and i-carrageenan), the marine hydrocolloids most commonly used in the 
food industry, to modify their paste and gel properties. Pasting properties of native flours combinations showed that all hydrocolloids produced an increase in peak viscosity (particularly Gelidium agar), but only agars decreased the onset temperature of gelatinization and increased breakdown, indicating a different mechanism of action. In general, carrageenans, besides producing stiffer and more stable pastes, gave rise to harder and clearer gels compared to those made with agar, for both their combination with extruded and native wheat flours. Meanwhile, pastes made with combinations of extruded flours and agar showed higher thixotropy, which could be beneficial when making of sauces.

The effect of the addition of extruded flour subjected to different extrusion conditions on gluten containing and gluten-free breads was also investigated. In wheat breads, results suggested that it is possible to obtain adequate dough and bread characteristics using dough with $5 \%$ extruded wheat flour. The addition of $5 \%$ extruded wheat flour allows the quantity of water in the formulation to be increased; the more intense the extrusion treatment, the greater the increase in the quantity of water that can be added, increasing the bread output. In gluten-free breads, the substitution of $10 \%$ of rice flour by extruded rice flour also increased the bakery yield. However, their addition also reduced the specific volume of breads and increased hardness. Nevertheless, these effects were minimized by using the coarse flour fractions, which also reduced the rate of staling. In another study to delay the bread staling in gluten-free breads, the addition of lipase and extruded flour increased bread volume and reduced the initial firmness and hardening of breads.

With the aim of exploiting the high susceptibility of extruded flours to the enzyme catalysis, the influence of an enzymatic amylolysis with $\alpha$-amylase and glucoamylase on native and extruded wheat flours was studied. 300\% and 500\% increases of glucose and maltose contents, respectively, in extruded flours compared with their native counterparts were achieved. Thereby, results suggested that extruded flours are good substrates for fermentative microflora and the main reactants that participate in Maillard and caramelisation thermal reactions.

From a nutritional point of view, that high susceptibility to the enzymatic hydrolysis also increases the action of the pancreatic $\alpha$-amylase, declining the digestion properties of those flours. In this way, branching enzyme (B) and maltogenic $\alpha$-amylase (MA) were studied to attenuate the starch digestion properties of maize extruded flours. The enzymatic treatment itself affected the formation of resistant supramolecular structures on extruded flours by increasing: 1) the long linear amylose chains susceptible to retrograde; 2) the level of short-range molecular order, typical from conformational ordering of amylose or amylopectin side chains; 3) and the amylose-lipid complexes. In particular, the combination of B and MA on extruded flours increased: 1) the number of branching points and the ratio of short chains to longer chains in amylopectin, associated 
with slowly digestible starch; 2) and the amount of panose and isomaltotriose, categorized as prebiotic. 


\section{Contents}

Acknowledgments

Summary

1. Introduction 1

1. Starch 2

1.1. Cereal grains

1.2. Granular structure of starch from cereals

1.3. Molecular and supramolecular organization within the starch granule

1.3.1. Differential scanning calorimetry studies

\subsubsection{Crystallinity}

1.4. Starch gelatinization and cooking. Pasting and swelling properties

1.5. Gelatinization and retrogradation

1.6. Interactions with other hydrocolloids

2. Physical treatments

2.1. Particle size classification

2.2. Thermal treatments. Extrusion

3. Starch active enzymes. The $\alpha$-amylase family of enzymes

3.1. Endo-acting $\alpha$-hydrolases

3.1.1. Catalytic action

3.1.2. Brief insight of the industrial applications

3.1.2.1. Application of endo-acting hydrolases in the conversion of starch hydrolysates

3.1.2.2. Application of endo-acting hydrolases in baking products

3.2. Exo-acting hydrolases

3.2.1. Exo-acting $\beta$-hydrolases. Glucoamylase

3.2.2. Exo-acting $\alpha$-hydrolases. Maltogenic $\alpha$-amylase

3.2.3. Brief insight of the industrial applications of exo-acting hydrolases

3.2.3.1. Application of exo-acting hydrolases in the conversion of starch hydrolysates 
3.2.3.2. Application of exo-acting hydrolases in baking products

3.3. Branching enzymes (BEs)

3.3.1. Catalytic action

3.3.2. Applications of branching enzymes (BEs)

2. Objectives

3. Structure

4. Section 1: Physicochemical characterization and digestive properties of different flours according to the extrusion conditions

4. 1. Modification of wheat flour functionality and digestibility through different extrusion conditions

4. 2. Effect of different extrusion treatments and particle size distribution on the physicochemical properties of rice flour

5. Section 2: Effect of extruded flours on intermediate products during processing: pastes, gels and batters

5.1. Influence of marine hydrocolloids on extruded and native wheat flour pastes and gels

5.2. Influence of wheat flour subjected to different extrusion conditions on the rheological behaviour and thermal properties of batter systems for coating

6. Section 3: Effect of extruded flours on final products: gluten containing and glutenfree breads

6.1. Effect of the addition of extruded wheat flours on dough rheology and bread quality

6.2. Influence of the addition of extruded flours on rice bread quality

6.3. Texture development in gluten-free breads: effect of different enzymes and extruded flour

7. Section 4: Taking advantage of the high chemical reactivity of extruded flours towards enzyme catalysis

7.1. Physicochemical modification of native and extruded wheat flours by enzymatic amylolysis 
7.2. Synergistic maltogenic $\alpha$-amylase and branching treatment to produce enzyme-resistant molecular and supramolecular structures in extruded maize matrices

8. Discussion of the results and final remarks

9. Conclusions 


\section{Introduction}

Members of the grass family (Gramineae), in which cereal grains are included, produce dry and one-seeded fruits. This type of fruit is commonly called a "kernel" or "grain." However, strictly speaking, it is a caryopsis. Among cereals, wheat, rice and maize are the most extensively cultivated all over the world (FAOSTAT, 2013).

Wheat is the most versatile cereal due to the capacity of its storage proteins to interact and develop the gluten network, which forms the basic framework of many bakery products. Because there is a deep crease in the kernel, flour is extracted by a sequence of breaking, sieving, and size-reducing processes, known as the milling process. This process makes it possible to contemporaneously separate the bran and germ regions and to break the endosperm cells into a very fine product, suitable for rapid hydration and gluten development. Milling yield and flour refinement are closely related both to the milling conditions and the variety of wheat used. The latter highly influences the technological performance of the flour (measured by several instrument tests) and bread characteristics. As well as refined flours, increasing attention is being given to whole wheat flours that include the bran and germ fractions, which are presently considered to be by-products despite their richness in several bioactive compounds (Zhou, et al., 2014).

Rice is one of the most consumed cereals. Even today, rice grains sustain two thirds of the world's population, although their contribution is different in the developing and developed countries. For instance, rice is the staple food for the Chinese and also for $65 \%$ of the total population in India. Rice is primarily consumed as milled rice. However, there are also a number of products where rice is added as an ingredient, conferring creaminess, crunchiness, and firmness. Among all the processed rice-based products that are being launched, bakery products have received special attention. Nowadays, more people are attracted to wheat-free foods because of health concerns or to avoid wheat in the diet. Moreover, rice-based products have been the solution for consumers with allergenic problems (Zhou, et al., 2014).

Maize, also known as corn, is a major cereal grown throughout the world, and approximately 800 million tons of maize is produced worldwide, accounting for $35 \%$ of the total cereal production and $32 \%$ of the total area harvested for the year 2010. Maize provides $15 \%$ of total calories and protein, and $7 \%$ of fat in Africa. More than $50 \%$ of total maize is produced in America (Zhou, et al., 2014).

In general, wheat, rice and maize grains are formed by the same parts and they are in approximately the same relationship to each other. Their caryopses develop within floral envelopes, which are actually modified leaves. These are called the "chaffy parts" or "glumes." In rice, the floral envelopes cover the caryopsis so closely and completely that they remain attached to the caryopsis when the grain is threshed and constitute the hull of those grains. In wheat and maize, the grain and hull separate readily during threshing, 
and the grains are said to be "naked" (i.e., to have an uncovered caryopsis). The structure of these industrially important cereal grains is important for many aspects of cereal technology, e.g., for milling of common wheat or durum wheat or for processing of maize or rice. However, it is important to highlight the high content of starch, which is around 60 and $75 \%$ of the weight of the grain. Cereal grains are an important part of the human diet, as much of the food that humans consume is in the form of starch. Starch is a major constituent of many food products, including bread, breakfast cereals, cooked rice, pasta, sauces, etc. Starch can be degraded to glucose, which provides the body with an important source of energy. In addition, starch is important because of its effect on the physical properties of many of our foods. For example, the gelling of puddings, the thickening of gravies, the structure of bread crumb and its staling, the structure of a crisp continuous, uniform layer over the food substrate, constituting its final outer coating and the setting of cakes are all strongly influenced by the properties of starch. Starch is also converted industrially into starch syrups, which are used as sweeteners in food and soft drinks as well as in several fermentation processes. Therefore, understanding the starch and its modifications will be crucial to elucidate the flour properties from cereal kernels (Delcour and Hoseney, 2010).

In this introduction, the molecular, supramolecular and granular starch structures and properties will be described to later understand their modifications when they are subjected to physical and enzymatic treatments. Subsequently, the effect of physical treatments, and in particular extrusion, on starch structure and functionality will be approached. To conclude, due to the higher susceptibility to the enzyme catalysis of extruded flours, different members of the $\alpha$-amylase family of enzymes will be described considering their catalytic activity towards starch of flours.

\section{$\underline{1 . \text { Starch }}$}

\subsection{Cereal grains}

Transitory starch is produced by photosynthesis in green leaves of cereal grains. Shortly after production, it is degraded to sucrose and, in the case of cereals and legumes, transported to seeds, where it is laid down in the endosperm tissue as water-insoluble granules that serve as the plant's main storage carbohydrate. The amyloplasts, which synthesize the starch, possess all the enzymes necessary for granule formation. The level of starch in a cereal grain varies but is generally between 60 and $75 \%$ of the weight of the grain (Delcour and Hoseney, 2010).

\subsection{Granular structure of starch from cereals}

In cereals and other higher plants, starch granules are formed in amyloplasts. In the cereals with simple starch granules, such as wheat and maize, each amyloplast contains one granule (Delcour and Hoseney, 2010). In rice, which has compound starch granules, many granules are found in each amyloplast (Table 1). 
Table 1. Properties of wheat, rice and maize starches

\begin{tabular}{|c|c|c|c|}
\hline $\begin{array}{c}\text { Source of } \\
\text { starch }\end{array}$ & $\begin{array}{c}\text { Gelatinization } \\
\text { temperature range }\left({ }^{\circ} \mathrm{C}\right)\end{array}$ & $\begin{array}{l}\text { Granule } \\
\text { Shape }\end{array}$ & $\begin{array}{c}\text { Granule size } \\
(\mu \mathrm{m})\end{array}$ \\
\hline \multirow{2}{*}{ Wheat } & \multirow{2}{*}{$51-60$} & Lenticular & 20 to 35 \\
\hline & & Round & 2 to 6 \\
\hline Rice & $68-78$ & Polygonal & 3 to 8 \\
\hline \multirow{2}{*}{ Maize } & \multirow{2}{*}{$62-72$} & Round & \\
\hline & & Polyhedral & 15 \\
\hline
\end{tabular}

Wheat, has two types and sizes of starch granules, as shown in Figure 1. The large, lenticular (lens-shaped) granules are $25-40 \mu \mathrm{m}$ in the long dimension; the small, spherical granules are $5-10 \mu \mathrm{m}$ in diameter. Figure 2 shows a scanning electron micrograph of isolated wheat starch granules.

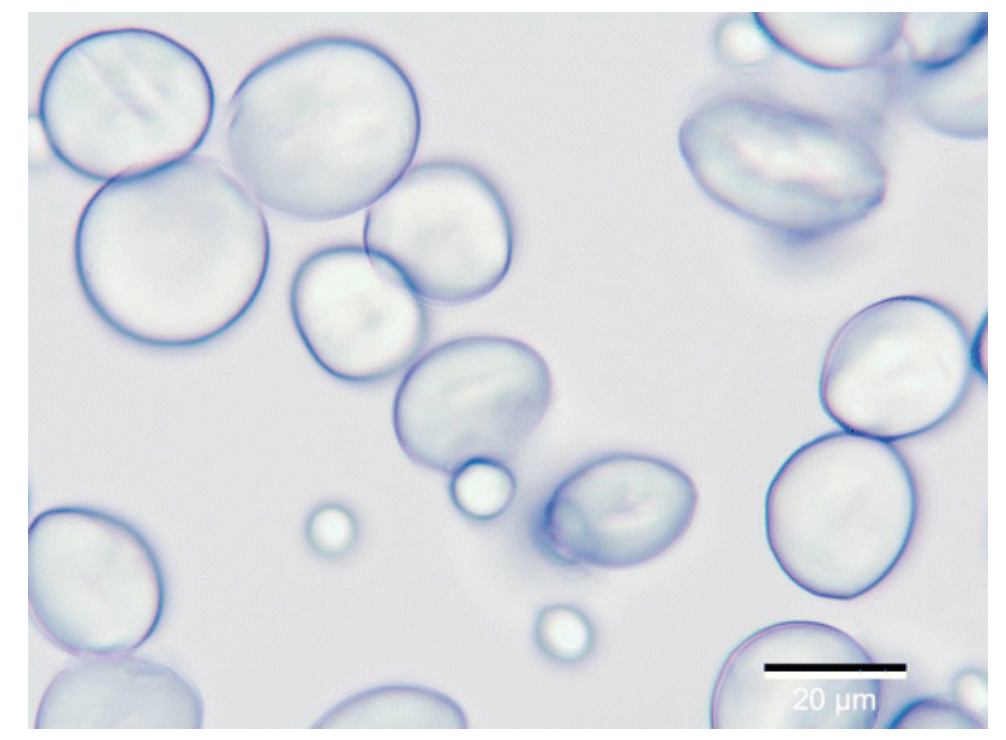

Figure 1. Light photomicrograph of wheat starch granules, showing large lenticular and small spherical granules. Bar is $20 \mu \mathrm{m}$. (Delcour and Hoseney, 2010) 


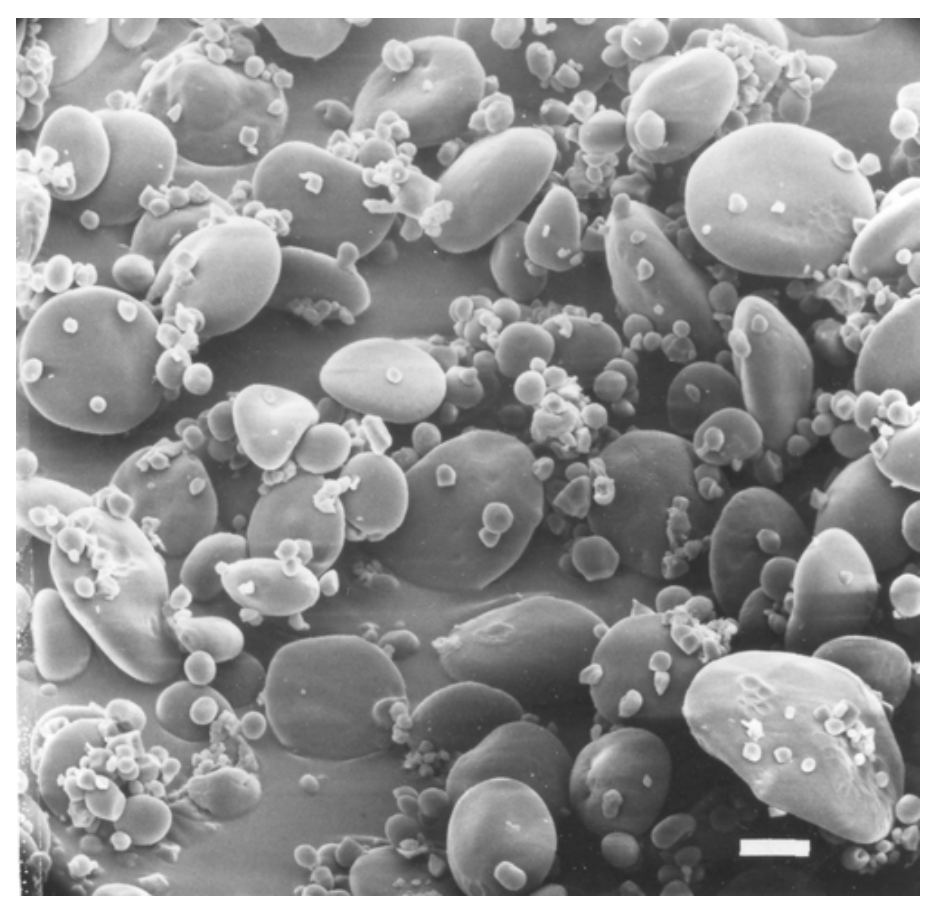

Figure 2. Scanning electron photomicrograph of isolated wheat starch granules. Bar is $10 \mu \mathrm{m}$ (Delcour and Hoseney, 2010).

The starch granules of maize are similar to each other in size and shape (Delcour and Hoseney, 2010). They average about $20 \mu \mathrm{m}$ in diameter, as shown in a light micrograph of maize starch (Figure 3), and their shape varies from polygonal to almost spherical, also shown by scanning electron microscopy (Figure 4). As far as it is known, the properties of the differently shaped granules are the same.

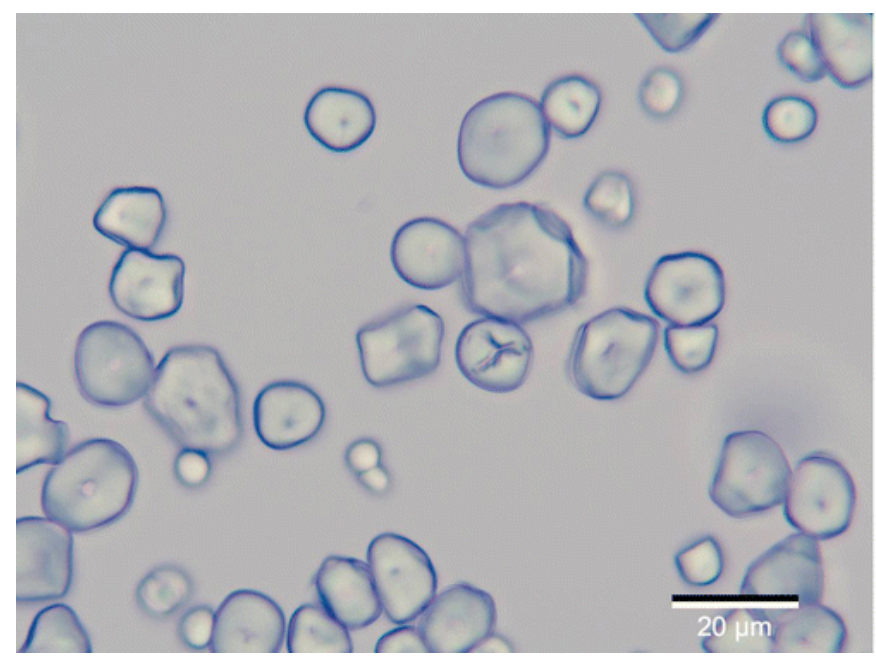

Figure 3. Light photomicrograph of isolated maize starch granules. Bar is $20 \mu \mathrm{m}$. (Delcour and Hoseney, 2010) 


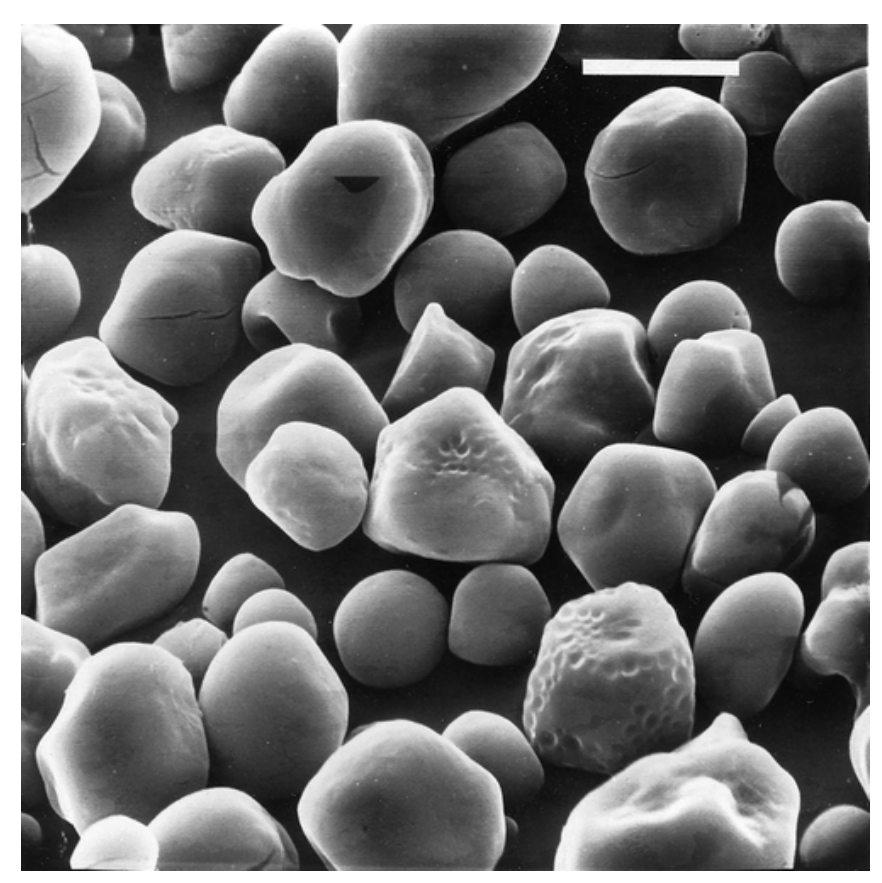

Figure 4. Scanning electron photomicrograph of isolated maize starch granules. Bar is $10 \mu \mathrm{m}$. (Delcour and Hoseney, 2010)

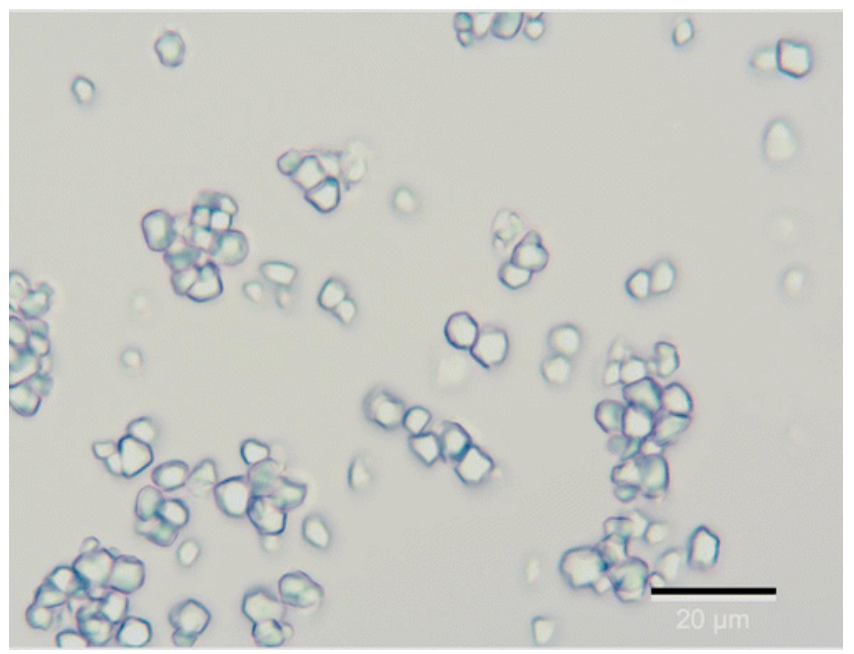

Figure 5. Light photomicrograph of isolated rice starch granules. Bar is $20 \mu \mathrm{m}$. (Delcour and Hoseney, 2010)

Individual starch granules of rice are similar to each other in that they are small $(2-5 \mu \mathrm{m})$, are polygonal in shape, and occur in the grain as compound granules (Delcour and Hoseney, 2010). Figure 5 shows isolated individual rice starch granules.

These different sizes and shapes influence the surface to volume ratio, important factor to take into account with a view to physical and enzymatic modifications.

\subsection{Molecular and supramolecular organization within the starch granule}

Starch is a polymer of glucoses linked through the $\mathrm{C}_{1}$ oxygen, known as the glycosidic bond. This bond is stable at high $\mathrm{pH}$ but is hydrolysed at low $\mathrm{pH}$. At the end of the 
polymeric chain, a latent aldehyde group is present, known as the reducing end. Starch is formed by two types of glucose polymers, amylose (Figure 6) and amylopectin (Figure 7). Amylose is a linear polymer consisting of up to 6000 glucose units with $\alpha, 1-4$ glycosidic bonds. The number of glucose residues varies with the origin. Amylose from, e.g. potato or tapioca starch has a degree of polymerization (DP) of 1000-6000, while amylose from maize or wheat has a DP varying between 200 and 1200 . The average amylose content in starches can vary between almost 0 to $75 \%$, but a typical value is $20-25 \%$.

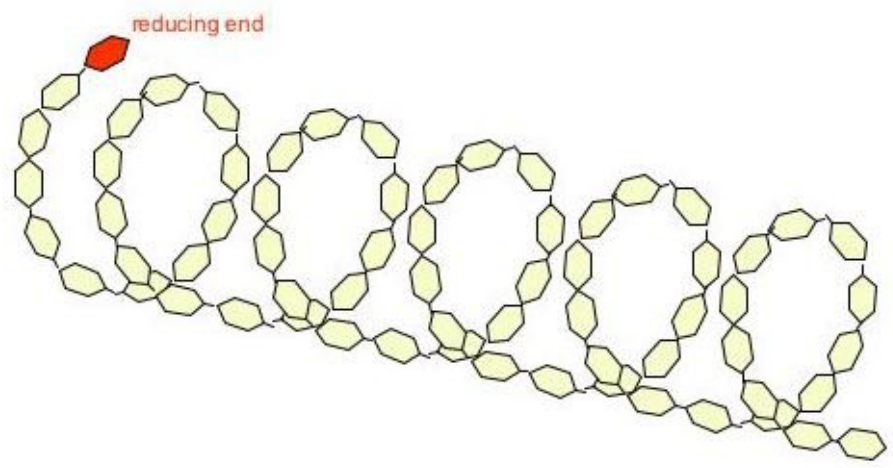

Figure 6. Depiction of an amylose helix

Amylopectin consists of short $\alpha, 1-4$ linked linear chains of 10-60 glucose units and $\alpha, 1-6$ linked side chains with 15-45 glucose units. The average number of branching points ( $\alpha, 1-6$ linkages) in amylopectin is $5 \%$, but varies with the botanical origin. The complete amylopectin molecule contains on average about 2,000,000 glucose units, therefore being one of the largest molecules in nature. The most commonly accepted model of the structure of amylopectin is the cluster model (Figure 7), in which the side chains are ordered in clusters on the longer backbone chains (Buleón et al. 1998, Myers et al. 2000).

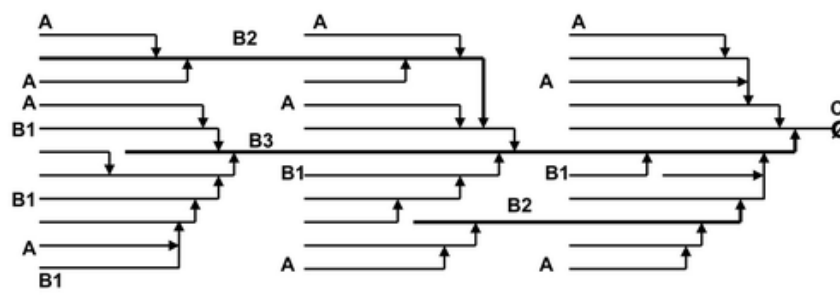

Figure 7. Cluster structure of amylopectin, with indication of $\mathrm{A}, \mathrm{B}$, and $\mathrm{C}$ chains and illustration of crystalline and amorphous lamellae. The solid lines represent $\alpha$-1,4-linked glucose units; arrows indicate $\alpha-1,6$ linkages. The only chain carrying a reducing end $(\varnothing)$ is the $\mathrm{C}$ chain. The external chains are A chains. B1 chains expand over one cluster only, while B2 and B3 chains expand over two and three clusters, respectively. (Delcour and Hoseney, 2010) 
Starch granules have a complex hierarchical structure, which can be described by at least four levels of organization (i.e., molecular, lamellae, growth ring, and granular levels), ranging in length scale from nanometer to micrometer (Figure 8). Several detailed comprehensive reviews on the heterogeneous organized structures of granular starch have been published (Oates 1997, Tester et al. 2004, Jane 2006, Le Corre et al. 2010). In tuber and root starches, the crystalline regions are solely composed of amylopectin, while the amylose is present in the amorphous regions. In cereal starches, the amylopectin is also the most important component of the crystalline regions, but certain amounts of amylose are also found. The amylose in cereal starches is complexed with lipids that form a weak crystalline structure. and reinforce the granule. While amylopectin is soluble in water, amylose and the starch granule itself are insoluble in cold water. This makes it relatively easy to extract starch granules from their plant source.

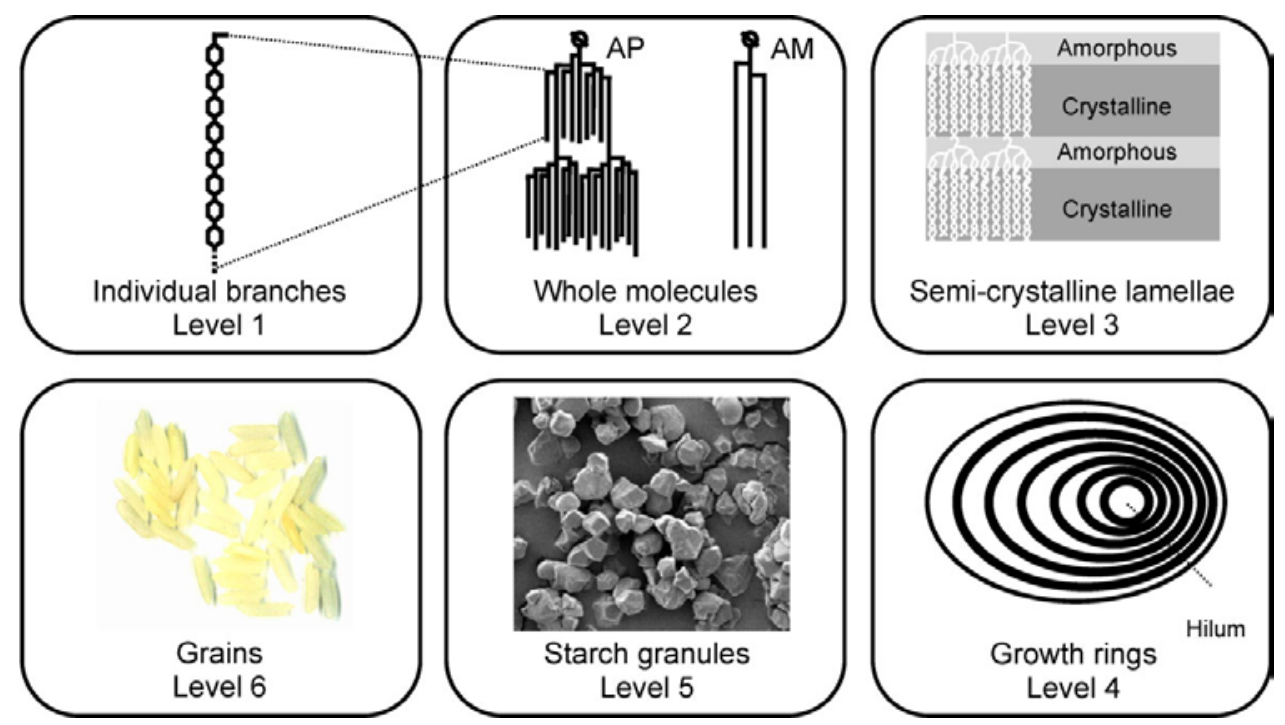

Figure 8. Six levels of starch structures in cereal grains (Tran, et al., 2011).

In order to have a better insight of the supramolecular structures of starch, differential scanning calorimetry and the analysis of the crystalline polymorphism through X-Ray diffraction can be performed.

\subsubsection{Differential scanning calorimetry studies}

DSC instrumentation is useful for following gelatinization, retrogradation, and crystallization of starch polymers. It can measure the enthalpies (heat flows) associated with melting of both crystalline amylose and amylopectin (melting temperatures of about $150^{\circ} \mathrm{C}$ and $50-60^{\circ} \mathrm{C}$, respectively), as well as the dissociation and melting enthalpies of amylose-lipid complexes. 
When starch is heated in excess water (water-starch, 2:1) in a DSC instrument, a sharp endothermic peak is obtained (Figure 9A). The start of the peak (where it deviates from the base line) corresponds to the start of birefringence loss. The area under the curve is a measure of the energy (enthalpy, $\Delta \mathrm{H}$ ) required for the transition from an ordered to a disordered state (crystalline to melted state) (Biliaderis, 2009).

As the amount of water in the sample is reduced, the DSC peak widens and becomes clearly bimodal (Fig. 9B). At low water contents (water-starch, 0.35:1), the loss of birefringence, as reflected by the endothermic peak in the DSC thermogram, occurs over a temperature range of more than $30^{\circ} \mathrm{C}$ (Fig. 9F). The slow loss of birefringence can also be seen directly in light photomicrographs. The amount of water above $30 \%$ available to the starch does not affect the temperature at which birefringence starts to disappear, but it does greatly affect the completion of the process (Biliaderis, 2009).

Several views on the impact of moisture content on DSC enthalpic transitions have been formulated. One of these maintains that, initially, water enters in the more-accessible, amorphous regions of the starch granules. Swelling of the amorphous regions induces stress on the crystallites, and starch chains are stripped from the surface of crystallites, thereby reducing the crystallinity and causing the loss of birefringence of the starch granules. In excess water, the degree of swelling is sufficient to completely gelatinize the granule. At lower water levels, swelling is insufficient to completely disrupt the starch granule. The remaining order is then disrupted at higher temperatures by a conventional melting transition. At very low moisture contents ( $<30 \%$, based on starch), only the latter process takes place. 


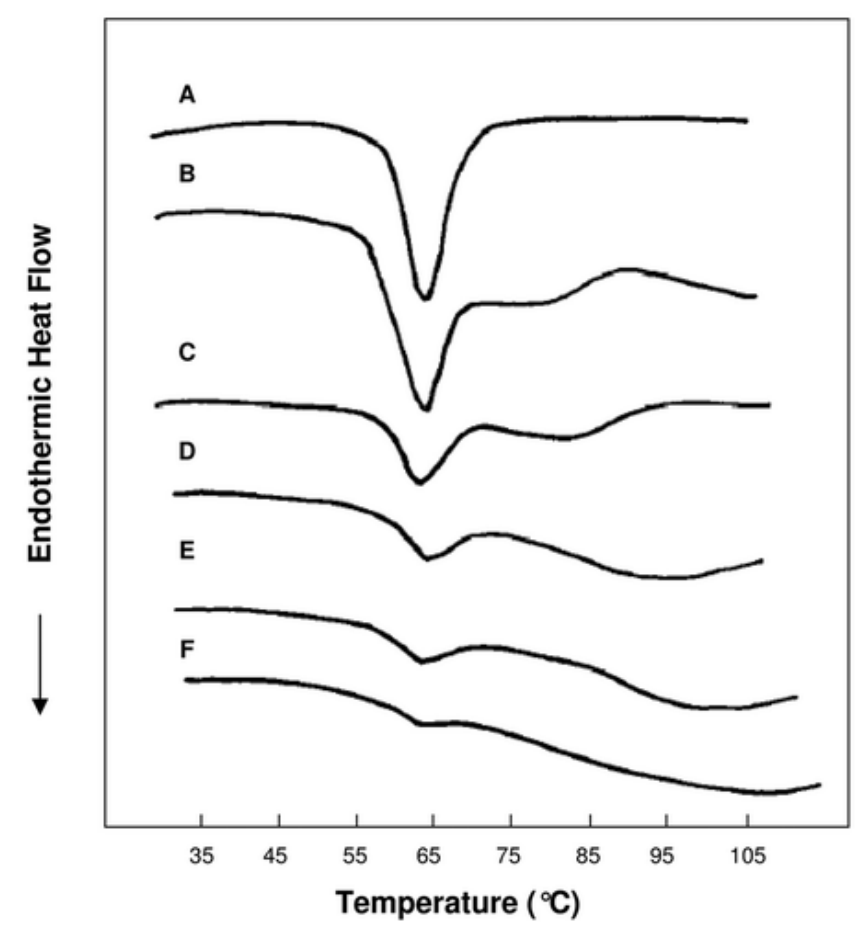

Figure 9. Differential scanning calorimeter thermograms of wheat starch heated with water-to-starch ratios of 2.0 (A), 1.0 (B), 0.75 (C), 0.5 (D), 0.44 (E), and 0.35 (F). (Delcour and Hoseney, 2010)

\subsubsection{Crystallinity}

That starch is a semicrystalline material has been clear since 1930s. Intact starch granules of different botanical origins give three types of X-ray patterns (designated A, B, and C) (Biliaderis, 2009). Most cereal starches give A patterns (Fig. 10). Potato, other root starches, and retrograded starch give $\mathrm{B}$ patterns, while smooth pea and bean starches give $\mathrm{C}$ patterns. The $\mathrm{C}$ pattern is an intermediate form, probably a mixture of the $\mathrm{A}$ and $\mathrm{B}$ types. The A-type unit cell has 12 glucose residues and four water molecules, which are buried deep in the crystalline structure and cannot be removed without complete destruction of that structure. The B polymorph has 12 glucose residues and 36 water molecules, which are located in a channel surrounded by six double helices and hydrogen-bonded to glucose residues and/or other water molecules; hence, they cannot move freely in the channel. The B pattern of potato starch can be converted to an A pattern by heat-moisture treatments (Biliaderis, 2009). 


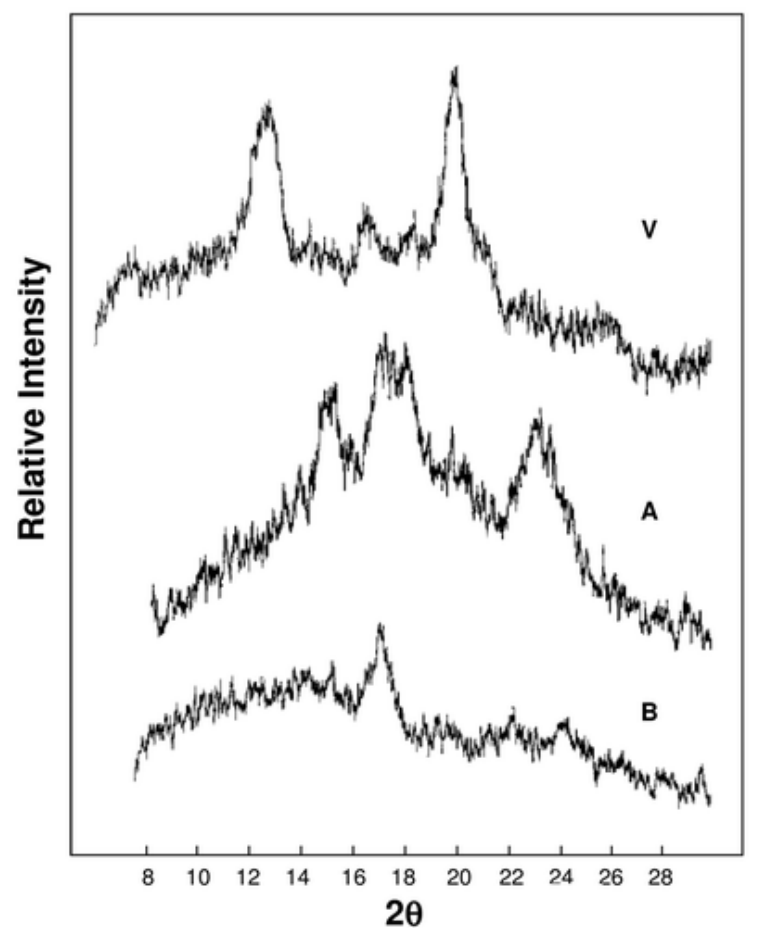

Figure 10. X-ray diffraction patterns of starch, showing the A, B, and V patterns (Delcour and Hoseney, 2010).

The fact that selective leaching of amylose from granular starch increases its crystallinity implies that amylopectin structural elements have a predominant role in imparting crystallinity to starch. It is now accepted that, for starches with regular or low amylose contents, short external amylopectin chains intertwine to form double helices. It is equally accepted that double helices belonging to the same cluster are arranged such that either the A or B crystalline unit cell is formed. Individual crystallites are thought to be aligned in high-density "crystalline" lamellae, while amylopectin branching points reside in the low-density "amorphous" lamellae (Fig. 7). Hence, it is accepted that the amylopectin fraction of starch accounts for (most of) the granular crystallinity. In line with this, variations in chain length distribution among amylopectins are accompanied by differences in the prevailing crystalline polymorph of the starch (A-type or B-type polymorph, see above). Moreover, it has recently been established that, on top of the differences in chain length distribution, starches bearing A- and B-type crystallites may also show a different branching pattern. X-ray diffraction of crystalline amylose helical inclusion compounds results in the V pattern (Fig. 10). Such patterns can be found after gelatinization and complexing with lipid or related compounds (Biliaderis, 2009).

\subsection{Starch gelatinization and cooking. Pasting and swelling properties}

When starch is heated in excess of water, the granules first swell until a point is reached at which the swelling is irreversible. This swelling process is termed gelatinization. During this process, amylose leaches out of the granule and causes an increase in the viscosity of the starch-slurry. Further increase in temperature leads to maximum swelling of the 
granules and increases viscosity. Finally, the granules break causing a complete viscous colloidal dispersion, resulting in a decrease of the viscosity. Subsequent cooling of concentrated colloidal starch dispersion results in the formation of an elastic gel, process known as retrogradation. This occurrence is primarily caused by the amylose, since amylopectin, due to its highly branched organization, is less prone to retrogradation (Ai and Jane 2015). These events lead to important changes in the viscosity of food systems in which starch/flour is added. Therefore, assessing the viscosity of starch in presence of water in heating-cooling cycles can help to predict the suitability of those flours to the elaboration of different products. The analysis of these properties, called pasting properties, can be measured through either an amylograph or a Rapid Visco Analyser (RVA). Both instruments measure the relative viscosity of a starch and water (buffer) system as it is subjected to shear during a controlled heating, a holding period at a constant temperature, and then a controlled cooling. The relative viscosities measured with these instruments are a function of the temperature profile and the shear used. In addition, they drastically change with the concentration of the starch used in the analysis.

Regarding the viscosity profiles in heating-cooling cycles, when starch is heated in the presence of sufficient water, it eventually loses its crystalline structure, leading to an increase in the viscosity of starch pastes. This phenomenon is known as pasting. Further heating of the water-starch mixture leads to rupture of the starch granules and a fall in paste viscosity (breakdown). Finally, if a paste is cooled, hydrogen bonds develop between the amylose chains, creating a new crystalline structure that loses the absorbed water, causing a renewed increase in viscosity, a phenomenon known as retrogradation (Figure 11). These events constitute the basis for the use of starch and flour in the preparation of fillings, sauces, creams and dairy desserts, and other products.

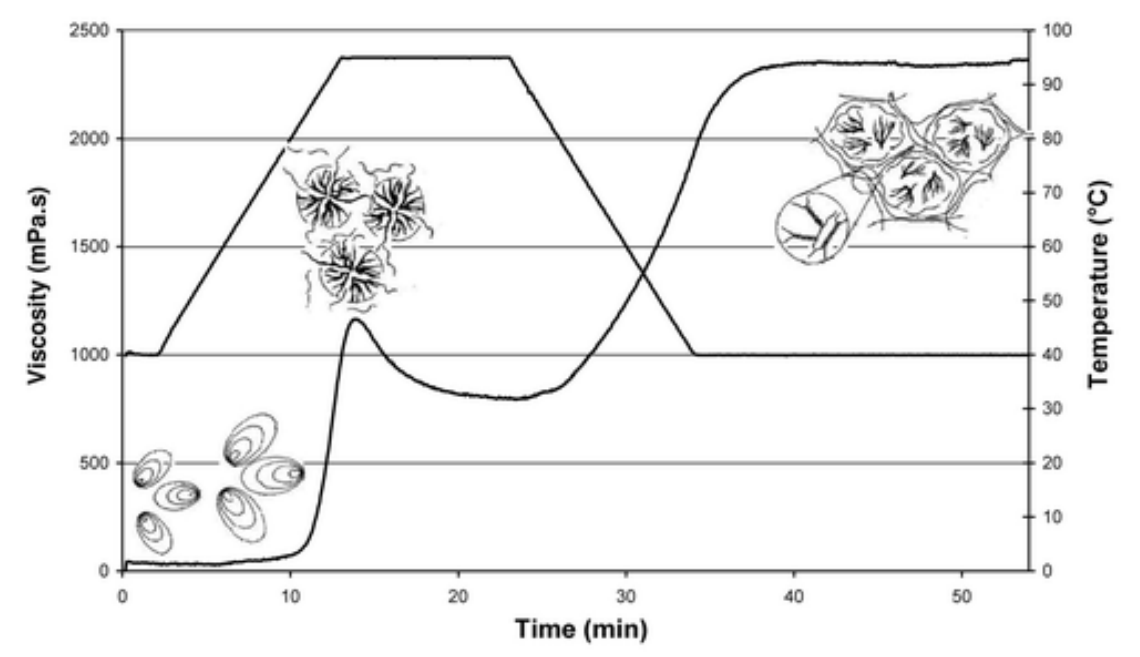

Figure 11. Conceptualized rapid viscogram of a starch suspension, showing the different phases of swelling, pasting, and setback (gel formation) as a function of the heating, constant temperature, and cooling profile used. At left, intact starch granules are shown, followed by gelatinized granules with leached amylose, and finally starch gel with indications of starch granule remnants containing intergranular crystalline amylose (Delcour and Hoseney, 2010). 
The rapid viscogram in Figure 11 shows a viscosity peak. Such a peak is generally referred to as the "swelling peak." As long as the granules remain intact as they take up water and release amylose, they increase the relative viscosity of the system. However, from a given moment onward, the relative viscosity of the starch system decreases markedly. The decrease in viscosity is caused by the molecules of soluble starch orienting themselves in the direction that the system is being stirred, as well as by shear-induced destruction of the (not necessarily fully) swollen (and hence fragile) granules. This phenomenon, called "shear thinning," is an important property of starch pastes. It is of practical relevance for many food systems. If one wants to make a thick soup, one must not stir excessively or pump the paste through a pipe, as, in both cases, shear thinning will occur, giving a lower viscosity. Different starches vary in the amount of shear thinning that they show, and starch modification affects this property. Generally, the more soluble the starch, the more it will thin on shearing.

Finally, it is of note that, while amylose-lipid inclusion complexes may be present in native starch already, additional quantities may be formed with free starch lipids during the starch gelatinization and pasting process. This complexation evidently influences the properties of starch as well. With differential scanning calorimetry (DSC), which measures heat flow as a function of temperature, one can detect two types of amylose-lipid complexes. The first type typically gives rise to an endothermic transition at about $98^{\circ} \mathrm{C}$, while the second type gives rise to an endothermic transition typically at about $110^{\circ} \mathrm{C}$. It has been stated that the first type corresponds to non-crystalline complexes and that the lower-melting endotherm is the result of the dissociation of the complexes, while the second, higher-melting endotherm can be ascribed to the melting of crystalline amyloselipid complexes. Whatever may be the case, it follows from the above that at least part of the amylose-lipid complexes present in the starch granules and those complexes formed during the starch gelatinization and pasting process dissociate during the cooking phase.

\subsection{Gelation and retrogradation}

A gel is a liquid system that has the properties of a solid. Some common examples are gelatins, pie fillings, and puddings. In gels, a small amount of solid material controls a large amount of water. It is amazing that water does not leak out of the gels when they are left standing. Calculations show that the distances between the starch chains in gels are very large compared to the size of the water molecule. Studies with diffusing solutes show that the water in gels has properties essentially equal to those of pure water. However, the water is held in the gels. We do not understand the forces involved in this. However, it seems very logical that hydrogen bonds are involved. One can indeed visualize a food system gel as protein or carbohydrate chains with layers of water molecules attached by hydrogen bonding (Delcour and Hoseney, 2010).

During storage, gelatinized starch undergoes a process called "retrogradation." The term retrogradation means to go back. In starch chemistry, it was first used to describe the 
observation that, following gelatinization, the starch would regain crystallinity. Strictly speaking, of course, only amylopectin molecules go back to a crystalline entity; hence, the term retrogradation should be used only for amylopectin crystallization. Under certain conditions, amylose may also crystallize. However, since it was not crystalline to start with, this should not be referred to as retrogradation.

The starch concentration, the temperature, and the shear applied during the steps preceding the cooling phase determine the structure of the starch suspension. The structure may vary from 1) densely packed swollen granules without a continuous amylose gel phase outside the granules, in which case the suspension forms a paste with flow properties rather than a gel, to 2) swollen granules dispersed in a continuous gel phase of leached amylose (Fig. 12), to 3) a macromolecular dispersion of amylose and amylopectin.

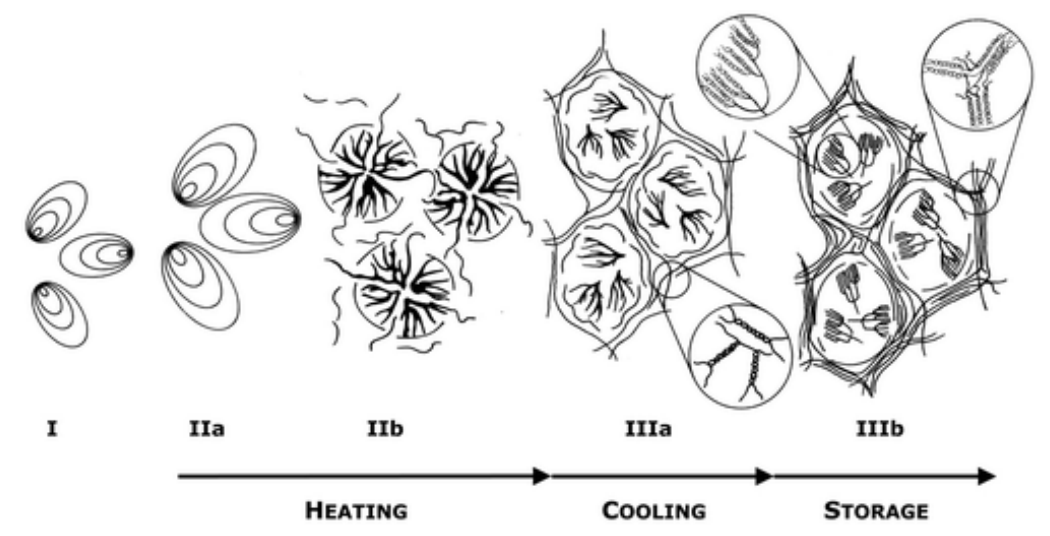

Figure 12. Schematic representation of changes that occur in a starch-water mixture during heating, cooling, and storage. I, Native starch granules; II, gelatinization (i.e., loss of birefringence associated with crystal melting): swelling (IIa) and amylose leaching and partial granule disruption (IIb), resulting in the formation of a starch paste; III, retrogradation: formation of an amylose network (gelation) during cooling of the starch paste (IIIa) and formation of ordered or crystalline amylopectin molecules (amylopectin retrogradation) during storage (IIIb) (Delcour and Hoseney, 2010)

In the second case (Fig. 12), gel formation has primarily been attributed to gelation of amylose in the continuous phase. Initially, double helices are formed between the amylose molecules that were solubilized during gelatinization and pasting, and a continuous network develops (gelation). After some hours, these double helices form very stable crystalline structures, as they have a melting temperature of about $150^{\circ} \mathrm{C}$. Indeed, such crystalline amylose structures have been recovered as insoluble residues following treatment of retrograded starch with thermostable amylase at $100^{\circ} \mathrm{C}$, a treatment that leads to complete dissociation of crystalline amylopectin. That this process occurs fast does not need to be a surprise. It is well known that crystallization (comprising the steps of both crystal nucleation and propagation) can occur between the glass transition temperature $(\mathrm{Tg})$ of a given system and the melting temperature $(\mathrm{Tm})$. When applying this concept to amylose systems, one comes to the following reasoning. Because the glass transition temperature of a starch system is typically below $0^{\circ} \mathrm{C}$ and the melting temperature of amylose crystals is about $150^{\circ} \mathrm{C}$, the temperature range between cooking 
starch (typically at $100^{\circ} \mathrm{C}$ ) and its subsequent cooling and storage at room temperature (typically $20^{\circ} \mathrm{C}$ ) is optimal for amylose crystal formation. Crystals can thus form over a broad temperature range. Similar reasoning, but now based on amylopectin crystal melting temperatures of about $50-60^{\circ} \mathrm{C}$, allows one to understand that amylopectin crystallization is much slower. As long as the starch is above the melting temperature of amylopectin, new crystals would not form. The crystal nucleation and propagation temperature range between room temperature and the crystal melting is narrower than that of amylose. In practice, upon storage, gel stiffness slowly increases because of crystallization of amylopectin within the granule remnants, which, in the second case described above, are embedded in and reinforce the continuous amylose matrix. Therefore, amylose crystallization determines to a great extent the initial hardness of a starch gel, while amylopectin retrogradation determines the long-term development of gel structure and crystallinity in starch systems (Delcour and Hoseney, 2010).

It was stated above that, during the cooking phase, at least part of the amylose lipid complexes dissociate. However, cooling of starch pastes leads to renewed formation and subsequent crystallization of amylose-lipid complexes. Finally, as the gel ages, the starch chains have a tendency to interact strongly with each other and thereby force water out of the system.

\subsection{Interactions with other hydrocolloids}

Occasionally, the properties of native flours are not suitable for their use in certain products and they must be modified or supplemented with other ingredients or additives. Examples of these additives added are marine hydrocolloids, such as carrageenans and agar. Carrageenans and agar, together with alginates, are the marine hydrocolloids most commonly used in the food industry. Carrageenans are extracted from certain red seaweeds of the Rhodophyceae class, which have been extensively used in the food industry as thickening and gelling agents (Campo, Kawano, da Silva, \& Carvalho, 2009). The structure of carrageenan is based on a disaccharide backbone of alternating 3-linked $\beta$-D-galactopyranose and 4-linked $\alpha$-D-galactopyranose units, named $G$ and D units, respectively, in Knutsen's nomenclature (Knutsen, Mylabodski, Larsen, \& Usov, 1994). Carrageenans are defined according to the position of sulphation (S) and the cyclization of the D units to form an anhydro ring (A). Carrageenans used in industry include the gelling k-, i-carrageenan and the non-gelling 1-carrageenan (Tischer, Noseda, Rilton de Freitas, Sierakowski, \& Duarte, 2006). The chemical structure of i-carrageenan differs from that of k-carrageenan by the presence of an additional sulphate group in the 3,6anhydrogalactosyl residue, which makes the molecule more hydrophilic (Renn, 1997). The distinct textural properties of $\mathrm{i}$ - and $\mathrm{k}$-carrageenan gels reflect the differences in their structures: i-carrageenan gels consist of double helices with little or no aggregation, which renders them flexible and soft. In contrast, k-carrageenan gels consist of aggregated helices, which do not gel without aggregation and the resulting gel relatively brittle and hard (Tischer et al., 2006). Agar is extracted from seaweeds of the genera Gelidium and 
Gracilaria and is composed of agarose and agaropectin molecules. Agarose, responsible for the gelling properties of agar, is a linear compound formed of alternating $\beta$-D. galactopyranose and $\alpha$-L-galactopyranose residues. Agaropectin has a similar structure but with a lower content of L-galactopyranose residues (Armisen, 1991). After solubilization in water, both agars and carrageenans have the property of forming reversible gels when they are cooled, and they are used extensively in the food industry as thickening and gelling agents.

Combinations of starch, or raw starchy ingredients, and hydrocolloids have been used in the food industry since the mid-twentieth century in order to achieve specific textures or to improve tolerance to certain processing conditions (heat, shear, and $\mathrm{pH}$ ), and their interactions have therefore been studied extensively (BeMiller, 2011). Among the marine hydrocolloids, interactions between the carrageenans and starchy ingredients have received most attention. Tye (1988) observed that these interactions depend on the type of carrageenan and type of starch (native or gelatinized). Differences between the types of carrageenan have been also studied by Shi and BeMiller (2002) and by Eidam, Kulicke, Kuhn, and Stute (1995), who observed that while k-carrageenan, like other hydrocolloids, accelerated the gelation process, i-carrageenan delayed it. However, interactions between carrageenans and wheat flour have not been investigated. Interactions between agar and flours have also received little attention and this has usually been limited to the study of interactions between agarose and different starches (Lai, Huang, \& Lii, 1999; Mohammed, Hember, Richardson, \& Morris, 1998).

\section{Physical treatments}

As mentioned, native starches and flours (mainly composed by starch) are widely used as ingredients, due to their particular complex polymeric characteristics, which make them suitable for numerous food applications. However, continuous innovation in foodstuff and their higher quality requirements force to adapt those commodities to the emerging needs in terms of functionality. Chemical, enzymatic and/or physical modifications have been the alternatives to modulate the functionality and properties of the raw starches (Chiu and Solarek, 2009). However, physical modifications are gaining prominence because of the absence of exogenous chemical agents (Jacobs and Delcour, 1998). Physical modifications comprise particle size classification, fine grinding/air classification, drying, annealing/HMT treatments and extrusion, which can produces flours with the properties depicted in figure 13. Nevertheless, extrusion was the main endpoint in this thesis. Added to that, the particle size was also taken into account in some studies of this thesis. Therefore, in this introduction, particle size classification and extrusion will be described. 


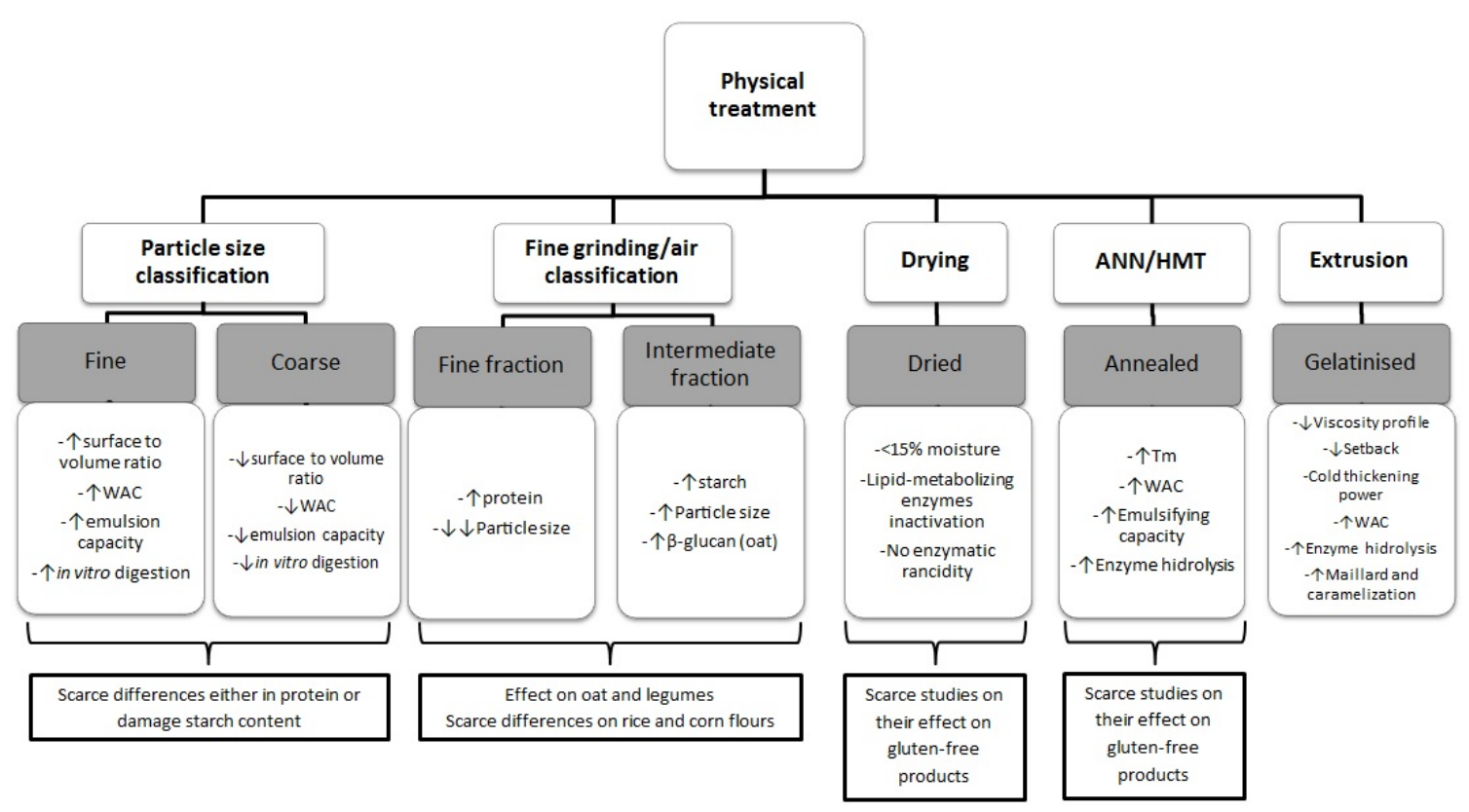

Fig. 13. Schematic depiction of the main physicochemical properties which could influence the gluten-free manufacturing of flours obtained through physical treatments. Grey boxes represent the different flours obtained by the physical treatments. WAC, water absorption capacity; Tm, gelatinization temperature.

\subsection{Particle size classification}

In general, research on the development of products does not go into depth on the characteristics of flours or starches for their adequacy to each of the bakery products. However, it is demonstrated that these characteristics have a strong influence on the quality of the final product. Thereby, apart from some characteristics which can be influenced by the genetic or cropping conditions, such as protein content or amylose/amylopectin ratio of starch, other features can be modified as a function of the production methods of flour and starch, such as damaged starch or particle size. These features will be determinant in the homogeneity and the final quality of the obtained products. In this way, Kadan et al. (2008) and Araki et al. (2009) observed that the milling system affected the damaged starch and particle size of rice flour and therefore the volume of breads was also affected. These authors found a high negative correlation between damaged starch and bread specific volume. Nevertheless, it is worth noting that these authors added wheat gluten to the recipe, thus these results would not be completely extrapolated to gluten-free breads, in which starch has a main role. In fact, de la Hera et al. (2013a) reported that as the particle size of rice flour was reduced by sieving, the specific volume of gluten-free breads, made with $80 \%$ of water flour basis (f.b), decreased. This effect was attributed to the behaviour of doughs during fermentation, since doughs made with fine flours were scarcely able to retain gas produced in this step, which in turn could be due to the structural differences observed among the different doughs. Nonetheless, in the case of flours made with higher hydration (110\% f.b), these effects became less clear and only a noticeable reduction of the gas retention and bread 
volume in the case of the finest flour $(<80 \mathrm{~mm})$ was reported. In general, the finest flour gave rise to doughs with lower gas retention capacity, but this effect only was observed from a certain fermentation time. These results seem to endorse the theory of a low volume of breads made with flours with higher damaged starch. However, differences in the damaged starch content among the flours classified by sieving were small and, converse to what was expected, the finest fractions were those which displayed a lower content of damaged starch (de la Hera et al., 2013b). In this study, the finest particles were obtained through sieving a set of particles of different sizes instead forcing to reduce the size of all particles during milling. Therefore, the scarce differences in the damaged starch content among flours can be due to the fact that the finest fractions come mainly from the softest parts of the grain which are broken into smaller pieces naturally, without forcing the milling. Therefore, the damaged starch itself cannot explain these differences on bread volume. Neither can these differences be attributed to the different protein content nor to the amylose/amylopectin ratio, since no correlations were appreciated. Nevertheless, the differences observed could be attributed to the higher water absorption capacity of the finest flour due to its greater surface to volume ratio. In fact, the effect observed would coincide with the lower volumes obtained using flours with higher damaged starch, which possesses higher water absorption capacity than native starch. This occurrence would also allow explaining the fact that the differences in bread volume diminish in excess of water. By studying semi-dry milled rice flours obtained by air classification, Park et al. (2014) also observed that the finest fractions gave rise to breads with lower volume, even though a low damaged starch content $(<5 \%)$ was presented. Meanwhile, in bread-making using corn flour, flour characteristics also had a strong influence on bread quality. Breads with the highest volume were those made with some flours of the highest particle size and with lower water absorption capacity. However, one of the finest flours with similar water absorption capacity gave rise to breads with much lower volume. Therefore, the water absorption capacity of flours cannot fully explain the effect of the particle size on bread volume. On the other hand, differences in bread volume could be attributed to the different hardness of flour particles and their morphology. In general, as it was observed with rice flour, finer flours gave rise to breads with lower specific volume (de la Hera et al., 2013c). Added to that, in whole grain oat flour bread-making, oat flours with coarse particle size, limited starch damage and low protein content resulted in superior oat bread quality (Hüttner et al., 2010). Therefore there is a clear effect of flour particle size on gluten-free bread-making. In general not too much fine flour is preferred, even though this can vary as a function of the milling method, type of grain and bread-making process. In Figure 14, this effect can be observed clearly. 
(a)

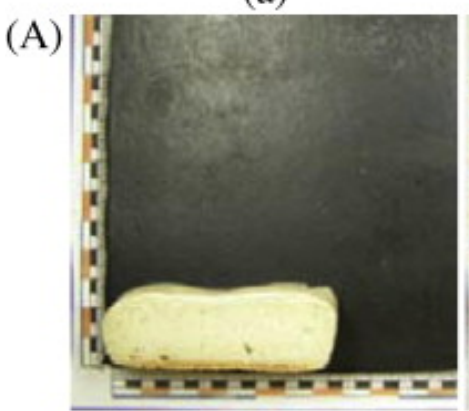

(a) (b)

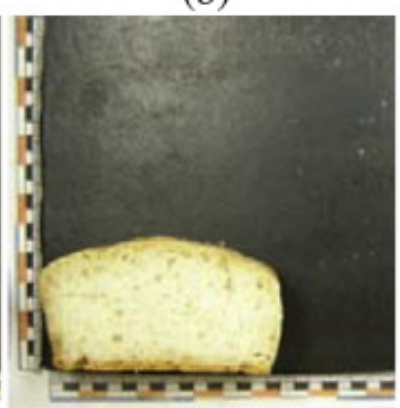

(b) (c)

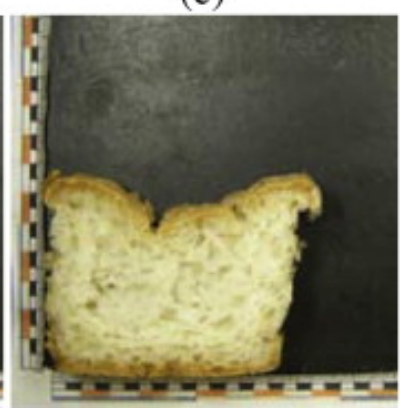

(c)

(B)
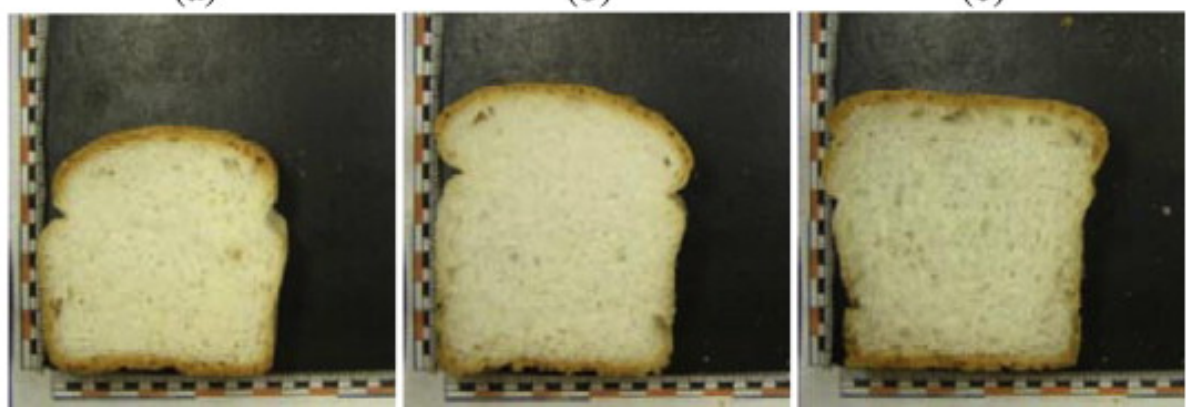

Fig. 14. Bread central slice cross section. Bread made with fine rice flour (particle size $<132 \mathrm{~mm}$ ) (A) and coarse flour (particle size 132-200 $\mu \mathrm{m}$ ) (B). Water content of 70\% (a), 90\% (b) and 110\% (c) was added.

From a nutritional perspective, and converse to a functional point of view, the best combination would be using the lowest dough hydration meaning a lower volume and greater bread hardness (de la Hera et al., 2014). Those authors reported that a reduction of the dough hydration could limit the starch gelatinization and hinder the in vitro starch digestibility. In addition, the coarsest flours exhibited a lower hydrolysis rate and a greater amount of slow digestible starch (SDS) and resistant starch (RS). Thus, besides the particle size, dough hydration should also be taken into account for modulating the enzymatic hydrolysis of starchy foods.

In general, there is a lack of studies which relate flour properties, including particle size or damaged starch, and not only their origin, with gluten-free cookie quality. In this way, this parameter should be included in the characterization of the flours used in these types of studies. According to these studies, a simple classification of flours based on their particle size, and the subsequent election of the proper fraction, could improve their suitability for the manufacturing of food products.

\subsection{Thermal treatments. Extrusion}

Continuous innovation of foodstuff and their higher quality requirements force the adaptation of flours to the emerging needs in terms of functionality. The modification of the functionality of starchy ingredients by hydrothermal treatments is becoming of great interest, as in many cases it is possible to achieve those properties of chemically modified starches while keeping the clean label (Jacobs and Delcour, 1998), without artificial ingredients and chemicals. 
When heating is carried out with enough amount of water (previous hydration of flour or starch), morphological changes within starch granules take place. The extent of these changes depends mainly on the processing conditions, such as temperature and moisture. Lately a wide range of hydrothermal treatments have been proposed in bibliography. However, they are mainly classified in two groups: those performed below gelatinization temperature (which will not be approached in this thesis), preserving the integrity of starch granules; and those treatments carried out above gelatinization temperature and therefore irreversibly destroying the molecular order of the starch granule.

When starches or flours are subjected to hydrothermal treatments carried out above gelatinization temperature, the molecular order of the starch granule undergoes irreversible breakage, known as gelatinization (sometimes also known as pregelatinization), making starch more prone to swell and thicken in contact with water (Mason, 2009; Martínez et al., 2014a, 2014b, 2015). Starch gelatinization can be industrially performed in various ways, such as drying a paste by atomization or heated drums; but one of the most versatile alternatives is extrusion (Chiu and Solarek, 2009; Doublier et al., 1986; Hagenimana et al., 2006).

Extrusion cooking can involve exposing flours to high temperatures and mechanical shearing with enough amount of water to produce starch gelatinization. Besides starch gelatinization, this treatment allows breakage of the amylose and amylopectin chains (dextrinization), denaturation of proteins, enzyme (in)activation and Maillard reactions, the extent of which are dependent on the severity of the extrusion (Mercier and Feillet, 1975; Wen et al., 1990). Those changes at the constituents' level modify the physicochemical characteristics of flours.

Martínez et al. (2014a, 2014b) reported changes in the emulsifying capacity and stability of rice and wheat extruded flours as a function of the extrusion conditions. These effects were attributed to the protein unfolding and aggregation along with starch gelatinization that increases the number of hydroxyl groups available to form hydrogen bonds with the proteins. Regarding foaming capacity, extrusion did improve foaming capacity and stability of rice flours. These different emulsifying and foaming properties could make extruded flours suitable for some gluten-free products. Pasting properties are also strongly influenced by the intensity of the extrusion conditions. In general, the viscosity during heating and cooling together with the setback decreases with the extrusion intensity (Hagenimana et al., 2006; Martínez et al., 2014a, 2014b). Nevertheless, when extrusion is severe enough to produce a noticeable amount of gelatinised starch, a high initial viscosity at $50^{\circ} \mathrm{C}$ is observed. This different cold thickening power of extruded flours also affects the action mechanism of other components such as hydrocolloids, giving rise to different heating and cooling viscosity profiles (Martínez et al., 2015a). Therefore, the presence of these flours in gluten-free bakery products, which are elaborated with other ingredients, such as gluten replacers (hydrocolloids), and in which dough viscosity and consistency are crucial for achieving a good volume, could be beneficial. The high water 
retention capacity of these flours can also turn flours into a suitable fat replacer ingredient, as Roman et al. (2015a, 2015b) observed adding extruded flours to cakes and mayonnaises respectively, although in some cases those flours had to be complemented with other ingredients, such as emulsifiers.

The functional modification of gelatinised flours, and especially their higher water absorption capacity, can be taken into account in bread-making for increasing dough consistency and reducing the typical dryness of breads. Thereby, Defloor et al. (1991) observed that a mixture of extruded starches and emulsifying agents improved the quality of breads prepared with a mixture of tapioca and soya and a high level of hydration. Sanchez et al. (2008) found that the addition of extruded rice flour improved bread volume and crumb structure, but this effect was more noticeable when the waxy varieties of rice were used. However, the latter authors had to increase the quantity of water in the formula when using extruded flours in order to compensate their higher consistency. The effect of the substitution of rice flour by extruded non-acidified and acidified rice flour has also been tested (Clerici and El-Dash, 2006; Clerici et al., 2009). However, the latter authors did not use hydrocolloids in their bread-making process and bread specific volume was excessively low in all cases. Later, Martínez et al. (2013b) observed how the substitution of native rice flour by extruded rice flour, in breads, increased bread volume, decreased initial hardness and delayed bread staling. Martínez et al. (2014c) observed that an increase of the severity of the extrusion conditions led to an increase of the viscoelastic moduli and dough consistency of gluten-free breads when incorporating extruded flour. Moreover, it was necessary to add larger amounts of water to achieve a constant consistency and therefore increasing the bakery yield, fact that was already achieved adding extruded wheat flour to wheat flour breads (Martínez et al., 2013a).

The disruption of the starch granules (gelatinization) during extrusion also enhances their chemical reactivity towards hydrolytic enzymes (Zhang et al., 2015). The different susceptibility to enzymatic hydrolysis, especially by amylases and glucoamylases, could give rise to different profile of oligosaccharides. This starch hydrolysis sugars are the fermentation substrates of bread-making and one of the principal compounds that participate in Maillard and Caramelisation thermal reactions that occur during baking (Hee Cho and Peterson, 2010; Salim-ur-Rehman et al., 2006). Sugars also influence the stickiness of doughs with a positive correlation (Every and Ross, 1996). Added to that, they are correlated with changes in the staling rate of bread, by delaying it (Gerrard et al., 1997). It is also noteworthy to highlight that sugars in flours used in pastry-making could, besides contributing to the sweet taste, act as bulking agents in whipped doughs such as cakes, sponge cakes or cupcakes. Therefore, gelatinised flours should also be considered as a function of their different starch hydrolysis susceptibility by different enzymes, such as amylases, glucoamylases or even other starch-catalysing enzymes such as branching enzyme or maltogenic $\alpha$-amylase, with a view to generating new molecules for specific 
cereal based products. In order to get a better of the starch-acting enzymes, the enzymes used in this thesis to modify extruded flours are discussed down below.

\section{Starch-active enzymes (the $\boldsymbol{\alpha}$-amylase family of enzymes)}

A classification scheme for glycosidic hydrolases and transferases based on structure rather than specificity has been stablished comparing their amino acid sequences (Henrissat and Bairoch 1993, 1996). These enzymes have been grouped into more than 80 families, where the members of one family share a common three-dimensional structure and mechanism, and have from a few to many sequence similarities. According to this classification, families 13, 70 and 77 contain structurally and functionally related enzymes catalysing hydrolysis or transglycosylation of $\alpha$-linked glucans (MacGregor et al. 2001). Many of these enzymes act on starch, and in particular, $\alpha$-amylase is one of the most important and widely-studied. In this way, this collection of enzymes, considered to consist of families 13, 70 and 77, is often known as the $\alpha$-amylase family of enzymes, but is, in fact, encompassed of enzymes with almost 30 different specifities. In some cases, specifities of different enzymes in the different families overlap and this, together with amino acid sequence similarities, has led to confusion in identification (MacGregor et al. 2001).

The $\alpha$-amylase family is formed by a group of enzymes with a variety of different specificities, having in common that all act on one type of substrate, glucose residues linked through an $\alpha, 1-1, \alpha, 1-4$, or $\alpha, 1-6$ glycosidic bond. Members of this family share a number of common characteristics but at least 21 different specificities have been found within the family. These differences in specificities are based not only on fine differences within the active site of the enzyme but also on the differences within the overall architecture of the enzymes. The $\alpha$-amylase family can roughly be divided into two subgroups: exo- and endo-acting hydrolases that hydrolyse the $\alpha, 1-4$ and/or $\alpha, 1-6$ glycosidic linkages consuming water; and glucanotransferases that break an $\alpha, 1-4$ glycosidic linkage and form a new $\alpha, 1-4$ or $\alpha, 1-6$ glycosidic one (van der Maarel and Leemhuis 2013). Most of these enzymes have a retaining mechanism, that is, they maintain the anomeric configuration of the hydroxyl group at the $\mathrm{C}_{4}$ atom at the nonreducing end of the newly formed dextrins and therefore generating oligosaccharides with $\alpha$-configuration. On the other hand, some starch-active enzymes, such as $\beta$-amylase, are inverting enzymes, therefore changing the anomeric configuration of the hydroxyl group at the $\mathrm{C} 4$ position from $\alpha$ to $\beta$ and therefore giving rise to oligosaccharides with $\beta$ configuration (Fig. 1). The enzymes that accomplish these criteria and belong to the $\alpha$ amylase family were listed by van der Maarel et al. (2002). A complete overview of all glycoside hydrolases known to date can be found on the Carbohydrate-active enzymes database (CAZY, http://www.cazy.org) developed by the Glycogenomics group at AFMB in Marseille, France. In addition, detailed information and the recommendations for enzyme nomenclature by the Nomenclature Committee of the International Union of Biochemistry and Molecular Biology (NC-IUBMB) can be found on a website with 
sophisticated search function dedicated to enzyme nomenclature (http://www.enzymedatabase.org). In this thesis, the effect of endo-acting $\alpha$-hydrolase, $\alpha$-amylase; the exoacting $\beta$-hydrolase, glucoamylase; the exo-acting $\alpha$-hydrolase, maltogenic alpha amylase; and the glucosylglucanotransferase, branching enzyme on the physicochemical and nutritional properties of native and extruded flours were studied. Therefore, only these enzymes will be approached in this introduction.

\subsection{Endo-acting $\alpha$-hydrolases, $\alpha$-Amylase}

The endo-acting hydrolases comprise the group of enzymes with two common features: retention of the anomeric configuration of the hydroxyl group at the $\mathrm{C}_{4}$ and $\mathrm{C}_{1}$ atoms at the non-reducing end of the newly formed dextrins and oligosaccharides respectively and an endo-mechanism of attacking the starch-derived molecules at glucose residues in the interior parts. The most well-known endo-acting hydrolase is the enzyme $\alpha$-amylase (EC 3.2.1.1) which hydrolyses $\alpha, 1-4$ linkages in the interior part of starch polymer randomly, leading to the formation of linear and branched oligosaccharides, or $\alpha$-limit dextrins.

\subsubsection{Catalytic action}

The endo-mechanism of $\alpha$-amylases rapidly fragments starch chains into smaller chains (Fig. 15) and thereby rapidly decreases the starch-iodine blue colour and the viscosity of starch pastes. This is the reason why endo-acting amylases are sometimes called liquefying amylases. $\alpha$-Amylases from different origins have been endorsed differences in their degree of multiple attack by comparing the drop of the blue starch-iodine colour versus the increase in reducing value (reducing sugars) (Robyt and French 1967). These authors showed that each of the $\alpha$-amylases had different degree of multiple attack, being curves, and they were also different from those that produced by acid-catalysed hydrolysis (Robyt and French 1967). These particular features of $\alpha$-amylase attack have produced an important misunderstanding; the final products of $\alpha$-amylase are glucose and maltose. $\alpha$ Amylases from different sources produce different products in different amounts, with glucose being invariably a very minor final product and almost never an early product (Robyt 2009). 


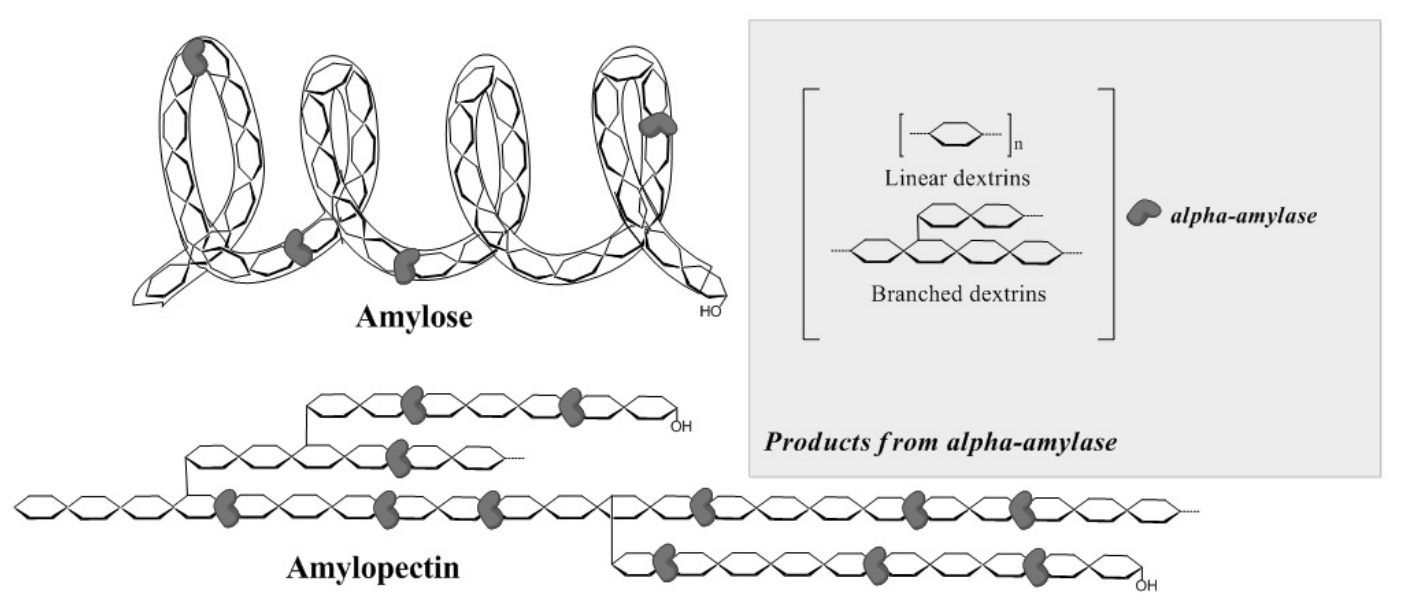

Figure 15. Substrate specificity and products formed by $\alpha$-amylase on amylose and amylopectin. The glycosidic bond hydrolysed in each case is marked with different symbols referred to the enzyme.

\subsubsection{Brief insight of the industrial applications}

Amylases are among the most important hydrolytic enzymes for all starch based industries, and the commercialisation of amylases is the oldest, having first been used in the 1980s. Several amylase preparations are available with various enzyme manufacturers for specific use in different industries. A great amount of commercial applications of endo-acting $\alpha$-hydrolases has been reported in several reviews (van der Maarel et al. 2002, van der Maarel 2010, Rana et al. 2013). However, the major market for endo-acting hydrolases lies in the conversion of starch hydrolysates (glucose syrups, crystalline glucose, high fructose corn syrups, maltose syrups or reduction of their viscosity), even though baking and brewing industries are also significant.

\subsubsection{Application of endo-acting hydrolases in the conversion of starch hydrolysates}

Because of the high sweetening property of starch hydrolysates, a large-scale starch processing industry has emerged since the mid-1900s. These products are used in huge quantities in the beverage industry as sweeteners for soft drinks, and to a lesser extent for solid foodstuffs. The traditional acid hydrolysis method for the production of glucose has been totally replaced by the enzymatic treatments at the end of the XX century (Crabb and Mitchinson 1997, Crabb and Shetty 1999). A brief overview of the production of starch hydrolysates is depicted in figure 16. Most enzymatic conversion processes start with the liquefaction of gelatinized starch into soluble and short chain dextrins. Liquefaction usually requires the use of a highly thermostable endo-acting amylase for optimising costs. Initially, the $\alpha$-amylase from Bacillus amyloliquefaciens was used during liquefaction, but this has been replaced by the $\alpha$-amylase of Bacillus stearothermophilus or Bacillus licheniformis (van der Maarel et al. 2002). These thermostable amylases will hydrolase both amylose and amylopectin of a 30-35\% dry solids starch slurry with an endo-action and therefore decreasing its viscosity. The liquefaction proceeds until a 
dextrose equivalent (DE) of $8-12$ is reached. The drawback of the $\alpha$-amylases used currently is that they are not active at a $\mathrm{pH}$ below 5.9 at the high temperatures used (95$100^{\circ} \mathrm{C}$ ). Therefore, the $\mathrm{pH}$ has to be adjusted from the natural $\mathrm{pH} 4.5$ of the starch slurry to $\mathrm{pH} 6$ by adding $\mathrm{NaOH}$. Also $\mathrm{Ca}^{2+}$ needs to be added because of the $\mathrm{Ca}^{2+}$-dependency of these enzymes (van der Maarel 2010).

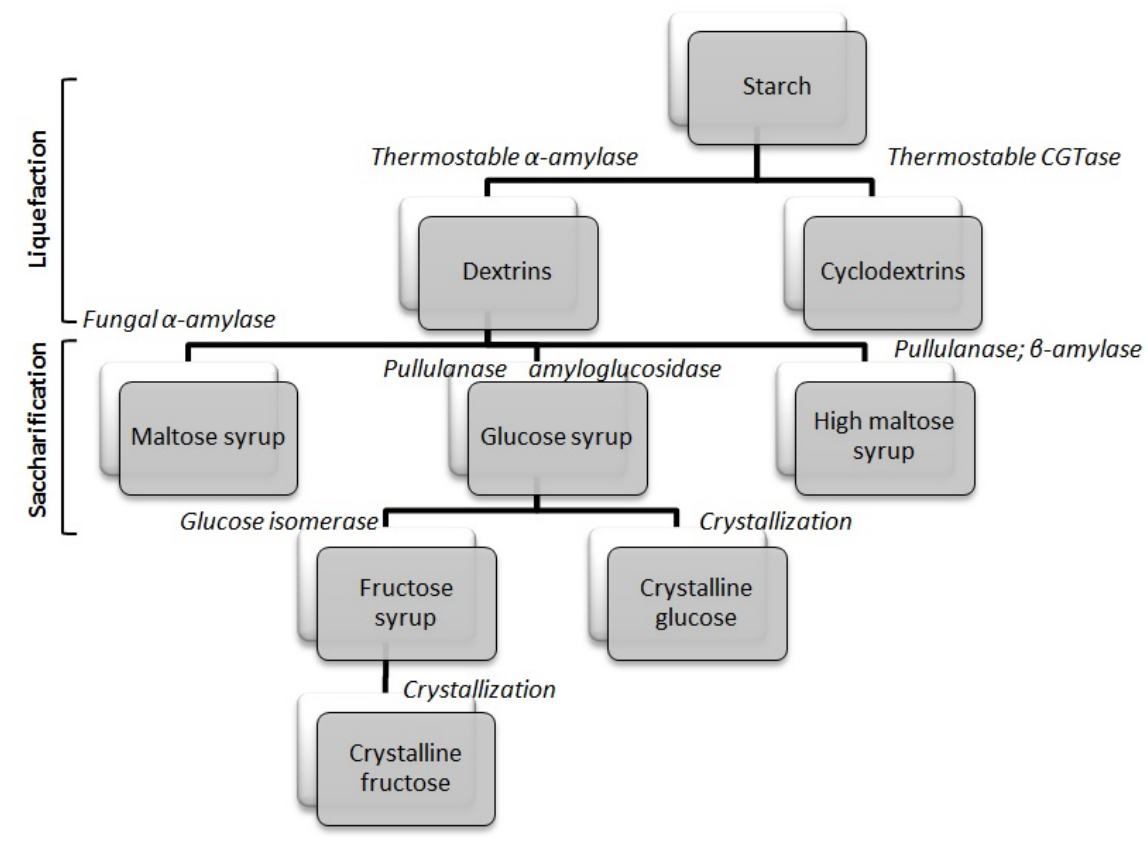

Figure 16. Schematic overview of the various steps in industrial starch processing.

\subsubsection{Application of endo-acting hydrolases in baking products}

The baking industry is other of the big markets for $\alpha$-amylases. Since enzymes are produced from natural sources, they are finding great acceptance by the consumers, thus several enzymes have been suggested to act as dough and/or bread improvers. Therefore, another important application of endo-acting enzymes on a large scale is the production of bakery products such as bread. Originally, $\alpha$-amylases Amylases were can be used both in flour supplementation and added during dough preparation in order to enhance the rate of fermentation, reduce the viscosity of the dough (resulting in improvements in the volume and texture of the product) and generate additional fermentable compoundssugars, which improve the taste, crust, colour and toasting qualities of the bread. However, $\alpha$-amylase supplementation in flour not only enhances the rate of fermentation and reduces the viscosity of dough (resulting in improvements in the volume and texture of the product), but also generates additional fermentable sugars in the dough, which improves the taste, crust, colour and toasting qualities of the bread (Kumar and Satyanarayana 2008). Moreover, when the bread is removed from the oven, a series of changes start, which eventually leads to the deterioration of quality. These 
changes include increase of crumb firmness, loss of crispness of the crust, decrease in moisture content of the crumb and loss of bread flavour. All undesirable changes that occur upon storage together are called staling. Among the different factors, which foster the bread staling, retrogradation of the starch fraction and especially retrogradation of amylopectin is considered crucial (Kulp and Ponte 1981, Champenois et al. 1999). Besides generating fermentable compounds, $\alpha$-amylases also have an anti-staling effect in bread baking, reducing the retrogradation of amylopectin (Dragsdorf and VarrianoMarston 1980; Lin and Lineback 1990; Rojas et al. 2001) and improving the softness retention of baked goods (De Stefanis and Turner 1981, Cole 1982, Sahlstrom and Brathen 1997). Despite this possible anti-staling effect, the use of endo-acting $\alpha$-amylases as anti-staling agent is not widespread because even a slight overdose of $\alpha$-amylase can lead to sticky breads. It is noteworthy that maltogenic $\alpha$-amylase is being used successfully for this purpose. However, due to the fact that this enzyme possesses both an endo- and exo-acting mechanism of action, it will be discussed in the next section.

\subsection{Exo-acting hydrolases}

Exo-acting hydrolases include a group of enzymes with an exo-mechanism, acting on the non-reducing ends of starch polymer chains, starch polymer-derived chains and glycogen. Some of these exo-acting enzymes possess inversion capacity by changing the anomeric configuration of the hydroxyl group at the $\mathrm{C}_{4}$ position from $\alpha$ to $\beta$ and therefore giving rise to oligosaccharides with $\beta$-configuration (Fig. 17). According to their inversion capacity, these enzymes can be grouped in two groups. The first group comprises the exoacting $\beta$-hydrolases $[\beta$-amylase (EC 3.2.1.2) and glucoamylase, also named amyloglucosidase, (EC 3.2.1.3)], that release $\beta$-maltose and $\beta$-glucose respectively. Meanwhile, the second group comprises the exo-acting $\alpha$-hydrolases, formed by $\alpha$ glucosidase (EC 3.2.1.20) and maltogenic $\alpha$-amylase (EC 3.2.1.133), that release glucose and maltose in their $\alpha$-configuration respectively, and amylases producing specific maltodextrin products. 


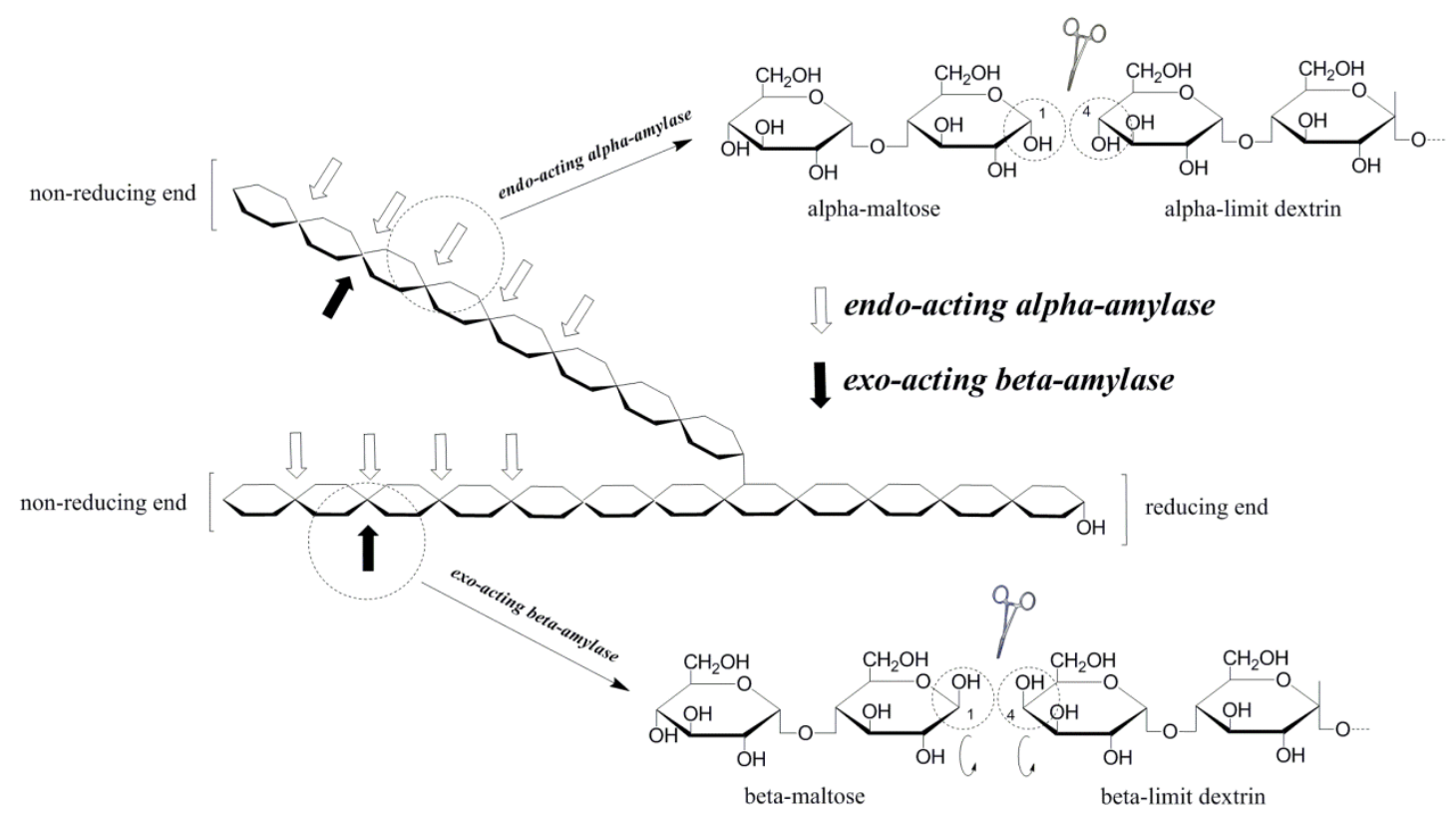

Figure 17. Catalysing effect of endo-acting $\alpha$-amylase and exo-acting $\beta$-amylase on starch. The effect of the hydrolysis from both enzymes on the anomeric configuration of the hydroxyl group at the C4 and C1 atoms of dextrin and maltose generated respectively is highlighted.

\subsubsection{Exo-acting $\beta$-hydrolases. Glucoamylase}

Exo-acting $\beta$-hydrolases, comprised by $\beta$-amylase and glucoamylase, catalyse starch, glycogen or related polysaccharides and oligosaccharides hydrolysis by a mechanism that produces the inversion of the configuration at the anomeric centre. This mechanism was is depicted in figure 17, where the action of the exo-acting $\beta$-amylase (black arrows) gives rise to $\beta$-amylase maltose and $\beta$-limit dextrins by the inversion mechanism. In this thesis, only glucoamylase will be approached. 


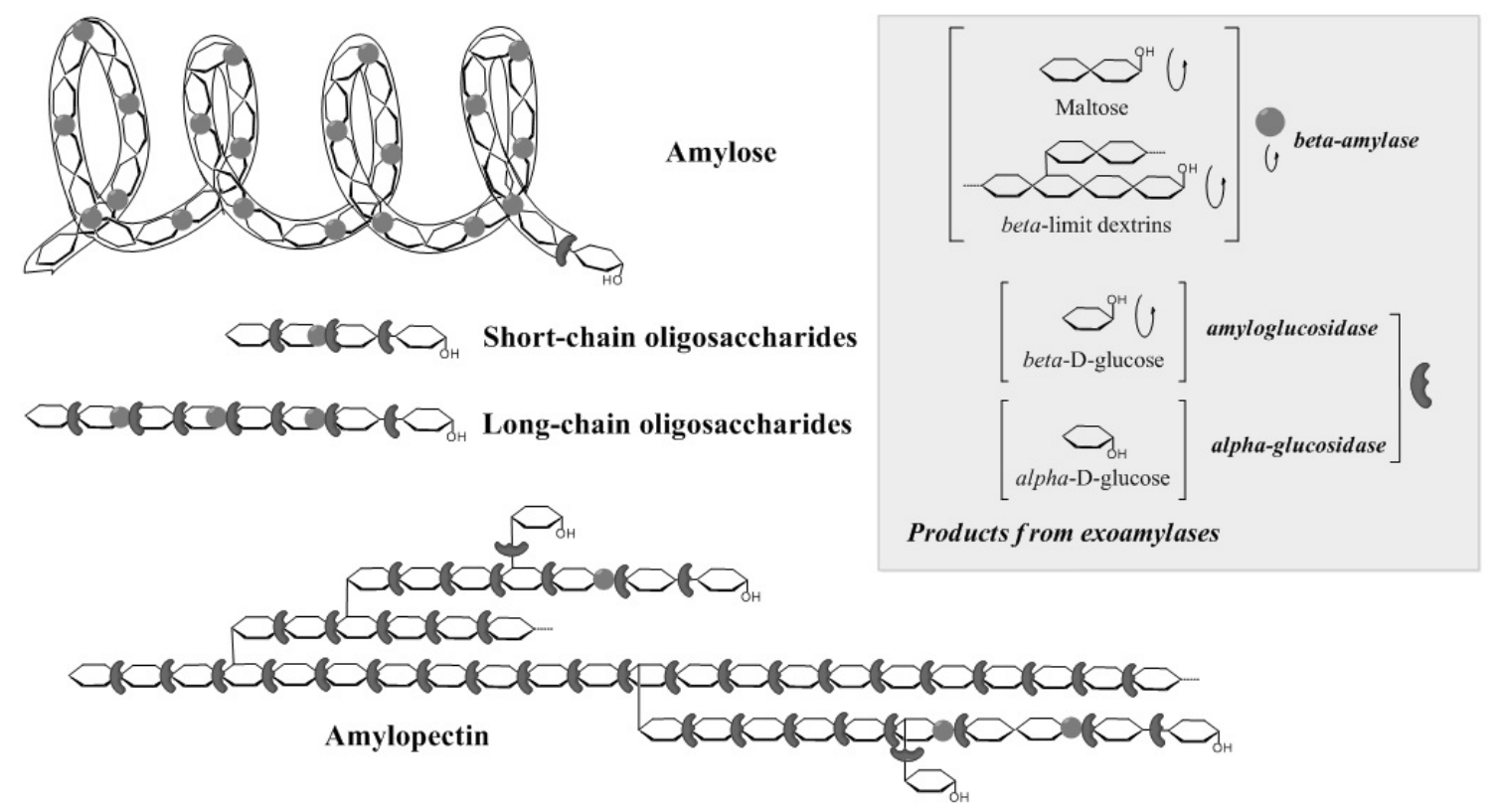

Figure 18. Substrate specificity and products formed by $\beta$-amylase, glucoamylase and $\alpha$-glucosidase on amylose, amylopectin and starch-derived oligosaccharides. The glycosidic bond hydrolysed in each case is marked with different symbols referred to the enzymes. Circular arrows indicate which final products were hydrolysed with the inversion of the anomeric centre of the non-reducing end from $\alpha$-to $\beta$-configuration

Conversely to other amylases, glucoamylases can catalyse the hydrolysis of both $\alpha, 1-4$ and a,1-6 glycosidic bonds in starch (Fig. 18), although the $\alpha, 1-4$ bond is hydrolysed approximately 500 times faster than the $\alpha, 1-6$ linkage (Hiromi et al. 1973). In this way, glucoamylase can completely hydrolyse starch to D-glucose, having a key role in the starch industry. In addition, when the concentration of maltose is sufficiently high, glucoamylase can also perform a transglycosylation reaction forming isomaltose, by coupling two glucose residues together via $\alpha, 1-6$ linkage (Ojha et al. 2015).

\subsubsection{Exo-acting $\alpha$-hydrolases. Maltogenic $\alpha$-amylase}

Maltogenic $\alpha$-amylase (EC 3.2.1.133) hydrolyse $\alpha, 1-4$ glycosidic linkages (and $\alpha, 1-6$ bonds in a lesser extent) in polysaccharides removing successive maltose residues from the nonreducing ends of the chains (Fig. 19). This enzyme exhibits both an endo- and an exoaction mechanism, with a high degree of multiple attack action and with endo-action increasing with temperature increase (Grewal et al. 2015). Maltogenic $\alpha$-amylase differs from typical $\alpha$-amylases by having substrate preference of cyclodextrins over starch and pullulan, possessing the relative hydrolytic activities cyclodextrins>pullulan>soluble starch. Added to that, maltogenic $\alpha$-amylase exerts its high degree multiple attack on starch granules during baking, when they begin to gelatinize, leading to a shortening of the amylopectin side chains and therefore preventing amylopectin recrystallization 
(retrogradation) and hindering water immobilization. This fact turns out to be very interesting for bread-manufactures in delaying the bread staling (see also section 3.2.3.2).

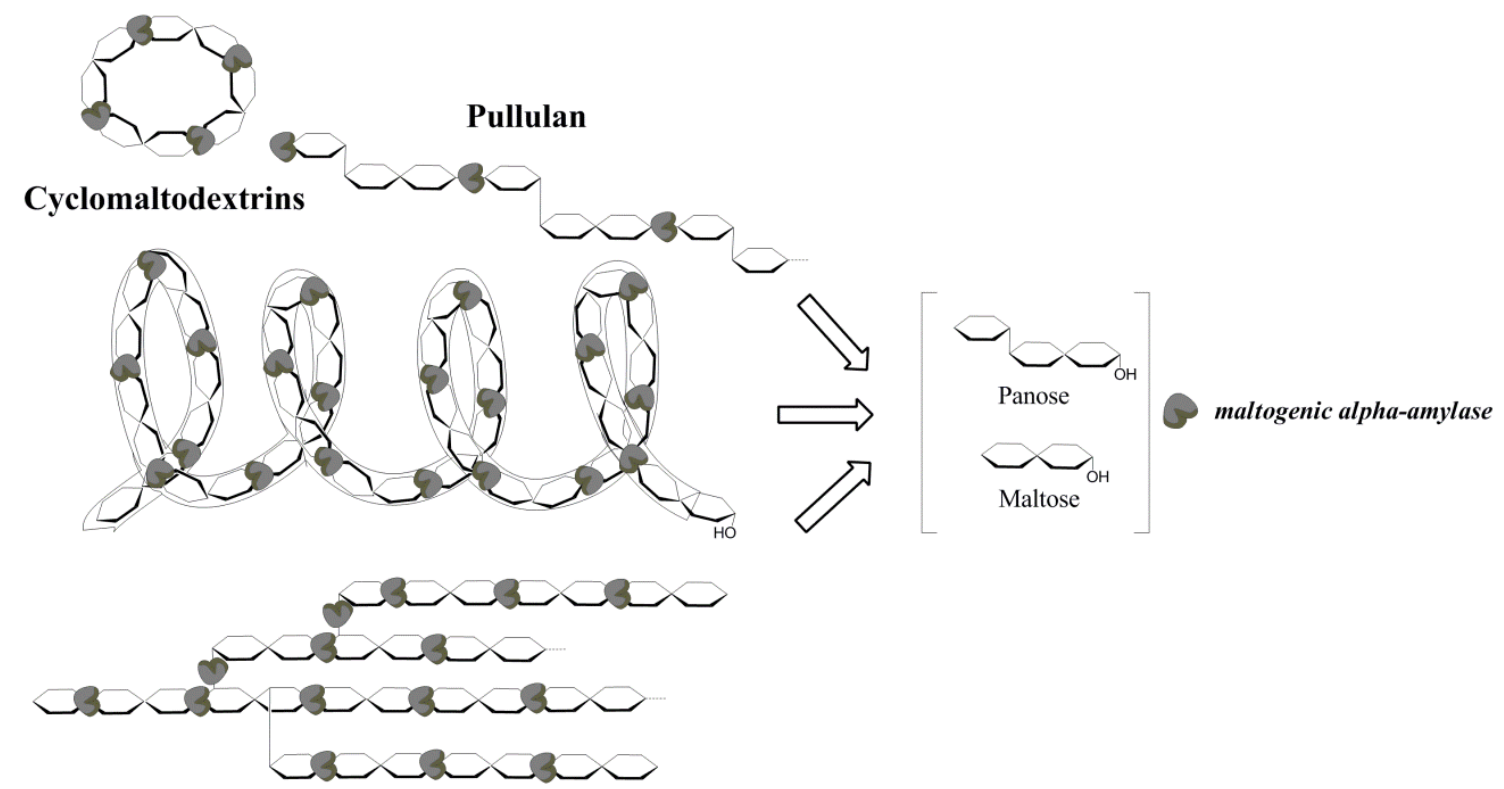

Amylopectin

Figure 19. Hydrolytic action of maltogenic $\alpha$-amylase on different substrates as well as the main products formed after hydrolysis.

Maltogenic $\alpha$-amylase not only exhibit hydrolytic activity but also, in certain conditions, possesses high transglycosylation capacity (Fig. 20). Thus, maltogenic $\alpha$-amylase from Bacillus stearothermophilus transfers glucose units and forms $\alpha, 1-6$ linkages. When this enzyme was incubated with 30\% liquefied corn starch, it mainly produced isomaltose, panose and branched tetraose, accounting for $66 \%$ of the total sugar (Kang et al. 1997). Kim et al. (1994) also reported the isolation of a novel maltogenic $\alpha$-amylase from Bacillus licheniformis which was able to produce branched oligosaccharides via formation of $\alpha, 1-6$ linkages in the presence of an excessive amount of glucose. Furthermore, Lee et al. (2002) used a Bacillus stearothermophilus maltogenic $\alpha$-amylase in combination with a Thermotoga maritima $\alpha$-glucanotransferase for the production of branched oligosaccharides. Therefore, this enzyme appears to be highly suited for the production of branched oligosaccharides, also called isomaltooligosaccharides (IMO).

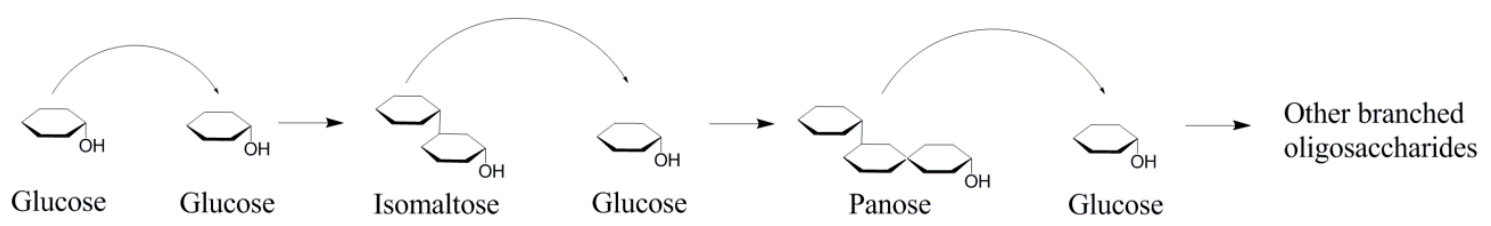

Figure 20. Repeated transglycosylation action of maltogenic $\alpha$-amylase in presence of glucose for the production of branched oligosaccharides. 


\subsubsection{Brief insight of the industrial applications of exo-acting hydrolases}

The catalytic action of microbial exo-acting hydrolases also turns out interesting for many applications of the food industry. However, as in the case of endo-acting hydrolases, their major market also resides in the starch conversion and baking industries.

\subsubsection{Application of exo-acting hydrolases in the conversion of starch hydrolysates}

The industrial starch processing is either stopped or followed by a saccharification step depending on the type of product to be produced (Fig. 16). In this step, pullulanase, glucoamylase, $\beta$-amylase or $\alpha$-amylase can be added to further degrade the liquefied starch into maltodextrins, maltose or glucose syrups, very used in food, beverages and fermentation industries.

The liquefied starch is pumped into a large stirrer vessel where glucoamylase is added. Most commonly used are glucoamylases from Aspergillus niger or a closely related species. This enzyme has an optimum $\mathrm{pH}$ of 4.2 , thus $\mathrm{pH}$ must be adjusted inducing some deactivation of the $\alpha$-amylase used in the liquefaction process. Moreover, glucoamylase is stable at $60^{\circ} \mathrm{C}$, thus temperature must also be adjusted. It is noteworthy that temperature must be lowered quickly to avoid retrogradation of the liquefied starch, which would become resistant to enzyme-hydrolysis. Depending on the specifications of the final product, saccharification is usually performed for $12-96 \mathrm{hr}$ at $60-62^{\circ} \mathrm{C}$ (Crabb and Mitchinson 1997). When the desired dextrose equivalent (DE) is reached, the solution is heated to $85^{\circ} \mathrm{C}$ for a few minutes to stop the reaction, by inactivating the enzymes (van der Maarel 2010). To make maltose syrup, traditionally barley $\beta$-amylase was added. Nevertheless, due to its high cost, its lack of thermal stability and its inhibition by copper and other metal ions, barley $\beta$-amylase has been replaced by fungal acid- $\alpha$-amylase. Another enzyme suggested to be used for the production of maltose syrups is the thermostable cyclodextrin glycosyltransferase of the bacterium Thermoanaerobacterium thermosulfirigenes (van der Maarel 2010), due to its first exo-acting hydrolytic mechanism.

A practical problem during saccharification is that the glucoamylase is specific for cleaving $\alpha, 1-4$ glycosidic bonds and slowly hydrolyses $\alpha, 1-6$ glycosidic bonds present in maltodextrins, turning out in the accumulation of isomaltose. A solution to this problem is to use a pullulanase that efficiently hydrolyses $\alpha, 1-6$ glycosidic bonds, having the same optimum $\mathrm{pH}$ and temperature as glucoamylase (Reilly 2006). When glucoamylase and pullulanase are used for saccharification, high glucose syrups are produced. It is important to achieve a high dry solid contents in order to make the production of high glucose syrups (>95\% glucose) cost-effective. Nevertheless, this high dry solid content together with the transglycosylation activity of glucoamylase can easily form reversion products such as maltose and isomaltose at the expense of the amount of glucose. The current solution is to balance the amount of enzyme, the temperature, and the time of incubation (Crabb and Mitchinson 1997). 
Glucose has about $75 \%$ of the sweetness of sucrose, while its isomer fructose is twice sweeter than sucrose. Consequently, fructose is preferred in some foodstuffs and it can be metabolized without insulin (Synowiecki 2007). Commercially, fructose is produced by the isomerization of glucose using bacterial glucose/xylose isomerase (E.C. 5.3.1.5) at 50$60^{\circ} \mathrm{C}$ and $\mathrm{pH} 7-8$. Glucose isomerase is the most expensive of all the enzymes involved in starch processing, and thus, is reused until it loses most of its activity (Crabb and Mitchinson 1997, Crabb and Shetty 1999, Reilly 1999). This enzyme does not belong to the $\alpha$-amylase family.

During the production of glucose from liquefied starch, we mentioned how the transglycosylation activity of glucoamylase can form negative reversion products. However, this feature can be beneficial with a view to manufacturing IMOs from starch, which are being used as substitutes for sucrose due to their low energy $(2 \mathrm{kcal} / \mathrm{g})$ and low cariogenic properties. In addition, they are known to improve the intestinal microflora by stimulating the growth of Bifidobacteria and suppressing the multiplication of harmful bacteria (Tomomatsu 1994). When the concentration of maltose is sufficiently high, glucoamylase perform a transglycosylation reaction forming isomaltose by coupling two glucose residues together via $\alpha, 1-6$ linkage. In a second step, the isomaltose is glycosylated to form isomaltotriose. Other IMOs such as panose and isopanose also are created. The glucoamylase used for their production is that from the fungus Aspergillus niger. Besides, glucoamylase and $\alpha$-glucosidase purified from cells of Microbacterium sp. efficiently utilized maltose and converted it into IMOs up to DP6. While isomaltotriose and isomaltotetraose were the major products formed with a conversion efficiency of $25 \%$, higher oligomers like pentaose and hexaose were also formed (Ojha et al. 2015). Another exo-acting enzyme with coupled transglycosylation and hydrolysis activities is the maltogenic $\alpha$-amylase from Bacillus stearothermophilus, which has also been utilised industrially for the efficient production of IMOs from liquefied starch (Kuriki et al. 1993, Kim et al. 1994, Lee et al. 1995, Yoo et al. 1995, Kang et al. 1997).

\subsubsection{Application of exo-acting hydrolases in baking products}

The baking industry has also resorted to the use of exo-acting hydrolases, alone or in combination with endo-acting hydrolases ( $\alpha$-amylase), for two main purposes. Firstly, the action of glucoamylase assists in saccharification of starch to glucose that can be easily fermented by the yeast and improve the bread crust colour (Kumar and Satyanarayana 2008). Secondly, both $\beta$-amylase and glucoamylase shorten the external side chains of amylopectin by cleaving maltose or glucose molecules, respectively. Therefore, these enzymes are suggested to delay bread staling by reducing the tendency of the amylopectin compound in bakery products to retrograde (Vidal and Gerrity 1979, Van Eijk 1991, Wursch and Gumy 1994). The synergetic use of $\alpha$ - and $\beta$-amylase is also claimed to increase the shelf life of baked goods (Van Eijk 1991). Nevertheless, $\alpha$ - and $\beta$-amylases and glucoamylases are inactivated at the beginning of baking, thus they act only on small amounts of damages starch, turning out to have scarce positive effects on bread staling. 
On the other hand, $\alpha$-amylases from bacterial possess high thermal stability, resisting the temperatures reached during baking. Thus they act on gelatinised starch even after baking producing sticky crumbs. In order to solve this problem, the use of other exo-acting hydrolases with intermediate thermal stability has been suggested. In this way, amylases producing specific maltodextrins such as maltose (Diderichsen and Christiansen 1988, Olesen 1991), maltotriose (Tanaka et al. 1997) and maltotetraose (Shigeji et al. 1999a, b) are claimed to increase the shelf life of bakery products. They delay retrogradation of the starch compound by producing linear oligosaccharides of 2-6 glucose residues. Among them, maltogenic $\alpha$-amylase and maltotetraose forming enzyme are the most used in bread-making.

\subsection{Branching enzymes (BEs).}

\subsubsection{Catalytic action}

Glycan branching enzymes (BE, EC 2.4.1.18) are involved in the biosynthesis of amylopectin in plants or glycogen (Zeeman et al. 2010). These enzymes initially break $\alpha, 1$ 4 glycosidic bonds and create new $\alpha, 1-6$ branches within linear $\alpha, 1-4$ segments, resulting in products devoid of long $\alpha, 1-4$ chains. BEs are widely distributed in plant and animal tissues as well as microorganisms. Glycogen branching enzyme (GBE) is responsible for the formation of the $\alpha, 1-6$ linkages in the glycogen molecule, whereas starch branching enzyme (SBE) is an analogue of glycogen branching enzyme in plants that introduces $\alpha$ 1,6-branches into amylose and amylopectin (Kim et al. 2008). However, there are major differences in the actions of GBE and SBE, manifested in the differences in the degree of branching between glycogen and amylopectin. The degree of branching is $8-9 \%$ in glycogen and $3.5 \%$ in amylopectin and the average chain-length of the branches is usually 10-12 glucose residues for glycogen and 20-23 glucose residues for amylopectin (Kim et al. 2008, van der Maarel 2010). These differences are thought to be primarily due to different specificities between GBE and SBE in terms of the size of transferred chains. Added to that, some SBEs have been reported to act only on amylose (Palomo et al. 2011), whereas others act on both amylopectin and amylose (Palomo et al. 2009).

\subsubsection{Applications of branching enzymes (BEs)}

$\mathrm{BE}$ are finding commercial applications mainly in the starch processing industry as well as in the baking industry. The demands of new starchy products are making manufacturers to considerer the use of $\mathrm{BE}$, in particular for the production of cluster dextrin (CCD), low viscosity dextrins which in turn do not retrograde and for the production of slowly digestible carbohydrates (Fig. 21). 


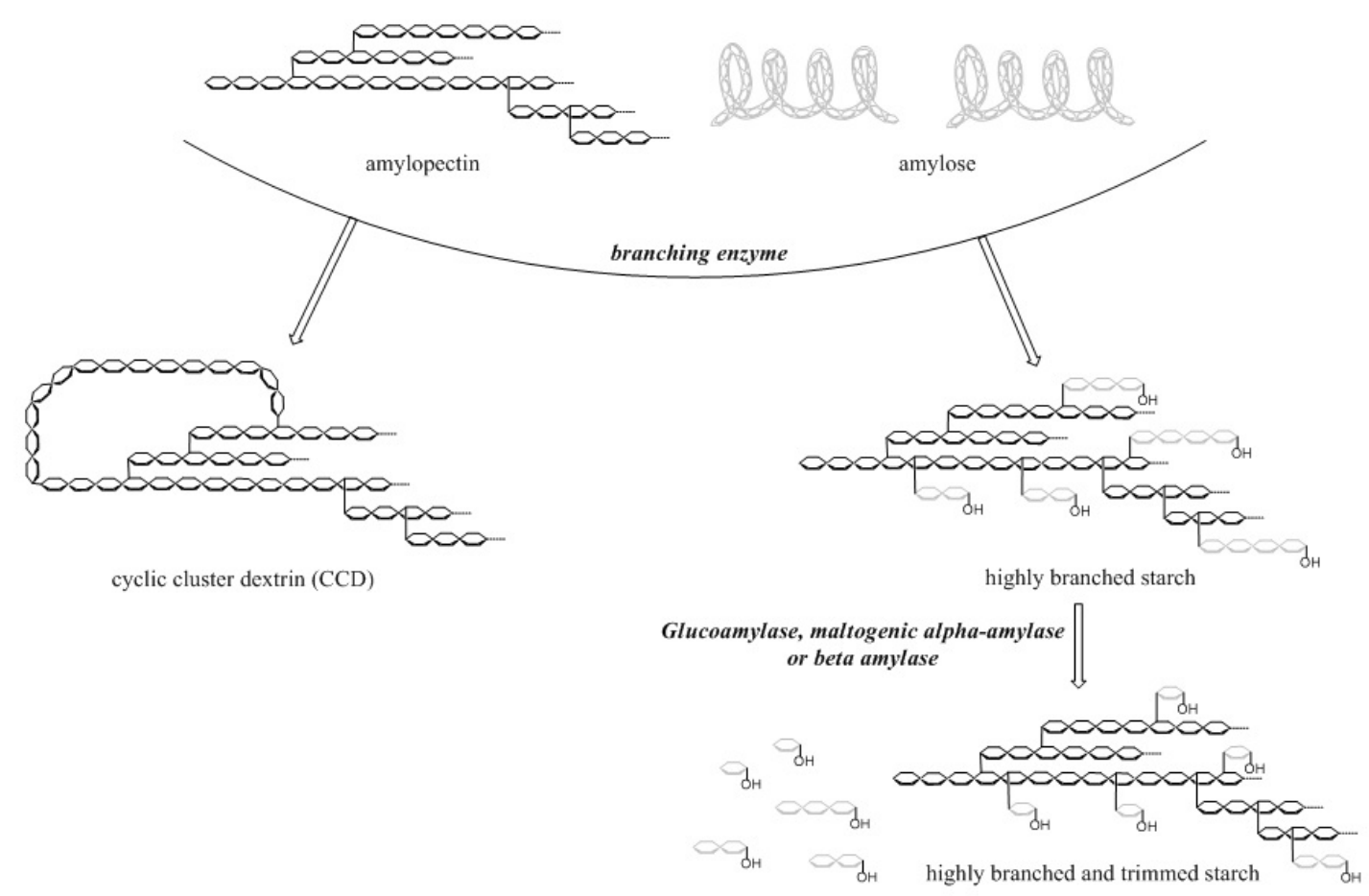

Figure 21. Effect of branching enzymes on amylose and amylopectin. Modification of slowly digestible starch and highly branched starch through glucoamylase, maltogenic $\alpha$-amylase or $\beta$-amylase treatment in the production of highly branched and trimmed starch.

CCD is a branched cyclic dextrin used as a sport drink ingredient (van der Maarel 2010). There are indications that fluids containing CCD influence the gastric empty time positively in humans (Takii et al. 2005) and have helpful effects on the endurance of mice (Shinohara et al. 2001). Another application of BE is the production of dextrins that at high concentrations have a low viscosity and do not retrograde. The BE treatment of liquefied starch leads to the transfer of parts of the amylose and long side chains of the amylopectin to other amylopectin molecules with the formation of new short side chains. This new branched structure leads to weakening the interactions among amylopectin molecules, leading to solutions with relatively low viscosity (van der Maarel 2010). Related to the creation of these branched structures, the action of BEs to convert regular starch, rapidly degraded by our digestive system, into slowly digestible starch are also being investigated, though it remains to be deeply explored. It is expected that by increasing the branching points, the pancreatic human $\alpha$-amylase will have more difficulties to catalyse the starch hydrolysis. This led to a reduction of the amount of glucose produced and therefore a lower blood glucose level. In this way, van der Maarel et al. (2007) patented an application of BE from bacterium Deinococcus radiodurans in which amylopectin was converted into a branched maltodextrin with a side chain distribution dominated by small side chains. In vitro digestion analysis indicated that the product showed a slower glucose release. In the same framework, Fuertes et al. (2005), Dermaux et al. (2007) and Le et al. (2009) patented a slow digestible starch by BE modification followed by a $\beta$ amylase, glucoamylase or maltogenic $\alpha$-amylase treatment, respectively. These enzymes 
have a limited hydrolytic capacity towards $\alpha, 1-6$ glycosidic linkages but trim the sidechains by cleaving the $\alpha, 1-4$ glycosidic linkages from the non-reducing ends. All of them considered that the shorter side chains make the product less prone to pancreatic $\alpha$ amylase digestion (Fig. 6).

With regard to the baking industry, Okada et al. (1984) and Spendler and Jorgensen (1997) patented the potential use of branching enzyme in bread as an anti-staling agent, increasing the shelf life and loaf volume of baked goods. These effects were achieved by modifying the starch material in the dough during baking. As it has been commented along this chapter, retrogradation of the amylopectin fraction in bread limits its shelf-life (Goesaert et al. 2009). However, BEs would create products that form a stable solution that cannot retrogradate since the side chains are too short to have a strong interaction. Improved quality of baked products was also obtained when the branching enzyme was used in combination with other enzymes, such as $\alpha$-amylase, maltogenic amylase, cyclodextrin glycosyltransferase, $\beta$-amylase, cellulase, oxidase and/or lipase (Spendler and Jorgensen 1997). 


\section{$\underline{\text { References }}$}

Ai, Y. and Jane, J-L. (2015). Gelatinization and rheological properties of starch. Starch/Stärke 67, 213-224.

Araki, E., Ikeda, T.M., Ashida, K., Takata, K., Yanaka, M., Iida, S., 2009. Effects of rice flour properties on specific loaf volume of one-loaf bread made from rice flour with wheat vital gluten. Food Sci. Technol. Res. 15, 439e448.

Armisen, R. (1991). Agar and agarose biotechnological applications. Hydrobiologia, 221, $157 \mathrm{e} 166$.

Balls, A.K. Walden, M.K. and Thompson, R.R. (1948). A crystalline $\beta$-amylase from sweet potatoes. The Journal of Biochemical Chemistry 173, 9-19.

BeMiller, J. N. (2011). Pasting, paste, and gel properties of starch e hydrocolloid combinations. Carbohydrate Polymers, 86, 386e423.

Biliaderis, C. (2009). Structural transitions and related physical properties of starch. In J. BeMiller, \& R. Whistler (Eds.), Starch. Chemistry and Technology (pp. 293-372). New York: Academic Press.

Buleón, A. Colonna, P. Planchot, V. and Ball, S. (1998). Starch granules: structure and biosynthesis. International Journal of Biological Macromolecules 23, 85-112.

Campo, V. L., Kawano, D. F., da Silva, D. B., \& Carvalho, I. (2009). Carrageenans: biological properties, chemical modifications and structural analysis e a review. Carbohydrate Polymers, 77, 167e180.

Cha, H.J. Yoon, H.G. Kim, Y.W. Lee, H.S. Kim, J.W. Kweon, K.S. Oh, B.H. and Park, K.H. (1998). Molecular and enzymatic characterization of a maltogenic amylase that hydrolyzes and transglycosylates acarbose. European Journal of Biochemistry 253, 251 262.

Champenois, Y. Della, V.G. Planchot, V. Buleon, A. and Colonna, P. (1999). Influence of alpha-amylases on the bread staling and on retrogradation of wheat starch models. Sciences des Aliments 19, 471-486.

Chiu, C., Solarek, D., 2009. Modification of starch. In: BeMiller, J., Whistler, R. (Eds.), Starch. Chemistry and Technology. Academic Press, New York. USA, pp. 629e656.

Cho, H.Y. Kim, Y.W. Kim, T.J. Kim, D.Y. Kim, J.W. Lee, Y.W. Park K.H. (2000). Molecular characterization of a dimeric intracellular maltogenic amylase of Bacillus subtilis SUH4-2. Biochimica et Biophysica Acta (BBA) 1478, 333-340.

Clerici, M., Arioldi, C., El-Dash, A., 2009. Production of acidic extruder rice flour and its influence on the qualities of gluten free bread. LWT Food Sci. Technol. 42, 618e623. 
Clerici, M., El-Dash, A., 2006. Extruder rice flour as a gluten substitute in the production of rice bread. Arch. Latinoam. Nutr. 56, $288 \mathrm{e} 294$.

Cole, M.S. (1982). Antistaling baking composition. Patent US4320151.

Crabb, W.D. and Mitchinson, C. (1997). Enzymes involved in the processing of starch to sugars. Trends in Biotechnology 15, 349-352.

Crabb, W.D. and Shetty, J.K. (1999). Commodity scale production of sugars from starches. Current Opinion in Microbiology 2, 252-256.

de la Hera, E., Gomez, M., Rosell, C.M., 2013b. Particle size distribution of rice flour affecting the starch enzymatic hydrolysis and hydration properties. Carbohydr. Polym. 98, $421 \mathrm{e} 427$.

de la Hera, E., Martinez, M., Gomez, M., 2013a. Influence of flour particle size on quality of gluten-free rice bread. LWT Food Sci. Technol. 54, 199e206.

de la Hera, E., Rosell, C.M., Gomez, M., 2014. Effect of water content and flour particle size on gluten-free bread quality and digestibility. Food Chem. 151, 526e531.

de la Hera, E., Talegon, M., Caballero, P., Gomez, M., 2013c. Influence of maize flour particle size on gluten-free breadmaking. J. Sci. Food Agric. 93, 924e932.

De Stefanis, V.A. and Turner, E.W. (1981). Modified enzyme system to inhibit bread firming method for preparing same and use of same in bread and other bakery products. Patent US4299848.

Defloor, I., De Geest, C., Schellekens, M., Martens, A., Delcour, J., 1991. Emulsifiers and/or extruded starch in the productions of breads from cassava. Cereal Chem. 68, $323 \mathrm{e} 327$.

Dermaux, L. Peptitjean, C. and Wills, D. (2007). Soluble, highly branched glucose polymers for enteral and parenteral nutrition and for peritoneal dialysis. Patent WO2007099212.

Diderichsen, B. and Christiansen, L. (1988). Cloning of a maltogenic alpha-amylase from Bacillus stearothermophilus. FEMS Microbiology Letters 56, 53-60.

Doublier, J.L., Colonna, P., Mercier, C., 1986. Extrusion cooking and drum drying of wheat starch. II. Rheological characterization of starch pastes. Cereal Chem. 63, 240e246.

Dragsdorf, R.D. and Varriano-Marston, E. (1980). Bread Staling: X-Ray Diffraction Studies on Bread Supplemented with Alpha-Amylases from Different Sources. Cereal Chemistry 57,310-314. 
Eidam, D., Kulicke, W.-M., Kuhn, K., \& Stute, R. (1995). Formation of maize starch gels selectively regulated by the addition of hydrocolloids. Starch/St€arke, 47, 378e384.

FAOSTAT. (2013). Database of food and agricultural organization. Available from http://faostat3.fao.org/compare/E Accessed January 2015.

Fogarty, W.M. and Kelly, C.T. (1990). Recent advances in microbial amylases. In: W.M. Fogarty and C.T. Kelly (eds.), Microbial Enzymes and Biotechnology. Elsevier Science Publishers, London, pp. 71-132.

Galliard, T., Gallagher, D.M., 1988. The effects of wheat bran particle size and storage period on bran flavor and baking quality of bran/flour blends. J. Cereal Sci. 8, 147e154.

Gerrard, J.A., Every, D., Sutton, K.H., Gilpin, M.J., 1997. The role of maltodextrins in the staling of bread. J. Cereal Sci. 26, 201e209.

Goesaert, H. Slade, L. Levine, H. and Delcour, J.A. (2009). Amylases and bread firming. An integrated view. Journal of Cereal Science 50, 345-352.

Gomez, M., Ruiz-París, E., Oliete, B., 2010. Original article: influence of flour mill streams on cake quality. Int. J. Food Sci. Technol. 45, 1794e1800.

Grewal N. Faubion J. Feng G. Kaufman R.C. Wilson J.D. and Shi Y-C. (2015). Structure of waxy maize starch hydrolyzed by maltogenic $\alpha$-amylase in relation to its retrogradation. Journal of Agricultural and Food Chemistry 63, 4196-4201.

Gruyer, S. Legin, E. Bliard, C. Ball, S. and Duchiron, F. (2002). The endopolysaccharide metabolism of the hyperthermophilic archaeon Thermococcus hydrothermalis: polymer structure and biosynthesis. Current Microbiology 44, 206-211.

Hagenimana, A., Ding, X., Fang, T., 2006. Evaluation of rice flour modified by extrusion cooking. J. Cereal Sci. 43, 38e46.

Hee Cho, I., Peterson, D.G., 2010. Chemistry of bread aroma: a review. Food Sci. Biotechnol. 19, 575e582.

Henrissat, B. and Bairoch, A. (1993). New families in the classification of glycosyl hydrolases based on amino acid sequence similarities. Biochemical Journal 293, 781-788.

Henrissat, B. and Bairoch, A. (1996). Updating the sequence-based classification of glycosyl hydrolases. Biochemical Journal 316, 695-696.

Hiromi, K. Nitta, Y. Numata, C. and Ono, S. (1973). Subsite affinities of glucoamylase: examination of the validity of the subsite theory. Biochim et Biophysica Acta 302, 362 375. 
Hüttner, E.H., Dal Bello, F., Arendt, E.K., 2010. Rheological properties and bread making performance of commercial wholegrain oat flours. J. Cereal Sci. 52, 65e71.

Hyun, H.H. and Zeikus, J.G. (1985). General biochemical characterization of thermostable extracellular $\beta$-amylase from Clostridium thermosulfurogenes. Applied and Environmental Microbiology 49, 1162-1167.

J. A. Delcour and R.C Hoseney (2010), Principles of Cereal Science and Technology (third edition). AACC International, Inc. St. Paul, Minnesota, U.S.A.

Jacobs, H., Delcour, J., 1998. Hydrothermal modifications of granular starch with retention of the granular structure: a review. J. Agric. Food Chem. 46, $2895 \mathrm{e} 2905$.

Jane, J.-L. (2006). Current understanding on starch granule structures. Journal of Applied Glycoscience 53, 205-213.

Kadan, R.S., Bryant, R.J., Miller, J.A., 2008. Effects of milling on functional properties of rice flour. J. Food Sci. 73, E151eE154.

Kang, G.J. Kim, M.J. Kim, J.W. and Park K.H. (1997). Immobilization of thermostable maltogenic amylase, from Bacillus stearothermophilus for continuous production of branched oligosaccharides. Journal of Agricultural and Food Chemistry 45, 4168-4172.

Kang, G.J. Kim, M.J. Kim, J.W. and Park K.H. (1997). Immobilization of thermostable maltogenic amylase, from Bacillus stearothermophilus for continuous production of branched oligosaccharides. Journal of Agricultural and Food Chemistry 45, 4168-4172.

Kim, E-J. Ryu, S-I. Bae, H-A. Huong, N.T. and Lee, S-B. (2008). Biochemical characterisation of a glycogen branching enzyme from Streptococcus mutans: Enzymatic modification of starch. Food Chemistry 110, 979-984.

Kim, I.C. Cha, J.H. Kim, J.R. Jang, S.Y. Seo, B.C. Cheong, T.K. Lee, D.S. Choi, Y.D. and Park, K.H. (1992). Catalytic properties of the cloned amylase from Bacillus licheniformis, Journal of Biological Chemistry 267, 22108-22114.

Kim, I.C. Yoo, S.H. Lee, S.J. Oh, B.H. Kim, J.W. Park, K.H. (1994). Synthesis of branched oligosaccharides from starch by two amylases cloned from Bacillus licheniformis. Bioscience, Biotechnology, and Biochemistry 58, 416-418.

King, J. (1967). The glucoamylase of Coniophora cerebella. Biochemical Journal 105, 577 583.

Knutsen, S. H., Mylabodski, D. E., Larsen, B., \& Usov, A. I. (1994). A modified system of nomenclature for red algal galactans. Botanica Marina, 37, 163e169. 
Kulp, K. and Ponte, J.G. (1981). Staling white pan bread: fundamental causes. Critical Reviews in Food Science and Nutrition 15, 1-48.

Kumar, P. and Satyanarayana, T. (2008). Potential applications of microbial enzymes in improving quality and shelf life of bakery products. In: A. Koutinas, A. Pandey and C. Larroche (eds.), Current Topics on Bioprocesses in Food Industry. Asiatech Publishers, New Delhi, India, pp. 132-142.

Kuriki, T. Yanase, M. Takata, H. Takesada, Y. Imanaka, T. and Okada, S. (1993). A new way of producing isomaltooligosaccharide syrup by using the transglycosylation reaction of neopullulanase. Applied and Environmental Microbiology 59, 953-959.

Kwan, H.S. So, K.H. Chan, K.Y. and Cheng, S.C. (1994). Purification and properties of $\beta$-amylase from Bacillus circulans S31. World Journal of Microbiology and Biotechnology 10, 597-598.

Lai, V. M. F., Huang, A.-L., \& Lii, C. Y. (1999). Rheological properties and phase transition of red algal polysaccharideestarch composites. Food Hydrocolloids, 13, $409 \mathrm{e} 418$.

Le Corre, D. Bras, J. and Dufresne, A. (2010). Starch nanoparticles: a review. Biomacromolecules 11, 1139-1153.

Le, Q.-T. Lee, C.-K. Kim, Y.-W. Lee, S.J. Zhang, R. Withers, S.G. Kim, Y-R. Auh, J-H. Park, K.W. (2009). Amylolytically-resistant tapioca starch modified by combined treatment of branching enzyme and maltogenic amylase. Carbohydrate Polymers 75, 9-14.

Lee, H.S. Auh, J.H. Yoon, H.G. Kim, M.J. Park, J.H. Hong, S.S. Kang, M.H. Kim, T.J. Moon, T.W. Kim, J.W. and Park, K.M. (2002). Cooperative action of alphaglucanotransferase and maltogenic amylase for an improved process of isomaltooligosaccharides (IMO) production. Journal of Agricultural and Food Chemistry 50, 2812-2817.

Lee, H.S. Auh, J.H. Yoon, H.G. Kim, M.J. Park, J.H. Hong, S.S. Kang, M.H. Kim, T.J. Moon, T.W. Kim, J.W. and Park, K.M. (2002). Cooperative action of alphaglucanotransferase and maltogenic amylase for an improved process of isomaltooligosaccharides (IMO) production. Journal of Agricultural and Food Chemistry 50, 2812-2817.

Lin,W. and Lineback, D.R. (1990). Changes in carbohydrate fractions in enzymesupplemented bread and the potential relationship to staling. Starch/ Stärke 42, 385-394.

MacGregor, E.A. Janecek, S. and Svensson, B. (2001). Relationship of sequence and structure to specifities in the $\alpha$-amylase family of enzymes. Biochimica et Biophysica Acta 1546, 1-20. 
Martínez, M., Oliete, B., Gomez, M., 2013a. Effect of the addition of extruded wheat flours on dough rheology and bread quality. J. Cereal Sci. 57, 424e429.

Martínez, M., Oliete, B., Roman, L., Gomez, M., 2014c. Influence of the addition of extruded flours on rice bread quality. J. Food Qual. 37, 83e94.

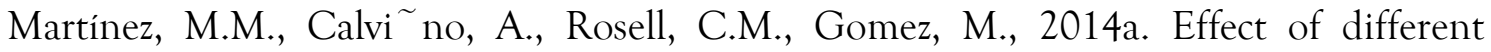
extrusion treatments and particle size distribution on the physicochemical properties of rice flour. Food Bioprocess Technol. 7, 2657e2665.

Martínez, M.M., Macias, A.K., Belorio, M.L., Gomez, M., 2015a. Influence of marine hydrocolloids on extruded and native wheat flour pastes and gels. Food Hydrocoll. 43, $172 \mathrm{e} 179$.

Martínez, M.M., Marcos, P., Gomez, M., 2013b. Texture development in gluten-free breads: effect of different enzymes and extruded flour. J. Texture Stud. 44, 480e489.

Martínez, M.M., Pico, J., Gomez, M., 2015b. Physicochemical modification of native and extruded wheat flours by enzymatic amylolysis. Food Chem. 167, 447e453.

Martínez, M.M., Rosell, C.M., Gomez, M., 2014b. Modification of wheat flour functionality and digestibility through different extrusion conditions. J. Food Eng. 143, $74 \mathrm{e} 79$.

Mason, W.R., 2009. Starch use foods. In: BeMiller, J., Whistler, R. (Eds.), Starch. Chemistry and Technology. Academic Press, New York. USA, pp. 743e795.

Mercier, C., Feillet, P., 1975. Modification of carbohydrate components by extrusioncooking of cereal products. Cereal Chem. 63, $283 \mathrm{e} 297$.

Mohammed, Z. H., Hember, M. W. N., Richardson, R. K., \& Morris, E. R. (1998). Cogelation of agarose and waxy maize starch. Carbohydrate Polymers, 36, 37e48.

Myers, A.M. Morell, M.K. James, M.G. and Ball, S.G. (2000). Recent progress towards understanding biosynthesis of the amylopectin crystal. Plant Physiology 122, 989-997.

Oates, C.G. (1997). Towards an understanding of starch granule structure and hydrolysis. Trends in Food Science \& Technology 8, 375-382.

Ojha, S. Mishra, S. and Chand, S. (2015). Production of isomalto-oligosaccharides by cell bound $\alpha$-glucosidase of Microbacterium sp. LWT-Food Science and Technology 60, 486494.

Okada, S. Kitahata, S. Yoshikawa, S. Sugimoto, T. and Sugimoto, K. (1984). Process for the production of branching enzyme, and a method for improving the qualities of food products therewith. Patent US4454161. 
Olesen, T. (1991). Antistaling process and agent. Patent WO9104669.

Palomo, M. Kralj, S. van der Maarel, M.J.E.C. and Dijkhuizen, L. (2009). The unique branching patterns of Deinococcus glycogen branching enzymes are determined by their $\mathrm{N}$ terminal domains. Applied and Environment Microbiology 75, 1355-1362.

Palomo, M. Pijning, T. Booiman, T. Dobruchowska, J.M. van der Vlist, J. Kralj, S. Planas, A. Loos, K. Kamerling, J.P. Dijkstra, B.W. van der Maarel, M.J. Dijkhuizen, L. and Leemhuis, H. (2011). Thermus thermophilus glycoside hydrolase family 57 branching enzyme: Crystal structure, mechanism of action, and products formed. Journal of Biological Chemistry 286, 3520-3530.

Pandey, A. Nigam, P. Soccol, C.R. Soccol, V.T. Singh, D. and Mohan, R. (2000). Advances in microbial amylases. Biotechnology and Applied Biochemistry 31, 135-152.

Park, J.H., Kim, D.C., Lee, S.E., Kim, O.W., Kim, H., Lim, S.T., Kim, S.S., 2014. Effects of rice flour size fractions on gluten free rice bread. Food Sci. Biotechnol. 23, 1875e1883.

Rana, N. Walia, A. and Gaur, A. (2013). a-Amylases from microbial sources and its potential applications in various industries. National Academy Science Letters 36, 9-17.

Ray, R.R. Jana S.C. and Nanda, G. (1997). Production of $\beta$-amylase from starchy wastes by a hyperamylolytic mutant of Bacillus megaterium. Indian Journal of Experimental Biology 35, 285-288.

Reilly, P.J. (1999). Protein engineering of glucoamylase to improve industrial performance. A review. Starch/Stärke 51, 269-274.

Reilly, P.J. (2006). Glucoamylase. In: J.R. Whitaker, A.G.J. Voragen, and D.W.S. Wong (eds.), Handbook of Enzymology. Marcel Dekker Inc., New York, pp. 727-738.

Renn, D. (1997). Biotechnology and the red seaweed polysaccharides industry: status, needs and prospects. Trends in Biotechnology, 15, 9e14.

Robyt, J.F. (2009). Enzymes and their action on starch. In: J. BeMiller and R. Whistler (eds.), Starch, Chemistry and Technology. Academic Press, New York, pp. 237-292.

Robyt, J.F. and French, D. (1967). Multiple attack hypothesis of $\alpha$-amylase action: Action of porcine pancreatic, human salivary, and Aspergillus oryzae $\alpha$-amylases. Archives of Biochemistry and Biophysics 122, 8-16.

Rojas, J.A. Rosell, C.M. and Benedito De Barber, C. (2001). Role of maltodextrins in the staling of starch gels. European Food Research and Technology 212, 364-368.

Roman, L., Martínez, M.M., Gomez, M., 2015a. Assessing of the potential of extruded flour paste as fat replacer in $\mathrm{O} / \mathrm{W}$ emulsion: a rheological and microstructural study. Food Res. Int. 74, $72 \mathrm{e} 79$. 
Roman, L., Santos, I., Martínez, M.M., Gomez, M., 2015b. Effect of extruded wheat flour as a fat replacer on batter characteristics and cake quality. J. Food Sci. Technol. Mysore. http://dx.doi.org/10.1007/s13197-015-1909-x.

Sahlstrom, S. and Brathen, E. (1997). Effects of enzyme preparations for baking, mixing time and resting time on bread quality and bread staling. Food Chemistry 58, 75-80.

Salim-ur-Rehman Paterson, A., Piggott, J.R., 2006. Flavour in sourdough breads: a review. Trends Food Sci. Technol. 17, 557e566.

Sanchez, H., Gonzalez, R., Osella, C., Torres, R., De La Torre, M., 2008. Elaboration of bread without gluten from extruded rice flour. Cienc. Tecnol. Aliment. 6, 109e116.

Shi, X., \& BeMiller, J. N. (2002). Effects of food gums on viscosities of starch suspensions during pasting. Carbohydrate Polymers, 50, 7e18.

Shigeji, M. Kimihiko, S. and Yoshiyuki, T. (1999a). Bread quality improving composition and bread production using the same. Patent JP11266773A2.

Shigeji, M. Kimihiko, S. and Yoshiyuki, T. (1999b). Quality improving composition for bread and production thereof using the same. Patent JP11178499A2.

Shinohara, M.L. Ihara, M. Abo, M. Hashida, M. Takagi, S. and Beck, T.C. (2001). A novel thermostable branching enzyme from an extremely thermophilic bacterial species, Rhodothermus obamensis. Applied Microbiology and Biotechnology 57, 653-659.

Spendler, T. and Jorgensen, O. (1997). Use of a branching enzyme in baking. Patent WO97/41736.

Swamy, M.V. Sai Ram, M. and Seenayya, G. (1994). $\beta$-Amylase from Clostridium thermocellum SS8. A thermophilic, anaerobic, cellulolytic bacterium. Letters in Applied Microbiology 18, 301-304.

Synowiecki, J. (2007). The use of starch processing enzymes in the food industry. In: J. Polaina and A.P. MacCabe (eds.), Industrial Enzymes: Structure, Function and Applications. Springer, Dordrecht, pp. 19-34.

Takii, H. Takii Nagao, Y. Kometani, T. Nishumura, T. Nakae, T. Kuriki, T. and Fushiki, T. (2005). Fluids containing a highly branched cyclic dextrin influence the gastric empty rate. International Journal of Sports Medicine 26, 314-319.

Tanaka, N. Nakai, K. Takami, K. and Takasaki, Y. (1997). Bread quality improving composition and bread producing process using the same. Patent US5698245.

Tester, R.F. Karkalas, J. and Qi, X. (2004). Starch- composition, fine structure and architecture. Journal of Cereal Science 39, 151-165. 
Tischer, P. C. S. F., Noseda, M. D., Rilton de Freitas, R. A., Sierakowski, M. R., \& Duarte, M. E. R. (2006). Effects of iota-carrageenan on the rheological properties of starches. Carbohydrate Polymers, 65, 49e57.

Tomomatsu, H. (1994). Health effects of oligosaccharides. Food Technology 48, 61-65.

Tran, T.T.B., Shelat, K.J., Tang, D., Li, E. et al., Milling of rice grains. The degradation on three structural levels of starch in rice flour can be independently controlled during grinding. J. Agric. Food. Chem. 2011, 59, 3964-3973.

Tye, R. J. (1988). The rheology of starch/carrageenan systems. Food Hydrocolloids, 2, $259 \mathrm{e} 266$.

van der Maarel, M.J.E.C. (2010). Starch-processing enzymes. In: R.J. Whitehurst and M. van Oort (eds.), Enzymes in Food Technology. Blackwell publishing Ltd., Ames, Iowa, USA, pp. 320-331.

van der Maarel, M.J.E.C. and Leemhuis, H. (2013). Starch modification with microbial alpha-glucanotransferase enzymes. Carbohydrate Polymers 93, 116-121.

van der Maarel, M.J.E.C. Binnema, D.J. Semeijn, C. and Buwalda, P.L. (2007). Novel slowly digestible storage carbohydrate. Patent EP1943908.

van der Maarel, M.J.E.C., van der Veen, B. Uitdehaag, J.C.M. Leemhuis, H. and Dijkhuizen, L. (2002). Properties and applications of starch-converting enzymes of the $\alpha$ amylase family. Journal of Biotechnology 94, 137-155.

Van Eijk, J.H. (1991). Retarding the firming of bread crumb during storage. Patent US5023094.

Vidal, F.D. and Gerrity, A.B. (1979). Antistaling agent for bakery products. Patent US4160848.

Wen, L., Rodis, P., Wasserman, B., 1990. Starch fragmentation and protein insolubilization during twin-screw extrusion of corn meal. Cereal Chem. 67, 268e275.

Wursch, P. and Gumy, D. (1994). Inhibition of amylopectin retrogradation by partial beta-amylolysis. Carbohydrate research 256, 129-137.

Yoo, S.H. Kweon, M.R. Kim, M.J. Auh, J.H. Jung, D.S. Kim, J.R. Yook, C. Kim, J.W. and Park, K.H. (1995). Branched oligosaccharides concentrated by yeast fermentation and effectiveness as a low sweetness humectant, Journal of Food Science 60, 516-519.

Zeeman, S.C. Kossmann, J. and Smith, A.M. (2010). Starch: Its metabolism, evolution, and biotechnological modification in plants. Annual Review of Plant Biology 61, 209. 234. 
Zhang, B., Dhital, S., Flanagan, B.M., Luckman, P., Halley, P.J. \& Gidley, M.J. (2015). Extrusion induced low-order starch matrices: Enzymic hydrolysis and structure. Carbohydrate Polymers, 134, 485-496.

Zhou, W., Therdthai, N. and Hui Y. H. (2014). Introduction to baking and bakery products, In, W. Zhou, Y. H. Hui, I. De Leyn, M. A. Pagani, C. M. Rosell, J. D. Selman, and N. Therdthai (eds.). Bakery Products Science and Technology (pp. 4-13). John Wiley $\&$ Sons, Ltd, NY, USA. 


\section{Objectives}

The main objective of this thesis is to develop cereal flours with different technologic and nutritional functionality through the application of extrusion and enzymes. The achievement of this objective would allow increasing the scientific knowledge on flour constituents, on the impact of the extrusion conditions and the enzymatic treatments, as well as obtaining novel products or ingredients that can increase the added value of flours.

In order to achieve the main objective, several specific objectives were also established:

1. To study the influence of raw flour characteristics, processing conditions and the final milling/sieving, on the functional properties of flours obtained through extrusion.

2. To study the influence of raw flour characteristics, processing conditions and the final milling/sieving, on the digestion properties of flours obtained through extrusion.

3. To study the effect of extruded flours on intermediate products during processing: pastes, gels and batters for coating.

4. To study the effect of the addition of extruded flours subjected to different extrusion conditions on the quality of gluten containing and gluten-free breads.

5. To study the physicochemical modification of native and extruded flours through enzymatic amylolysis with a view to generating flours with a wide oligosaccharide profile.

6. To study the synergistic effect of branching enzyme and maltogenic $\boldsymbol{\alpha}$-amylase on the generation of molecular and supramolecular structures in extruded matrices with the aim to attenuate the starch digestion properties. 
STRUCTURE 


\section{Structure}

The research carried out during this thesis has given rise to several scientific publications which respond to the objectives proposed and whose content is presented in the different sections that form this thesis. The references to the scientific publications ordered according to the respective section are:

\section{Introduction:}

Gómez, M. and Martínez, M.M. (In press). Changing flour functionality through physical treatments for the production of gluten-free baking goods. Journal of Cereal Science. http://dx.doi.org/10.1016/i.jcs.2015.07.009.

Martínez, M.M. and Gómez, M. (In press). Insight of the $\alpha$-Amylase Family of Enzymes: endo- and exo-acting $\alpha, 1-4$ hydrolases, In, R. C. Ray and C.M. Rosell (eds.), Microbial Enzyme Technology $\mathcal{E}$ Food Applications. CRC press, Taylor and Francis Group, UK.

Martínez, M.M. and Gómez, M. (In press). Starch-active debranching and $\alpha$ glucanotransferase enzymes, In, R. C. Ray and C.M. Rosell (eds.), Microbial Enzyme Technology $\mathcal{E}$ Food Applications. CRC press, Taylor and Francis Group, UK.

Section 1: Physicochemical characterization and digestive properties of different flours according to the extrusion conditions

Martínez, M.M., Rosell, C.M. and Gómez, M. (2014). Modification of wheat flour functionality and digestibility through different extrusion conditions. Journal of Food Engineering 143, 74-79.

Martínez, M.M., Calviño, A. Rosell, C.M. and Gómez, M. (2014). Effect of different extrusion treatments and particle size distribution on the physicochemical properties of rice flour. Food and Bioprocess Technology 7, 2657-2665.

Section 2: Effect of extruded flours on intermediate products during processing: pastes, gels and batters

Martínez, M.M., Macias, A.K., Belorio, M.L. and Gómez, M. (2015). Influence of marine hydrocolloids on extruded and native wheat flour pastes and gels. Food Hydrocolloids 43, 172-179.

Martínez, M.M., Sanz, T. and Gómez, M. (2015). Influence of wheat flour subjected to different extrusion conditions on the rheological behaviour and thermal properties of batter systems for coating. LWT-Food Science and Technology 64, 1309-1314.

Section 3: Effect of extruded flours on gluten containing and gluten-free breads 
Martínez, M.M., Oliete, B. and Gómez, M. (2013). Effect of the addition of extruded wheat flours on dough rheology and bread quality. Journal of Cereal Science 57, 424-429.

Martínez, M.M., Oliete, B., Román, L. and Gómez, M. (2013). Influence of the addition of extruded flours on rice bread quality. Journal of Food Quality 37, 83-94.

Martínez, M.M., Marcos, P. and Gómez, M. (2013). Texture development in gluten-free breads: effect of different enzymes and extruded flour. Journal of Texture Studies 44, 480489.

Section 4: Taking advantage of the high chemical reactivity of extruded flours towards enzyme catalysis

Martínez, M.M., Pico, J. and Gómez, M. (2015). Physicochemical modification of native and extruded wheat flours by enzymatic amylolysis. Food Chemistry 167, 447-453.

Martínez, M.M., Pico, J. and Gómez, M. (With editor). Synergistic maltogenic $\alpha$-amylase and branching treatment to produce enzyme-resistant molecular and supramolecular structures in extruded maize matrices. Food Hydrocolloids.

First of all, it is noteworthy that the introduction gave rise to one review and two chapters of a book. This was the result of an extensive search and the important amount of information handled and learnt during the development of this doctoral thesis. However, in this case those publications were not incorporated as published, but certain parts were extracted and adapted to be used in the introduction of this doctoral thesis.

Section 1 approaches the influence of the different extrusion conditions on the physicochemical and digestive properties of extruded flours. In this way, the barrel temperature, feed moisture content and feed rate were modified during extrusion to study their effects on hydration, emulsifying, foaming and pasting properties of extruded flours. Also, the free sugars, damaged starch content and amylopectin gelatinization were assessed. Added to that, in the study with rice flours, the effect of the particle size after extrusion was also studied.

In section 2, the different physicochemical properties of extruded flours were exploited to study the effect of their incorporation in intermediate products during processing, such as pastes, gels and batters for coating. In this way, the hydration, pasting and rheological properties of native and extruded pastes in combination with agar and carrageenan was studied and compared. The objective was to investigate the interactions between the two most common marine hydrocolloids with starch from wheat flours in its native and gelatinised state. Also, the interaction between those marine hydrocolloids and native and extruded wheat flours in flour-hydrocolloid gels was studied in terms of texture and colour. Finally, taking into account that one of the most crucial parameters of batter coatings is their viscosity and rheological properties, the effect of substitution of native 
wheat flour by wheat flour subjected to different extrusion conditions on the rheological and thermal properties of batters was investigated.

Section 3 approaches the effect of the addition of extruded flour subjected to different extrusion conditions on gluten containing and gluten-free breads. In this way, the effect of extruded flours on dough rheology and bread quality was assessed. The objective was to take advantage of the high hydration properties of extruded flours to make breads with high yield and less staling. Moreover, the effect of extruded flours on bread staling was compared with the addition of common enzymes used for this purpose. In order to study that comparison in depth, a study of different mathematical models for each texture parameter of bread crumb over time were performed.

Finally, in section 4, the molecular disruption of extruded flours was expected to yield a high chemical reactivity towards enzyme catalysis. Therefore, the enzymatic amylolysis with $\alpha$-amylase and glucoamylase was carried out in order to get flours with different functionality and high oligosaccharide content. Nevertheless, that high susceptibility to the enzymatic hydrolysis can also increase the action of the pancreatic $\alpha$-amylase and therefore it can decline the digestion properties of those flours. Thus, a synergistic maltogenic $\alpha$-amylase and branching treatment to produce enzyme-resistant molecular and supramolecular structures in extruded maize matrices was carried out in order to attenuate the starch digestion properties of extruded flours. 


\section{Physicochemical characterization and digestive properties of different flours according to the extrusion conditions}

Journal of Food Engineering 143 (2014) 74-79

Modification of wheat flour functionality and digestibility through different extrusion conditions

\section{Effect of Different Extrusion Treatments and Particle Size}

\section{Distribution on the Physicochemical Properties of Rice Flour}

Mario M. Martínez • Adelina Calviño •

Cristina M. Rosell • Manuel Gómez 


\subsection{Modification of wheat flour functionality and digestibility through different extrusion conditions}

Journal of Food Engineering 143 (2014) 74-79

Contents lists available at ScienceDirect

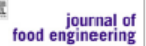

Journal of Food Engineering

journal homepage: www.elsevier.com/locate/jfoodeng

Modification of wheat flour functionality and digestibility through different extrusion conditions

Mario M. Martínez ${ }^{\mathrm{a}}$, Cristina M. Rosell ${ }^{\mathrm{b}}$, Manuel Gómez ${ }^{\mathrm{a}, *}$

${ }^{a}$ Food Technology Area, E.T.S. Ingenierías Agrarias, Valladolid University, Ed. La Yutera, Avd. Madrid, 44, 34004 Palencia, Spain

${ }^{\mathrm{b}}$ Institute of Agrochemistry and Food Technology (IATA-CSIC), Avda Agustin Escardino, 7, Paterna 46980, Spain

\section{Introduction}

Native starches and flours are widely used as ingredients, due to their particular complex polymeric characteristics, which make them suitable for numerous food applications. However, continuous innovation in foodstuff and their higher quality requirements force to adapt those commodities to the emerging needs in terms of functionality. Chemical, enzymatic and/or physical modifications have been the alternatives to modulate the functionality and properties of the raw starches (Chiu and Solarek, 2009).

Extrusion is a high-temperature-short-time (HTST) physical treatment during which flours or starches are subjected to high temperatures and mechanical shearing at relatively low levels of moisture content (Camire et al., 1990). Extrusion allows starch gelatinization, denaturation of protein, microbial reduction, enzyme (in)activation and color changes, the extent of which are dependent on the conditions of the extrusion (Wen et al., 1990). Those changes at the constituents' level modify the rheological behavior of flour batters (Hagenimana et al., 2006). Extrusion cooking is also responsible for changing the extent of molecular associations between components, e.g. the amylose - lipid complex that can affect the in vitro starch digestibility of the flours. Besides, it could be obtained an increase in the content of resistant starch, which is dependent on the treatment intensity (Hagenimana et al., 2006). It must be remarked that extrusion allows changing functionality by keeping the Green label (Jacobs and Delcour, 1998).

Mason (2009) reported that starches and flours modified by extrusion could be used in food products as thickening and gelling agents. This same author indicated that spray and drum-dried starches provided a suitable thickening, creamy and smooth texture for 
instant dry mixes such as puddings, desserts, soups and gravy and sauce bases, and these characteristics could also be achieved by extrusion treatments. Wheat extruded flours have been also useful to increase the bread yield in bakery process (Martinez et al., 2013). Rheological and water absorption properties of these flours define their adequacy for different uses.

However, research carried out in extrusion processes has been focused on starch, owing to the important changes that are produced on starch functional properties, such as gelatinization temperature, cold viscosity of pastes, retrogradation (Mason, 2009); without considering a possible flour treatment. Nevertheless, the presence of other flour constituents might also affect starch functionality. In fact, some interactions between starch and non-starch components of flours have been reported due to the heat-moisture treatment of sorghum (Sun et al., 2013) or rice flours (Puncha-arnon and Uttapap, 2013). For this reason it is possible that those interactions are also produced during the extrusion process.

The aim of this work was to modify wheat flour functionality by using physical treatments like extrusion. With that purpose, different extrusion conditions were applied to vary the severity of the treatment on the flour constituents. The impact of processing on the flours was also followed by assessing functional properties of flours (damaged starch, hydration, emulsifying, foaming, pasting and thermal properties) and their susceptibility to enzymatic hydrolysis.

\section{$\underline{\text { 2. Materials and methods }}$}

\subsection{Materials}

Wheat flour was provided by Harinera Los Pisones (Zamora, Spain) that carried out the extrusion treatment in a single screw extruder Bühler Basf (Bühler S.A., Uzwil, Switzerland). The length to diameter (L/D) ratio for the extruder was 20:1. Wheat flour was subjected to different extrusion treatments, where barrel temperature and/or feed rate and moisture content of the mass feed were modified, as specified in Table 1. Five types of extruded flours numbered from 1 to 5 indicating the severity of the extrusion treatment ( 1 the mildest and 5 the strongest), were obtained. Wheat flour without any treatment (wheat flour 0 ) was used as a control. The first factor took into account to number flours according to their treatment intensity, was the barrel temperature. Then, within the same temperature, the lower feed rate and the higher feed moisture content, the more intense the extrusion treatment is, since not only the mean residence time increases and therefore the treatment time, but also the water amount available for starch gelatinization.

Extruded product was dried by convection air and then ground with a compression roller till particle size was lower than $200 \mu \mathrm{m}$. Flours were stored in air-tight plastic containers and held at $4^{\circ} \mathrm{C}$ until analysis. 


\subsection{Methods}

\subsubsection{Free sugars}

The glucose content was measured using a glucose oxidase-peroxidase (GOPOD) kit. The absorbance was measured using an Epoch microplate reader (BIOTEK EPOCH, Izasa, Barcelona, Spain) at $510 \mathrm{~nm}$. In all cases four replicates were assayed for each experimental point.

\subsubsection{Damage starch}

The content of damaged starch was determined according to AACC 76-30A method (AACC, 2012). A fungal alfa amylase from Aspergillus oryzae (A6211, Sigma Chemical Co., St. Louis, MO, USA) was used in that analysis. Three determinations were made for each sample. Damaged starch was expressed as percentage of flour weight on dry basis.

\subsubsection{Hydration properties}

Hydration properties included swelling and water binding capacity (WBC) (Nelson, 2001). Swelling volume or the volume occupied by a known weight of flour was evaluated by mixing $5 \mathrm{~g}( \pm 0.1 \mathrm{mg})$ of flour with $100 \mathrm{ml}$ distilled water and allowing it to hydrate during $16 \mathrm{~h}$. Water binding capacity defined as the amount of water retained by the flour after it has been subjected to centrifugation was measured as described in the method 56.30 (AACC, 2012). Determinations were carried out in duplicate.

\subsubsection{Emulsifying properties}

Flour suspension $(360 \mathrm{~mL})$ of $0.5 \%(\mathrm{w} / \mathrm{v})$ starch concentration was mixed with commercial sunflower oil (Langosta, F. Faiges S.L, Daimiel, Ciudad Real) (36 mL). The content was stirred for one min with a beater (Taurus Bapi $350 \mathrm{CP} / \mathrm{CM}$, Taurus, Oliana, Lérida) to disperse the sample in the oil. The suspensions were then centrifuged at $800 \mathrm{~g}$ for $10 \mathrm{~min}$. The emulsifying capacity (EC) was calculated as:

$$
E C=\left(\frac{e v}{t v}\right) * 100
$$

where $\mathrm{e} v$ is the emulsion volume and $\mathrm{t} v$ is total volume.

Emulsion stability (ES) against high temperatures, were determined in the emulsions that were heated in a water bath at $80^{\circ} \mathrm{C}$ for $30 \mathrm{~min}$, and centrifuged at $800 \mathrm{~g}$ for $10 \mathrm{~min}$. ES was calculated as:

$$
E S=\left(\frac{f e v}{i e v}\right) * 100
$$

where $\mathrm{fev}$ is the final emulsion volume and iev is initial emulsion volume. Determinations were carried out in duplicate. 


\subsubsection{Foaming properties}

Aliquots $(150 \mathrm{~mL})$ of $4 \% \mathrm{w} / \mathrm{v}$ suspension were whipped at moderate speed for one min using a beater (Taurus Bapi $350 \mathrm{CP} / \mathrm{CM}$, Taurus, Oliana, Lérida). Foam volumes were recorded after $30 \mathrm{~s}$. The foam capacity (FC) was calculated as follows:

$$
F C=\left(\frac{i f v}{t s v}\right) * 100
$$

where if $v$ is the initial foam volume and tsv is the total suspension volume.

The foam stability (FS) was calculated as the foam volume after $20 \mathrm{~min}$.

$$
F S=\left(\frac{f f v}{t s v}\right) * 100
$$

where $\mathrm{ffv}$ is the foam volume after $20 \mathrm{~min}$ and tsv is total suspension volume. Results were the average of two determinations.

\subsubsection{Pasting characteristics}

Pasting properties of flours were analyzed using the standard method (AACC, 2012), (AACC, 61-02.01) with a Rapid Visco Analyser (RVA-4) (Newport Scientific Pty Ltd., Warriewood, Australia) controlled by Thermocline software (Newport Scientific Pty. Limited, Warriewood, Australia) for Windows. The flour slurry was prepared by dispersing $3.5 \mathrm{~g}( \pm 0.1 \mathrm{~g})$ of the flour in $25 \mathrm{~g}( \pm 0.1 \mathrm{~g})$ of distilled water.

\subsubsection{Thermal properties}

Analyses were performed in a differential scanning calorimeter DSC-7 (Perkin-Elmer, USA), using aluminum pans (PE 0219-0062). The equipment was calibrated with Indium and an empty pan was used as a reference. Flour $(3 \mathrm{mg})$ was loaded into the aluminium pan and distilled water $(10 \mathrm{lL})$ was added with the help of a Hamilton micro syringe. Samples were hermetically sealed and allowed to stand for $1 \mathrm{~h}$ at room temperature before heating in the DSC oven. The calorimeter scan conditions were set as follows: samples were kept at $30^{\circ} \mathrm{C}$ for $2 \mathrm{~min}$, heated from 30 to $110^{\circ} \mathrm{C}$ at $5^{\circ} \mathrm{C} / \mathrm{min}$.

Onset temperature (To), peak temperature $(\mathrm{Tp})$, gelatinization temperature range $(\mathrm{Tp}-\mathrm{To})$, peak height index $(\Delta \mathrm{Hg} / \mathrm{Tp}-\mathrm{To})$ as well as the enthalpy of starch gelatinization $(\Delta \mathrm{Hg})$ (expressed as $\mathrm{mJ} / \mathrm{mg}$ of sample) were determined. All samples were run in quadruplicate.

\subsubsection{Enzymatic hydrolysis of starch}

Starch hydrolysis was measured following the method described by Gularte and Rosell (2011) with minor modifications. Briefly, for free sugars removal, flour sample (100 mg) suspended in two milliliters of $80 \%$ ethanol was kept in a shaking water bath at $85{ }^{\circ} \mathrm{C}$ for five minutes, and then centrifuged for $10 \mathrm{~min}$ at $1000 \mathrm{~g}$. The pellet was incubated with 
porcine pancreatic a-amylase $(10 \mathrm{mg} / \mathrm{ml})$ (Type VI-B, P10 units/mg solid, Sigma Chemical, St. Louis, USA) and amyloglucosidase $(3300 \mathrm{U} / \mathrm{ml}$ ) (Sigma Chemical, St. Louis, USA) in $10 \mathrm{ml}$ of $0.1 \mathrm{M}$ sodium maleate buffer ( $\mathrm{pH} \mathrm{6.0)} \mathrm{in} \mathrm{a} \mathrm{shaking} \mathrm{water} \mathrm{bath} \mathrm{at}$ $37{ }^{\circ} \mathrm{C}(0.25-16 \mathrm{~h})$. Aliquots of $200 \mathrm{ll}$ were withdrawn during the incubation period and mixed with 20011 of ethanol (96\%) to stop the enzymatic reaction, then the sample was centrifuged for $5 \mathrm{~min}$ at $10,000 \mathrm{~g}$ and $4{ }^{\circ} \mathrm{C}$. The precipitate was washed twice with $50 \%$ ethanol (100 11) and the supernatants were pooled together and kept at $4{ }^{\circ} \mathrm{C}$ for further glucose determination.

The remnant starch after $16 \mathrm{~h}$ hydrolysis was solubilized with $2 \mathrm{ml}$ of $2 \mathrm{M} \mathrm{KOH}$ using a Polytron ultraturrax homogenizer IKAT18 (IKA works, Wilmington, USA) during $1 \mathrm{~min}$ at speed 3. The homogenate was diluted with $8 \mathrm{ml} 1.2 \mathrm{M}$ sodium acetate $\mathrm{pH} 3.8$ and incubated with $100 \mathrm{ll}$ amyloglucosidase $(3300 \mathrm{U})$ at $50^{\circ} \mathrm{C}$ for $30 \mathrm{~min}$ in a shaking water bath. After centrifuging at $2000 \mathrm{~g}$ for $10 \mathrm{~min}$, supernatant was kept for glucose determination.

The glucose content was measured using a glucose oxidase-peroxidase (GOPOD) kit. The absorbance was measured using an Epoch microplate reader (Biotek Instruments, Winooski, USA) at $510 \mathrm{~nm}$. Starch was calculated as glucose $(\mathrm{mg}) \times 0.9$. Replicates $(\mathrm{n}=2$ 4) were carried out for each determination.

Experimental data were fitted to a first-order equation (Goñi et al., 1997):

$$
C_{t}=C_{\infty}\left(1-e^{-k t}\right)
$$

where $\mathrm{Ct}$ is the concentration of product at time $t, \mathrm{C}^{\infty}$ is the concentration at the end point, and $\mathrm{k}$ is the pseudo-first order rate constant. Although this equation requires the estimation of an accurate $\mathrm{C} 1$, it was useful because long reaction times were applied to determine resistant starch after complete enzymatic hydrolysis. The plot of $\ln [(\mathrm{C} \infty$, $\mathrm{Ct}) / \mathrm{C} \infty]=-\mathrm{kt}$ against $\mathrm{t}$ was used to estimate the slope that corresponded to $-\mathrm{k}$.

However, as recently suggested Butterworth et al. (2012), the linear plot of $\ln (\mathrm{dC} / \mathrm{dt}$ ) against $\mathrm{t}$ was also represented to calculate the slope $(-\mathrm{k})$, and the intercept on the $\mathrm{y}$ axis was used for calculating the $\ln (\mathrm{k} \mathrm{C} \infty)$. This plot was used to demonstrate if the data were of logarithmic form and the rate constant remained unchanged along the whole hydrolysis reaction, as recommended (Poulsen et al., 2003).

\subsubsection{Statistical analysis}

Simple analyses of variance were used to determine the effects of thermal treatment. Fisher's least significant differences test was used to calculate the means with their $95 \%$ confidence intervals. Several correlations were also run. The statistical analysis was performed with the Statgraphics Plus Centurion XVI software (Statpoint Technologies, Inc., Warrenton, VA, USA). 
Physicochemical characterization and digestive properties of different flours according to the extrusion conditions

\section{Results and discussion}

Wheat flour was subjected to different extrusion treatments that differed on the maximum barrel temperature, screw speed and feed moisture content in order to obtain different extrusion intensities. Overall five flours subjected to extrusion treatments were obtained identified as 1-5 and the flour without any treatment (control) was named as flour 0 (Table 1).

Table 1: Extrusion conditions applied to wheat flours.

\begin{tabular}{cccc}
\hline $\begin{array}{c}\text { Flour } \\
\text { Code }\end{array}$ & $\begin{array}{c}\text { Barrel } \\
\text { Temperature } \\
\left({ }^{\circ} \mathrm{C}\right)\end{array}$ & $\begin{array}{c}\text { Feed Rate } \\
(\mathrm{Kg} / \mathrm{h})\end{array}$ & $\begin{array}{c}\text { Feed Moisture } \\
\text { Content }(\%)\end{array}$ \\
\hline 0 & - & - & - \\
1 & 80 & 275 & 103.6 \\
2 & 120 & 900 & 404.4 \\
3 & 120 & 400 & 6015 \\
4 & 120 & 275 & 6021.8 \\
5 & 160 & 500 & 5010 \\
\hline
\end{tabular}

\subsection{Damage starch and free sugars}

Extrusion intensity had a significant effect on free sugars content, although a minimum intensity was necessary for promoting changes (Table 2). No significant differences were observed between the free sugars content of the control (flour 0 ) and the mild extrusion treatment (flour 1). In the mild treatments (low barrel temperature, low feed moisture content and/or high feed rate), damages and changes of starch did not influence free sugars content, and thus no hydrolysis was produced. As extrusion intensity increases, higher starch gelatinization was produced, breaking the starch granules physically and opening their crystalline structure, thus the access of hydrolytic enzymes was made easier (Mu et al., 2013). In order to produce the gelatinization of starch, a minimum barrel temperature and feed moisture content are necessary (Camire et al., 1990; Chao-Chi Chuang and Yeh, 2004), which are not reached in milder treatments. Feed rate have an influence on mean residence time and therefore would also have an influence on gelatinization process.

Extrusion is also able to promote enzyme inactivation, however, in light of the results, extrusion conditions used in this study did not produce enough enzyme inactivation to stop their activity. 
Table 2: Effect of extrusion treatment (0-5) on free sugars, damaged starch, hydration, emulsifying and foaming properties of wheat flours.

\begin{tabular}{lrrrrrr} 
& \multicolumn{7}{c}{ Extrusion treatment } \\
\hline & \multicolumn{1}{c}{0} & \multicolumn{1}{c}{$\mathbf{1}$} & \multicolumn{1}{c}{$\mathbf{2}$} & \multicolumn{1}{c}{3} & \multicolumn{1}{c}{4} & \multicolumn{1}{c}{5} \\
\hline Free Sugars (\%) & $5.84 \mathrm{a}$ & $5.42 \mathrm{a}$ & $9.74 \mathrm{~b}$ & $13.80 \mathrm{c}$ & $18.04 \mathrm{~d}$ & $44.22 \mathrm{e}$ \\
Damaged Starch (\%) & $4.97 \mathrm{a}$ & $8.49 \mathrm{~b}$ & $9.14 \mathrm{~b}$ & $21.03 \mathrm{c}$ & $26.08 \mathrm{~d}$ & $37.95 \mathrm{e}$ \\
WBC (g water/g solid) & $0.78 \mathrm{a}$ & $0,83 \mathrm{a}$ & $1.28 \mathrm{~b}$ & $1.91 \mathrm{c}$ & $2.19 \mathrm{~d}$ & $4.97 \mathrm{e}$ \\
Swelling (mL/g) & $0.10 \mathrm{a}$ & $0.40 \mathrm{a}$ & $0.65 \mathrm{a}$ & $2.12 \mathrm{~b}$ & $2.98 \mathrm{c}$ & $9.50 \mathrm{~d}$ \\
EC & $82.97 \mathrm{a}$ & $82.97 \mathrm{a}$ & $85.00 \mathrm{ab}$ & $85.16 \mathrm{~b}$ & $85.78 \mathrm{~b}$ & $90.78 \mathrm{c}$ \\
ES & $115.18 \mathrm{~d}$ & $115.27 \mathrm{~d}$ & $106.8 \mathrm{~b}$ & $114.25 \mathrm{~d}$ & $110.16 \mathrm{c}$ & $100.16 \mathrm{a}$ \\
FC & $51.72 \mathrm{c}$ & $51.99 \mathrm{c}$ & $28.55 \mathrm{~b}$ & $19.59 \mathrm{a}$ & $18.06 \mathrm{a}$ & $30.58 \mathrm{~b}$ \\
FS & $86.33 \mathrm{~d}$ & $27.70 \mathrm{~b}$ & $69.64 \mathrm{c}$ & $0.00 \mathrm{a}$ & $0.00 \mathrm{a}$ & $0.00 \mathrm{a}$ \\
\hline
\end{tabular}

WBC, water binding capacity; EC, emulsifying capacity; ES, emulsion stability; FC, foaming capacity; FS, foam stability.

Numbers in sample codes are referred to extrusion intensity, being number 0 ascribed to control sample.

Values followed by different letters within a row indicate significant differences $(\mathrm{P}<0.05)$.

Extrusion lead to a progressive increase of damage starch content with the increasing of extrusion treatment, probably due to the damage produced by shear stress and temperature on starch granules during extrusion (Camire et al., 1990). Nonetheless, no differences were observed between flour 1 and 2 in spite of barrel temperature differences. Moreover, considering differences observed in damaged starch content of flour 2 and 3, which were extruded at the same temperature, feed rate and feed moisture content significantly affected the damage produced on starch granules as Chao-Chi Chuang and Yeh (2004) observed studying the effects of three types of screw elements on glutinous rice flour in a single screw extruder.

\subsection{Hydration, emulsifying and foaming properties}

Hydration, emulsifying and foaming properties were significantly affected by the extrusion process (Table 2). A progressive increase in the hydration properties (WBC and swelling) was observed as the extrusion intensity increased, but a minimum temperature besides feed rate and feed moisture content in the extrusion was needed to promote changes in hydration properties. No differences were appreciated between flour 0 and flour 1 in both hydration properties, neither among control (flour 0 ) and flour 1 and 2 in the case of swelling. Thus, not only was high barrel temperature necessary but also low feed rate and high feed moisture content were necessary to modify hydration properties 
of flours. Chao-Chi Chuang et al. (2004) observed that the degree of starch gelatinization in extrudates was dependent on the mean residence time during extrusion, which in turn was correlated with the feed rate, increasing the degree of gelatinization by decreasing the feed rate.

The effects on hydration properties could be partially attributed to the increase in damaged starch content since it showed a significant positive correlation with WBC $(\mathrm{r}=$ 0.92) and swelling $(r=0.92)$. On the other hand, Camire et al. (1990) proposed that the breakage of the starch granule integrity led to a poorly ordered molecular phase with hydroxyl groups prone to bind water molecules. Moreover, the cooking produced during extrusion led to starch gelatinization that contributes to raise WBC and swelling, as Hagenimana et al. (2006) appreciated in their values of water absorption index.

The extrusion significantly increased the emulsifying capacity of the wheat flours when sufficient feeding water was available and adequate barrel temperature. To become evident changes in EC of the flours, $120^{\circ} \mathrm{C}$ were necessary (flours 2, 3 and 4) and the greatest effect (flour 5) was observed when temperature of $160{ }^{\circ} \mathrm{C}$ was reached. Barrel temperature could produce protein and starch changes during extrusion process. Extrusion forces protein unfolding and aggregation due to protein crosslinking involving $\mathrm{SH} / \mathrm{SS}$ interchange, oxidation and hydrophobic interactions (Rosell and Foegeding, 2007) along with starch gelatinization that increases the number of hydroxyl groups available to form hydrogen bonds with the proteins, leading to better emulsion capacity (Mason, 2009).

Emulsion stabilities did not follow a steady trend with the extrusion severity, having flour 3 the same ES than the control. Emulsion stability depends greatly on the oil globule size and its interfacial tension. As it has been commented previously, extrusion forces the protein unfolding and aggregation, which could minimize the barrier effect against oil droplet coalescence (Aluko et al., 2009). Thereby, extruded flours although had high capacity to form emulsions, those were not stable due to coalescence phenomena, as indicated the significant negative correlation between EC and ES $(r=-0.84, \mathrm{P}<0.001)$.

In general, extrusion worsened the foaming capacity (with the exception of flour 1 which did not have significant difference with control) and foaming stability of wheat flours, even though no clear trend was observed. Similar results were exposed by Bolade et al. (2002), who observed how corn flours subjected to intense hydrothermal treatments did not improve their foaming capacity. This diminution of foaming capacity of flours could be due to protein unfolding and aggregation induced by the extrusion process. The FC results from microstructure, size and distribution of the gas cells and the interfacial properties (Zhang et al., 2011). The opposite trend observed in the emulsifying and foaming properties supports the different mechanisms involved during interfacial membrane formation at the air-water and oil-water interfaces (Stauffer, 1990). 


\subsection{Pasting characteristics}

Pasting plots of the extruded flours are displayed in Fig. 1. When wheat flours were suspended in water, the major value for the initial viscosity at $50{ }^{\circ} \mathrm{C}$ was observed in the flour 5, which suggested the presence of already pregelatinized starch. Chao-Chi Chuang et al. (2004) in a study with glutinous rice flour observed that with the increase of the mean residence time, an increase of temperature and starch gelatinization took place. This greater gelatinization in the most severe treatments can be the reason for the differences in the initial viscosity at $50^{\circ} \mathrm{C}$.

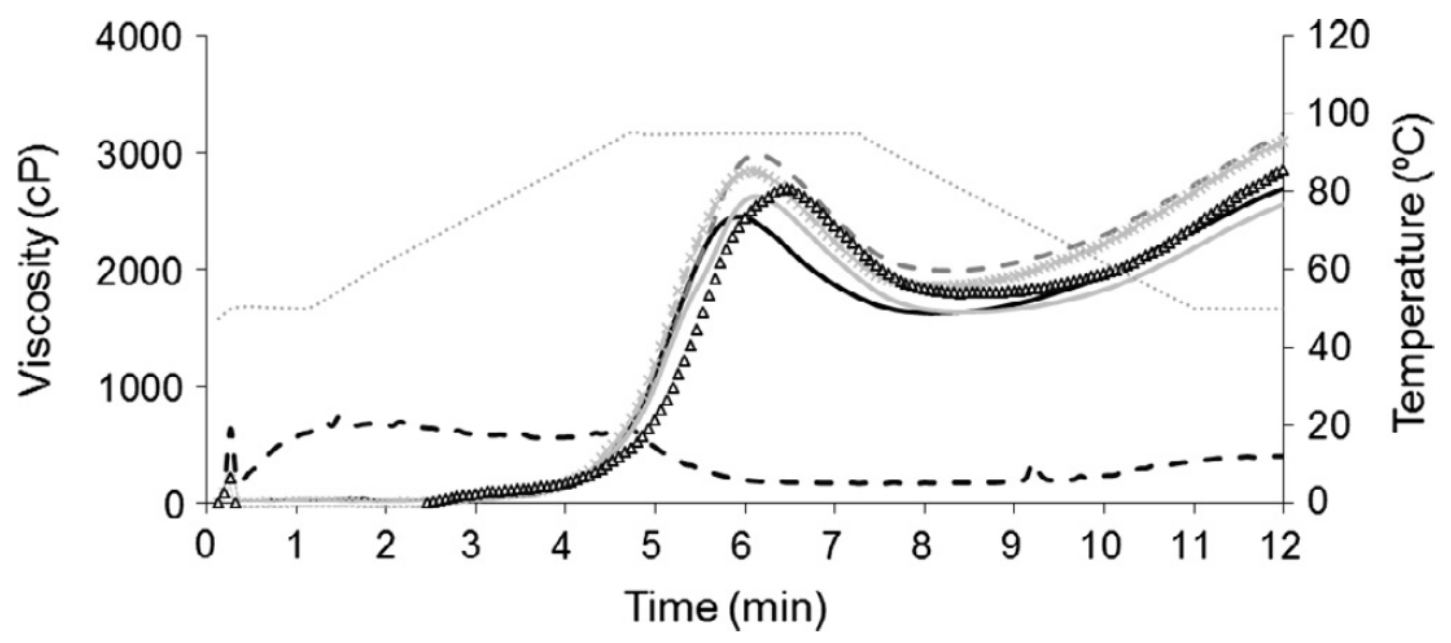

Fig. 1. Effect of extrusion treatment on the pasting properties of wheat flours. Flour 0 (open triangle), flour 1 (clear grey line), flour 2 (discontinuous clear grey line with + ), flour 3 (discontinuous intense tone grey line), flour 4 (black grey line), flour 5 (discontinuous black grey line). Temperature profile (discontinuous points).

When flours were subjected to heating-cooling cycle in RVA, extrusion effect was readily evident on the plots. Pasting temperatures were shifted to lower values as the extrusion intensity increased, with exception of flour 5 that showed a completely different viscosity plot with low viscosity along the heating-cooling cycle. A minimum barrel temperature and moisture content was needed to induce changes in the flour viscosity, because of that minimum changes were observed in flour 1 . As the extrusion treatment intensified on the flours, the viscosity during heating and cooling increased, but it seems that viscosity decreased when extrusion induced partial starch breakdown (flour 4), and that effect was even more dramatic when changes beyond gelatinization occurred (flour 5). The intermediate extrusion conditions applied to flour 2 and 3 seems to affect the starch granules increasing the viscosity in the cycle. Hoover and Vasanthan (1994) already observed this effect when conditions were no sufficient to induce starch gelatinization. Those authors attributed it to an increase of the granular rigidity resulting from an increase in the crystalline order and in the amylo-lipids complexes amount; and starch chain interactions within the amorphous region. Nonetheless, Biliaderis (2009) commented that cereals subjected to heat-moisture treatment, lose their crystallinity. In 
extrusion process, where the combination of heating and swelling of amorphous starch destabilizes crystalline regions, extrusion severity might be an alternative to control the degree of flours modification (Camire et al., 1990).

The extensive gelatinization that the wheat flours undergo when are subjected to severe extrusion intensity (flour 5) could promote the viscosity decrease during the heatingcooling cycle, as it was observed by Hagenimana et al. (2006) and Sharma et al. (2013).

Peak viscosity obtained during heating was significantly dependent on the damage starch content $(r=-0.71)$, which might be explained by the changes in the polymerization degree of the starch granules after damaging (Barres et al., 1990).

The reduction observed in the final viscosity and setback (difference between the minimum viscosity during heating and the final viscosity after cooling) in flour subjected to harsh extrusion (flour 5), indicated the extension of the effect on the amylose chains, which might lose the ability to retrograde during cooling owing to their fragmentation during extrusion. This effect agrees with previous results of Doublier et al. (1986).

\subsection{Differential Scanning Calorimetry (DSC)}

The effect of extrusion treatment on the thermal properties of the wheat flours is shown in Table 3. In the range of temperature tested, flours exhibited one endothermic peak, with the exception of flour 5, corresponding to amylopectin gelatinization. Therefore, the diverse extrusion conditions applied to wheat flours were sufficient to change some starch features but were not strongly enough to complete starch gelatinization. Only in the case of flour 5, the absence of an endothermic peak confirmed total gelatinization of amylopectin. Indeed, this result agrees with that previously discussed regarding the very small viscosity plot obtained for flour 5 . The extrusion treatment significantly modified the gelatinization temperatures of the flours. Gelatinization temperatures were progressively sifted to higher values when flours were treated at increasing extrusion intensity, but the temperature range and the peak height index were not affected. Higher gelatinization temperature indicated that more energy is required to initiate gelatinization of the starch suggesting that extrusion is affecting the outer and more amorphous part of the granule and is progressing to the core of the granule till no crystalline structure is left for gelatinization (flour 5). Those results agree with the viscosity plots recorded by the RVA. Additionally, pasting temperature was sifted to lower temperatures due to the effect of extrusion on the outer structure of the granules, without affecting the crystalline internal one, which will lead higher gelatinization temperatures. 
Physicochemical characterization and digestive properties of different flours according to the extrusion conditions

Table 3. Effect of extrusion treatment (0-5) on the thermal properties of wheat flours.

\begin{tabular}{|c|c|c|c|c|c|c|}
\hline & \multicolumn{6}{|c|}{ Extrusion treatment } \\
\hline & 0 & 1 & 2 & 3 & 4 & 5 \\
\hline$\overline{\mathrm{T}_{\mathrm{o}}\left({ }^{\circ} \mathrm{C}\right)}$ & $55.4 \mathrm{a}$ & $55.8 \mathrm{ab}$ & $58.8 \mathrm{bc}$ & $59.2 c$ & $61.3 \mathrm{c}$ & n.d \\
\hline $\mathrm{T}_{\mathrm{p}}\left({ }^{\circ} \mathrm{C}\right)$ & $60.7 \mathrm{a}$ & $61.6 \mathrm{ab}$ & $63.1 b$ & $64.9 c$ & $65.2 \mathrm{c}$ & n.d \\
\hline $\mathrm{T}_{\mathrm{c}}\left({ }^{\circ} \mathrm{C}\right)$ & $68.7 \mathrm{ab}$ & $66.7 \mathrm{a}$ & $67.7 \mathrm{a}$ & $70.1 \mathrm{bc}$ & $71.6 \mathrm{c}$ & n.d \\
\hline $\mathrm{T}_{\mathrm{p}}-\mathrm{T}_{\mathrm{o}}\left({ }^{\circ} \mathrm{C}\right)$ & $5.3 \mathrm{a}$ & $5.7 \mathrm{a}$ & $4.3 \mathrm{a}$ & $5.6 \mathrm{a}$ & $3.9 \mathrm{a}$ & n.d \\
\hline$\Delta \mathrm{H}(\mathrm{J} / \mathrm{g})$ & $4.18 b$ & $2.86 b$ & $3.26 b$ & $2.85 b$ & $0.80 \mathrm{a}$ & n.d \\
\hline $\mathrm{PHI}\left(\mathrm{J} / \mathrm{g}^{*_{\circ}} \mathrm{C}\right)$ & $0.76 \mathrm{~b}$ & $0.49 \mathrm{ab}$ & $0.77 b$ & $0.51 \mathrm{ab}$ & $0.21 \mathrm{a}$ & n.d \\
\hline
\end{tabular}

n.d.: Not detected.

To, gelatinization onset; $\mathrm{Tp}$, peak temperature; $\mathrm{Tc}$, conclusion temperature, $\mathrm{Tp}-\mathrm{To}$, gelatinization range, enthalpy and PHI, peak high index.

Numbers in sample codes are referred to extrusion intensity, being number 0 ascribed to control sample.

Values followed by different letters within a row indicate significant differences $(\mathrm{P}<0.05)$.Values followed by different letters within each parameter indicate significant differences.

When comparing extruded flours, the gelatinization enthalpy was significantly reduced due to the intensity of the extrusion, which was expected since extrusion induces starch gelatinization and an increase of the damage starch content (Chiu and Solarek, 2009), leading to a reduction of the native starch granules able to gelatinize (Biliaderis et al., 1986). The extrusion process modifies the crystalline structure of the starch granule affecting the temperature at which swelling starts (Camire et al., 1990).

\subsection{Starch hydrolysis}

The susceptibility of the extruded flours to the enzymatic hydrolysis was analyzed, following the kinetic plots (Fig. 2). The hydrolysis curves were fitted to a first order kinetics according to Goñi et al. (1997) and also to Butterworth et al. (2012) to obtain the kinetic parameters (Table 4). As it was observed in the plots, there was a slight increase in the equilibrium concentration reached after hydrolysis of the wheat flours extruded at $120{ }^{\circ} \mathrm{C}$. Our study are consistent with the one presented by Hagenimana et al. (2006), who stated that the susceptibility of the extruded starches to be enzymatically hydrolyzed was directly related to the intensity of the extrusion treatment. However, wheat flours extruded at lower temperature (flour 1) displayed much faster and extensive hydrolysis, and the same trend was observed at the most intense extrusion treatment (flour 5). Therefore, depending on extrusion parameters, starch modifications could be different. The lower barrel temperature and the lower feed moisture content of flour 1 (insufficient to gelatinize the starch), together with the longer residence time, would produce major structural rearrangements without gelatinization, increasing the contact between amorphous starch and enzymes and therefore the susceptibility to enzyme-catalyzed hydrolysis. 
Physicochemical characterization and digestive properties of different flours according to the extrusion conditions

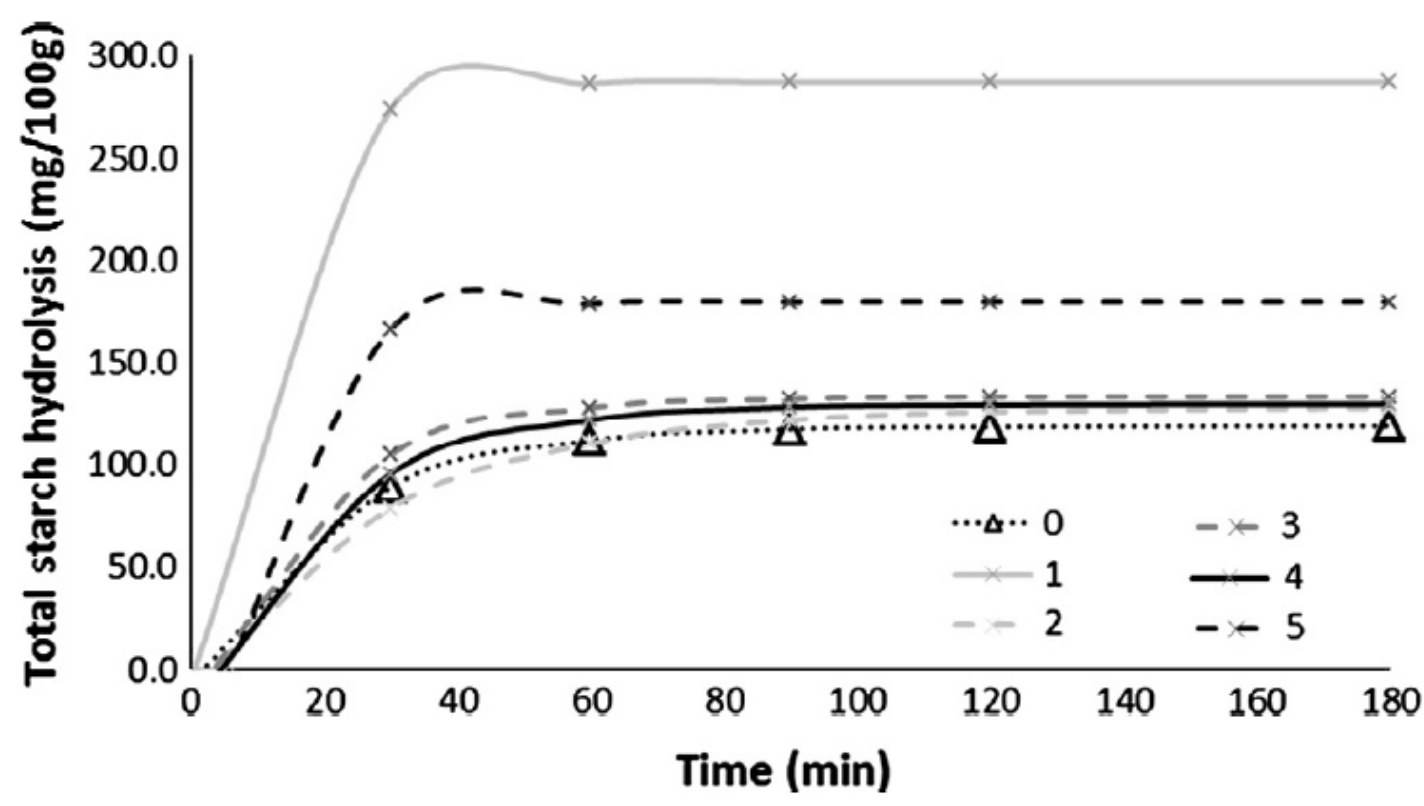

Fig. 2. Effect of extrusion treatment on the enzymatic hydrolysis of wheat flours. Flour 0 (open triangle), flour 1 (clear grey line), flour 2 (discontinuous clear grey line), flour 3 (discontinuous intermediate tone grey line), flour 4 (dark grey line), flour 5 (discontinuous dark grey line).

When the kinetic parameters were extracted from the hydrolysis time curves (Table 4), no general trend was observed between the rate of hydrolysis $(\mathrm{k})$ and the extrusion intensity. There was great agreement with the equilibrium concentration estimated from both fitting methods, indicating that the kinetic parameters can be fitted to a logarithmic function and that the rate constant did not vary along the hydrolysis reaction (Poulsen et al., 2003).

Table 4. Kinetic parameters extracted from first-order and LOS plots of wheat flours subjected to different extrusion conditions.

\begin{tabular}{cccccc}
\hline & $\begin{array}{c}k\left(\mathrm{~min}^{-1}\right) \text { by first } \\
\text { order eq. }\end{array}$ & $k\left(\mathrm{~min}^{-1}\right)$ by LOS & $C_{\infty}(\%)$ & $\begin{array}{c}C_{\infty}(\%) \text { by } \\
\text { LOS }\end{array}$ & $\begin{array}{c}\text { Resistant } \\
\text { starch (\%) }\end{array}$ \\
\hline 0 & 0.048 & 0.046 & 125.00 & 130.32 & 6.11 \\
1 & 0.103 & 0.094 & 292.46 & 306.15 & 8.96 \\
2 & 0.034 & 0.034 & 137.82 & 142.06 & 4.50 \\
3 & 0.055 & 0.053 & 147.10 & 156.94 & 5.80 \\
4 & 0.049 & 0.047 & 147.90 & 155.73 & 3.69 \\
5 & 0.093 & 0.088 & 223.81 & 255.40 & 2.29 \\
\hline
\end{tabular}

$\mathrm{k}$, kinetic constant; $\mathrm{C} \infty$, equilibrium concentration

Numbers in sample codes are referred to extrusion intensity, being number 0 ascribed to control sample.

Values followed by different letters within a row indicate significant differences $(P<0.05)$. 
Resistant starch was also quantified to determine the potential impact of the extrusion on the structural level of starch. In general, a decrease in the amount of resistant starch present in the extruded flours was observed, with the exception of flour 1 that showed higher content of resistant starch. This finding disagrees with previous observations of Hagenimana et al. (2006) who found an increase in RS content with the treatment severity in high-amylose long rice. Those authors attributed the increase in RS to the formation of amylose-lipid complexes during the extrusion, which retarded the enzymatic digestion (Collier and O' Dea, 1983). Therefore, results divergence might be explained due to the high amylose content of rice flour and also its higher gelatinization temperature compared with the wheat flour. In addition, Chinnaswamy and Hannah (1990) reported a change in the percentage of amylose/amylopectin ratio in extruded corn flours that was ascribed to both chains fragmentation, being more intense in the former. That fact could affect the amount of RS. It is convenient to highlight the greater values of RS and starch hydrolysis of flour 1. de Mosqueda et al., 1986 observed that extrusion mild treatments did not modify the amylose chain length in rice flours, thus the creation of V-type structures would be higher protecting starch from degradation. Moreover, as it was commented by Biliaderis (2009), the mild treatment heat-moist also increase the susceptibility to enzyme-catalysed hydrolysis, thus the non-resistant starch in our flour 1 would be more easily hydrolysed.

\section{$\underline{4 . \text { Conclusion }}$}

Extrusion of wheat flours might be an alternative to obtain wheat flours with different technological functionality. Hydration, thermal, emulsifying and pasting properties of wheat flours besides their susceptibility to enzymatic hydrolysis can be modified by extrusion. Starch gelatinization increased with the extrusion severity, augmenting the hydration properties and the viscosity in cold solution of wheat flours. In parallel, extrusion also enhanced the emulsifying capacity and increased the free sugars of wheat flours, making them suitable for some foodstuff. In general, the susceptibility to enzymatic hydrolysis increased and the amount of RS decreased as the extrusion severity increased.

\section{$\underline{\text { Acknowledgements }}$}

Authors acknowledge the financial support of Junta de Castilla y León (VA054A12-2) and Generalitat Valenciana (Project Prometeo 2012/064). Authors are also grateful to Harinera Los Pisones, (Zamora, Spain) for supplying the wheat flours. Mario M. Martínez would like to thank predoctoral fellowship from University of Valladolid. 


\section{$\underline{\text { References }}$}

AACC, 2012. Approved methods of the American Association of Cereal Chemists, 7630a (damaged starch), 56-30 (WBC), 61-02.01 (RVA), 11th ed., St. Paul, Minnesota, American Association of Cereal Chemists.

Aluko, R., Mofolasayo, O., Watts, B., 2009. Emulsifying and foaming properties of commercial yellow pea (Pisum sativum L.) seed flours. J. Agric. Food Chem. 57, 97939800.

Barres, C., Verges, B., Tayeb, J., Della Valle, G., 1990. Transformation of wheat flour by extrusion cooking. Influence of screw configuration and operating conditions. Cereal Chem. 67, 427-433.

Biliaderis, C., 2009. Structural transitions and related physical properties of starch. In: BeMiller, J., Whistler, R. (Eds.), Starch. Chemistry and Technology. Academic Press, New York. USA, pp. 293-372.

Biliaderis, C., Page, C., Maurice, T., Juliano, B., 1986. Thermal characterization of rice starches: a polymeric approach to phase-transitions of antigranulocytes starch. J. Agric. Food Chem. 34, 6-14.

Bolade, M., Usman, M., Rasheed, A., Benson, E., Salifou, I., 2002. Influence of hydrothermal treatment of maize grains on the quality and acceptability of Tuwon masara (traditional maize gel). Food Chem. 79, 479-483.

Butterworth, P., Warren, F., Grassby, T., Patel, H., Ellis, P., 2012. Analysis of starch amylolysis using plots for first-order kinetics. Carbohydr. Polym. 87, 2189-2197.

Camire, M.E., Camire, A., Krumhar, K., 1990. Chemical and nutritional changes in foods during extrusion. Crit. Rev. Food Sci. Nutr. 29, 35-57.

Chao-Chi Chuang, G., Yeh, A.I., 2004. Effect of screw profile on residence time distribution and starch gelatinization of rice flour during single screw extrusion cooking. J. Food Eng. 63, 21-31.

Chinnaswamy, R., Hannah, M.A., 1990. Macromolecular and functional properties of native and extruded corn starch. Cereal Chem. 67, 490-499.

Chiu, C., Solarek, D., 2009. Modification of starch. In: BeMiller, J., Whistler, R. (Eds.), Starch. Chemistry and Technology. Academic Press, New York. USA, pp. 629-656.

Collier, G.,O' Dea, K., 1983. The effect of coingestion of fat on the glucose, insulin and gastric inhibitory polypeptide responses to carbohydrate and protein. Am. J. Clin. Nutr. 37, 941-944. 
de Mosqueda, M.B., Perez, C.M., Juliano, B.O., del Rosario, R.R., Bechtel, D.B., 1986. Varietal differences in properties of extrusion-cooked rice flour. Food Chem. 19, 173187.

Doublier, J.L., Colonna, P., Mercier, C., 1986. Extrusion cooking and drum drying of wheat-starch. 2. Rheological characterization of starch pastes. Cereal Chem. 63, 240-246.

Goñi, I., Garcia-Alonso, A., Saura-Calixto, F., 1997. A starch hydrolysis procedure to estimate glycemic index. Nutr. Res. 17, 427-437.

Gularte, M.A., Rosell, C.M., 2011. Physicochemical properties and enzymatic hydrolysis of different starches in the presence of hydrocolloids. Carbohydr. Polym. 85, 237-244.

Hagenimana, A., Ding, X., Fang, T., 2006. Evaluation of rice flour modified by extrusion cooking. J. Cereal Sci. 43, 38-46.

Hoover, R., Vasanthan, T., 1994. Effect of heat-moisture treatment on the structure and physicochemical properties of cereal, legume and tuber starches. Carbohydr. Res., 33-53.

Jacobs, H., Delcour, J., 1998. Hydrothermal modifications of granular starch, with retention of the granular structure: a review. J. Agric. Food Chem. 46, 2895-2905.

Martinez, M., Oliete, B., Gomez, M., 2013. Effect of the addition of extruded wheat flours on dough rheology and bread quality. J. Cereal Sci. 57, 424-429.

Mason, W.R., 2009. Starch use in foods. In: BeMiller, J., Whistler, R. (Eds.), Starch. Chemistry and Technology. Academic Press, New York, USA, pp. 745-795.

Mu, T., Abegunde, O., Sun, H., Deng, F., Zhang, M., 2013. Physicochemical characterization of enzymatically hydrolyzed heat treated granular starches. Starch-Starke 65, 893-901.

Nelson, A.L., 2001. Properties of high-fibre ingredients. Cereal Foods World 46, 93-97.

Poulsen, B., Ruiter, G., Visser, J., Iversen, J., 2003. Determination of first order rate constants by natural logarithm of the slope plot exemplified by analysis of Aspergillus niger in batch culture. Biotechnol. Lett. 25, 565-571.

Puncha-Arnon, S., Uttapap, D., 2013. Rice starch vs. rice flour: differences in their properties when modified by heat-moisture treatment. Carbohydr. Polym. 91, 85-91.

Rosell, C., Foegeding, A., 2007. Interaction of hydroxypropylmethylcellulose with gluten proteins: small deformation properties during thermal treatment. Food Hydrocolloids 21, 1092-1100. 
Sharma, P., Singh, V., Subramanian, R., 2013. Pasting, swelling, and solubility characteristics of rice batter prepared from different wet grinding systems. Starch-Starke $65,374-381$.

Stauffer, C., 1990. Functional additives for bakery products. Van Nostrand Reinhold, New York.

Sun, Q., Han, Z., Wang, L., Xiong, L., 2013. Physicochemical differences between sorghum starch and sorghum flour modified by heat-moisture treatment.

Wen, L., Rodis, P., Wasserman, B., 1990. Starch fragmentation and protein insolubilization during twin-screw extrusion of corn meal. Cereal Chem. 67, 268-275.

Zhang, M., Bai, X., Zhang, Z., 2011. Extrusion process improves the functionality of soluble dietary fiber in oat bran. J. Cereal Sci. 54, 98-113. 


\subsection{Effect of different extrusion treatments and particle size distribution on the physicochemical properties of rice flour}

Food Bioprocess Technol (2014) 7:2657-2665

DOI 10.1007/s11947-014-1252-7

ORIGINAL PAPER

\section{Effect of Different Extrusion Treatments and Particle Size Distribution on the Physicochemical Properties of Rice Flour}

Mario M. Martínez • Adelina Calviño •

Cristina M. Rosell • Manuel Gómez

Received: 6 September 2013 /Accepted: 1 January 2014 /Published online: 29 January 2014

(C) Springer Science+Business Media New York 2014

\section{$\underline{1 . \text { Introduction }}$}

Lately, there is an increasing interest for gluten free products that has prompted extensive research, which has been mainly focused on improving the quality of gluten free products. Nevertheless, the potential of flours from gluten free cereals has been scarcely exploited. Physical treatments have the benefit over the chemical ones of changing starch functionalities keeping the Green label (Jacobs and Delcour 1998).

Rice flour functional properties are fully dependent on genotype and environmental conditions (Yeh 2004) and besides that, postharvest treatments could be an alternative for modulating flour functional features. It is well known that rice grinding significantly affects rice flour properties, such as water binding capacity and swelling power (Perdon et al 2001). Recently, it has been shown that particle size fractionation of rice flour might be advisable for selecting specific physicochemical properties, such as different hydration properties and enzymatic starch hydrolysis (de la Hera et al 2013a); rheological properties (Moreira et al 2013) or even oil barrier properties (Lee et al 2013). Moreover, those fractionated flours showed different processing behavior more suitable for bread or cake making depending on the particle size (de la Hera et al 2013b,c).

Thermal treatments are highly attractive to modify the functional properties of the cereal flours. Extrusion cooking is considered high-temperature-short-time duringwhich flours are submitted to high temperatures and mechanical shearing at relatively low levels of moisture content (Camire et al 1990). This treatment allows starch pregelatinization, denaturation of protein, enzyme (in)activation and Maillard reactions, the extent of 
which are dependent on the severity of the extrusion. Those changes at the constituents' level modify the rheological behavior of flour (Hagenimana et al 2006). During extrusion, the starch properties are dependent on the temperature, initial moisture content and the screw speed (Wen et al 1990). By raising the intensity of the treatment, it is possible to break down the amylopectin chains (Mercier and Feillet 1975). In fact, Colonna et al. (1984) described that extruded wheat starches have amylose and amylopectin chains of lower molecular weight than the ones obtained by drum drying, attributable to the shear effect, and that gave low thickening ability at low temperature (Doublier et al.1986).

The extrusion also promotes important nutritional changes in the flours, such as an increase in the soluble fiber content and a reduction in the lipid oxidation tendency, the content of antinutritional factors and the microbial population (Camire et al. 1990). Besides, it could increase the content of resistant starch in rice flours (Hagenimana et al 2006), which is dependent on the treatment intensity (Alsaffar 2011). Extrusion cooking is responsible for gelatinization and degradation of starch and also for changing the extent of molecular associations between components (e.g., the amylose- lipid complex that can affect the in vitro starch digestibility of the flours [Hagenimana et al. 2006]).

Despite the impact of the extrusion on the molecular level, little attention has been paid to the variation of the functional properties of the flours by hydrothermal treatments (Clerici et al. 2009), even though physically modified flours are considered to be natural materials with high safety (Jacobs and Delcour 1998). In fact, Clerici et al. (2009) included $10 \%$ of extruded acid-modified rice flours for making gluten free breads. When using rice flours extruded in the presence of different amount of lactic acid, gluten free breads presented crust and crumb color and texture values similar to those of wheat bread, although specific volume was rather low.

Considering the influence of the flour fractionation on the functional properties of the rice flours (de la Hera et al. 2013b) and the molecular changes induced by extrusion cooking, the combination of both physical treatments could modify rice flour functional properties keeping the green label. The aim of this study was to modify the functional properties of rice flour by combining extrusion and size fractionation. With that purpose, different extrusion conditions were applied to vary the severity of the treatment on the flour constituents. The impact of processing on the flours was also followed by assessing the susceptibility of the flours to enzymatic hydrolysis.

\section{Materials and Methods}

\subsection{Materials}

Rice flours were provided by Harinera Los Pisones (Zamora, Spain) that carried out the extrusion treatment in a single screw extruder Bühler Basf (Bühler S.A., Uzwil, Switzerland). Extrusion parameters were chosen according to the manufacturer advice in order to achieve flours with different properties. The length to diameter (L/D) ratio for 
the extruder was 20:1. Rice flour was subjected to different extrusion intensities (barrel temperature, moisture content of the mass feed and feed rate) yielding three types of extrudedflours (1-3). Rice flour 1 and 2 were extruded at a maximum barrel temperature of $110^{\circ} \mathrm{C}$ with a feed rate of $700 \mathrm{~kg} / \mathrm{h}$. For flours 1 and 2 feed moisture content and screw speed was $17 \%$ and $30 \%$, and 453 and $397 \mathrm{rpm}$, respectively. The diameter of the die hole and the number of holes used in those flours was $8 \mathrm{~mm}$ and 18 holes, respectively. Rice flour 3 was extruded at a maximum barrel temperature of $140^{\circ} \mathrm{C}$ with a feed-rate of $500 \mathrm{~kg} / \mathrm{h}$ and feed moisture content of $25 \%$. The screw speed was $340 \mathrm{rpm}$, the diameter of the die hole was 6 mmand the number of holes was 9 . The same rice flour (rice flour 0 ) without any treatment was used as a control.

Extruded product was dried by convection air and then ground with a compression roller till particle size was lower than $200 \mu$. Ground extrudates were sifted in a Bühler MLI 300B (Bühler AG, Uzwil, Switzerland) with screens of 132 and 200 microns to obtain fine (f)-lower than $132 \mu \mathrm{m}$ - and coarse (c)-132 $200 \mu \mathrm{m}$ - extruded flours.

Flours were stored in air-tight plastic containers and held at $4{ }^{\circ} \mathrm{C}$ until analysis.

Both the extruded and nonextruded flours were involved in the analytical measurements.

\subsection{Methods}

\subsubsection{Flours Characterization}

Flours were analyzed following AACC method (AACC 2012) for protein (AACC 4630.01) with a Leco TruSpec device (Leco, St. Joseph, MI, USA). The particle size distribution was measured using a particle size analyzer with laser diffraction Helos \& Rodos (Sympatec, Clausthal-Zellerfeld, Germany) following AACC method (AACC, 55 40.01). Determinations were carried out in duplicate.

\subsubsection{Free Sugars}

The glucose content was measured using a glucose oxidaseperoxidase kit. The absorbance was measured using an Epoch microplate reader (Biotek Epoch, Izasa, Barcelona, Spain) at $510 \mathrm{~nm}$. In all cases four replicates were assayed for each experimental point.

\subsubsection{Damage Starch}

The content of damaged starch was determined according to AACC 76-30A method (AACC 2012).A fungal enzyme from Aspergillus oryzae (A6211; Sigma Chemical Co., St. Louis, MO, USA) was used in that analysis. Three determinations were made for each sample. Damaged starch was expressed as percentage of flour weight on dry basis.

\subsubsection{Hydration Properties}


Hydration properties included swelling and water binding capacity (WBC) (Nelson 2001). Swelling volume or the volume occupied by a known weight of flour was evaluated by mixing $5 \mathrm{~g}( \pm 0.1 \mathrm{mg})$ of flour with $100 \mathrm{~mL}$ distilled water and allowing it to hydrate during $16 \mathrm{~h}$. Water binding capacity defined as the amount of water retained by the flour after it has been subjected to centrifugation was measured as described the method 56.30 (AACC 2012). Determinations were carried out in duplicate.

\subsubsection{Emulsifying Properties}

Flour suspension $(360 \mathrm{~mL})$ of $0.5 \%(\mathrm{w} / \mathrm{v})$ starch concentration was mixed with commercial sunflower oil (Langosta, F. Faiges S.L, Daimiel, Ciudad Real, Spain) (36 mL). The content was stirred for one min with a beater (Taurus Bapi $350 \mathrm{CP} / \mathrm{CM}$; Taurus, Oliana, Lérida, Spain) to disperse the sample in the oil. The suspensions were then centrifuged at $800 \times \mathrm{g}$ for $10 \mathrm{~min}$. The emulsifying capacity (EC) was calculated as:

$$
E C=\left(\frac{e v}{t v}\right) * 100
$$

where $\mathrm{e} v$ is the emulsion volume and $\mathrm{t} v$ is total volume.

Emulsion stability (ES) against high temperatures, were determined in the emulsions that were heated in a water bath at $80^{\circ} \mathrm{C}$ for $30 \mathrm{~min}$, and centrifuged at $800 \times \mathrm{g}$ for $10 \mathrm{~min}$. ES was calculated as:

$$
E S=\left(\frac{f e v}{i e v}\right) * 100
$$

where fev is the final emulsion volume and iev is initial emulsion volume. Determinations were carried out in duplicate.

\subsubsection{Foaming Properties}

Aliquots $(150 \mathrm{~mL})$ of $4 \% \mathrm{w} / \mathrm{v}$ suspension were whipped at moderate speed for one min using a beater (Taurus Bapi $350 \mathrm{CP} / \mathrm{CM}$; Taurus, Oliana, Lérida, Spain). Foam volumes were recorded after $30 \mathrm{~s}$. The foam capacity (FC) was calculated as follows:

$$
F C=\left(\frac{i f v}{t s v}\right) * 100
$$

where ifv is the initial foam volume and tsv is the total suspension volume.

The foam stability (FS) was calculated as the foam volume after $20 \mathrm{~min}$.

$$
F S=\left(\frac{f f v}{t s v}\right) * 100
$$

where $\mathrm{ffv}$ is the foam volume after $20 \mathrm{~min}$ and tsv is total suspension volume. Results were the average of two determinations. 


\subsubsection{Pasting Characteristics}

Pasting properties of flours were analyzed using the standard method (AACC 2012), (AACC 61-02.01) with a Rapid Visco Analyser (RVA-4) (Newport Scientific Pty Ltd., Warriewood, Australia) controlled by Thermocline software (Newport Scientific Pty. Limited, Warriewood, Australia) for Windows.

\subsubsection{Thermal Properties}

Analyses were performed in a differential scanning calorimeter (DSC)-7 (Perkin-Elmer, Waltham, MA, USA), using aluminium pans (PE 0219-0062). The equipment was calibrated with Indium and an empty pan was used as a reference. Flour $(3 \mathrm{mg}$ ) was loaded into the aluminum pan and distilled water $(10 \mu \mathrm{L})$ was added with the help of a Hamilton micro syringe. Samples were hermetically sealed and allowed to stand for $1 \mathrm{~h}$ at room temperature before heating in the DSC. The calorimeter scan conditions were set as follows: samples were kept at $30^{\circ} \mathrm{C}$ for $2 \mathrm{~min}$, heated from 30 to $110^{\circ} \mathrm{C}$ at $5^{\circ} \mathrm{C} / \mathrm{min}$. Onset temperature $(\mathrm{To})$, peak temperature $(\mathrm{Tp})$, gelatinization temperature range $(\mathrm{Tp}$ To), peak height index $(\Delta \mathrm{Hg} / \mathrm{Tp}-\mathrm{To})$ as well as the enthalpy of starch gelatinization $(\Delta \mathrm{Hg})$ (expressed as $\mathrm{mJ} / \mathrm{mg}$ of sample) were determined. All samples were run in quadruplicate.

\subsubsection{Color of Flours}

Color was measured using a Minolta CN-508i spectrophotometer (Minolta, Co., Ltd. Tokyo, Japan) with the D65 standard illuminant and the $2^{\circ}$ standard observer. Results were expressed in the CIEL* $\mathrm{a}^{*} \mathrm{~b}^{*}$ color space. Color determinations were made $5 \times 2$ times on each sample of flour.

\subsubsection{Enzymatic Hydrolysis of Starch}

Starch hydrolysis was measured following the method described by Gularte and Rosell (2011) with minor modifications. Briefly, for free sugars removal, flour sample (100 mg) suspended in $2 \mathrm{~mL}$ of $80 \%$ ethanol was kept in a shaking water bath at $85^{\circ} \mathrm{C}$ for $5 \mathrm{~min}$, and then centrifuged for $10 \mathrm{~min}$ at $1,000 \times \mathrm{g}$. The pellet was incubated with porcine pancreatic $\alpha$-amylase (10 mg/mL) (Type VI-B, $\geq 10$ units/mg solid; Sigma Chemical, St. Louis,MO, USA) and amyloglucosidase $(3,300 \mathrm{U} / \mathrm{ml})$ (Sigma Chemical, St. Louis, MO, USA) in $10 \mathrm{~mL}$ of $0.1 \mathrm{M}$ sodium maleate buffer ( $\mathrm{pH} 6.0$ ) in a shaking water bath at $37^{\circ} \mathrm{C}$ (0.25-16 h). Aliquots of $200 \mu \mathrm{L}$ were withdrawn during the incubation period. Aliquots were mixed with $200 \mu \mathrm{L}$ of ethanol (96\%) to stop the enzymatic reaction and the sample was centrifuged for $5 \mathrm{~min}$ at $10,000 \times \mathrm{g}$ and $4{ }^{\circ} \mathrm{C}$. The precipitate was washed twice with 50 $\%$ ethanol $(100 \mu \mathrm{L})$ and the supernatants were pooled together and kept at $4{ }^{\circ} \mathrm{C}$ for further glucose determination. 
The remnant starch after 16 h hydrolysis was solubilized with $2 \mathrm{~mL}$ of $2 \mathrm{M} \mathrm{KOH}$ using a Polytron ultraturrax homogenizer IKA-T18 (IKA works, Wilmington, NC, USA) during 1 min at speed 3 . The homogenate was diluted with $8 \mathrm{~mL} 1.2 \mathrm{M}$ sodium acetate $\mathrm{pH} 3.8$ and incubated with $100 \mu \mathrm{L}$ amyloglucosidase $(3,300 \mathrm{U})$ at $50^{\circ} \mathrm{C}$ for $30 \mathrm{~min}$ in a shaking water bath. After centrifuging at 2,000×g for $10 \mathrm{~min}$, supernatant was kept for glucose determination.

The glucose content was measured using a glucose oxidase-peroxidase kit. The absorbance was measured using an Epoch microplate reader (Biotek Instruments, Winooski, VT, USA) at $510 \mathrm{~nm}$. Starch was calculated as glucose $(\mathrm{mg}) \times 0.9$. Replicates $(\mathrm{n}=2-4)$ were carried out for each determination.

Experimental data were fitted to a first-order equation (Goñi et al. 1997):

$$
C_{t}=C_{\infty}\left(1-e^{-k t}\right)
$$

Where $\mathrm{Ct}$ is the concentration of glucose released at time $\mathrm{t}, \mathrm{C} \infty$ is the concentration at the end point, and $\mathrm{k}$ is the pseudofirst order rate constant. Although this equation requires the estimation of an accurate $C \infty$, it was useful because long reaction times were applied to determine resistant starch after complete enzymatic hydrolysis. The plot of $\ln$ $\left[\left(\mathrm{C}^{\infty}-\mathrm{Ct}\right) / \mathrm{C} \infty\right]=-\mathrm{kt}$ against $\mathrm{t}$ was used to estimate the slope that corresponded to $-\mathrm{k}$.

However, as recently suggested Butterworth et al. (2012), the linear plot of $\ln (\mathrm{dC} / \mathrm{dt})$ against $\mathrm{t}$ was also represented to calculate the slope $(-\mathrm{k})$, and the intercept on the $\mathrm{y}$ axis was used for calculating the $\ln (\mathrm{k} \mathrm{C} \infty)$. This plot was used to demonstrate if the data were of logarithmic form and the rate constant remained unchanged along the whole hydrolysis reaction, as recommended Poulsen et al. (2003).

\subsubsection{Statistical Analyses}

Multiple analyses of variance were used to determine the individual effects of thermal treatment and particle size of flours. Fisher least significant differences test was used to calculate the means with their $95 \%$ confidence intervals. Several correlations were also run. The statistical analysis was performed with the Statgraphics Plus Centurion XVI software (Statpoint Technologies, Inc., Warrenton, VA, USA).

\section{Results and Discussion}

Rice flour was subjected to different extrusion treatments that differed on the maximum barrel temperature and feed moisture content in order to obtain different extrusion intensities. de la Hera et al. (2013b, c) reported the functional properties and processing behavior of fractionated flours. Size fractionation allowed obtaining flours more suitable for bread- or cake-making depending on the particle size. In this study, extruded flours were ground and then separated in two fractions coarse extruded flour $(132200 \mu \mathrm{m})$ and fine extruded flour $(<132 \mu \mathrm{m})$. Overall eight samples were obtained from each batch, 
which differed on the level of extrusion (identified as 03 , higher values are related to higher intensity of extrusion conditions) and the particle size (coarse, fine). Flour 0 was not subjected to any extrusion treatment and was used as a reference.

\subsection{Damage Starch and Free Sugars}

To get a complete picture of the effect of extrusion and particle size a multiple analysis of variance was applied to the experimental results (Table 1). The extrusion intensity (barrel temperature, moisture content) and particle size (fine and coarse) had a significant effect on the content of free sugars (Table 1), which increased with the extrusion temperature and moisture content and with the reduction of the particle size $(18.74 \%$ in coarse flour vs $24.21 \%$ in fine flour). In fact, flour 3 (treated at higher barrel temperature) showed $49.91 \%$ free sugars whereas no treated flour (or flour 0 ) had a sugar content of $6.92 \%$. Nevertheless, no significant differences were observed between the free sugars content of the control (flour 0) and the mild extrusion treatment (flour 1). Thus the hydrolysis responsible of the sugar release required a minimum barrel temperature and also sufficient feed moisture content, since flours 1 and 2 were extruded at the same temperature and with different moisture feeding. Extrusion induced a progressive increase of the damage starch content with the temperature raise in the extrusion treatment, likely attributable to damage produced by the shears force and the heat during extrusion (Camire et al 1990). Conversely, damage starch decreased with the particle size, showing coarse flours the greatest amount of damage starch (19.98 \%), which agrees with the trend observed by de la Hera et al. (2013a), when studying the features of different particle size fractions of rice flours.

\subsection{Hydration, Emulsifying and Foaming Properties}

Hydration, emulsifying and foaming properties were significantly affected by the extrusion process $\left(\begin{array}{l}0 \\ 3\end{array}\right)$ and the particle size of the flours (coarse and fine) (Table 1). Hydrations properties (WBC and swelling) increased with the extrusion temperature and moisture content and also with the particle size of the flour. WBC increased from $1.26 \mathrm{~g}$ water/g solid (flour 0) to $4.94 \mathrm{~g}$ water $/ \mathrm{g}$ solid when extrusion was carried out at the maximum temperature (flour 3). Those effects were partially attributed to the increase in the amount of damage starch since it was found a positive correlation between the amount of damage starch and WBC $(\mathrm{r}=0.88)$ and with the swelling $(\mathrm{r}=0.88)$. Moreover, the cooking produced during extrusion led to gelatinized starch that would have higher WBC and swelling, as occurred with the water absorption index (Hagenimana et al. 2006). Camire et al. (1990) proposed that the breakage of the starch granule integrity led to a poorly ordered molecular phase with hydroxyl groups prone to bind water molecules. 
Table 1: Significant individual effects of extrusion treatment (1-3) and particle size (coarse, fine) on free sugars, damaged starch, emulsifying, foaming and colorimetric properties of rice flours.

\begin{tabular}{|c|c|c|c|c|c|c|c|}
\hline & \multirow[b]{2}{*}{$\begin{array}{c}\text { Overall } \\
\text { Mean }\end{array}$} & \multicolumn{4}{|c|}{ Extrusion treatment } & \multicolumn{2}{|c|}{ Particle size } \\
\hline & & 0 & 1 & 2 & 3 & $\mathrm{c}$ & $\mathrm{f}$ \\
\hline FS (\%) & 21.47 & $6.92 \mathrm{a}(2.08)^{* * *}$ & $9.49 \mathrm{a}(0.88)$ & $19.58 b(0.64)$ & $49.91 c(10.52)$ & $18.74 \mathrm{a}(15.08)^{* *}$ & $24.21 \mathrm{~b}(21.73)^{* *}$ \\
\hline DS (\%) & 18.08 & $6.66 \mathrm{a}(1.69)^{* * *}$ & $9.85 b(1.38)$ & $23.33 \mathrm{c}(5.95)$ & $32.49 \mathrm{~d}(4.66)$ & $19.98 \mathrm{~b}(13.71)^{* *}$ & $16.18 \mathrm{a}(8.83)$ \\
\hline WBC ( $\mathrm{g} \mathrm{H}_{2} \mathrm{O} / \mathrm{g}$ solid) & 2.42 & $1.26 \mathrm{a}(0.05)^{* * *}$ & $1.35 b(0.06)$ & $2.13 c(0.25)$ & $4.94 \mathrm{~d}(0.05)$ & $2.46 b(1.60)^{*}$ & $2.39 \mathrm{a}(1.59)$ \\
\hline $\mathrm{SV}(\mathrm{mL} / \mathrm{g})$ & 3.50 & $0.95 \mathrm{a}(0.25)^{* * *}$ & $1.55 b(0.19)$ & $2.90 \mathrm{c}(1.10)$ & $8.60 \mathrm{~d}(0.43)$ & $3.85 \mathrm{~b}(3.30)^{* *}$ & $3.15 \mathrm{a}(3.22)$ \\
\hline EC & 86.21 & $87.58 \mathrm{c}(1.25)^{* *}$ & $84.92 \mathrm{a}(0.53)$ & $85.70 \mathrm{ab}(0.39)$ & $86.34 \mathrm{bc}(1.35)$ & $86.60 \mathrm{a}(1.71)$ & $85.82 \mathrm{a}(0.80)$ \\
\hline ES & 112.21 & $111.49 \mathrm{a}(2.47)^{* * *}$ & $113.20 b(0.55)$ & $113.23 b(0.72)$ & $110.90 \mathrm{a}(2.93)$ & $110.80 \mathrm{a}(2.12)^{* * *}$ & $113.61 b(0.27)$ \\
\hline $\mathrm{FC}$ & 24.85 & $17.94 \mathrm{a}(1.17)^{\star * *}$ & $29.97 \mathrm{c}(7.15)$ & $21.44 b(1.86)$ & $30.04 c(1.51)$ & $22.92 \mathrm{a}(5.47)^{* * *}$ & $26.77 b(7.12)$ \\
\hline$L^{*}$ & 91.0 & $94.36 \mathrm{c}(0.42)^{* * *}$ & $90.55 b(2.01)$ & $90.43 b(1.42)$ & $88.62 \mathrm{a}(2.56)$ & $89.66 \mathrm{a}(3.05)^{* * *}$ & $92.31 b(1.46)$ \\
\hline$a^{*}$ & 0.19 & $-0.17 \mathrm{a}(0.21)^{* * *}$ & $0.23 c(0.19)$ & $0.16 b(0.04)$ & $0.55 \mathrm{~d}(0.14)$ & $0.23 \mathrm{~b}(0.40)^{* * *}$ & $0.15 \mathrm{a}(0.17)$ \\
\hline$b^{*}$ & 9.63 & $6.82 \mathrm{a}(0.46)^{* * *}$ & $10.22 b(1.68)$ & $10.37 b(1.32)$ & $11.13 c(2.14)$ & $10.83 \mathrm{~b}(2.35)^{* * *}$ & $8.44 \mathrm{a}(1.23)$ \\
\hline
\end{tabular}

Particle size: coarse (c), fine (f). Extrusion treatment: control (0); barrel temperature $110^{\circ} \mathrm{C}$, feed rate $700 \mathrm{~kg} / \mathrm{h}$, moisture content $17 \%(1)$; barrel temperature $110^{\circ} \mathrm{C}$, feed rate $700 \mathrm{~kg} / \mathrm{h}$, moisture content $30 \%$ (2); barrel temperature $140^{\circ} \mathrm{C}$, feed rate $500 / \mathrm{h}$, moisture content $25 \%$ (3)

Values followed by different letters within each parameter for each factor (thermal treatment and particle size) indicate significant differences. ${ }^{*} \mathrm{P}<0.05 ;{ }^{* *} \mathrm{P}<0.01 ;{ }^{* * *} \mathrm{P}<0.001$

Average values followed by the standard deviation (in parenthesis)

WBC, water binding capacity; EC, emulsifying capacity; ES, emulsion stability; FC, foaming capacity 
The extrusion significantly reduced the emulsifying capacity (EC) of the flours, with the exception of flour 3 (86.34), compared with the control flour (flour 0) (87.58), being the values for flour 1 and 2, 84.92 and 85.70, respectively. And an increase of the EC was observed with the severity of the extrusion, namely flour 3 (86.34)>flour 2 (85.70)>flour 1(84.92). That effect must result from the protein and starch changes during extrusion process. Considering the proteins, extrusion forces the unfolding and aggregation due to protein crosslinking involving $\mathrm{SH} / \mathrm{SS}$ interchange, oxidation and hydrophobic interactions (Rosell and Foegeding 2007), which might result in a decrease of the EC of the flour. As the extrusion temperature increase, starch modification might partially mask the protein denaturation. Gelatinized starch has greater number of hydroxyl groups, which would be available to form hydrogen bonds with the proteins leading to better emulsion capacity.

Emulsion stabilities (ES) were higher in the flours obtained from lower extrusion temperature (flour 1 and 2), showing values of 113.20 and 113.23, respectively. Likely the denaturation of the rice proteins during extrusion increased the stability. The particle size (coarse or fine) of the rice flours did not affect significantly the EC, but the ES significantly increased with the particle size reduction, from 110.80 in coarse flours to 113.61 in fine flours. A reduction in the particle size of the flour improves the emulsifying properties of the flours (Aluko et al. 2009). In the present study, it was observed a significant positive relationship between the ES and the free sugars content $(\mathrm{r}=0.93$; $\mathrm{P}<0.001)$, which could reduce the total charge of the proteins leading the formation of interfacial protein membranes that stabilize the emulsion (Aluko et al. 2009).

Extrusion improved the foaming capacity (FC) of the rice flours (Table 1), but there was no trend with the extrusion severity (temperature or moisture content). The foam stability (FS) could be only measured in flour 3 (50.00 for fine flour and 45.18 for coarse flour) because very unstable foams were obtained with the other flours. The FC has been attributed to its microstructure, size and distribution of the gas cells and the interfacial properties (Zhang et al. 2011). Hydrothermal treatments can improve the foaming properties, as has been reported with corn kernels (Boladea et al. 2002). Nevertheless, the minor effect observed in the extruded rice flours could be attributed to the low protein content of the rice flour. Protein isolates show great foaming capacity that improves with the hydrothermal treatments (Wang and Johnson 2001). The effect of extrusion on foam formation followed an opposite trend to the one observed on the emulsion formation, which suggests that different mechanisms are involved during interfacial membrane formation at the air-water and oil-water interfaces. Concerning the particle size, the major FC was observed in fine flours (26.77) compared with coarse flours (22.92). This effect could be explained by the greater availability of lowering interfacial components in those flour fractions, as proposed Aluko et al. (2009). 


\subsection{Color}

Luminosity $\left(\mathrm{L}^{*}\right)$ of the flours significantly decreased with the extrusion temperature and moisture content (Table 1), from 90.55 in flour 0 to 88.62 in flour 3. Conversely, the a* and $b^{*}$ increased. Nevertheless, although a steady increased with the extrusion temperature and moisture content (flours 0 to 3) was observed in the case of the luminosity and $\mathrm{b}^{*}$, no trend was observed in the case of $\mathrm{a}^{*}$. The extrusion process could lead to Maillard reactions and a reduction of the lipids oxidation due to enzymes inactivation that induces the formation of melanoidins and the pigments protection, which in turn produces the modification of the flours color (Camire et al. 1990). Moreover, higher $\mathrm{L}^{*}$ and lower $\mathrm{a}^{*} \mathrm{y} \mathrm{b}^{*}$ were obtained in the fine flours. It has been proposed that fine flours had higher surface area that favors the contact of the constituents with the oxygen promoting the pigments oxidation (Atwell 2001).

\subsection{Pasting Characteristics}

Pasting plots of the extruded flours are displayed in Fig. 1a (coarse flour) and in Fig. 1b (fine flour). Concerning the extrusion treatment (flours 0 3), the viscosity during heating and cooling decreased with the extrusion intensity, obtaining minimum viscosity in flour 3 (with the highest intensity). Nevertheless, when particle size was taken into account, a progressive decrease of viscosity was observed in the coarse flours (Fig. 1a), but fine flours (Fig. $1 \mathrm{~b}$ ) from treatment 1 and 2 did not show any difference in the pasting profile. Since flour 1 and 2 were treated at maximum barrel temperature of $110^{\circ} \mathrm{C}$ and the unique variation was the feed moisture content, it seems that the effect on pasting profiles was independent on the feed moisture content during extrusion when small particle size were subjected to this treatment. 

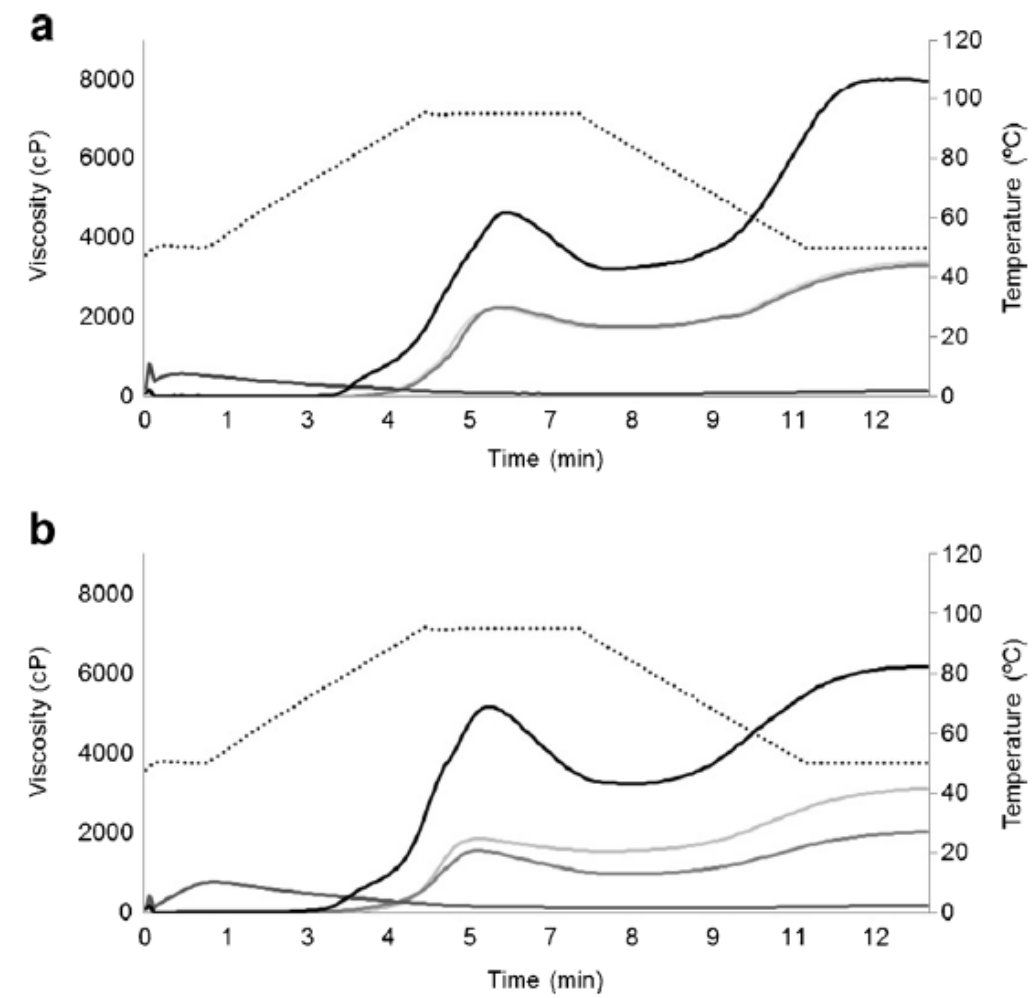

Fig 1 a. Effect of extrusion treatment on the pasting properties of coarse rice flours. Flour 0 (black line), flour 1 (clear grey line), flour 2 (intermediate tone grey line), flour 3 (dark grey line). Temperature profile (discontinuous line). b. Effect of extrusion treatment on the pasting properties of fine rice flours. Flour 0 (black line), flour 1 (clear grey line), flour 2 (intermediate tone grey line), flour 3 (dark grey line). Temperature profile (discontinuous line)

Peak viscosity was significantly dependent on the damage starch content $(r=-0.79)$, which agree with previous studies connecting peak viscosity with gelatinized and damage starch that was related to the polymerization degree of the starch granules (Barres et al. 1990). The reduction observed in the final viscosity and setback was displaying the extension of the effect on the amylose chains, which might lose the ability to retrograde during cooling due to their fragmentation during extrusion. This effect agrees with previous results of Doublier et al. (1986).

\subsection{Differential Scanning Calorimetry (DSC)}

The effect of extrusion treatment and particle size on the thermal properties of the starch is shown in Table 2. In the range of temperature tested (from 30 to $110^{\circ} \mathrm{C}$ ), flours exhibited one endothermic peak corresponding to amylopectin gelatinization, with the exception of flour 3 (no peak detected). The absence of an endothermic peak for flours 3 indicated total gelatinization of amylopectin. Indeed, these results agree with those previously discussed regarding the very small pasting curve observed in the extruded flours 3 at $50^{\circ} \mathrm{C}$. The extrusion treatment significantly modified the gelatinization temperatures (To, $\mathrm{Tp}, \mathrm{Tc}$ ) of the flours, and those temperatures were also dependent on the particle size of the flours (coarse and fine flours). Gelatinization temperatures (Tp) 
were sifted to higher values when flours were treated at increasing extrusion intensity (3was the highest intensity), but the temperature range (Tp-To) was not affected. Higher gelatinization temperature indicated that more energy is required to initiate gelatinization of the starch suggesting that extrusion is affecting the outer and more amorphous part of the granule and is progressing to the core of the granule till no crystalline structure is left for gelatinization (flour 3).

Table 2. Significant individual effects (extrusion treatment and particle size) on thermal properties.

Extrusion treatment

\begin{tabular}{|c|c|c|c|c|c|c|c|}
\hline \multirow{2}{*}{\multicolumn{8}{|c|}{ Overall }} \\
\hline & & & & & & & \\
\hline & Mean & 0 & 1 & 2 & 3 & c & $\mathrm{f}$ \\
\hline $\mathrm{T}_{\mathrm{o}}\left({ }^{\circ} \mathrm{C}\right)$ & 68.0 & $65.5 \mathrm{a}(5.7)^{* * *}$ & $67.4 b(1.7)$ & $71.1 \mathrm{c}(0.9)$ & n.d & $70.3 \mathrm{~b}(1.4)^{* * *}$ & $65.7 \mathrm{a}(4.5)$ \\
\hline $\mathrm{T}_{\mathrm{p}}\left({ }^{\circ} \mathrm{C}\right)$ & 74.0 & $71.2 \mathrm{a}(4.6)^{* * *}$ & $74.4 \mathrm{~b}(0.7)$ & $76.4 c(0.7)$ & n.d & $75.6 \mathrm{~b}(1.0)^{* * *}$ & $72.4 a(4.1)$ \\
\hline $\mathrm{T}_{\mathrm{c}}\left({ }^{\circ} \mathrm{C}\right)$ & 80.6 & $77.9 \mathrm{a}(3.9)^{* *}$ & $81.4 b(1.5)$ & $82.5 b(1.18)$ & n.d & $81.8 \mathrm{~b}(1.0)^{* *}$ & $79.3 \mathrm{a}(4.0)$ \\
\hline $\mathrm{T}_{\mathrm{p}}-\mathrm{T}_{\mathrm{o}}\left({ }^{\circ} \mathrm{C}\right)$ & 6.0 & $5.8 \mathrm{a}(1.1)$ & $7.0 \mathrm{a}(1.8)$ & $5.3 \mathrm{a}(0.2)$ & n.d & $5.3 \mathrm{a}(0.6)$ & $6.7 \mathrm{a}(1.6)$ \\
\hline$\Delta \mathrm{H}(\mathrm{J} / \mathrm{g})$ & 2.383 & $2.525 b(0.330)^{* * *}$ & $3.075 c(0.754)$ & $1.550 \mathrm{a}(0.191)$ & n.d & $2.483 \mathrm{a}(1.049)$ & $2.283 \mathrm{a}(0.507)$ \\
\hline PHI (J/g $\left.{ }^{*_{\circ}} \mathrm{C}\right)$ & 0.392 & $0.450 \mathrm{~b}(0.057)^{*}$ & $0.450 b(0.191)$ & $0.275 \mathrm{a}(0.050)$ & n.d & $0.433 \mathrm{a}(0.163)$ & $0.350 \mathrm{a}(0.104)$ \\
\hline
\end{tabular}

Particle size: coarse (c), fine (f). Extrusion treatment: control (0); barrel temperature $110^{\circ} \mathrm{C}$, feed rate 700 $\mathrm{kg} / \mathrm{h}$, moisture content $17 \%$ (1); barrel temperature $110^{\circ} \mathrm{C}$, feed rate $700 \mathrm{~kg} / \mathrm{h}$, moisture content $30 \%$ (2); barrel temperature $140^{\circ} \mathrm{C}$, feed rate $500 / \mathrm{h}$, moisture content $25 \%$ (3)

Values followed by different letters within each parameter for each factor (thermal treatment and particle size) indicate significant differences. ${ }^{*} \mathrm{P}<0.05 ;{ }^{*} \mathrm{P}<0.01 ;{ }^{* *} \mathrm{P}<0.001$

n.d.: Not detected.

Average values followed by the standard deviation (in parenthesis)

To, gelatinization onset; Tp, peak temperature; Tc, conclusion temperature, Tp-To, gelatinization range, $\Delta \mathrm{H}$, enthalpy and PHI, peak high index

Comparing extruded flours, the gelatinization enthalpy $(\Delta \mathrm{H})$ was significantly reduced in flour 2, where extrusion temperature and moisture content were sufficient to induce starch gelatinization, likely due to an increase of the damage starch content (Chiu and Solarek 2009). Nevertheless, the mild extrusion treatment (flour 1) gave significantly higher gelatinization enthalpy $(3.075 \mathrm{~J} / \mathrm{g})$ compared with the untreated flour (flour 0 ) $(2.525 \mathrm{~J} / \mathrm{g})$. Taking into account that treatment 1 was applied using lower feed moisture content (insufficient to complete gelatinization), the higher enthalpy of this sample could be attributed to a reorientation of the structure of the amorphous region to resemble that of the crystalline region (Camire et al. 1990). The extrusion process modifies the crystalline structure of the starch granule affecting the temperature at which swelling starts (Camire et al. 1990). Fine flours showed lower gelatinization temperatures than the corresponding coarse flours, but without affecting the peak high index and the gelatinization enthalpy (Table 2). 


\subsection{Starch Hydrolysis}

The susceptibility of the extruded flours to the enzymatic hydrolysis was analyzed. Figure 2 shows the kinetic plots of the extruded flours and the effect of the particle size. The enzymatic hydrolysis profiles were dependent on the particle size, and fine flours showed faster hydrolysis and reached higher asymptotic values than course flours. de la Hera et al. (2013a) observed lower hydrolysis rate in the coarse flours when studied the effect of particle size distribution on the rice flour functionality. This result could be attributed to the high surface area of the fine flours that increases the water diffusion and enzyme accessibility. The hydrolysis curves were fitted to a first order kinetics according to Goñi et al. (1997) and also to Butterworth et al. (2012) to obtain the kinetic parameters (Table $3)$. As it was observed in the plots, there was an increase in the equilibrium concentration $(\mathrm{C} \infty)$ parallel to the extrusion intensity (except flour 2f). Regarding the rate of the hydrolysis, $\mathrm{k}$, there was no general trend with the extrusion intensity. There was great agreement with the equilibrium concentration estimated from both fitted methods, indicating that the kinetic parameters can be fitted to a logarithmic function and that the rate constant did not vary along the hydrolysis reaction (Poulsen et al. 2003).
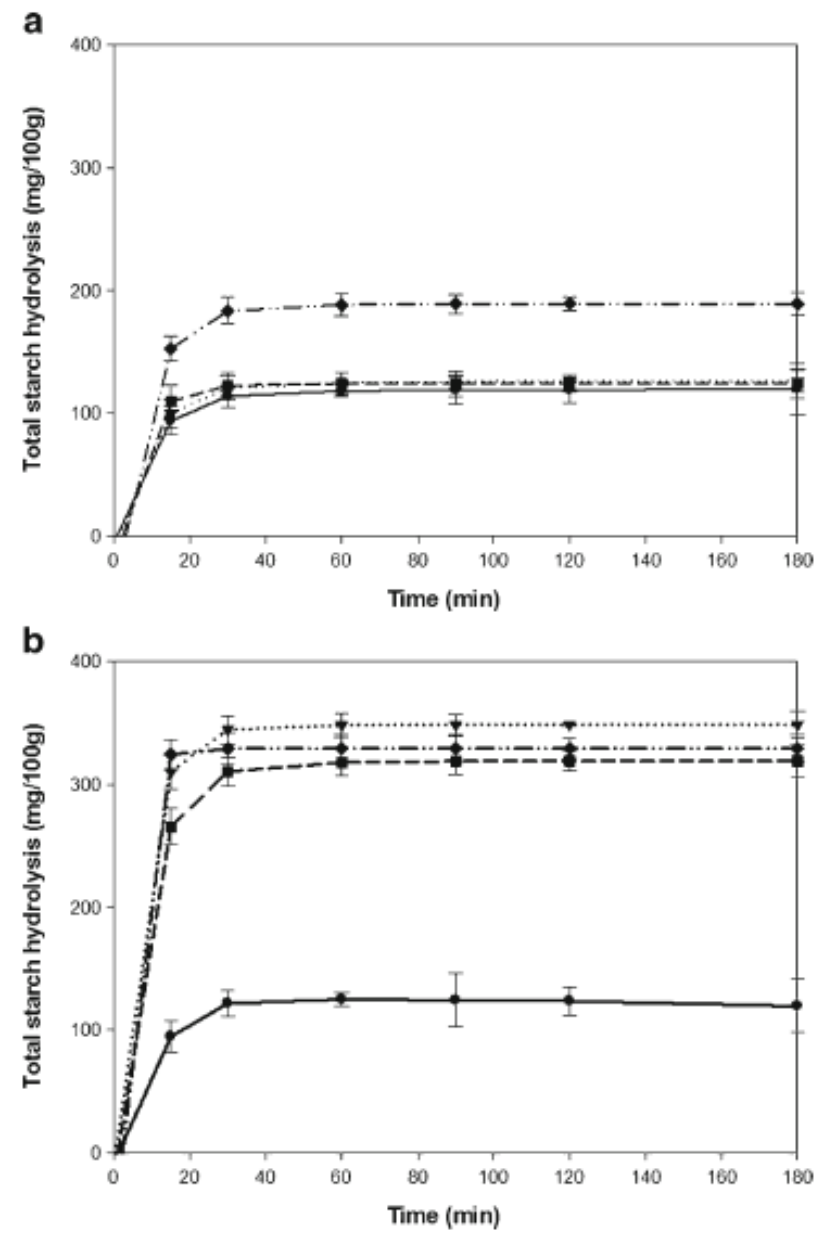
Fig 2 Effect of extrusion treatment on the enzymatic hydrolysis of rice flours with different particle size. Flour $0(\bullet$,black line), flour $1(\boldsymbol{\nabla}$, clear grey line), flour $2(\boldsymbol{\bullet}$, intermediate tone grey line $)$, flour $3(\bullet$, dark grey line). Coarse flours (a), fine flours (b)

Resistant starch was also quantified to determine the potential impact of the extrusion on the structural level of starch. Although there was no clear tendency about the resistant starch content, the highest extrusion intensity gave the flours with the lower level of RS (flour 3). This finding disagrees with previous observations of Hagenimana et al. (2006), whofound an increase in RS content with the treatment severity.

Those authors attributed the increase in RS to the formation of amylose-lipid complexes during the extrusion, which retarded the enzymatic digestion. Therefore, results divergence might be explained because of the lower content of amylose of the flours in the present study compared with the reported ones. In addition, Chinnaswamy and Hannah (1990) reported a change in the percentage of amylose/amylopectin ratio in extruded corn flours that was ascribed to both chains fragmentation, being more intense in the former. That fact could affect the starch hydrolysis rate. Moreover, Hagenimana et al. (2006) stated that the susceptibility of the extruded starches to be enzymatically hydrolyzed was directly related to the intensity of the extrusion treatment.

The particle size did not significantly affect the hydrolysis rate, but fine flours showed higher values of $\mathrm{C}^{\infty}$ and lower amount in RS. Al-Rabadi et al. (2011) stated that fine extruded flours of barley and sorghum had major digestibility than the coarser ones. The most compact structure, besides the smaller surface area of coarser flours, could hinder the accessibility of the enzymes within the starch structure, since diffusion of the enzyme is the first stage in the enzymatic hydrolysis (Al-Rabadi et al. 2011; Ghaid et al. 2009).

\section{Conclusion}

Extrusion and mechanical fractionation of the rice flours modified their behavior affecting hydration, thermal and pasting features, besides their susceptibility to enzymatic hydrolysis. The severity of the extrusion treatment was accompanied by an increase in the amount of damage starch and free sugars content, the former contributing to the Maillard reaction, which affected the luminosity of the flours. In parallel, hydration ability increased with the extrusion intensity, leading higher viscosity in cold solution, which might be very interesting for some food applications. Thermal properties (temperature and enthalpy) increased with the intensity of the extrusion and that effect was intensified with the greatest particle size of the flours. Fine flours with stronger extrusion showed the highest susceptibility to enzymatic hydrolysis and extrusion process increased that effect. Therefore, extrusion and fractionation can be an alternative to produce flours with different functional properties, which might be useful in gluten free breadmaking. Future studies will be undertaken to test these flours in breadmaking process. 
Physicochemical characterization and digestive properties of different flours according to the extrusion conditions

\section{$\underline{\text { Acknowledgement }}$}

The authors acknowledge the financial support of Junta de Castilla y León (VA054A122), the Spanish Ministry of Economy and Sustainability (Project AGL2011-23802) and the European Regional Development Fund (FEDER). The authors are also grateful to Harinera Los Pisones, (Zamora, Spain) for supplying the rice flours. 


\section{$\underline{\text { References }}$}

AACC. (2012). Approved methods of the american association of cereal chemists, methods 46-30.01 (Protein), 55-40.01 (Particle size), 76- 30a (damaged starch), 56-30 (WBC), 61-02.01 (RVA) (11th ed.). St. Paul: American Association of Cereal Chemists.

Al-Rabadi, G., Torley, P., Williamsa, B., Brydena, W., \& Gidley, M. (2011). Effect of extrusion temperature and pre-extrusion particle size on starch digestion kinetics in barley and sorghum grain extrudates. Animal Feed Science and Technology, 168, 267-279.

Alsaffar, A. (2011). Effect of food processing on the resistant starch content of cereals and cereal products-A review. International Journal of Food Science and Technology, 46, $455-462$.

Aluko, R.,Mofolasayo, O.,\&Watts, B. (2009). Emulsifying and foaming properties of commercial yellow pea (Pisum sativumL.) seed flours. Journal of Agriculture and. Food Chemistry, 57, 9793-9800.

Atwell,W. (2001). Composition of commercial flour. InW. Atwell (Ed.), Wheat Flour (pp. 27-42). St. Paul: American Association of Cereal Chemists.

Barres, C., Verges, B., Tayeb, J., \& Della Valle, G. (1990). Transformation of wheat flour by extrusion cooking. Influence of screw configuration and operating conditions. Cereal Chemistry, 67, 427-433.

Boladea, M., Usman, M., Rasheed, A., Benson, E., \& Salifou, I. (2002). Influence of hydrothermal treatment of maize grains on the quality and acceptability of tuwon masara (traditional maize gel). Food Chemistry, 79, 479-483.

Butterworth, P. J., Warren, F. J., Grassby, T., Patel, H., \& Ellis, P. R. (2012). Analysis of starch amylolysis using plots for first-order kinetics. Carbohydrate Polymers, 87, 21892197.

Camire,M., Camire, A., \& Krumhar, K. (1990). Chemical and nutritional changes in foods during the extrusion. Critical Reviews in Food Science and Nutrition, 29, 35-57.

Chinnaswamy, R.,\& Hannah,M. (1990). Macromolecular and functional properties of native and extruded corn starch. Cereal Chemistry, 67, 490-499.

Chiu, C., \& Solarek, D. (2009). Modification of starch. In J. BeMiller \& R. Whistler (Eds.), Starch. Chemistry and Technology (pp. 629- 656). New York: Academic Press.

Clerici, M., Arioldi, C., \& El-Dash, A. (2009). Production of acidic extruder rice flour and its influence on the qualities of gluten free bread. LWT-Food Science and Technology, 42, 618-623. 
Colonna, P., Doublier, J.,Melcion, J.,Demonredon, F.,\&Mercier, C. (1984). Extrusion cooking and drum drying of wheat-starch.1. Physical and macromolecular modifications. Cereal Chemistry, 61, 538-543.

de la Hera, E., Gómez,M.,\& Rosell, C. (2013a). Particle size distribution affecting the starch enzymatic digestion and hydration of rice flour carbohydrates. Carbohydrate Polymers, 98, 421-427.

de la Hera, E., Martínez, M., \& Gómez, M. (2013b). Influence of flour particle size on quality of gluten-free rice bread. LWT-Food Science and Technology, 54, 199-206.

de la Hera, E., Martínez, M., Oliete, B., \& Gómez, M. (2013c). Influence of flour particle size on quality of gluten-free rice cakes. Food and Bioprocess Technology, 6, 2280-2288.

Doublier, J., Colonna, P., \& Mercier, C. (1986). Extrusion cooking and drum drying of wheat-starch. 2. Rheological characterization of starch pastes. Cereal Chemistry, 63, 240246.

Ghaid, J., Al-Rabadi, G., Gilbert, R., \& Gidley, M. (2009). Effect of particle size on kinetics of starch digestion in milled barley and sorghum grains by porcine alpha-amylase. Journal of Cereal Science, 50, 198-204.

Goñi, I., Garcia-Alonso, A., \& Saura-Calixto, F. (1997). A starch hydrolysis procedure to estimate glycemic index. Nutrition Research, 17, 427-437.

Gularte, M. A., \& Rosell, C. M. (2011). Physicochemical properties and enzymatic hydrolysis of different starches in the presence of hydrocolloids. Carbohydrate Polymers, $85,237-244$.

Hagenimana, A., Ding, X., \& Fang, T. (2006). Evaluation of rice flour modified by extrusion cooking. Journal of Cereal Science, 43, 38- 46.

Jacobs, H., \& Delcour, J. (1998). Hydrothermalmodifications of granular starch, with retention of the granular structure: A review. Journal of Agricultural and Food Chemistry, 46, 2895-2905.

Lee, S. M., Yoo, J., Inglett, G. E., \& Lee, S. (2013). Particle size fractionation of highamylose rice (Goami 2) flour as an oil barrier in a batter-coated fried system. Food and Bioprocess Technology, 6, 726-733.

Mercier, C., \& Feillet, P. (1975). Modification of carbohydrate components by extrusioncooking of cereal products. Cereal Chemistry, 63, 283-297.

Moreira, R., Chenlo, F., \& Torres,M. D. (2013). Rheology of gluten-free doughs from blends of chestnutand rice flours. Food and Bioprocess Technology, 6, 1476-1485. 
Nelson, A. (2001). Properties of Hihg-fibre ingredientes. Cereal Foods World, 46, 93-97.

Perdon, A., Siebenmorgen, T., Mauromoustakos, A., Griffin, V., \& Johnson, E. (2001). Degree of milling effects on rice pasting properties. Cereal Chemistry, 78, 205-209.

Poulsen, B., Ruiter, G., Visser, J., \& Iversen, J. (2003). Determination of first order rate constants by natural logarithm of the slope plot exemplified by analysis of Aspergillus niger in batch culture. Biotechnology Letters, 25, 565-571.

Rosell, C. M., \& Foegeding, A. (2007). Interaction of hydroxypropylmethylcellulose with gluten proteins: Small deformation properties during thermal treatment. Food Hydrocolloids, 21, 1092-1100.

Wang, C., \& Johnson, L. (2001). Functional properties of hydrothermally cooked soy protein products. Journal of the American Oil Chemists Society, 78, 189-195.

Wen, L., Rodis, P., \& Wasserman, B. (1990). Starch fragmentation and protein insolubilization during twin

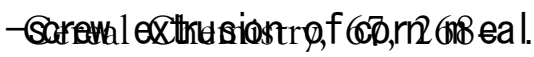
275.

Yeh, A. (2004). Preparation and applications of rice flour. In E. Champagne (Ed.), Rice: Chemistry and tehnology (pp. 495-540). St. Paul: American Association of Cereal Chemist.

Zhang, M., Bai, X., \& Zhang, Z. (2011). Extrusion process improves the functionality of soluble dietary fiber in oat bran. Journal of Cereal Science, 54, 98-113. 


\section{CHAPTER 2}

\section{Effect \\ of \\ extruded \\ flours \\ on \\ intermediate \\ products \\ during}

processing: pastes, gels and batters

Food Hydrocolloids 43 (2015) 172-179

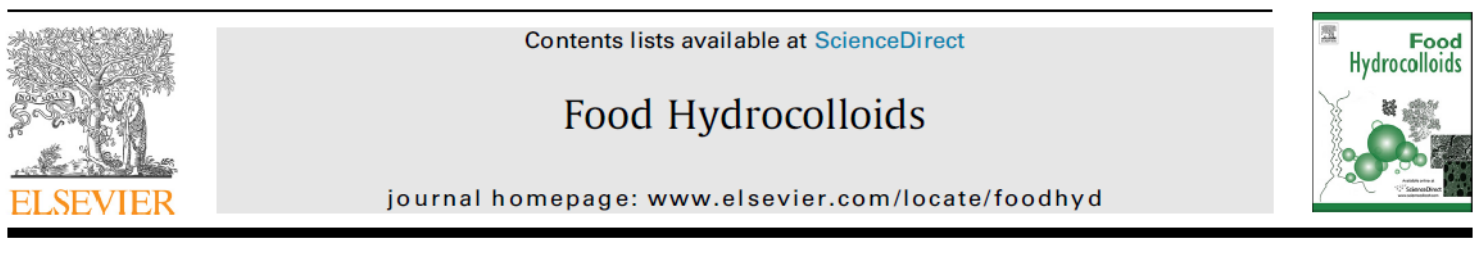

Influence of marine hydrocolloids on extruded and native wheat flour pastes and gels

Mario M. Martínez*, Ana K. Macias, Mayara L. Belorio, Manuel Gómez

Food Technology Area, College of Agricultural Engineering, University of Valladolid, 34004 Palencia, Spain

LWT - Food Science and Technology 64 (2015) 1309-1314

LWT - Food Science and Technology

Influence of wheat flour subjected to different extrusion conditions on the rheological behaviour and thermal properties of batter systems for coating

Mario M. Martínez ${ }^{\text {a, }}{ }^{*}$, Teresa Sanz ${ }^{\text {b }}$, Manuel Gómez ${ }^{\text {a }}$

a Food Technology Area, College of Agricultural Engineering, University of Valladolid, 34004 Palencia, Spain

$\mathrm{b}$ Institute of Agrochemistry and Food Technology (IATA-CSIC), Avda Agustin Escardino, 7, Paterna 46980, Spain 


\subsection{Influence of marine hydrocolloids on extruded and native wheat flour pastes and gels}

Food Hydrocolloids 43 (2015) 172-179

\begin{tabular}{ccc}
\hline Contents lists available at ScienceDirect & Food Hydrocolloids \\
ELSEVIER & journal homepage: www.elsevier.com/locate/foodhyd \\
\hline
\end{tabular}

Influence of marine hydrocolloids on extruded and native wheat flour pastes and gels

Mario M. Martínez*, Ana K. Macias, Mayara L. Belorio, Manuel Gómez

Food Technology Area, College of Agricultural Engineering, University of Valladolid, 34004 Palencia, Spain

\section{Introduction}

Wheat flour is one of the most widely used ingredients both in the food industry and in cooking. Besides being the key ingredient in bread and other bakery products, where its proteins play a special role, wheat flour is used as thickening agent in numerous dishes. These thickening properties are based on the capacity of wheat starch granules to absorb water. When starch is heated in the presence of sufficient water, it eventually loses its crystalline structure, leading to an increase in the viscosity of starch pastes. This phenomenon is known as pasting. Further heating of the water-starch mixture leads to rupture of the starch granules and a fall in paste viscosity (breakdown). Finally, if a paste is cooled, hydrogen bonds develop between the amylose chains, creating a new crystalline structure that loses the absorbed water, causing a renewed increase in viscosity, a phenomenon known as retrogradation. These events constitute the basis for the use of starch and flour in the preparation of fillings, sauces, creams and dairy desserts, and other products.

Occasionally, the properties of native flours are not suitable for their use in certain products and they must be modified or supplemented with other ingredients or additives. Hydrothermal treatments can produce flours with different degrees of gelatinization, with greater thickening power after heating, or with no need for heating (Camire, Camire, \& Krumhar, 1990). Flours with the greatest degrees of gelatinization show notable thickening power in cold liquids. Particularly important among hydrothermal treatments that can be applied to flours for this purpose are drum drying and extrusion (Doublier, Colonna, \& Mercier, 1986).

Carrageenans and agar, together with alginates, are the marine hydrocolloids most commonly used in the food industry. Carrageenans are extracted from certain red 
seaweeds of the Rhodophyceae class, which have been extensively used in the food industry as thickening and gelling agents (Campo, Kawano, da Silva, \& Carvalho, 2009). The structure of carrageenan is based on a disaccharide backbone of alternating 3-linked b-D-galactopyranose and 4-linked a-D-galactopyranose units, named G and D units, respectively, in Knutsen's nomenclature (Knutsen, Mylabodski, Larsen, \& Usov, 1994). Carrageenans are defined according to the position of sulphation $(\mathrm{S})$ and the cyclization of the D units to form an anhydro ring (A). Carrageenans used in industry include the gelling k-, i-carrageenan and the non-gelling l-carrageenan (Tischer, Noseda, Rilton de Freitas, Sierakowski, \& Duarte, 2006). The chemical structure of i-carrageenan differs from that of kcarrageenan by the presence of an additional sulphate group in the 3,6anhydrogalactosyl residue, which makes the molecule more hydrophilic (Renn, 1997). The distinct textural properties of $\mathrm{i}$ - and $\mathrm{k}$-carrageenan gels reflect the differences in their structures: icarrageenan gels consist of double helices with little or no aggregation, which renders them flexible and soft. In contrast, k-carrageenan gels consist of aggregated helices, which do not gel without aggregation and the resulting gel relatively brittle and hard (Tischer et al., 2006). Agar is extracted from seaweeds of the genera Gelidium and Gracilaria and is composed of agarose and agaropectin molecules. Agarose, responsible for the gelling properties of agar, is a linear compound formed of alternating b-Dgalactopyranose and a-L-galactopyranose residues. Agaropectin has a similar structure but with a lower content of L-galactopyranose residues (Armisen, 1991). After solubilization in water, both agars and carrageenans have the property of forming reversible gels when they are cooled, and they are used extensively in the food industry as thickening and gelling agents.

Combinations of starch, or raw starchy ingredients, and hydrocolloids have been used in the food industry since the midtwentieth century in order to achieve specific textures or to improve tolerance to certain processing conditions (heat, shear, and $\mathrm{pH}$ ), and their interactions have therefore been studied extensively (BeMiller, 2011). Among the marine hydrocolloids, interactions between the carrageenans and starchy ingredients have received most attention. Tye (1988) observed that these interactions depend on the type of carrageenan and type of starch (native or gelatinized). Differences between the types of carrageenan have been also studied by Shi and BeMiller (2002) and by Eidam, Kulicke, Kuhn, and Stute (1995), who observed that while k-carrageenan, like other hydrocolloids, accelerated the gelation process, i-carrageenan delayed it. However, interactions between carrageenans and wheat flour have not been investigated. Interactions between agar and flours have also received little attention and this has usually been limited to the study of interactions between agarose and different starches (Lai, Huang, \& Lii, 1999; Mohammed, Hember, Richardson, \& Morris, 1998).

Despite the particular physicochemical characteristics of extruded flours and their high potential as cold thickening agents, the properties of their pastes/gels in combination with hydrocolloids have never been studied, nor have they been compared with the 
pastes/gels of native flours. The objective of the present studywas to investigate the effects of interactions between different types of agar (Gracilaria and Gelidium) and carrageenans (k-carrageenan and i-carrageenan) and wheat flours (native and extruded) on the properties of their pastes (hydration, pasting and rheological) and gels (textural and colorimetric) using Rapid Visco Analysis (RVA), hydration measurements, dynamic and steady shear measurements, and texture and colour analysis.

\section{Materials and methods}

\subsection{Materials}

Native wheat flour $(11.73 \%$ moisture, $69.09 \mathrm{~mm}$ particle size, $11.02 \%$ protein, $6.18 \%$ free sugars and 5.89\% damaged starch) was supplied by Harinera Castellana (Medina del Campo, Valladolid, Spain). Hydrothermally modified wheat flour (11.20\% moisture, 99.37 mmparticle size, $8.74 \%$ protein, $44.80 \%$ free sugars and $38.09 \%$ damaged starch) was provided by Harinera Los Pisones (Zamora, Spain), which performed the extrusion treatment using a Bühler Basf single screw extruder (Bühler S.A., Uzwil, Switzerland). The length to diameter (L/D) ratio for the extruder was 20:1. Wheat flour was extruded at a maximum barrel temperature of $160 \mathrm{C}$ with a feed rate of $500 \mathrm{~kg} / \mathrm{h}$. The moisture content of this flour was $17 \%$ and the screw speed was $453 \mathrm{rpm}$. The extruded product was dried by convection air and then ground with a compression roller to a particle size below 200 microns. Flours were stored in airtight plastic containers at $4 \mathrm{C}$ until analysis. Gelidium agar RG-ST and Gracilaria agar RGM-900 were supplied by (ROKO, Galicia, Spain). k-carrageenan Ceamgel 1860 (with potassium chloride) and i-carrageenan Ceamvis 3383 were supplied by (Ceamsa, Pontevedra, Spain).

\subsection{Methods}

Samples used in the different tests were prepared by addition, in order to compare a $100 \%$ flour paste/gel to one made with $100 \%$ flour with a $7.14 \%$ and a $10.71 \%$ of hydrocolloid addition (flour basis) for pastes and gels making respectively. Hydrocolloid powder and flour were mixed and added jointly to water; the suspension was then heated.

\subsubsection{Hydration properties}

Hydration properties include swelling volume (SV), water holding capacity (WHC) and water binding capacity (WBC) (Nelson, 2001). Swelling volume (SV), or the volume occupied by a known weight of the mix, was evaluated by adding $100 \mathrm{~mL}$ of distilled water to $5 \mathrm{~g}( \pm 0.1 \mathrm{~g})$ of flour with $0.357 \mathrm{~g}( \pm 0.001 \mathrm{~g})$ of hydrocolloid and allowing it to hydrate for $16 \mathrm{~h}$. Water holding capacity, defined as the amount of water retained by the sample without being subjected to any stress, was determined on the same suspension used to evaluate swelling; the hydrated solid was weighed after removing the excess of water and values were expressed as grams of water per gram of solid. Water binding capacity (WBC), or the amount of water retained by the sample after it has been 
centrifuged, was measured as described in method 56-30 (AACC, 2012), using $5 \mathrm{~g}( \pm 0.1$ $\mathrm{g})$ of flour mixed with $0.357 \mathrm{~g}( \pm 0.01 \mathrm{~g})$ of hydrocolloid before the addition of distilled water. Hydration properties were analysed twice.

\subsubsection{Pasting properties}

Pasting and paste properties of the normal and extruded flours were determined in the presence and absence of the hydrocolloids using a Rapid Visco Analyser (Model RVA-4C, Newport Scientific Pty. Ltd., Warriewood, Australia). The flour-only slurrywas prepared by dispersing $3.5 \mathrm{~g}( \pm 0.1 \mathrm{~g})$ of the flour in $25 \mathrm{~g}( \pm 0.1 \mathrm{~g})$ of distilled water. When hydrocolloids were used, the mix of flour $(3.5 \pm 0.1 \mathrm{~g})$ and hydrocolloid powder $0.25 \mathrm{~g}$ $( \pm 0.01 \mathrm{~g})$ were thoroughly dry blended prior to slurrying in water. The slurries were then poured into aluminium canisters and stirred manually using plastic paddles for $20 \mathrm{~s}$ before pouring into the RVA machine. The heating and cooling cycles were programmed following general pasting method 61.02.01 (AACC, 2012). The slurrywas held at $50 \mathrm{C}$ for $1 \mathrm{~min}$, then heated to $95 \mathrm{C}$ and held at that temperature for $2 \mathrm{~min} 30 \mathrm{~s}$. It was subsequently cooled to $50 \mathrm{C}$ and held at that temperature for $2 \mathrm{~min}$, while maintaining a rotation speed of $160 \mathrm{rpm}$. When pasting and paste properties of the hydrocolloids alone in distilled water were performed, pastes were cooled to $30 \mathrm{C}$ and held at that temperature for $2 \mathrm{~min} 30 \mathrm{~s}$ in order to assist the gelation process of the hydrocolloids. All measurements were performed in duplicate.

\subsubsection{Rheological measurements}

Dynamic viscoelastic and steady flow properties of the freshly prepared pastes of flour alone and flour ehydrocolloid mixtures obtained from pasting in the RVA were performed using a rheometer (Haake RheoStress 1, Thermo Fischer Scientific, Scheverte, Germany) with a titanium parallel serrated plate geometry sensor PP60 Ti $(60 \mathrm{~mm}$ diameter, and $3 \mathrm{~mm}$ gap). The sample was placed into the rheometer which was stabilized at $50 \mathrm{C}$ and was covered with Panreac vaseline oil (Panreac Química S.A., Castellar del Valles, Spain) to avoid drying. The pastes were rested for $500 \mathrm{~s}$ before the test was started. Two dynamic viscoelastic measurements were made: (1) deformation sweeps at a constant frequency $(1 \mathrm{~Hz})$ to determine the maximum deformation attainable by a sample in the linear viscoelastic range, and (2) frequency sweeps over a range of $0.01 \mathrm{e} 100 \mathrm{~Hz}$ at a constant deformation within the linear viscoelastic range. The storage modulus ( $\left.G^{\prime}\right)$, loss modulus $\left(G^{\prime \prime}\right)$ and loss factor $\left(\tan \delta=G^{\prime \prime} / G^{\prime}\right)$ as a function of frequency $(\omega)$ were obtained.

Steady-flow tests were also performed on freshly prepared paste samples at $50{ }^{\circ} \mathrm{C}$ to obtain shear rate versus shear stress data. The plate was programmed to increase the shear rate from 0.06 to $500 \mathrm{~s} 1$ (up curve) over $400 \mathrm{~s}$ immediately followed by a reduction from 500 to $0.06 \mathrm{~s}^{-1}$ over $400 \mathrm{~s}$ (down curve). Data from the up curve of the shear cycle were used to characterize the flow of the paste samples and to estimate the power law parameters by application of the equation $\sigma=K \cdot \gamma^{\mathrm{n}}$, where $\sigma$ is the shear stress $(\mathrm{Pa}), \gamma$ is the 
shear rate $\left(s^{-1}\right), K$ is the consistency coefficient $\left(\mathrm{Pa} . \mathrm{s}^{\mathrm{n}}\right)$, and $\mathrm{n}$ is the dimensionless flow behaviour index. In addition, the area between the up and down curves was calculated in order to obtain the thixotropic behaviour of samples. All measurements were made in duplicate in both rheological tests.

\subsubsection{Gel preparation}

Hydrocolloid gels were made using a $1 \mathrm{~L}$ beaker, dispersing $9 \mathrm{~g}( \pm 0.1 \mathrm{~g})$ of hydrocolloid and $84 \mathrm{~g}( \pm 0.1 \mathrm{~g})$ of flour into $600 \mathrm{~g}$ of distilled water. Hydrocolloid solutions were heated to boiling $(95 \mathrm{C})$ on a heater plate at a constant stirring speed in order to achieve sufficient hydration and homogenous dispersions. Samples were held at boiling temperature for $15 \mathrm{~min}$. During heating, the beaker was cover with plastic film with small orifices to avoid water loss due to evaporation. Hydrocolloid solutions were poured into cylindrical containers (35 mm internal diameter, $65 \mathrm{~mm}$ height), then allowed to rest at room temperature for $25 \mathrm{~min}$ and were stored in a fridge at $4 \mathrm{C}$ for $24 \mathrm{~h}$ to achieve gel stabilization. Each gel was made in triplicate.

\subsubsection{Gel texture and colour}

Samples $(z 25 \mathrm{~g})$ were taken from the fridge and maintained at room temperature $(z 25 \mathrm{C})$ for $1 \mathrm{~h}$ prior to colour and texture measurement. Texture measurements of the prepared gels were performed at room temperature $(z 25 \mathrm{C})$ using a TA.XT2i Texture Analyzer (Stable Micro Systems Ltd., Surrey, UK) equipped with Texture Expert version 1 software for Windows; a $5 \mathrm{~kg}$ load was used for force calibration. One compression cycle was applied using a $25 \mathrm{~mm}$-diameter cylindrical probe (P25a) at a constant crosshead velocity of $0.5 \mathrm{~mm} \cdot \mathrm{s}^{-1}$ to a sample depth of $10 \mathrm{~mm}$, followed by a return to the original position. The force-time curve thus obtained was used to calculate the values of the texture attributes: hardness (the peak force observed during the compression cycle) and breaking strain (strain to reach the highest value of force).

Gel colour was measured using a Minolta CN-508i spectrophotometer (Minolta Co., Ltd, Osaka, Japan). Results were expressed in the CIE L*a*b* colour space and were obtained using standard illuminant D65 with the 2standard observer. Colour and texture determinations were performed in triplicate.

\subsubsection{Statistical analysis}

Differences between the parameters for the gels were studied by analysis of variance (oneway ANOVA). Fisher's least significant difference (LSD) was used to describe means with 95\% confidence intervals. The statistical analysis was performed using the Statgraphics Plus V5.1 software (Statpoint Technologies, Inc., Warrenton, USA). 


\section{$\underline{\text { 3. Results and discussion }}$}

\subsection{Hydration properties}

The hydration properties of the flours and of their mixtures with hydrocolloids are shown in Table 1. In general, extruded flours and their combinations showed a higher WHC, SV and WBC; the differences were significant for all combinations except those with icarrageenan. Camire et al. (1990) proposed that the rupture of starch granule integrity that occurs during gelatinization in the extrusion process, leads to a poorly ordered molecular phase with hydroxyl groups made available to bind water molecules. This mechanism would explain the higher WHC, SV and WBC of mixtures of hydrocolloids and extruded flours.

Table 1: Individual effects of flour-hydrocolloid combinations on hydration and steady flow properties.

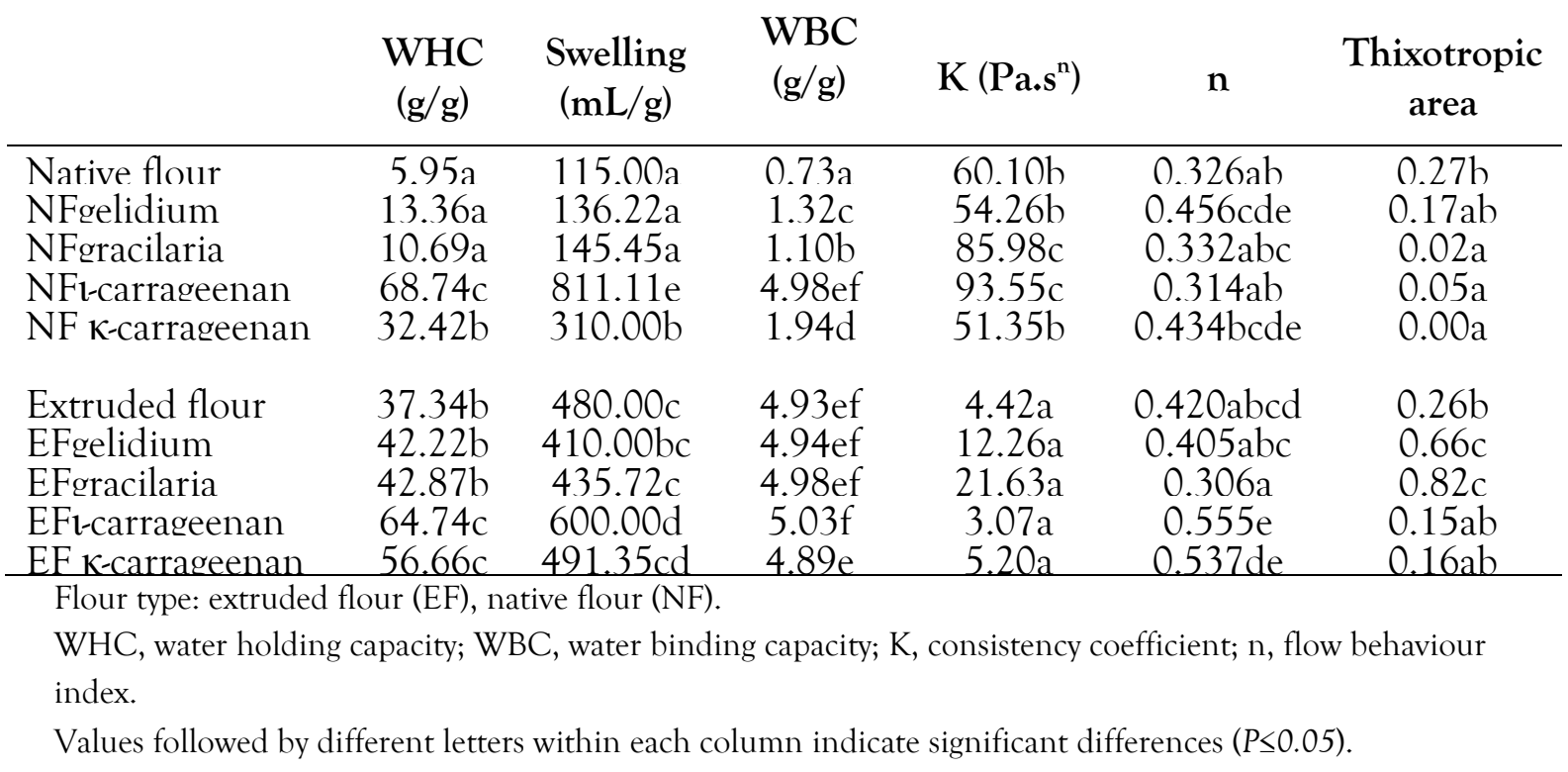

In general, hydrocolloids increased the WHC, SV and WBC of non-treated flours, and this increasewas greater with carrageenans than with agar, particularly with i-type carrageenan. A number of authors have already observed higher SV values in starchecarrageenanewater pastes (Tecante \& Doublier, 1999; Techawipharat, Suphantharika, \& BeMiller, 2008). According to Christianson, Hodge, Osborne, and Detroy (1981), the addition of hydrocolloids can considerably increase the shear forces exerted on the swollen granules in the shaking phase compared with theforces present in starchewater suspensions. This can enhance water uptake (increasing swelling), granule breakdown and the amount of material exuded into the continuous phase.

In the case of agar, significant differences of the WBC values were only observed with non-treated flour, with highest values being obtained with agar from Gracilaria seaweeds. When combined with extruded flours, agar did not modify the hydration properties of 
the flours, whereas carrageenans increased WHC but not WBC, and only i-carrageenan increased SV.

The different effect of the hydrocolloids on the hydration properties reflects different interactions between each hydrocolloid and the flour, and this in turn depends on the chemical structure of the hydrocolloids added.

\subsection{Pasting properties}

The RVA curves of different flourehydrocolloid combinations are shown in Fig. 1. In Fig. 1 (native flourehydrocolloid combinations) it can be seen that there was no change in the interaction between the flour and the hydrocolloid until a certain temperature was reached, and the viscosity of the combinations increased in a number of different ways. As hydrocolloids alone (without the presence of flour) showed no significant thickening power on the medium until their solutions were cooled, as observed in Fig. 1, changes observed in the pasting properties of flours must be interpreted based on the different interactions that take place between the starch granules and the hydrocolloid. Both agars produced a fall in the onset temperature of gelatinization and an increase in peak viscosity (PV) and breakdown (BR); the increase in the latter two parameters was more marked in the case of Gelidium agar than Gracilaria agar. Shi and BeMiller (2002) and Liu and Eskin (1998) detected a decrease in the onset temperature of gelatinization, measured by RVA when studying the interaction between different starches and hydrocolloids, despite the fact that there were no changes in the gelatinization temperature measured by DSC; it could therefore be deduced that these hydrocolloids do not affect the availability of water required by the starch granules for the gelatinization process to occur. On the other hand, Christianson et al. (1981) proposed that this fall in the temperature necessary to initiate the increase in viscosity was due to associations betweensolubilized/leached starch (primarily amylose) molecules and hydrocolloid molecules that developed before granule pasting, a finding supported by Eidam et al. (1995) and Shi and BeMiller (2002). 

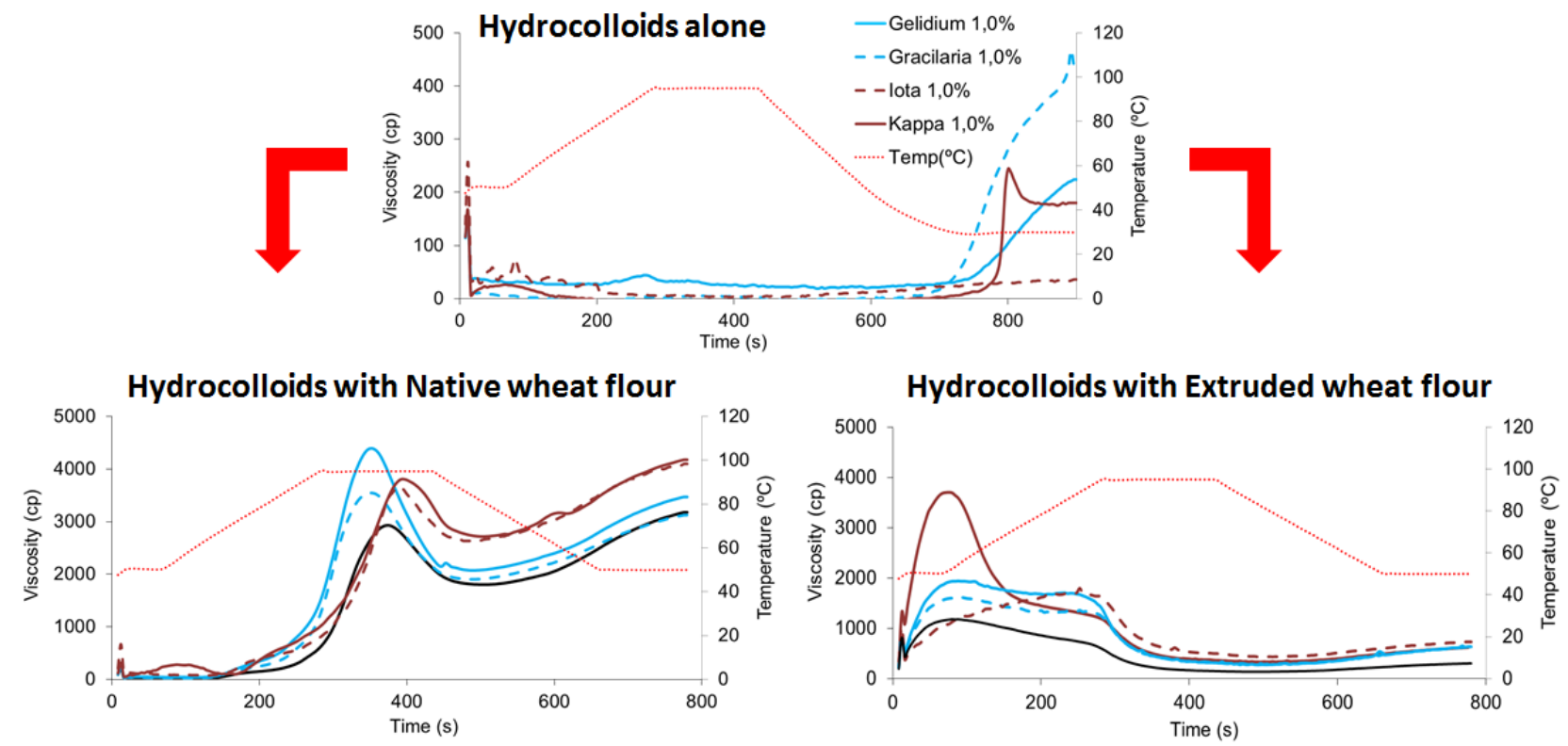

Fig. 1. Pasting properties of hydrocolloids without flour (hydrocolloids alone), native wheat flour with hydrocolloids and extruded wheat flour with hydrocolloids. Flours without hydrocolloids (black line), kcarrageenan (continuous dark red line), i-carrageenan (discontinuous dark red line), Gelidium agar (continuous blue line), Gracilaria agar (discontinuous blue line). Temperature profile (dotted red line). (For interpretation of the references to colour in this figure legend, the reader is referred to the web version of this article.)

After reaching the PV, pastes presented a fall in their viscosity due to rupture of the starch granules, known as breakdown (BR); this was more pronounced in combinations of flour and agar than in preparations of flour alone or in combination with carrageenans. The higher PV and lower BR would support the hypothesis that agars enhance granule swelling, leading to much higher forces within the granules and further granule disintegration, permitting greater dissolution of the polymeric starch molecules.

In the case of carrageenans, an increase in the onset of viscosity was observed with the first increase in the gradient of the curve, but this increase was slow compared with the agar combinations. As in the case of agar, carrageenans also increased PV, but the time to reach that peak was longer; there were no marked differences between the two carrageenans studied. These findings do not coincide with results reported by Tye (1988), who detected a synergic effect between starch and i-carrageenan but did not between starch and k-carrageenan. Nonetheless, it should be stated that the composition of the kcarrageenan used in our study included a potassium salt, which induces gelation (Tecante \& Doublier, 1999). Those same authors also appreciated an increase in the PV after the incorporation of carrageenans; this was attributed to increased swelling of the starch granules in the presence of carrageenans. The increase in the time to peak viscosity in the samples with carrageenans could be due to the formation of hydrogen bonds between the carrageenans and the starch polymer molecules within swollen granules (Liu, Eskin, \& 
Cui, 2003), assuming the hydrocolloid molecules could penetrate into the granules, a phenomenon for which there is some evidence (Savary, Handschin, Conde-Petit, Cayot, $\&$ Doublier, 2008). The viscosity of carrageenan pastes in our study was higher than nontreated samples or the combinations with agars, both while the temperature was held at $95 \mathrm{C}$ and during the cooling stage. Those results could also be due to the interactions among proteins such as gluten and carrageenans, as several authors reported (Huebner \&Wall, 1979; Leon et al., 2000). Meanwhile, Ribotta, Ausar, Beltramo, and Leon (2005) demonstrated that carrageenan isoforms could form hydrophilic complexes with gluten proteins and the capacity of the complexation appeared to be related to the density of the anionic group in the hydrocolloid. Additionally, Wang, Zhao, Yang, and Jiang (2006) reported that those electrostatic interactions could involve lysine and terminal $\mathrm{NH} 2$ in gluten protein, thus not only starch granules could interact with hydrocolloids but also the protein fraction of wheat flours.

The curves of the agar combinations during these stages were very similar to the nontreated flour curves, though the viscosity was somewhat higher in the case of Gelidium combinations. These final viscosity increases in the presence of carrageenans have been observed previously by Lai et al. (1999) and Huang, Kennedy, Li, Xu, and Xie (2007), who concluded that interactions between the hydrocolloid and the starch polymers (especially amylose) created bonds forming a network with crosslinking. Appleqvist and Debet (1997) stated that $\mathrm{i}$ - and k-carrageenan protected starch systems against shear stress, which would explain the decrease in BR. Another possible explanation of this decrease in BR in the carrageenan combinations would be the increase in the hydrocolloid concentration in the continuous phase as the starch granules absorb water and swell, simultaneously increasing the viscosity of the paste (BeMiller, 2011). In the case of carrageenans, retrogradation could be affected both by the increase in the effective concentration of starch molecules (primarily amylose) resulting from the immobilization of water by the hydrocolloid molecules (Yoshimura, Takata \& Nishinari, 1988), and by the associative interactions between carrageenan and gluten.

As general conclusions, it may be considered that agars and carrageenans have different mechanisms of action on pasting properties. Agars would create bonds with solubilized/leached (primarily amylose) molecules, with a lower onset temperature of gelatinization, and no increase in amylose retrogradation in comparison with controls. Furthermore, the presence of agar would assist swelling of the granule, as indicated by the increase in PV and BR. The carrageenans, on the other hand, would not create bonds with solubilized/leached (primarily amylose) molecules, evidenced by the absence both of a decrease in the onset temperature of gelatinization and of final viscosity. Additionally, carrageenans would interact with gluten protein and would foster the water immobilization, resulting in an increase of the effective concentration of starch molecules (primarily amylose), which would favour retrogradation. 
Fig. 1 shows the results with extruded flour ehydrocolloid combinations. These flours showed a much greater cold thickening power than non-treated flours, but the viscosity of pastes decreased with increasing temperature and there was no significant increase in viscosity during the cooling stage. Theincorporation of the different hydrocolloids increased the viscosity of flours without heating through distinct mechanisms. Gelidium and Gracilaria agars increased the viscosity in a similar way, with Gelidium having a greater effect. In the case of carrageenans, on the other hand, while k-carrageenan produced a marked increase in the initial stage, followed by a sharp decline, i-carrageenan produced a less intense increase in viscosity and its effect was delayed. This increase could be secondary to the concentration of hydrocolloid in the continuous phase as a result of the higher water absorption capacity of the extruded flour components without increasing the temperature (Martínez, Oliete, \& Gomez, 2013). Differences between the different hydrocolloids could be due to their capacity to form a network that immobilizes the water, increasing the viscosity of the continuous phase and the effective concentration of amylose (Savary et al., 2008); this could be particularly important in the case of $\mathrm{k}$ carrageenan in the presence of potassium ions (Therkelsen, 1993). Meanwhile, interactions among gluten proteins with carrageenan could be even higher in presence of extruded flours, since extrusion forces the unfolding and aggregation of proteins (Martínez, Calvi no, Rosell, \& Gomez, 2014), which could boost additional electrostatic interactions. In the cooling stage, all hydrocolloids behave in a similar way, slightly increasing the viscosity of extruded flour pastes, showing the same trend as the majority of fluids as temperature decreases.

\subsection{Steady shear rheological properties}

The results of steady shear rheology are shown in Table 1. For the range of shear rates used in this study, the power law model accurately described the flow behaviour of each paste. All the pastes showed $\mathrm{n}<1$, thus exhibiting shear-thinning behaviour. The $\mathrm{K}$ values were higher in native flours than in extruded flours. In the case of hydrocolloids, an increase in $\mathrm{K}$ was only observed with Gracilaria agar and i-carrageenan with non-treated flour, indicating a higher consistency. Techawipharat et al. (2008) also reported a higher $K$ value in pastes with $\mathrm{i}$-carrageenan. Regarding the $\mathrm{n}$ value, there was no clear trend and we can only state that combinations of extruded flours with carrageenans showed higher values than the same flours with agar. Finally, we observed an increase in the thixotropic area in extruded flours when they were combined with agars, whereas carrageenans had the opposite effect, decreasing thixotropy both with extruded and with non-treated flours, although the differences were not significant in the case of extruded flours. In conclusion, depending on requirements, pastes made with combinations of extruded flours and agar could be a good option due to their greater thixotropy, which could be beneficial when making of sauces such as ketchup(Sahin \& Ozdemir, 2004), whereas pastes made with combinations of carrageenans (particularly i-carrageenan) and native or extruded flours could be suitable for their low thixotropy and high consistency. As it was commented 
earlier, (Section 3.2), agar and carrageenans have different mechanisms of action. While carrageenans may interact with gluten proteins (Wang et al., 2005) and increase the amylose concentration in the continuous phase due to the immobilization of water molecules by the hydrocolloid (Yoshimura et al., 1988), agars may interact with solubilized/leached (primarily amylose) molecules and promote swelling of the granule, which could explain the different rheological behaviour among agars and carrageenans. In addition, the greater water holding capacity of the gelatinized starch of extruded flours (Martínez et al., 2013) could contribute to a fluidizing of pastes in the presence of stress.

\subsection{Dynamic rheological properties}

Table 2 shows the dynamic rheological values. In all cases higher values were found for G0 compared to G00, which indicates that all pastes are elastic and develop distinct solid properties. Furthermore, it must be remembered that starch pastes, even when cooled, are in a metastable, non-equilibrium state (Biliaderis \& Zawistowski, 1990) and, as a result, they will undergo further aggregation and partial crystallization during storage and thus become firmer pastes/gels. The addition of hydrocolloid to a starch paste or gel thus makes an already complex system even more complex.

Table 2: Individual effects of flour-hydrocolloid combinations on oscillatory tests.

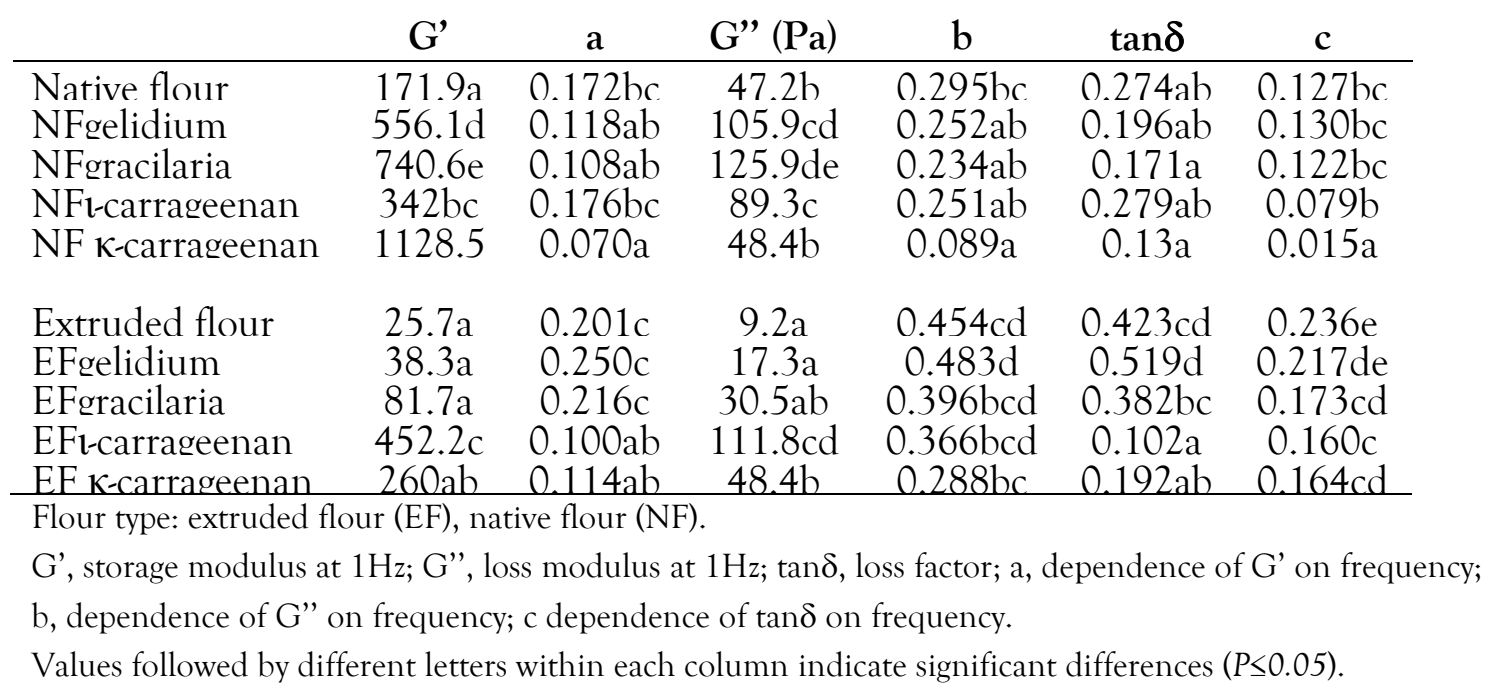

All hydrocolloids except i-carrageenan increased $G$ ' in non-treated flours whereas, in extruded flours, this effect was only observed in combinations with carrageenans. All hydrocolloids except k-carrageenan increased G" in the case of non-treated flours. In the case of extruded flours, with lower G" than non-treated flours, only carrageenans achieved a significant increase in this value. A reduction in the tan $\mathrm{d}$ value was observed both with native and with extruded flours when the flours were combined with carrageenans (this did not occur with agars) and this coincides with the increase observed in G' and G'. Therefore, carrageenans increased G' and G' in extruded flours and decreased $\tan \delta$ both in extruded and in non-treated flours. Lai and Lii (2003) have 
previously reported an increase in the elastic component of the sample $\left(G^{\prime}\right)$ and a decrease in $\tan \delta$; they attributed this to a network formation after the addition of $\mathrm{k}$ carrageenan. In Table 2, it can also be seen that carrageenans decreased the "a" value, both in non-treated and extruded flours, with the exception of i-type in combination with non-treated flours, while agars did not modify this parameter. Regarding the "b" parameter, no clear effect was observed except for a decrease in this parameter in the case of non-treated flours combined with k-carrageenans. The incorporation of hydrocolloids also reduced the "c" parameter in extruded flours, with the exception of Gelidium agar. In non-treated flours, however, with lower "c" values, this effect was only observed with kcarrageenan. Consequently, carrageenans, and particularly k-carrageenan, provoked a decrease in the dependence of the modulus on frequency, which would produce pastes/gels with greater stability than flours without hydrocolloid or agar-flour combinations.

As has already been discussed, carrageenans besides not developing links with amylose, could increase its concentration (Yoshimura et al., 1988); this, together with the possible association with gluten proteins and the creation of crosslinking and entanglement of hydrocolloid molecules, would contribute to increase the stiffness and stability of samples against shear stress. In contrary, agars only increased elastic (G') and viscous (G') modulus in non-treated flour pastes. As indicated in Section 3.2, agars may develop interactions with solubilized/leached (primarily amylose) molecules, which could increase the viscosity and elasticity ofpastes. Nonetheless, starch granules (Camire et al., 1990) and amylose chains (Mercier \& Feillet, 1975) in flours that have undergone extrusion would fragment as a consequence of the high shear stress and temperatures, and linking between amylose molecules and agars would therefore be different, and the elastic and viscosity components of these pastes could be maintained.

\subsection{Colour and textural properties of gels}

The colour and texture results of the hydrocolloid-flour-water gels are shown in Table 3. With respect to colour, all gels were darker (lower values of $\mathrm{L}^{*}$ ) when elaborated with extruded flours, with the exception of gels obtained with Gelidium agar. Gels made with carrageenans were lighter than agar gels when they were made with non-treated flours. However, the differences were smaller between the gels made with treated flours and no significant trend was observed, though the Gracilaria gels were darker and the icarrageenan gels lighter. Regarding the $\mathrm{a}^{*}$ parameter, the values were lower in carrageenan gels with non-treated flours than in the agar gels with these flours; the gels obtained with extruded flours showed no significant differences. Nor were there any significant differences in the $a^{*}$ values between the carrageenan gels made with extruded flours and with non-treated flour, but significantly higher $\mathrm{a}^{*}$ values were obtained when agar gel were combined with non-treated flours. Flour type had a greater effect on the $b^{*}$ parameter, with higher values being observed with non-treated flour gels. Of the hydrocolloids, icarrageenan gels achieved the highest values, but in the case of gels of hydrocolloids with 
nontreated flour, significant differences were only observed with Gelidium agar. Extruded flours showed a darker colour due to Maillard reactions that occur during the extrusion process (Camire et al. 1990), which could have an influence on the colour of gels obtained. In addition, the greater proportion of damaged and gelatinized starch in extruded flours (Martínez et al., 2013) would favour the accumulation of solutes in the continuous phase, decreasing the luminosity of samples. In general, differences between the distinct hydrocolloids were small, with the exception of the lighter colours (high $\mathrm{L}^{*}$ ) of the gels elaborated with carrageenans and non-treated flours. Thus, although it seems that the flour colour dominates the final colour of gels, the different molecular structures of the hydrocolloids and their interactions with flour components could also have an influence on the colour of pastes/gels.

Table 3: Individual effects of flour-hydrocolloid gels on colour and textural properties.

\begin{tabular}{lccccc} 
& $\mathbf{L}^{*}$ & $\mathbf{a}^{*}$ & $\mathrm{~b}^{*}$ & $\begin{array}{c}\text { Hardness } \\
(\mathbf{N})\end{array}$ & $\begin{array}{c}\text { Breaking } \\
\text { Strain }(\mathbf{m m})\end{array}$ \\
\hline NF Control & $70.75 \mathrm{f}$ & $-0.44 \mathrm{de}$ & $7.56 \mathrm{f}$ & $2.18 \mathrm{ab}$ & $4.97 \mathrm{c}$ \\
NFgelidium & $64.95 \mathrm{ab}$ & $-0.49 \mathrm{de}$ & $5.19 \mathrm{~d}$ & $7.19 \mathrm{c}$ & $1.64 \mathrm{a}$ \\
NFgracilaria & $65.54 \mathrm{bc}$ & $-0.40 \mathrm{e}$ & $5.79 \mathrm{de}$ & $11.18 \mathrm{~d}$ & $1.93 \mathrm{ab}$ \\
NFt-carrageenan & $71.02 \mathrm{f}$ & $-0.68 \mathrm{~cd}$ & $6.13 \mathrm{e}$ & $2.88 \mathrm{ab}$ & $4.82 \mathrm{c}$ \\
NF -carrageenan & $70.00 \mathrm{e}$ & $-0.93 \mathrm{abc}$ & $5.68 \mathrm{de}$ & $18.19 \mathrm{e}$ & $3.75 \mathrm{bc}$ \\
& & & & & \\
EH Control & $66.18 \mathrm{~cd}$ & $-0.86 \mathrm{abc}$ & $2.53 \mathrm{c}$ & $1.66 \mathrm{a}$ & $4.29 \mathrm{bc}$ \\
EHgelidium & $65.56 \mathrm{bc}$ & $-1.08 \mathrm{a}$ & $1.49 \mathrm{~b}$ & $2.76 \mathrm{ab}$ & $4.91 \mathrm{c}$ \\
EHgracilaria & $64.34 \mathrm{a}$ & $-0.99 \mathrm{ab}$ & $1.07 \mathrm{ab}$ & $4.03 \mathrm{~b}$ & $4.31 \mathrm{bc}$ \\
EHt-carrageenan & $66.68 \mathrm{~d}$ & $-0.82 \mathrm{bc}$ & $3.27 \mathrm{c}$ & $2 . \mathrm{ab}$ & $4.92 \mathrm{c}$ \\
EH -carrageenan & $65.38 \mathrm{~b}$ & $-1.01 \mathrm{ab}$ & $0.65 \mathrm{a}$ & $22.73 \mathrm{f}$ & $3.20 \mathrm{~b}$ \\
\hline
\end{tabular}

Flour type: extruded flour (EF), native flour (NF).

Values followed by different letters within each column indicate significant differences $(P \leq 0.05)$

Gels containing k-carrageenan were harder, whether using extruded flours or native flours. In the case of extruded flours gels, no differences in hardness were observed with the other hydrocolloids, but in the case of non-treated flours, the i-carrageenangels were softer, followed by Gelidium agar gels. Regarding the breaking strain, the native flourecarrageenan combination gels together with the native control sample presented higher values, but no clear trend was observed in the combinations with extruded flours. Lafargue, Lourdin, and Doublier (2007) showed how the addition of k-carrageenan (with potassium) produced an increase in the hardness of modified pea starch gel. In contrast, Eidam et al. (1995) reported greater gel strength after the incorporation of i-carrageenan than if k-carrageenan was used, contrary to the findings of the present study. However, those authors used pure k-carrageenan without potassium ions, which increase the gelling power of carrageenan (Therkelsen, 1993) and would explain the greater hardness of the $\mathrm{k}$ carrageenan gels used in our study. 
Despite the fact that seaweed agars, particularly Gracilaria agar, showed a greater gelling power than carrageenans when used alone in water (Fig. 1), the hardness of their gels in combination with flour was lower than observed with k-carrageenanflour gels. Therefore, the nature of the interaction between the hydrocolloid and the flour starch is a key factor in the hardness of flourehydrocolloidewater gels. Lai et al. (1999) and Huang et al. (2007) concluded that hydrocolloidestarch (particularly amylose) interactions resulted in the formation of a network and/or crosslinking, which could explain gel hardness. Nonetheless, considering the hypothesis that carrageenans do not interact with solubilized/leached starch molecules, the greater hardness of these gels may also be due to the associations among carrageenans and gluten proteins (Wang et al., 2006) and the increase in the concentration of amylose in the continuous phase resulting from water immobilization by the hydrocolloid (Yoshimura et al., 1988).

\section{$\underline{4 .}$ Conclusions}

Native and extruded wheat flourehydrocolloid pastes/gels exhibit different properties depending on the type of hydrocolloid. Results suggested that agars and carrageenans have different mechanisms of action on pasting properties. Agars could create bonds with solubilized/leached (primarily amylose) molecules, with a lower onset temperature of gelatinization, and no increase in amylose retrogradation in comparison with controls. Furthermore, the presence of agar could assist swelling of the granule, as indicated by the increase in PV and BR. The carrageenans, on the other hand, could create associations with gluten proteins and could not create bonds with solubilized/leached (primarily amylose) molecules, evidenced by the absence both of a decrease in the onset temperature of gelatinization and of final viscosity. In the case of extruded flours, marked differences are also observed in flour viscosity without heating after the incorporation of distinct hydrocolloids. Furthermore, results showed that carrageenans, besides producing stiffer and more stable pastes, gave rise to harder and clearer gels compared to those made with agar, both for their combination with extruded and native wheat flours, thus carrageenans could be suitable for product stability. Meanwhile, pastes made with combinations of extruded flours and agar could be a good option due to their greater thixotropy, which could be beneficial when making of sauces.

\section{$\underline{\text { Acknowledgements }}$}

This study was financially supported by Junta de Castilla y Leon (VA054A12-2), Spain. The authors are grateful to Harinera Los Pisones, Roko and CEAMSA for supplying the raw materials. 


\section{$\underline{\text { References }}$}

AACC. (2012). Approved methods of the American Association of Cereal Chemists, method 61-02.01 (pasting properties), 56.30 (water binding capacity) (11th ed.). St. Paul, Minnesota: American Association of Cereal Chemists.

Appleqvist, I. A. M., \& Debet, M. R. M. (1997). Starch-biopolymer interactionsda review. Food Reviews International, 13, 163e224.

Armisen, R. (1991). Agar and agarose biotechnological applications. Hydrobiologia, 221, $157 \mathrm{e} 166$.

BeMiller, J. N. (2011). Pasting, paste, and gel properties of starchehydrocolloid combinations. Carbohydrate Polymers, 86, 386e423.

Biliaderis, C. G., \& Zawistowski, J. (1990). Viscoelastic behavior of aging starch gels: effects of concentration, temperature, and starch hydrolysates on network properties. Cereal Chemistry, 67, 240e246.

Camire, M., Camire, A., \& Krumhar, K. (1990). Chemical and nutritional changes in foods during extrusion. Critical Reviews in Food Science and Nutrition, 29, 35 e57.

Campo, V. L., Kawano, D. F., da Silva, D. B., \& Carvalho, I. (2009). Carrageenans: biological properties, chemical modifications and structural analysis e a review. Carbohydrate Polymers, 77, 167e180.

Christianson, D. D., Hodge, J. E., Osborne, D., \& Detroy, R.W. (1981). Gelatinization of wheat starch as modified by xanthan gum, guar gum, and cellulose gum. Cereal Chemistry, 58, 513e517.

Doublier, J., Colonna, P., \& Mercier, C. (1986). Extrusion cooking and drum drying of wheat-starch 2. Rheological characterization of starch pastes. Cereal Chemistry, 63, $240 \mathrm{e} 246$.

Eidam, D., Kulicke, W.-M., Kuhn, K., \& Stute, R. (1995). Formation of maize starch gels selectively regulated by the addition of hydrocolloids. Starch/St€arke, 47, 378e384.

Huang, M., Kennedy, J. F., Li, B., Xu, X., \& Xie, B. J. (2007). Characters of rice starch gel modified by gellan, carrageenan, and glucomannan: a texture profile analysis study. Carbohydrate Polymers, 69, 411e418.

Huebner, F., \& Wall, J. (1979). Polysaccharide interactions with wheat proteins and flour doughs. Cereal Chemistry, 56, 68e73.

Knutsen, S. H., Mylabodski, D. E., Larsen, B., \& Usov, A. I. (1994). A modified system of nomenclature for red algal galactans. Botanica Marina, 37, $163 \mathrm{e} 169$. 
Lafargue, D., Lourdin, D., \& Doublier, J.-L. (2007). Film-forming properties of a modified starch/k-carrageenan mixture in relation to its rheological behaviour. Carbohydrate Polymers, 70, 101e111.

Lai, V. M. F., Huang, A.-L., \& Lii, C. Y. (1999). Rheological properties and phase transition of red algal polysaccharideestarch composites. Food Hydrocolloids, 13, $409 \mathrm{e} 418$.

Lai, V. M. F., \& Lii, C. Y. (2003). The influences of starch fillers on the viscoelasticity of agarose and k-carrageenan gels. Food Science and Agricultural Chemistry, 5, 27 e34.

Leon, A. E., Ribotta, P. D., Ausar, S. F., Fernandez, C., Landa, C. A., \& Beltramo, D. M. (2000). Interactions of different carrageenan isoforms and flour components in breadmaking. Journal of Agricultural and Food Chemistry, 48, 2634e2638.

Liu, H., \& Eskin, N. A. M. (1998). Interactions of native and acetylated pea starch with yellow mustard mucilage, locust bean gum and gelatin. Food Hydrocolloids, 12, 37e41.

Liu, H., Eskin, N. A. M., \& Cui, S. W. (2003). Interaction of wheat and rice starches with yellow mustard mucilage. Food Hydrocolloids, 17, 863e869.

Martínez, M. M., Calvi ${ }^{\sim}$ no, A., Rosell, C. M., \& Gomez, M. (2014). Effect of different extrusion treatments and particle size distribution on the physicochemical properties of rice flour. Food and Bioprocess Technology. http://dx.doi.org/ 10.1007/s11947-014$1252-7$.

Martínez, M., Oliete, B., \& Gomez, M. (2013). Effect of the addition of extruded wheat flours on dough rheology and bread quality. Journal of Cereal Science, 57, 424e429.

Mercier, C., \& Feillet, P. (1975). Modification of carbohydrate components by extrusioncooking of cereal products. Cereal Chemistry, 63, $283 \mathrm{e} 297$.

Mohammed, Z. H., Hember, M. W. N., Richardson, R. K., \& Morris, E. R. (1998). Cogelation of agarose and waxy maize starch. Carbohydrate Polymers, 36, 37e48.

Nelson, A. (2001). Properties of high-fibre ingredients. Cereal Foods World, 46, 93e97.

Renn, D. (1997). Biotechnology and the red seaweed polysaccharides industry: status, needs and prospects. Trends in Biotechnology, 15, 9e14.

Ribotta, P. D., Ausar, S. F., Beltramo, D. M., \& Leon, A. E. (2005). Interactions of hydrocolloids and sonicated-gluten proteins. Food Hydrocolloids, 19, 93e99.

Sahin, H., \& Ozdemir, F. (2004). Effect of some hydrocolloids on the rheological properties of different formulated ketchups. Food Hydrocolloids, 18, 1015e1022. 
Savary, G., Handschin, S., Conde-Petit, B., Cayot, N., \& Doublier, J.-L. (2008). Structure of polysaccharide-starch composite gels by rheology and confocal laser scanning microscopy: effect of the composition and of the preparation procedure. Food Hydrocolloids, 22, 520e530.

Shi, X., \& BeMiller, J. N. (2002). Effects of food gums on viscosities of starch suspensions during pasting. Carbohydrate Polymers, 50, 7e18.

Tecante, A., \& Doublier, J. L. (1999). Steady flow and viscoelastic behavior of crosslinked waxy corn starch-k-carrageenan pastes and gels. Carbohydrate Polymers, 40, 221e231.

Techawipharat, J., Suphantharika, M., \& BeMiller, J. N. (2008). Effects of cellulose derivatives and carrageenans on the pasting, paste, and gel properties of rice starches. Carbohydrate Polymers, 73, 417e426.

Rice flour functional properties are fully dependent on genotype and environmental conditions (Yeh 2004) and besides that, postharvest treatments could be an alternative for modulating flour functional features. It is well known that rice grinding significantly affects rice flour properties, such as water binding capacity and swelling power (Perdon et al 2001). Recently, it has been shown that particle size fractionation of rice flour might be advisable for selecting specific physicochemical properties, such as different hydration properties and enzymatic starch hydrolysis (de la Hera et al 2013a); rheological properties (Moreira et al 2013) or even oil barrier properties (Lee et al 2013). Moreover, those fractionated flours showed different processing behavior more suitable for bread or cake making depending on the particle size (de la Hera et al 2013b,c).

Thermal treatments are highly attractive to modify the functional properties of the cereal flours. Extrusion cooking is considered high-temperature-short-time duringwhich flours are submitted to high temperatures and mechanical shearing at relatively low levels of moisture content (Camire et al 1990). This treatment allows starch pregelatinization, denaturation of protein, enzyme (in)activation and Maillard reactions, the extent of which are dependent on the severity of the extrusion. Those changes at the constituents' level modify the rheological behavior of flour (Hagenimana et al 2006). During extrusion, the starch properties are dependent on the temperature, initial moisture content and the 
screw speed (Wen et al 1990). By raising the intensity of the treatment, it is possible to break down the amylopectin chains (Mercier and Feillet 1975). In fact, Colonna et al. (1984) described that extruded wheat starches have amylose and amylopectin chains of lower molecular weight than the ones obtained by drum drying, attributable to the shear effect, and that gave low thickening ability at low temperature (Doublier et al.1986).

The extrusion also promotes important nutritional changes in the flours, such as an increase in the soluble fiber content and a reduction in the lipid oxidation tendency, the content of antinutritional factors and the microbial population (Camire et al. 1990). Besides, it could increase the content of resistant starch in rice flours (Hagenimana et al 2006), which is dependent on the treatment intensity (Alsaffar 2011). Extrusion cooking is responsible for gelatinization and degradation of starch and also for changing the extent of molecular associations between components (e.g., the amylose- lipid complex that can affect the in vitro starch digestibility of the flours [Hagenimana et al. 2006]).

Despite the impact of the extrusion on the molecular level, little attention has been paid to the variation of the functional properties of the flours by hydrothermal treatments (Clerici et al. 2009), even though physically modified flours are considered to be natural materials with high safety (Jacobs and Delcour 1998). In fact, Clerici et al. (2009) included $10 \%$ of extruded acid-modified rice flours for making gluten free breads. When using rice flours extruded in the presence of different amount of lactic acid, gluten free breads presented crust and crumb color and texture values similar to those of wheat bread, although specific volume was rather low.

Considering the influence of the flour fractionation on the functional properties of the rice flours (de la Hera et al. 2013b) and the molecular changes induced by extrusion cooking, the combination of both physical treatments could modify rice flour functional properties keeping the green label. The aim of this study was to modify the functional properties of rice flour by combining extrusion and size fractionation. With that purpose, different extrusion conditions were applied to vary the severity of the treatment on the flour constituents. The impact of processing on the flours was also followed by assessing the susceptibility of the flours to enzymatic hydrolysis.

\section{Materials and Methods}

\section{Materials}

Rice flours were provided by Harinera Los Pisones (Zamora, Spain) that carried out the extrusion treatment in a single screw extruder Bühler Basf (Bühler S.A., Uzwil, Switzerland). Extrusion parameters were chosen according to the manufacturer advice in order to achieve flours with different properties. The length to diameter (L/D) ratio for the extruder was 20:1. Rice flour was subjected to different extrusion intensities (barrel temperature, moisture content of the mass feed and feed rate) yielding three types of extrudedflours (1-3). Rice flour 1 and 2 were extruded at a maximum barrel temperature 
of $110^{\circ} \mathrm{C}$ with a feed rate of $700 \mathrm{~kg} / \mathrm{h}$. For flours 1 and 2 feed moisture content and screw speed was $17 \%$ and $30 \%$, and 453 and $397 \mathrm{rpm}$, respectively. The diameter of the die hole and the number of holes used in those flours was $8 \mathrm{~mm}$ and 18 holes, respectively. Rice flour 3 was extruded at a maximum barrel temperature of $140^{\circ} \mathrm{C}$ with a feed-rate of $500 \mathrm{~kg} / \mathrm{h}$ and feed moisture content of $25 \%$. The screw speed was $340 \mathrm{rpm}$, the diameter of the die hole was 6 mmand the number of holes was 9 . The same rice flour (rice flour 0 ) without any treatment was used as a control.

Extruded product was dried by convection air and then ground with a compression roller till particle size was lower than $200 \mu$. Ground extrudates were sifted in a Bühler MLI 300B (Bühler AG, Uzwil, Switzerland) with screens of 132 and 200 microns to obtain fine (f)-lower than $132 \mu \mathrm{m}$ - and coarse (c)-132 $200 \mu \mathrm{m}$ - extruded flours.

Flours were stored in air-tight plastic containers and held at $4{ }^{\circ} \mathrm{C}$ until analysis.

Both the extruded and nonextruded flours were involved in the analytical measurements.

Methods

Flours Characterization

Flours were analyzed following AACC method (AACC 2012) for protein (AACC 4630.01) with a Leco TruSpec device (Leco, St. Joseph, MI, USA). The particle size distribution was measured using a particle size analyzer with laser diffraction Helos \& Rodos (Sympatec, Clausthal-Zellerfeld, Germany) following AACC method (AACC, 5540.01). Determinations were carried out in duplicate.

Free Sugars

The glucose content was measured using a glucose oxidaseperoxidase kit. The absorbance was measured using an Epoch microplate reader (Biotek Epoch, Izasa, Barcelona, Spain) at $510 \mathrm{~nm}$. In all cases four replicates were assayed for each experimental point.

Damage Starch

The content of damaged starch was determined according to AACC 76-30A method (AACC 2012).A fungal enzyme from Aspergillus oryzae (A6211; Sigma Chemical Co., St. Louis, MO, USA) was used in that analysis. Three determinations were made for each sample. Damaged starch was expressed as percentage of flour weight on dry basis.

Hydration Properties

Hydration properties included swelling and water binding capacity (WBC) (Nelson 2001). Swelling volume or the volume occupied by a known weight of flour was evaluated by mixing $5 \mathrm{~g}( \pm 0.1 \mathrm{mg})$ of flour with $100 \mathrm{~mL}$ distilled water and allowing it to hydrate during $16 \mathrm{~h}$. Water binding capacity defined as the amount of water retained by the flour 
after it has been subjected to centrifugation was measured as described the method 56.30 (AACC 2012). Determinations were carried out in duplicate.

Emulsifying Properties

Flour suspension $(360 \mathrm{~mL})$ of $0.5 \%(\mathrm{w} / \mathrm{v})$ starch concentration was mixed with commercial sunflower oil (Langosta, F. Faiges S.L, Daimiel, Ciudad Real, Spain) (36 mL). The content was stirred for one min with a beater (Taurus Bapi $350 \mathrm{CP} / \mathrm{CM}$; Taurus, Oliana, Lérida, Spain) to disperse the sample in the oil. The suspensions were then centrifuged at $800 \times \mathrm{g}$ for $10 \mathrm{~min}$. The emulsifying capacity (EC) was calculated as:

$$
E C=\left(\frac{e v}{t v}\right) * 100
$$

where $\mathrm{e} v$ is the emulsion volume and $\mathrm{t} v$ is total volume.

Emulsion stability (ES) against high temperatures, were determined in the emulsions that were heated in a water bath at $80^{\circ} \mathrm{C}$ for $30 \mathrm{~min}$, and centrifuged at $800 \times \mathrm{g}$ for $10 \mathrm{~min}$. ES was calculated as:

$$
E S=\left(\frac{f e v}{i e v}\right) * 100
$$

where fev is the final emulsion volume and iev is initial emulsion volume. Determinations were carried out in duplicate.

Foaming Properties

Aliquots $(150 \mathrm{~mL})$ of $4 \% \mathrm{w} / \mathrm{v}$ suspension were whipped at moderate speed for one min using a beater (Taurus Bapi 350 CP/CM; Taurus, Oliana, Lérida, Spain). Foam volumes were recorded after $30 \mathrm{~s}$. The foam capacity (FC) was calculated as follows:

$$
F C=\left(\frac{i f v}{t s v}\right) * 100
$$

where ifv is the initial foam volume and tsv is the total suspension volume.

The foam stability (FS) was calculated as the foam volume after $20 \mathrm{~min}$.

$$
F S=\left(\frac{f f v}{t s v}\right) * 100
$$

where $\mathrm{ffv}$ is the foam volume after $20 \mathrm{~min}$ and tsv is total suspension volume. Results were the average of two determinations.

Pasting Characteristics

Pasting properties of flours were analyzed using the standard method (AACC 2012), (AACC 61-02.01) with a Rapid Visco Analyser (RVA-4) (Newport Scientific Pty Ltd., 
Warriewood, Australia) controlled by Thermocline software (Newport Scientific Pty. Limited, Warriewood, Australia) for Windows.

\section{Thermal Properties}

Analyses were performed in a differential scanning calorimeter (DSC)-7 (Perkin-Elmer, Waltham, MA, USA), using aluminium pans (PE 0219-0062). The equipment was calibrated with Indium and an empty pan was used as a reference. Flour (3 mg) was loaded into the aluminum pan and distilled water $(10 \mu \mathrm{L})$ was added with the help of a Hamilton micro syringe. Samples were hermetically sealed and allowed to stand for $1 \mathrm{~h}$ at room temperature before heating in the DSC. The calorimeter scan conditions were set as follows: samples were kept at $30^{\circ} \mathrm{C}$ for $2 \mathrm{~min}$, heated from 30 to $110^{\circ} \mathrm{C}$ at $5^{\circ} \mathrm{C} / \mathrm{min}$. Onset temperature (To), peak temperature $(\mathrm{Tp})$, gelatinization temperature range $(\mathrm{Tp}$ To), peak height index $(\Delta \mathrm{Hg} / \mathrm{Tp}-\mathrm{To})$ as well as the enthalpy of starch gelatinization $(\Delta \mathrm{Hg})$ (expressed as $\mathrm{mJ} / \mathrm{mg}$ of sample) were determined. All samples were run in quadruplicate.

\section{Color of Flours}

Color was measured using a Minolta CN-508i spectrophotometer (Minolta, Co., Ltd. Tokyo, Japan) with the D65 standard illuminant and the $2^{\circ}$ standard observer. Results were expressed in the CIEL ${ }^{*}{ }^{*} b^{*}$ color space. Color determinations were made $5 \times 2$ times on each sample of flour.

Enzymatic Hydrolysis of Starch

Starch hydrolysis was measured following the method described by Gularte and Rosell (2011) with minor modifications. Briefly, for free sugars removal, flour sample (100 mg) suspended in $2 \mathrm{~mL}$ of $80 \%$ ethanol was kept in a shaking water bath at $85^{\circ} \mathrm{C}$ for $5 \mathrm{~min}$, and then centrifuged for $10 \mathrm{~min}$ at $1,000 \times \mathrm{g}$. The pellet was incubated with porcine pancreatic $\alpha$-amylase (10 mg/mL) (Type VI-B, $\geq 10$ units/mg solid; Sigma Chemical, St. Louis,MO, USA) and amyloglucosidase $(3,300 \mathrm{U} / \mathrm{ml}$ ) (Sigma Chemical, St. Louis, MO, USA) in $10 \mathrm{~mL}$ of $0.1 \mathrm{M}$ sodium maleate buffer ( $\mathrm{pH} 6.0$ ) in a shaking water bath at $37^{\circ} \mathrm{C}$ (0.25-16 h). Aliquots of $200 \mu \mathrm{L}$ were withdrawn during the incubation period. Aliquots were mixed with $200 \mu \mathrm{L}$ of ethanol (96\%) to stop the enzymatic reaction and the sample was centrifuged for $5 \mathrm{~min}$ at $10,000 \times \mathrm{g}$ and $4^{\circ} \mathrm{C}$. The precipitate was washed twice with 50 $\%$ ethanol $(100 \mu \mathrm{L})$ and the supernatants were pooled together and kept at $4{ }^{\circ} \mathrm{C}$ for further glucose determination.

The remnant starch after 16 h hydrolysis was solubilized with $2 \mathrm{~mL}$ of $2 \mathrm{M} \mathrm{KOH}$ using a Polytron ultraturrax homogenizer IKA-T18 (IKA works, Wilmington, NC, USA) during 1 min at speed 3. The homogenate was diluted with $8 \mathrm{~mL} 1.2 \mathrm{M}$ sodium acetate $\mathrm{pH} 3.8$ and incubated with $100 \mu \mathrm{L}$ amyloglucosidase $(3,300 \mathrm{U})$ at $50^{\circ} \mathrm{C}$ for $30 \mathrm{~min}$ in a shaking 
water bath. After centrifuging at 2,000×g for $10 \mathrm{~min}$, supernatant was kept for glucose determination.

The glucose content was measured using a glucose oxidase-peroxidase kit. The absorbance was measured using an Epoch microplate reader (Biotek Instruments, Winooski, VT, USA) at $510 \mathrm{~nm}$. Starch was calculated as glucose $(\mathrm{mg}) \times 0.9$. Replicates $(\mathrm{n}=2-4)$ were carried out for each determination.

Experimental data were fitted to a first-order equation (Goñi et al. 1997):

$$
C_{t}=C_{\infty}\left(1-e^{-k t}\right)
$$

Where $\mathrm{Ct}$ is the concentration of glucose released at time $t, \mathrm{C} \infty$ is the concentration at the end point, and $\mathrm{k}$ is the pseudofirst order rate constant. Although this equation requires the estimation of an accurate $\mathrm{C} \infty$, it was useful because long reaction times were applied to determine resistant starch after complete enzymatic hydrolysis. The plot of $\ln$ $\left[\left(\mathrm{C}^{\infty}-\mathrm{Ct}\right) / \mathrm{C} \infty\right]=-\mathrm{kt}$ against $\mathrm{t}$ was used to estimate the slope that corresponded to $-\mathrm{k}$.

However, as recently suggested Butterworth et al. (2012), the linear plot of $\ln (\mathrm{dC} / \mathrm{dt})$ against $\mathrm{t}$ was also represented to calculate the slope $(-\mathrm{k})$, and the intercept on the $\mathrm{y}$ axis was used for calculating the $\ln \left(\mathrm{k} \mathrm{C}^{\infty}\right)$. This plot was used to demonstrate if the data were of logarithmic form and the rate constant remained unchanged along the whole hydrolysis reaction, as recommended Poulsen et al. (2003).

Statistical Analyses

Multiple analyses of variance were used to determine the individual effects of thermal treatment and particle size of flours. Fisher least significant differences test was used to calculate the means with their $95 \%$ confidence intervals. Several correlations were also run. The statistical analysis was performed with the Statgraphics Plus Centurion XVI software (Statpoint Technologies, Inc., Warrenton, VA, USA).

\section{Results and Discussion}

Rice flour was subjected to different extrusion treatments that differed on the maximum barrel temperature and feed moisture content in order to obtain different extrusion intensities. de la Hera et al. (2013b, c) reported the functional properties and processing behavior of fractionated flours. Size fractionation allowed obtaining flours more suitable for bread- or cake-making depending on the particle size. In this study, extruded flours were ground and then separated in two fractions coarse extruded flour $(132200 \mu \mathrm{m})$ and fine extruded flour $(<132 \mu \mathrm{m})$. Overall eight samples were obtained from each batch, which differed on the level of extrusion (identified as 03 , higher values are related to higher intensity of extrusion conditions) and the particle size (coarse, fine). Flour 0 was not subjected to any extrusion treatment and was used as a reference. 


\section{Damage Starch and Free Sugars}

To get a complete picture of the effect of extrusion and particle size a multiple analysis of variance was applied to the experimental results (Table 1). The extrusion intensity (barrel temperature, moisture content) and particle size (fine and coarse) had a significant effect on the content of free sugars (Table 1), which increased with the extrusion temperature and moisture content and with the reduction of the particle size $(18.74 \%$ in coarse flour vs $24.21 \%$ in fine flour). In fact, flour 3 (treated at higher barrel temperature) showed $49.91 \%$ free sugars whereas no treated flour (or flour 0 ) had a sugar content of $6.92 \%$. Nevertheless, no significant differences were observed between the free sugars content of the control (flour 0) and the mild extrusion treatment (flour 1). Thus the hydrolysis responsible of the sugar release required a minimum barrel temperature and also sufficient feed moisture content, since flours 1 and 2 were extruded at the same temperature and with different moisture feeding. Extrusion induced a progressive increase of the damage starch content with the temperature raise in the extrusion treatment, likely attributable to damage produced by the shears force and the heat during extrusion (Camire et al 1990). Conversely, damage starch decreased with the particle size, showing coarse flours the greatest amount of damage starch $(19.98 \%)$, which agrees with the trend observed by de la Hera et al. (2013a), when studying the features of different particle size fractions of rice flours.

Table 1: Significant individual effects of extrusion treatment (1-3) and particle size (coarse, fine) on free sugars, damaged starch, emulsifying, foaming and colorimetric properties of rice flours.

Extrusion treatment

Particle size

\begin{tabular}{|c|c|c|c|c|c|c|}
\hline Mean & 0 & 1 & 2 & 3 & c & $\mathrm{f}$ \\
\hline 21.47 & $6.92 \mathrm{a}(2.08)^{* * *}$ & $9.49 \mathrm{a}(0.88)$ & $19.58 \mathrm{~b}(0.64)$ & $49.91 \mathrm{c}(10.52)$ & $18.74 \mathrm{a}(15.08)^{* *}$ & $24.21 \mathrm{~b}(21.73)^{* *}$ \\
\hline 18.08 & $6.66 \mathrm{a}(1.69)^{* * *}$ & $9.85 \mathrm{~b}(1.38)$ & $23.33 c(5.95)$ & $32.49 \mathrm{~d}(4.66)$ & $19.98 \mathrm{~b}(13.71)^{* *}$ & $16.18 \mathrm{a}(8.83)$ \\
\hline 2.42 & $1.26 \mathrm{a}(0.05)^{* * *}$ & $1.35 \mathrm{~b}(0.06)$ & $2.13 c(0.25)$ & $4.94 \mathrm{~d}(0.05)$ & $2.46 \mathrm{~b}(1.60)^{*}$ & $2.39 \mathrm{a}(1.59)$ \\
\hline 3.50 & $0.95 \mathrm{a}(0.25)^{* * *}$ & $1.55 \mathrm{~b}(0.19)$ & $2.90 \mathrm{c}(1.10)$ & $8.60 \mathrm{~d}(0.43)$ & $3.85 \mathrm{~b}(3.30)^{* *}$ & $3.15 \mathrm{a}(3.22)$ \\
\hline 86.21 & $87.58 \mathrm{c}(1.25)^{* *}$ & $84.92 \mathrm{a}(0.53)$ & $85.70 \mathrm{ab}(0.39)$ & $86.34 \mathrm{bc}(1.35)$ & $86.60 \mathrm{a}(1.71)$ & $85.82 \mathrm{a}(0.80)$ \\
\hline 112.21 & $111.49 \mathrm{a}(2.47)^{* * *}$ & $113.20 \mathrm{~b}(0.55)$ & $113.23 \mathrm{~b}(0.72)$ & $110.90 \mathrm{a}(2.93)$ & $110.80 \mathrm{a}(2.12)^{* * *}$ & $113.61 \mathrm{~b}(0.27)$ \\
\hline 24.85 & $17.94 \mathrm{a}(1.17)^{* * *}$ & $29.97 \mathrm{c}(7.15)$ & $21.44 b(1.86)$ & $30.04 c(1.51)$ & $22.92 \mathrm{a}(5.47)^{* * *}$ & $26.77 \mathrm{~b}(7.12)$ \\
\hline 91.0 & $94.36 \mathrm{c}(0.42)^{* * *}$ & $90.55 b(2.01)$ & $90.43 b(1.42)$ & $88.62 \mathrm{a}(2.56)$ & $89.66 \mathrm{a}(3.05)^{* * *}$ & $92.31 \mathrm{~b}(1.46)$ \\
\hline 0.19 & $-0.17 \mathrm{a}(0.21)^{* * *}$ & $0.23 c(0.19)$ & $0.16 \mathrm{~b}(0.04)$ & $0.55 \mathrm{~d}(0.14)$ & $0.23 \mathrm{~b}(0.40)^{* * *}$ & $0.15 \mathrm{a}(0.17)$ \\
\hline 9.63 & $6.82 \mathrm{a}(0.46)^{* * *}$ & $10.22 \mathrm{~b}(1.68)$ & $10.37 \mathrm{~b}(1.32)$ & $11.13 c(2.14)$ & $10.83 \mathrm{~b}(2.35)^{* * *}$ & $8.44 \mathrm{a}(1.23)$ \\
\hline
\end{tabular}

Particle size: coarse (c), fine (f). Extrusion treatment: control (0); barrel temperature $110^{\circ} \mathrm{C}$, feed rate 700 $\mathrm{kg} / \mathrm{h}$, moisture content $17 \%$ (1); barrel temperature $110^{\circ} \mathrm{C}$, feed rate $700 \mathrm{~kg} / \mathrm{h}$, moisture content $30 \%$ (2); barrel temperature $140^{\circ} \mathrm{C}$, feed rate $500 / \mathrm{h}$, moisture content $25 \%$ (3) 
Values followed by different letters within each parameter for each factor (thermal treatment and particle size) indicate significant differences. ${ }^{*} \mathrm{P}<0.05 ;{ }^{* *} \mathrm{P}<0.01 ;{ }^{* * *} \mathrm{P}<0.001$

Average values followed by the standard deviation (in parenthesis)

WBC, water binding capacity; EC, emulsifying capacity; ES, emulsion stability; FC, foaming capacity

\section{Hydration, Emulsifying and Foaming Properties}

Hydration, emulsifying and foaming properties were significantly affected by the extrusion process $\left(\begin{array}{l}0 \\ 3\end{array}\right)$ and the particle size of the flours (coarse and fine) (Table 1). Hydrations properties (WBC and swelling) increased with the extrusion temperature and moisture content and also with the particle size of the flour. WBC increased from $1.26 \mathrm{~g}$ water/g solid (flour 0) to $4.94 \mathrm{~g}$ water $/ \mathrm{g}$ solid when extrusion was carried out at the maximum temperature (flour 3). Those effects were partially attributed to the increase in the amount of damage starch since it was found a positive correlation between the amount of damage starch and WBC $(\mathrm{r}=0.88)$ and with the swelling $(\mathrm{r}=0.88)$. Moreover, the cooking produced during extrusion led to gelatinized starch that would have higher WBC and swelling, as occurred with the water absorption index (Hagenimana et al. 2006). Camire et al. (1990) proposed that the breakage of the starch granule integrity led to a poorly ordered molecular phase with hydroxyl groups prone to bind water molecules.

The extrusion significantly reduced the emulsifying capacity $(\mathrm{EC})$ of the flours, with the exception of flour 3 (86.34), compared with the control flour (flour 0) (87.58), being the values for flour 1 and 2, 84.92 and 85.70, respectively. And an increase of the EC was observed with the severity of the extrusion, namely flour 3 (86.34)>flour 2 (85.70)>flour 1(84.92). That effect must result from the protein and starch changes during extrusion process. Considering the proteins, extrusion forces the unfolding and aggregation due to protein crosslinking involving $\mathrm{SH} / \mathrm{SS}$ interchange, oxidation and hydrophobic interactions (Rosell and Foegeding 2007), which might result in a decrease of the EC of the flour. As the extrusion temperature increase, starch modification might partially mask the protein denaturation. Gelatinized starch has greater number of hydroxyl groups, which would be available to form hydrogen bonds with the proteins leading to better emulsion capacity.

Emulsion stabilities (ES) were higher in the flours obtained from lower extrusion temperature (flour 1 and 2), showing values of 113.20 and 113.23, respectively. Likely the denaturation of the rice proteins during extrusion increased the stability. The particle size (coarse or fine) of the rice flours did not affect significantly the EC, but the ES significantly increased with the particle size reduction, from 110.80 in coarse flours to 113.61 in fine flours. A reduction in the particle size of the flour improves the emulsifying properties of the flours (Aluko et al. 2009). In the present study, it was observed a significant positive relationship between the ES and the free sugars content $(\mathrm{r}=0.93 ; \mathrm{P}<0.001)$, which could reduce the total charge of the proteins leading the 
formation of interfacial protein membranes that stabilize the emulsion (Aluko et al. 2009).

Extrusion improved the foaming capacity (FC) of the rice flours (Table 1), but there was no trend with the extrusion severity (temperature or moisture content). The foam stability (FS) could be only measured in flour 3 (50.00 for fine flour and 45.18 for coarse flour) because very unstable foams were obtained with the other flours. The FC has been attributed to its microstructure, size and distribution of the gas cells and the interfacial properties (Zhang et al. 2011). Hydrothermal treatments can improve the foaming properties, as has been reported with corn kernels (Boladea et al. 2002). Nevertheless, the minor effect observed in the extruded rice flours could be attributed to the low protein content of the rice flour. Protein isolates show great foaming capacity that improves with the hydrothermal treatments (Wang and Johnson 2001). The effect of extrusion on foam formation followed an opposite trend to the one observed on the emulsion formation, which suggests that different mechanisms are involved during interfacial membrane formation at the air-water and oil-water interfaces. Concerning the particle size, the major FC was observed in fine flours (26.77) compared with coarse flours (22.92). This effect could be explained by the greater availability of lowering interfacial components in those flour fractions, as proposed Aluko et al. (2009).

Color

Luminosity $\left(\mathrm{L}^{*}\right)$ of the flours significantly decreased with the extrusion temperature and moisture content (Table 1), from 90.55 in flour 0 to 88.62 in flour 3. Conversely, the a* and $b^{*}$ increased. Nevertheless, although a steady increased with the extrusion temperature and moisture content (flours 0 to 3 ) was observed in the case of the luminosity and $b^{*}$, no trend was observed in the case of $a^{*}$. The extrusion process could lead to Maillard reactions and a reduction of the lipids oxidation due to enzymes inactivation that induces the formation of melanoidins and the pigments protection, which in turn produces the modification of the flours color (Camire et al. 1990). Moreover, higher $\mathrm{L}^{*}$ and lower $\mathrm{a}^{*} \mathrm{y} \mathrm{b}^{*}$ were obtained in the fine flours. It has been proposed that fine flours had higher surface area that favors the contact of the constituents with the oxygen promoting the pigments oxidation (Atwell 2001).

\section{Pasting Characteristics}

Pasting plots of the extruded flours are displayed in Fig. 1a (coarse flour) and in Fig. 1b (fine flour). Concerning the extrusion treatment (flours 0 3), the viscosity during heating and cooling decreased with the extrusion intensity, obtaining minimum viscosity in flour 3 (with the highest intensity). Nevertheless, when particle size was taken into account, a progressive decrease of viscosity was observed in the coarse flours (Fig. 1a), but fine flours (Fig. $1 \mathrm{~b}$ ) from treatment 1 and 2 did not show any difference in the pasting profile. Since flour 1 and 2 were treated at maximum barrel temperature of $110^{\circ} \mathrm{C}$ and the unique variation was the feed moisture content, it seems that the effect on pasting profiles was 
independent on the feed moisture content during extrusion when small particle size were subjected to this treatment.
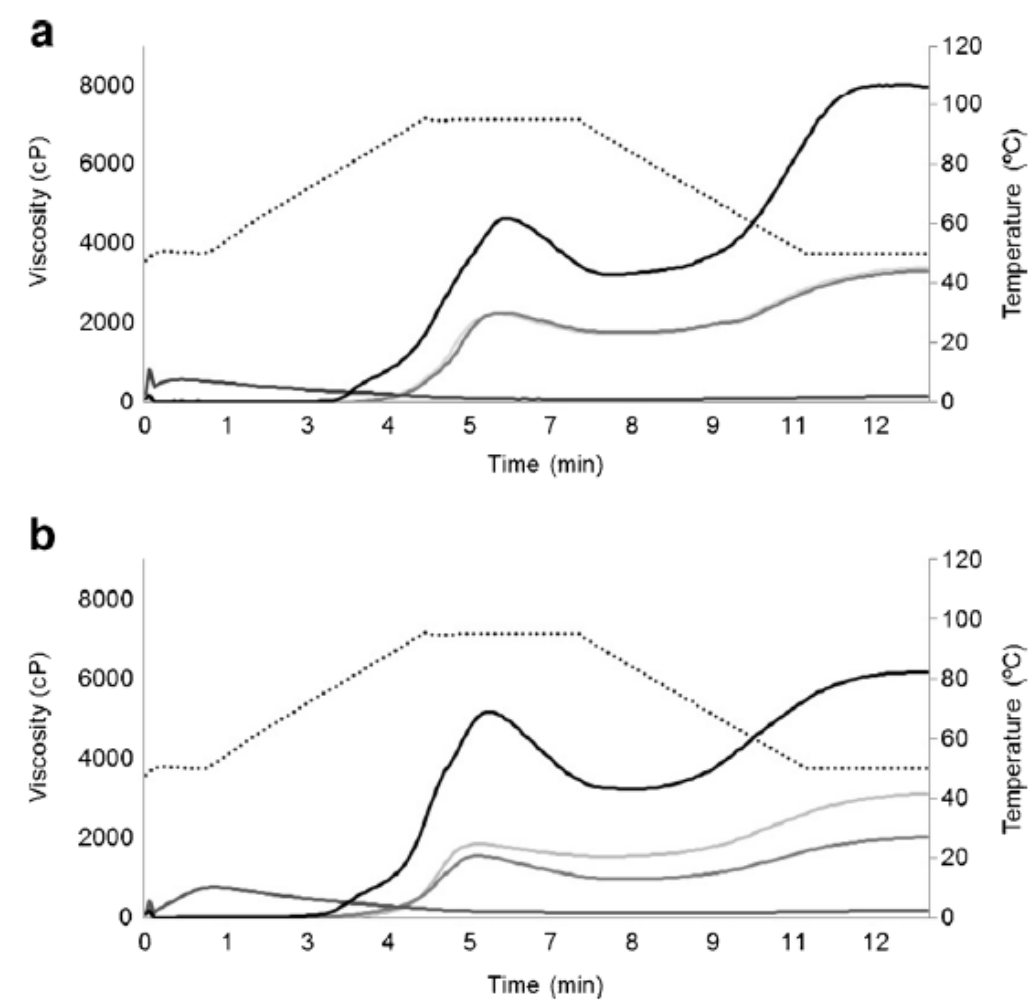

Fig 1 a. Effect of extrusion treatment on the pasting properties of coarse rice flours. Flour 0 (black line), flour 1 (clear grey line), flour 2 (intermediate tone grey line), flour 3 (dark grey line). Temperature profile (discontinuous line). b. Effect of extrusion treatment on the pasting properties of fine rice flours. Flour 0 (black line), flour 1 (clear grey line), flour 2 (intermediate tone grey line), flour 3 (dark grey line). Temperature profile (discontinuous line)

Peak viscosity was significantly dependent on the damage starch content $(r=-0.79)$, which agree with previous studies connecting peak viscosity with gelatinized and damage starch that was related to the polymerization degree of the starch granules (Barres et al. 1990). The reduction observed in the final viscosity and setback was displaying the extension of the effect on the amylose chains, which might lose the ability to retrograde during cooling due to their fragmentation during extrusion. This effect agrees with previous results of Doublier et al. (1986).

\section{Differential Scanning Calorimetry (DSC)}

The effect of extrusion treatment and particle size on the thermal properties of the starch is shown in Table 2. In the range of temperature tested (from 30 to $110^{\circ} \mathrm{C}$ ), flours exhibited one endothermic peak corresponding to amylopectin gelatinization, with the exception of flour 3 (no peak detected). The absence of an endothermic peak for flours 3 indicated total gelatinization of amylopectin. Indeed, these results agree with those 
previously discussed regarding the very small pasting curve observed in the extruded flours 3 at $50^{\circ} \mathrm{C}$. The extrusion treatment significantly modified the gelatinization temperatures (To, $\mathrm{Tp}, \mathrm{Tc}$ ) of the flours, and those temperatures were also dependent on the particle size of the flours (coarse and fine flours). Gelatinization temperatures (Tp) were sifted to higher values when flours were treated at increasing extrusion intensity ( 3 was the highest intensity), but the temperature range ( $\mathrm{Tp}-\mathrm{To}_{\mathrm{O}}$ ) was not affected. Higher gelatinization temperature indicated that more energy is required to initiate gelatinization of the starch suggesting that extrusion is affecting the outer and more amorphous part of the granule and is progressing to the core of the granule till no crystalline structure is left for gelatinization (flour 3).

Table 2. Significant individual effects (extrusion treatment and particle size) on thermal properties.

Extrusion treatment

Particle size

Overall

$\begin{array}{llllllll}\text { Mean } & 0 & 1 & 2 & 3 & c & f\end{array}$

$\mathrm{T}_{\mathrm{o}}\left({ }^{\circ} \mathrm{C}\right)$

$68.065 .5 \mathrm{a}(5.7)^{* * *}$

$67.4 \mathrm{~b}(1.7)$

$71.1 \mathrm{c}(0.9)$

n.d

$70.3 \mathrm{~b}(1.4)^{* * *}$

$65.7 \mathrm{a}(4.5)$

$\mathrm{T}_{\mathrm{p}}\left({ }^{\circ} \mathrm{C}\right)$

$74.071 .2 \mathrm{a}(4.6)^{* * *}$

$74.4 b(0.7)$

$76.4 \mathrm{c}(0.7)$

n.d $75.6 b(1.0)^{* * *}$

$72.4 \mathrm{a}(4.1)$

$\mathrm{T}_{\mathrm{c}}\left({ }^{\circ} \mathrm{C}\right)$

$80.677 .9 \mathrm{a}(3.9)^{* *}$

$81.4 \mathrm{~b}(1.5)$

$82.5 b(1.18)$

n.d $81.8 \mathrm{~b}(1.0)^{* *}$

$79.3 \mathrm{a}(4.0)$

$\mathrm{T}_{\mathrm{p}}-\mathrm{T}_{\mathrm{o}}\left({ }^{\circ} \mathrm{C}\right)$

$6.0 \quad 5.8 \mathrm{a}(1.1)$

$7.0 \mathrm{a}(1.8)$

$5.3 \mathrm{a}(0.2)$

n.d $5.3 \mathrm{a}(0.6)$

$6.7 \mathrm{a}(1.6)$

$\Delta \mathrm{H}(\mathrm{J} / \mathrm{g})$

$2.3832 .525 \mathrm{~b}(0.330)^{* * *}$

$3.075 \mathrm{c}(0.754)$

$1.550 \mathrm{a}(0.191)$ n.d

2.483a(1.049)

2.283a $(0.507)$

PHI $\left(\mathrm{J} / \mathrm{g}^{*_{\mathrm{o}}} \mathrm{C}\right)$

$0.3920 .450 \mathrm{~b}(0.057)^{*}$

$0.450 \mathrm{~b}(0.191) \quad 0.275 \mathrm{a}(0.050) \quad n . d$

$0.433 \mathrm{a}(0.163)$

$0.350 a(0.104)$

Particle size: coarse (c), fine (f). Extrusion treatment: control (0); barrel temperature $110^{\circ} \mathrm{C}$, feed rate 700 $\mathrm{kg} / \mathrm{h}$, moisture content $17 \%$ (1); barrel temperature $110^{\circ} \mathrm{C}$, feed rate $700 \mathrm{~kg} / \mathrm{h}$, moisture content $30 \%$ (2); barrel temperature $140^{\circ} \mathrm{C}$, feed rate $500 / \mathrm{h}$, moisture content $25 \%$ (3)

Values followed by different letters within each parameter for each factor (thermal treatment and particle size) indicate significant differences. ${ }^{*} \mathrm{P}<0.05 ;{ }^{* *} \mathrm{P}<0.01 ;{ }^{* * *} \mathrm{P}<0.001$

n.d.: Not detected.

Average values followed by the standard deviation (in parenthesis)

To, gelatinization onset; Tp, peak temperature; Tc, conclusion temperature, Tp-To, gelatinization range, $\Delta \mathrm{H}$, enthalpy and PHI, peak high index

Comparing extruded flours, the gelatinization enthalpy $(\Delta \mathrm{H})$ was significantly reduced in flour 2, where extrusion temperature and moisture content were sufficient to induce starch gelatinization, likely due to an increase of the damage starch content (Chiu and Solarek 2009). Nevertheless, the mild extrusion treatment (flour 1) gave significantly higher gelatinization enthalpy $(3.075 \mathrm{~J} / \mathrm{g})$ compared with the untreated flour (flour 0 ) $(2.525 \mathrm{~J} / \mathrm{g})$. Taking into account that treatment 1 was applied using lower feed moisture content (insufficient to complete gelatinization), the higher enthalpy of this sample could be attributed to a reorientation of the structure of the amorphous region to resemble that of the crystalline region (Camire et al. 1990). The extrusion process modifies the crystalline structure of the starch granule affecting the temperature at which swelling 
starts (Camire et al. 1990). Fine flours showed lower gelatinization temperatures than the corresponding coarse flours, but without affecting the peak high index and the gelatinization enthalpy (Table 2).

Starch Hydrolysis

The susceptibility of the extruded flours to the enzymatic hydrolysis was analyzed. Figure 2 shows the kinetic plots of the extruded flours and the effect of the particle size. The enzymatic hydrolysis profiles were dependent on the particle size, and fine flours showed faster hydrolysis and reached higher asymptotic values than course flours. de la Hera et al. (2013a) observed lower hydrolysis rate in the coarse flours when studied the effect of particle size distribution on the rice flour functionality. This result could be attributed to the high surface area of the fine flours that increases the water diffusion and enzyme accessibility. The hydrolysis curves were fitted to a first order kinetics according to Goñi et al. (1997) and also to Butterworth et al. (2012) to obtain the kinetic parameters (Table 3). As it was observed in the plots, there was an increase in the equilibrium concentration $(\mathrm{C} \infty)$ parallel to the extrusion intensity (except flour $2 \mathrm{f}$ ). Regarding the rate of the hydrolysis, $\mathrm{k}$, there was no general trend with the extrusion intensity. There was great agreement with the equilibrium concentration estimated from both fitted methods, indicating that the kinetic parameters can be fitted to a logarithmic function and that the rate constant did not vary along the hydrolysis reaction (Poulsen et al. 2003). 

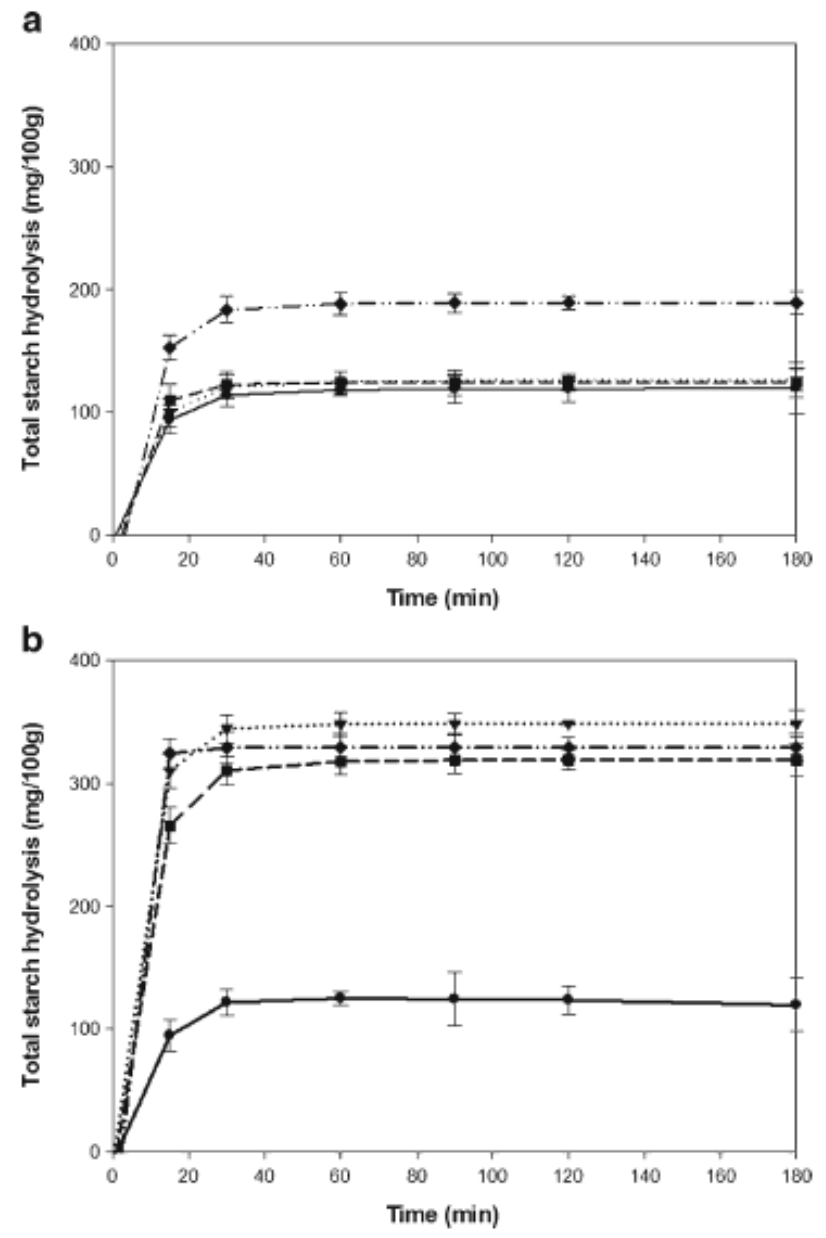

Fig 2 Effect of extrusion treatment on the enzymatic hydrolysis of rice flours with different particle size. Flour $0(\bullet$, black line), flour $1(\boldsymbol{\nabla}$, clear grey line), flour $2(\boldsymbol{\nabla}$, intermediate tone grey line $)$, flour $3(\bullet$, dark grey line). Coarse flours (a), fine flours (b)

Resistant starch was also quantified to determine the potential impact of the extrusion on the structural level of starch. Although there was no clear tendency about the resistant starch content, the highest extrusion intensity gave the flours with the lower level of RS (flour 3). This finding disagrees with previous observations of Hagenimana et al. (2006), whofound an increase in RS content with the treatment severity.

Those authors attributed the increase in RS to the formation of amylose-lipid complexes during the extrusion, which retarded the enzymatic digestion. Therefore, results divergence might be explained because of the lower content of amylose of the flours in the present study compared with the reported ones. In addition, Chinnaswamy and Hannah (1990) reported a change in the percentage of amylose/amylopectin ratio in extruded corn flours that was ascribed to both chains fragmentation, being more intense in the former. That fact could affect the starch hydrolysis rate. Moreover, Hagenimana et al. (2006) stated that the susceptibility of the extruded starches to be enzymatically hydrolyzed was directly related to the intensity of the extrusion treatment. 
The particle size did not significantly affect the hydrolysis rate, but fine flours showed higher values of $\mathrm{C}^{\infty}$ and lower amount in RS. Al-Rabadi et al. (2011) stated that fine extruded flours of barley and sorghum had major digestibility than the coarser ones. The most compact structure, besides the smaller surface area of coarser flours, could hinder the accessibility of the enzymes within the starch structure, since diffusion of the enzyme is the first stage in the enzymatic hydrolysis (Al-Rabadi et al. 2011; Ghaid et al. 2009).

\section{Conclusion}

Extrusion and mechanical fractionation of the rice flours modified their behavior affecting hydration, thermal and pasting features, besides their susceptibility to enzymatic hydrolysis. The severity of the extrusion treatment was accompanied by an increase in the amount of damage starch and free sugars content, the former contributing to the Maillard reaction, which affected the luminosity of the flours. In parallel, hydration ability increased with the extrusion intensity, leading higher viscosity in cold solution, which might be very interesting for some food applications. Thermal properties (temperature and enthalpy) increased with the intensity of the extrusion and that effect was intensified with the greatest particle size of the flours. Fine flours with stronger extrusion showed the highest susceptibility to enzymatic hydrolysis and extrusion process increased that effect. Therefore, extrusion and fractionation can be an alternative to produce flours with different functional properties, which might be useful in gluten free breadmaking. Future studies will be undertaken to test these flours in breadmaking process.

\section{Acknowledgement}

The authors acknowledge the financial support of Junta de Castilla y León (VA054A122), the Spanish Ministry of Economy and Sustainability (Project AGL2011-23802) and the European Regional Development Fund (FEDER). The authors are also grateful to Harinera Los Pisones, (Zamora, Spain) for supplying the rice flours.

\section{References}

AACC. (2012). Approved methods of the american association of cereal chemists, methods 46-30.01 (Protein), 55-40.01 (Particle size), 76- 30a (damaged starch), 56-30 (WBC), 61-02.01 (RVA) (11th ed.). St. Paul: American Association of Cereal Chemists.

Al-Rabadi, G., Torley, P., Williamsa, B., Brydena, W., \& Gidley, M. (2011). Effect of extrusion temperature and pre-extrusion particle size on starch digestion kinetics in barley and sorghum grain extrudates. Animal Feed Science and Technology, 168, 267-279.

Alsaffar, A. (2011). Effect of food processing on the resistant starch content of cereals and cereal products-A review. International Journal of Food Science and Technology, 46, $455-462$. 
Aluko, R.,Mofolasayo, O.,\&Watts, B. (2009). Emulsifying and foaming properties of commercial yellow pea (Pisum sativumL.) seed flours. Journal of Agriculture and. Food Chemistry, 57, 9793-9800.

Atwell,W. (2001). Composition of commercial flour. InW. Atwell (Ed.), Wheat Flour (pp. 27-42). St. Paul: American Association of Cereal Chemists.

Barres, C., Verges, B., Tayeb, J., \& Della Valle, G. (1990). Transformation of wheat flour by extrusion cooking. Influence of screw configuration and operating conditions. Cereal Chemistry, 67, 427-433.

Boladea, M., Usman, M., Rasheed, A., Benson, E., \& Salifou, I. (2002). Influence of hydrothermal treatment of maize grains on the quality and acceptability of tuwon masara (traditional maize gel). Food Chemistry, 79, 479-483.

Butterworth, P. J., Warren, F. J., Grassby, T., Patel, H., \& Ellis, P. R. (2012). Analysis of starch amylolysis using plots for first-order kinetics. Carbohydrate Polymers, 87, 21892197.

Camire,M., Camire, A., \& Krumhar, K. (1990). Chemical and nutritional changes in foods during the extrusion. Critical Reviews in Food Science and Nutrition, 29, 35-57.

Chinnaswamy, R.,\& Hannah,M. (1990). Macromolecular and functional properties of native and extruded corn starch. Cereal Chemistry, 67, 490-499.

Chiu, C., \& Solarek, D. (2009). Modification of starch. In J. BeMiller \& R. Whistler (Eds.), Starch. Chemistry and Technology (pp. 629- 656). New York: Academic Press.

Clerici, M., Arioldi, C., \& El-Dash, A. (2009). Production of acidic extruder rice flour and its influence on the qualities of gluten free bread. LWT-Food Science and Technology, 42, 618-623.

Colonna, P., Doublier, J.,Melcion, J.,Demonredon, F.,\&Mercier, C. (1984). Extrusion cooking and drum drying of wheat-starch.1. Physical and macromolecular modifications. Cereal Chemistry, 61, 538-543.

de la Hera, E., Gómez,M.,\& Rosell, C. (2013a). Particle size distribution affecting the starch enzymatic digestion and hydration of rice flour carbohydrates. Carbohydrate Polymers, 98, 421-427.

de la Hera, E., Martínez, M., \& Gómez, M. (2013b). Influence of flour particle size on quality of gluten-free rice bread. LWT-Food Science and Technology, 54, 199-206.

de la Hera, E., Martínez, M., Oliete, B., \& Gómez, M. (2013c). Influence of flour particle size on quality of gluten-free rice cakes. Food and Bioprocess Technology, 6, 2280-2288. 
Doublier, J., Colonna, P., \& Mercier, C. (1986). Extrusion cooking and drum drying of wheat-starch. 2. Rheological characterization of starch pastes. Cereal Chemistry, 63, 240246.

Ghaid, J., Al-Rabadi, G., Gilbert, R., \& Gidley, M. (2009). Effect of particle size on kinetics of starch digestion in milled barley and sorghum grains by porcine alpha-amylase. Journal of Cereal Science, 50, 198-204.

Goñi, I., Garcia-Alonso, A., \& Saura-Calixto, F. (1997). A starch hydrolysis procedure to estimate glycemic index. Nutrition Research, 17, 427-437.

Gularte, M. A., \& Rosell, C. M. (2011). Physicochemical properties and enzymatic hydrolysis of different starches in the presence of hydrocolloids. Carbohydrate Polymers, $85,237-244$.

Hagenimana, A., Ding, X., \& Fang, T. (2006). Evaluation of rice flour modified by extrusion cooking. Journal of Cereal Science, 43, 38- 46.

Jacobs, H., \& Delcour, J. (1998). Hydrothermalmodifications of granular starch, with retention of the granular structure: A review. Journal of Agricultural and Food Chemistry, 46, 2895-2905.

Lee, S. M., Yoo, J., Inglett, G. E., \& Lee, S. (2013). Particle size fractionation of highamylose rice (Goami 2) flour as an oil barrier in a batter-coated fried system. Food and Bioprocess Technology, 6, 726-733.

Mercier, C., \& Feillet, P. (1975). Modification of carbohydrate components by extrusioncooking of cereal products. Cereal Chemistry, 63, 283-297.

Moreira, R., Chenlo, F., \& Torres,M. D. (2013). Rheology of gluten-free doughs from blends of chestnutand rice flours. Food and Bioprocess Technology, 6, 1476-1485.

Nelson, A. (2001). Properties of Hihg-fibre ingredientes. Cereal Foods World, 46, 93-97.

Perdon, A., Siebenmorgen, T., Mauromoustakos, A., Griffin, V., \& Johnson, E. (2001). Degree of milling effects on rice pasting properties. Cereal Chemistry, 78, 205-209.

Poulsen, B., Ruiter, G., Visser, J., \& Iversen, J. (2003). Determination of first order rate constants by natural logarithm of the slope plot exemplified by analysis of Aspergillus niger in batch culture. Biotechnology Letters, 25, 565-571.

Rosell, C. M., \& Foegeding, A. (2007). Interaction of hydroxypropylmethylcellulose with gluten proteins: Small deformation properties during thermal treatment. Food Hydrocolloids, 21, 1092-1100.

Wang, C., \& Johnson, L. (2001). Functional properties of hydrothermally cooked soy protein products. Journal of the American Oil Chemists Society, 78, 189-195. 
Wen, L., Rodis, P., \& Wasserman, B. (1990). Starch fragmentation and protein insolubilization during twin 275.

Yeh, A. (2004). Preparation and applications of rice flour. In E. Champagne (Ed.), Rice: Chemistry and tehnology (pp. 495-540). St. Paul: American Association of Cereal Chemist.

Zhang, M., Bai, X., \& Zhang, Z. (2011). Extrusion process improves the functionality of soluble dietary fiber in oat bran. Journal of Cereal Science, 54, 98-113. 


\subsection{Influence of wheat flour subjected to different extrusion conditions on the rheological behaviour and thermal properties of batter systems for coating}

LWT - Food Science and Technology 64 (2015) 1309-1314

\begin{tabular}{lc|}
\hline & Contents lists available at ScienceDirect \\
\hline ELSEVIER & LWT - Food Science and Technology \\
\hline
\end{tabular}

Influence of wheat flour subjected to different extrusion conditions on the rheological behaviour and thermal properties of batter systems for coating

Mario M. Martínez ${ }^{\text {a, }}$, Teresa Sanz ${ }^{\text {b }}$, Manuel Gómez ${ }^{\text {a }}$

${ }^{a}$ Food Technology Area, College of Agricultural Engineering, University of Valladolid, 34004 Palencia, Spain

${ }^{\mathrm{b}}$ Institute of Agrochemistry and Food Technology (IATA-CSIC), Avda Agustin Escardino, 7, Paterna 46980, Spain

\section{Introduction}

Fried battered products have been historically made at home and in food industries, but in the last decades they have gained popularity due to their easiness of being stored frozen and finished in a quickway for instant consumption. A batter can be defined as a liquid paste, basically consisting of wheat flour and water, into which a product is dipped before it is cooked, normally by frying (Fiszman \& Salvador, 2003). Tempura-type batters form a crisp, continuous, uniform layer over the food substrate, constituting its final outer coating. Batter coatings enhance the flavour, texture and appearance of foods. Batter recipes are very diverse, and besides wheat flour and water, other ingredients such as flour, starch, hydrocolloids, egg, dairy products, salt and seasonings can be incorporated. Among these ingredients, multiple interactions in the different stages of the frying process are produced, which turn batters into very complex systems (Baixauli, Sanz, Salvador, \& Fiszman, 2003; Xue \& Ngadi, 2007).

The quality of the batters is determined by the uniformity and thickness of the coating, its general appearance, colour, crunchytexture, adhesion and taste (Loewe, 1990). One of the most crucial parameters of the batters are their rheological properties, which affect the amount and the quality of the batter adhered to the product as well as its texture, appearance and handling properties. Apparent viscosity of batters measured at a single shear rate has been reported in several studies (Mohamed, Hamid, \& Hamid, 1998; Olewnik \& Kulp, 1993; Prakash \& Rajalakshmi, 1999). However, these batters generally present shear-thinning behaviour, time dependency and thixotropy. Thus a rheological characterization of their flow behaviour over a range of shear stresses and time gives more complete information for optimization of the processes of mixing, pumping and coating, 
with a view to keeping the batter properties, pickup and adhesion uniform (Fiszman \& Salvador, 2003). At very low strains dynamic rheology provides supplementary information that may be connected with the unaltered structure of batter systems (Fiszman \& Salvador, 2003). The structural changes that took place during the cooking process of batters, corresponding to the transition from fluid to solid state, has been monitored by studying their mechanical spectra at different temperatures (Baixauli et al., 2003) and by assessing the dynamic viscoelastic functions in temperature sweeps (Sanz, Fernandez, Salvador, Mu noz, \& Fiszman, 2005a; Sanz, Salvador, Velez, Mun oz, \& Fiszman, 2005b; Xue \& Ngadi, 2006).

The use of hydrocolloids is habitual in batter making as they act as thickening agents or viscosity controllers, improve the adherence, texture and stability to freezing and thawing (Amboon, Tulyathan, \& Tattiyakul, 2012; Varela \& Fiszman, 2011; Xue \& Ngadi, 2009). Similarly, it has been demonstrated that chemically (Purcell,Wang, \& Seo, 2014b) or enzymatically (Jeon, Lim, Inglett, \& Lee, 2013; Purcell, Wang, \& Seo, 2014a) modified starches can enhance the quality of the batters, increasing their adhesiveness or reducing the final oil content. With the same aim, gelatinized tapioca starch has been also successfully studied (Altunakar, Sahin, \& Sumnu, 2004), decreasing the oil absorption and increasing the cooking yield and coating pickup.

Starch of flour can be partially or totally modified by extrusion. Extrusion is a hightemperature-short-time (HTST) physical treatment during which flours or starches are subjected to high temperatures and mechanical shearing at relatively low levels of moisture content (Camire, Camire, \& Krumhar, 1990). This process allows starch gelatinization, denaturation of protein, enzyme (in) activation and colour changes, the extent of which are dependent on the conditions of the extrusion (Wen, Rodis, \& Wasserman, 1990). Those changes at the constituents' level modify the rheological behaviour of flour batters (Hagenimana, Ding, \& Fang, 2006). Moreover, an increase in the content of resistant starch could be achieved, which is dependent on the treatment intensity (Hagenimana et al., 2006; Martínez, Rosell, \& Gomez, 2014b). It must be also remarked that extrusion allows changing functionality by keeping the Green label (Jacobs $\&$ Delcour, 1998). Rheological and water absorption properties of these flours define their adequacy for different uses. However, research carried out in extrusion processes has been focused on starch, without considering a possible flour treatment. Nevertheless, the presence of other flour constituents might also affect starch functionality.

Therefore, flours obtained by extrusion and the posterior milling of the extruded products can be used in batter recipes with similar effects to those achieved by hydrocolloids or modified starches, but with a cleaner label and lower costs. However, there are no studies about the use of extruded flours and in particular, about the effect of flours subjected to different extrusion conditions on batters for coating. Therefore, the aim of this work was to study the influence of different percentages of replacement of 
native wheat flour by wheat flour subjected to different extrusion conditions on the rheological and thermal properties of batters with a view to achieving high quality batter.

\section{$\underline{\text { 2. Materials and methods }}$}

\subsection{Materials}

Native wheat flour $(11.73 \%$ and $11.20 \% \mathrm{w} / \mathrm{w}$ of moisture and protein contents, respectively) was supplied by Harinera Castellana (Medina del Campo, Valladolid, Spain). Extruded modified wheat flours (flour 1, 2 and 3) were provided by Molendum Ingredients (Zamora, Spain), which performed the extrusion treatment using a Bühler Basf single screw extruder (Bühler S.A., Uzwil, Switzerland). The length-to-diameter (L/D) ratio for the extruder was 20:1. An initial wheat flour was subjected to different extrusion treatments, where barrel temperature, feed rate and moisture content of the mass feed were modified. Three types of extruded flours, numbered from 1 to 3 indicating the severity of the extrusion treatment ( 1 the mildest and 3 the strongest), were obtained. Flour $1(12.4 \%$ and $9.87 \% \mathrm{w} / \mathrm{w}$ of moisture and protein contents) and 2 (13.9\% and $9.36 \% \mathrm{w} / \mathrm{w}$ of moisture and protein contents) were extruded at a maximum barrel temperature of $120 \mathrm{C}$ and a screw speed of $397 \mathrm{rpm}$. Flour 1 and flour 2 were extruded with a feed rate of 700 and $400 \mathrm{~kg} / \mathrm{h}$ and a feed moisture content of 50 and $60 \mathrm{~L} / \mathrm{h}$, respectively. Flour $3(11.2 \%$ and $8.74 \% \mathrm{w} / \mathrm{w}$ of moisture and protein contents)was extruded at a maximum barrel temperature of $160 \mathrm{C}$ and a feed moisture content of 50 $\mathrm{L} / \mathrm{h}$, with a feed rate of $500 \mathrm{~kg} / \mathrm{h}$ and with a screw speed of $340 \mathrm{rpm}$. Then extruded flours were ground with a compression roller to a particle size below 200 microns.

\subsection{Methods}

\subsubsection{Batter preparation}

The batter formulation was composed of native wheat flour or a mixture of native wheat flour and extruded flour (91.4\%), sodium pyrophosphate (1.78\%), sodium bicarbonate $(1.32 \%)$ and salt $(5.5 \%)$. The wheat extruded flour concentration in the flour mixture was 7.5 and $15 \%$. Batters were prepared with the three different types of wheat extruded flour. The pre-blended powders were mixed with water $(20 \mathrm{C})$ in a Kenwood Major Classic mixer (Kenwood Ltd, UK) at speed two for $2 \mathrm{~min}$. The water/dry mix proportion was always 1.2:1.

\subsubsection{Rheological properties}

Before conducting any rheological measurement, samples were allowed to rest in the measurement position for $5 \mathrm{~min}$ as equilibration time, i.e. the necessary time to allow the stresses induced during sample loading to relax. The required equilibration time was selected according to previous time sweep tests carried out within the linear region $(0.2$ $\mathrm{Pa}$ ) at $1 \mathrm{~Hz}$ during $30 \mathrm{~min}$ at $20^{\circ} \mathrm{C}$. The time sweep test showed that in less than $5 \mathrm{~min}$ values of G' and G' became independent of time. The exposed edges of the samples were 
always covered with vaseline oil (Panreac Química S.A., Castellar del Valles, Spain) to avoid sample drying during measurements. As the rheological properties of batter slowly change with ageing due to physical and chemical factors (Letang, Piau, \& Verdier, 1999), special care was taken to maintain the same thermomechanical history for all the samples in the different tests. Although all the systems have a high water content, dough consistency was always high enough to avoid problems of starch sedimentation during the time taken to conduct the rheological tests at $20 \mathrm{C}$. All rheological tests were run in duplicate.

\subsubsection{Flow properties.}

Shear stress versus shear rate data was recorded using a rheometer (Haake RheoStress 1, Thermo Fischer Scientific, Scheverte, Germany) with a titanium parallel plate geometry sensor PP60 Ti (60 mm diameter, and $1 \mathrm{~mm}$ gap). The plate was programmed to increase the shear rate from 1 to $100 \mathrm{~s}^{-1}$ for $100 \mathrm{~s}$ (up curve), then to maintain this shear rate for $60 \mathrm{~s}$ and immediately followed by a reduction from 100 to $1 \mathrm{~s}^{-1}$ for $100 \mathrm{~s}$ (down curve). Data from the up curve of the shear cycle were fitted to the Ostwald-de Waele model $\left(\sigma=K \cdot \gamma^{n}\right)$, where $s$ is the shear stress $(\mathrm{Pa}), \gamma$ is the shear rate $\left(s^{-1}\right), K$ is the consistency coefficient (Pa.sn), and $\mathrm{n}$ is the flow behaviour index (dimensionless). In addition, the "relative thixotropic area" was calculated as the area between the up and down curves divided by the area under the up curve, which allows a correct comparison of the rate of internal structural breakdown in systems with different viscosities (Dolz, Gonzalez, Delegido, Hernandez, \& Pellicer, 2000). All measurements were made in duplicate.

\subsubsection{Viscoelastic properties.}

Linear viscoelastic properties were studied by small amplitude oscillatory test (SAOS) in a controlled stress AR G2 rheometer (TA Instruments, Crawley, UK) equipped with a Peltier temperature controlling system, using a $40 \mathrm{~mm}$ steel serrated plateeplate sensor geometry with a $1 \mathrm{~mm}$ gap. Data was recorded with the TA Rheology Advantage Data Analysis equipment software V 5.8.2. Dynamic linear viscoelastic range was estimated by performing a stress sweep from 0.05 to $60 \mathrm{~Pa}$ at a frequency of $1 \mathrm{~Hz}$.

To study the changes due to the effect of cooking temperature on the batters, storage modulus and loss tangent were monitored as a function of temperature. The samples were heated from 20 to $80 \mathrm{C}$ at a heating rate of $1 \mathrm{C} / \mathrm{min}$ and a fixed frequency of $1 \mathrm{~Hz}$. The applied strain was always selected to guarantee the existence of a linear viscoelastic response throughout the temperature range under study. The applied strain varied from $1.0 \times 10^{4}$ to $3.8 \times 10^{-4}$, depending on the specific batter sample.

Frequency dependence experiments were conducted from 10 to $0.01 \mathrm{~Hz}$ at $20{ }^{\circ} \mathrm{C}$ and at $80 \mathrm{C}$ after the application of the described temperature sweep plus an equilibration time of $10 \mathrm{~min}$ at $80{ }^{\circ} \mathrm{C}$ to eliminate thermal inertia before running the frequency sweep test. 
The applied stress was always selected to guarantee the existence of linear viscoelastic response. At least two replicates of each oscillatory shear test were conducted.

\subsubsection{Thermal properties}

Analyses were performed in a differential scanning calorimeter Q-2000 (TA instruments, Crawley, UK) equipped with a refrigerated cooling system (RCS 90). Prior to sample measurements, the calibration for enthalpy and temperature was completed using indium (Tonset $=155.74{ }^{\circ} \mathrm{C}$ and $\left.\Delta \mathrm{H}=28.69 \mathrm{~J} / \mathrm{g}\right)$. High volume DSC pans $(100 \mathrm{~mL})(\mathrm{TA}$ Instruments) were employed. An empty panwas used as reference and dry nitrogen at a flow rate of $50 \mathrm{~mL} / \mathrm{min}$, was used as the purge gas. Batter $(40 \mathrm{mg})$ was loaded into the pan and hermetically sealed. The calorimeter scan conditions were set as follows: samples were kept at $10 \mathrm{C}$ for $5 \mathrm{~min}$, heated from 10 to $150 \mathrm{C}$ at $10 \mathrm{C} / \mathrm{min}$. Onset temperature (To), peak temperature (Tp), gelatinization temperature range ( $\mathrm{Tp}$ e $\mathrm{To}$ ) as well as the enthalpy of starch gelatinization $(\Delta \mathrm{Hg})$ (expressed as $\mathrm{mJ} / \mathrm{mg}$ of sample) were determined. All samples were run in duplicate.

\subsubsection{Statistical analysis}

Simple analysis of variance was used to determine the individual effects of the type of flour. Fisher's least significant difference (LSD) was used to describe means with 95\% confidence intervals. Statistical analysis was performed with Statgraphics Centurion XVI software (Statpoint Technologies, Inc., Warrenton, VA, USA).

\section{Results and discussion}

\subsection{Flow properties}

Values of shear stress versus shear rate at $20 \mathrm{C}$ for batters with $15 \%$ extruded flour replacement are shown in Fig.1. The flow curves reveal the time dependency and the shear thinning behaviour (increase in shear stress as shear rate increases) of the batters. Data from the up curve were well adjusted to the Ostwald de Waele model ( 1 1/4 0.99). This could be mainly attributed to the alignments of particles in batters and breakdown of their interactions under the influence of shear flow (Jeon et al., 2013). The consistency $(\mathrm{K})$ and flow behaviour (n) indices for the different batter formulations are given in Table 1. The consistency coefficient $(\mathrm{k})$, which is a measure of viscosity at a shear rate of $1 \mathrm{~s}^{-1}$, increased as the percentage of extruded flour and its severity of treatment increased. An increase of the batter viscosity with steamed wheat flour addition was reported by Prakash and Rajalakshmi (1999). Differences among the batters made with different extruded wheat flours are owed to the different fixed parameters in the extrusion process of flours. Thereby, the higher barrel temperature reached in flour 3 (160 C) could have fostered the most severe changes on starch and protein. Regarding flour 1 and 2, even though both were extruded at the same barrel temperature $(120 \mathrm{C})$, feed rate of flour 2 was lower (400 $\mathrm{kg} / \mathrm{h})$ than that of flour $1(700 \mathrm{~kg} / \mathrm{h})$, giving rise to a lower mean residence time in the 
extruder and therefore a more intense treatment. Batter viscosity is function of several variables including protein and starch contents, as well as the amount of the water (solid concentration). Therefore the presence of wheat flour containing gelatinised starch, which possesses high water absorption capacity (Martínez et al., 2014b), could diminish the free water content producing an increase in the viscosity. On the other hand, the higher solubility of starch components of extruded flour, related to their lower molecular weight, (Doublier, Colonna, \& Mercier, 1986) could also assist the increase of the viscosity. Extrusion of rice and wheat flours induced and increase in both flour viscosities at low temperature (Martínez, Calvi no, Rosell, \& Gomez, 2014a; Martínez at al., 2014b). In addition, protein unfolding as a consequence of the extrusion (Martínez et al., 2014a) could also have an influence on the water absorption and therefore on the apparent viscosity. Discussion about these interactions will be approached in depth using dynamic rheology. With regard to the flow behaviour index, a decrease with the use of extruded flours was observed, indicating higher shear-thinning behaviour than control sample. Therefore, batters made with extruded flours were more susceptible to either the alignments of particles and breakdown of their interactions under the influence of shear stress. Time dependency of the batterwas evaluated by determining the relative thixotropic area (Table 1). All batter types were found to have thixotropic behaviour, however significant differences among samples were not found.

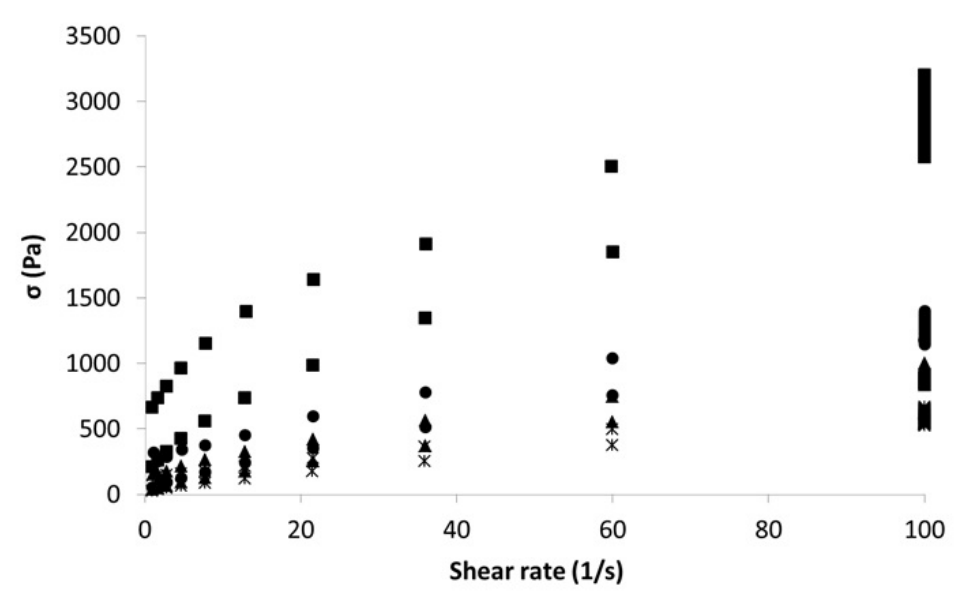

Fig. 1 Flow curves at $20^{\circ} \mathrm{C}$ of the batters with a $15 \%$ of extruded flour extruded flour substitution. Control (ж); Flour 1 (triangles); Flour 2 (circles) and Flour 3 (squares).

In conclusion, the different types of wheat extruded flour increased the viscosity and affected the flow behavior of batters to a different extent, increasing the variety of batter possibilities in terms of coating pickup, texture, appearance and handling properties.

\subsection{Oscillatory shear properties}

3.2.1. Dynamic linear viscoelastic range 
Critical amplitudes of the shear stress $(\sigma c)$ and strain $\left(\gamma_{c}\right)$ for the onset of the non-linear response, were estimated from the normalized plot of G' and G", taking as reference the average of their initial values at the lower torques reached by the rheometer (data not shown).

Table 1. Flow behaviour and loss tangent of batters made with native wheat flour substitution by different extruded wheat flours.

\begin{tabular}{|c|c|c|c|c|c|}
\hline Extruded Flour & $\mathrm{K}\left(\mathrm{Pa}_{\mathrm{s}} \mathrm{s}^{\mathrm{n}}\right)$ & $\mathbf{n}$ & $\begin{array}{c}\text { Relative } \\
\text { thixotropic area }\end{array}$ & $\tan \delta\left(20^{\circ} \mathrm{C}\right)$ & $\tan \delta\left(80^{\circ} \mathrm{C}\right)$ \\
\hline Control & $15.54 \mathrm{a}$ & $0.78 b$ & $26.76 a, b$ & $0,35565 b, c$ & 0,092115a,b \\
\hline 7,5\% Flour 1 & $35.03 a, b$ & $0.67 a, b$ & $25.28 \mathrm{a}, \mathrm{b}$ & $0,3883 d$ & 0,09841a,b \\
\hline $7,5 \%$ Flour 2 & $44.25 a, b$ & $0.64 a$ & $30.45 a, b$ & $0,3801 c, d$ & 0,094355a,b \\
\hline 7,5\% Flour 3 & $67.14 b$ & $0.67 a, b$ & $27.19 a, b$ & $0,35015 b$ & 0,090435a,b \\
\hline 15\% Flour 1 & $50.89 \mathrm{~b}$ & $0.61 \mathrm{a}$ & $32.11 \mathrm{~b}$ & $0,36685 b, c, d$ & $0,12875 b$ \\
\hline $15 \%$ Flour 2 & $40.11 \mathrm{ab}$ & $0.73 \mathrm{ab}$ & $24.23 \mathrm{a}$ & $0,35555 b, c$ & $0,071695 a$ \\
\hline $15 \%$ Flour 3 & $177.25 c$ & $0.62 \mathrm{a}$ & $29.73 a, b$ & $0,31725 a$ & 0,096495a,b \\
\hline
\end{tabular}

$\mathrm{K}$, consistency coefficient; $\mathrm{n}$, flow behaviour index; tan $\mathrm{d}$, loss tangent.

Numbers in sample codes are referred to extrusion intensity.

Values followed by different letters within each column indicate significant differences (P 0.05).

There were not differences between control batter and batters made with extruded flour 1 and 2. However, a remarkable increase in sc with the addition of flour 3 was observed (from 0.199 to $0.250 \mathrm{~Pa}$ with $7.5 \%$ flour replacement, and to $0.629 \mathrm{~Pa}$ with $15 \%$ flour replacement). Nevertheless, no effect in gc, which was 0.001 in all of the batters, was observed. Thereby, addition of flour 3 turnedbatters into more resistant to the applied stress. Sanz et al., (2005b) reported an increase in the batter stress resistance with gluten addition. Protein unfolding as a consequence of extrusion process (Martínez et al., 2014a) could augment the exposure of hydrophobic groups and therefore yielding more batter stress resistance. In addition, starch structure of flour 3, characterized by higher gelatinised starch content (Martínez et al., 2014b), could also have an influence on batter stress resistance.

\subsubsection{Mechanical spectra at $20^{\circ} \mathrm{C}$}

The influence of extruded flours on the mechanical spectra obtained at $20 \mathrm{C}$ is shown in Fig. 2. In the available frequency window the so-called plateau relaxation zone is observed 
in all the batters. This region is characterised by the fact that G' is higher than G" , both moduli depending on frequency but following a different pattern (Calero, $\mathrm{Mu}^{\sim}$ noz, $\mathrm{Cox}$, Heuer, \& Guerrero, 2013). This region is characteristic of the occurrence of physical entanglements in polymeric materials (Ferry, 1980).

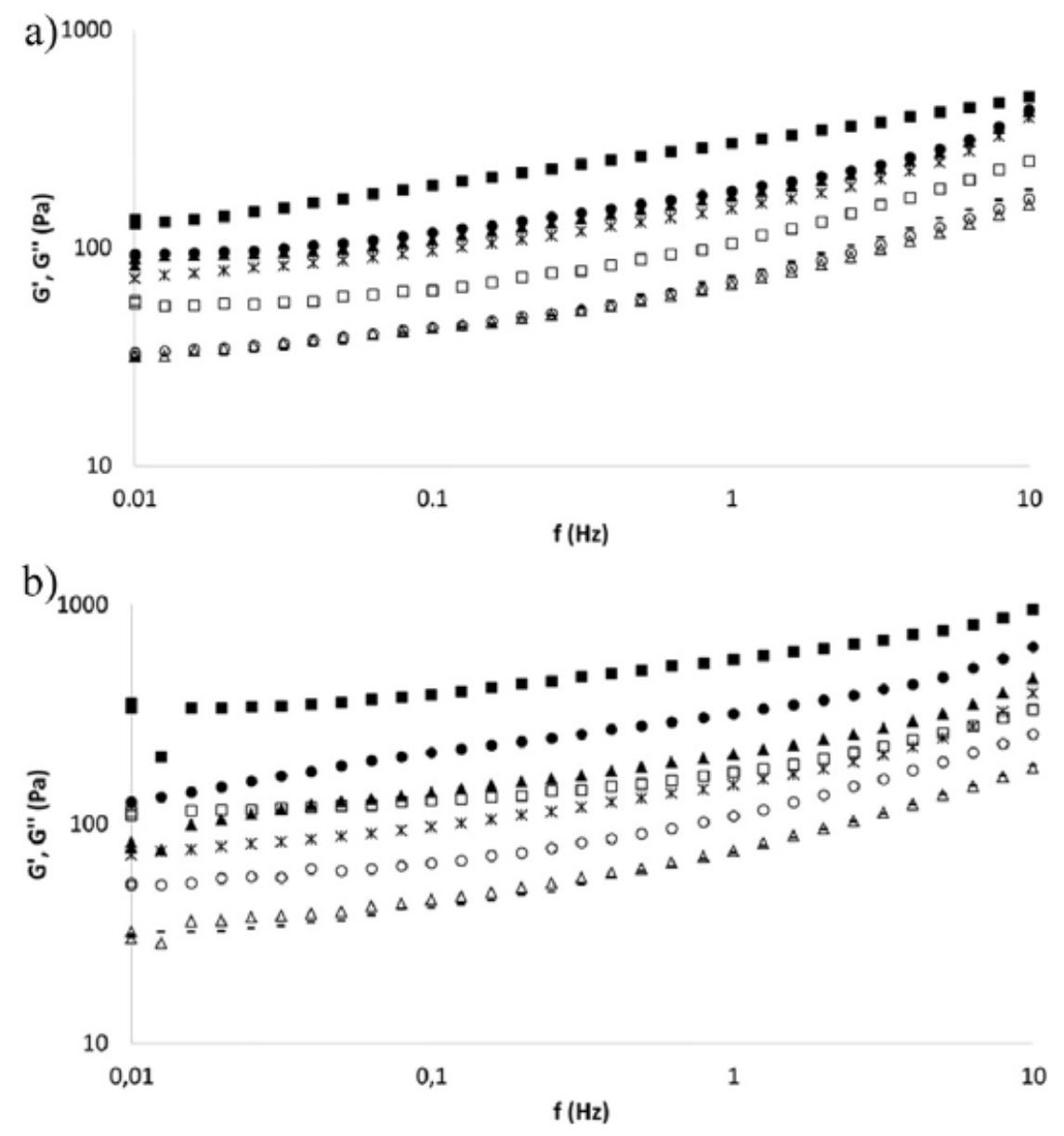

Fig. 2. Frequency sweep tests at $20^{\circ} \mathrm{C}$ of batters with $7.5 \%$ (a) and $15 \%$ (b) wheat flour replacement by different extruded flours. G' and G' are elicited by filled and unfilled symbols, respectively. Control (G' is represented by ж and G” by -); Flour 1 (triangles); Flour 2 (circles) and Flour 3 (squares). Frequency: $1 \mathrm{~Hz}$.

The dynamic moduli increased with the severity of the extrusion treatment of extruded flour along the whole frequency range in $15 \%$ of replacement. In $7.5 \%$ of replacement, only flour 3 displayed an increase of both dynamic moduli. The higher water absorption capacity of extruded flours (Martínez et al., 2014b) could diminish the free water content enhancing the structure and increasing both dynamic moduli. These results, in accordance with those of flow curves, reflect the development of raw batters with enhanced structure upon increasing the content and the intensity of the extrusion treatment of extruded wheat flours. In addition, high temperatures reached during the extrusion treatment would give rise to protein unfolding (Martínez et al., 2014a) enhancing the exposure of hydrophobic groups and therefore yielding more interactions with water (Sanz et al., 2005b). With regard to tan d, only a noticeable decrease was 
observed in batters made with $15 \%$ of flour 3 . This fact would indicate that, with the exception of batters made with a $15 \%$ of flour 3, additional interactions between new rheological units would not be created. Thereby, the concentration phenomena of the already present rheological units, as a consequence of the high water absorption capacity of gelatinised starch of extruded flour, would be a more likely explanation.

\subsubsection{Temperature sweep}

The influence of the extruded flour on the gelation characteristics of batters is shown in Fig. 3, where the behaviour of the batters with 15\% extruded flour replacement is depicted. Above around $60 \mathrm{C}$, the gelation processes was triggered as demonstrated by the dramatic increase in elastic modulus and the decrease of $\tan \mathrm{d}$. These occurrences are attributed to starch gelatinization, resulting in the onset of structure formation in which the fluid-like batter transforms into a solid like coating. As expected, Flour 3, which possess the lowest amount of non-gelatinised starch (Martínez et al., 2014a; Martínez et al., 2014b), displayed the lowest rate of increase and decrease of G0 and $\tan \mathrm{d}$, respectively. In addition, flour 3 showed the highest and the lowest values of G0 and tan $\mathrm{d}$ respectively, up to $60 \mathrm{C}$, as it was already seen in the frequency sweep at $20 \mathrm{C}$. A delay in the onset temperature for G0 and tan $\mathrm{d}$ was observed in flour 3. Xue and Ngadi (2006), analysing the thermorheological properties of batters made with wheat flour and gluten free flours, observed how native wheat flour, displayed an earlier onset temperature than gluten free flour, attributing this phenomena to a gluten gelation. Gluten gelation, which occurs at a lower temperature than starch gelatinization (Olewnik \& Kulp, 1993), could be responsible for that earlier increase of G0 of batters without Flour 3. Therefore, the protein denaturisation during the severe extrusion treatment of flour 3 (Camire et al., 1990), could delay the onset temperature of the increase of viscosity. In addition, wheat extruded flours subjected to severe extrusion treatment possess higher gelatinization temperature, as it was reported by Martínez et al. (2014b) and as it will be commented later in thermal properties section. This fact would indicate that more energy is required to initiate gelatinization of the starch suggesting that extrusion is affecting the outer and more amorphous part of the granule and is progressing to the core of the granule till no crystalline structure is left for gelatinization (Martínez et al., 2014b). 

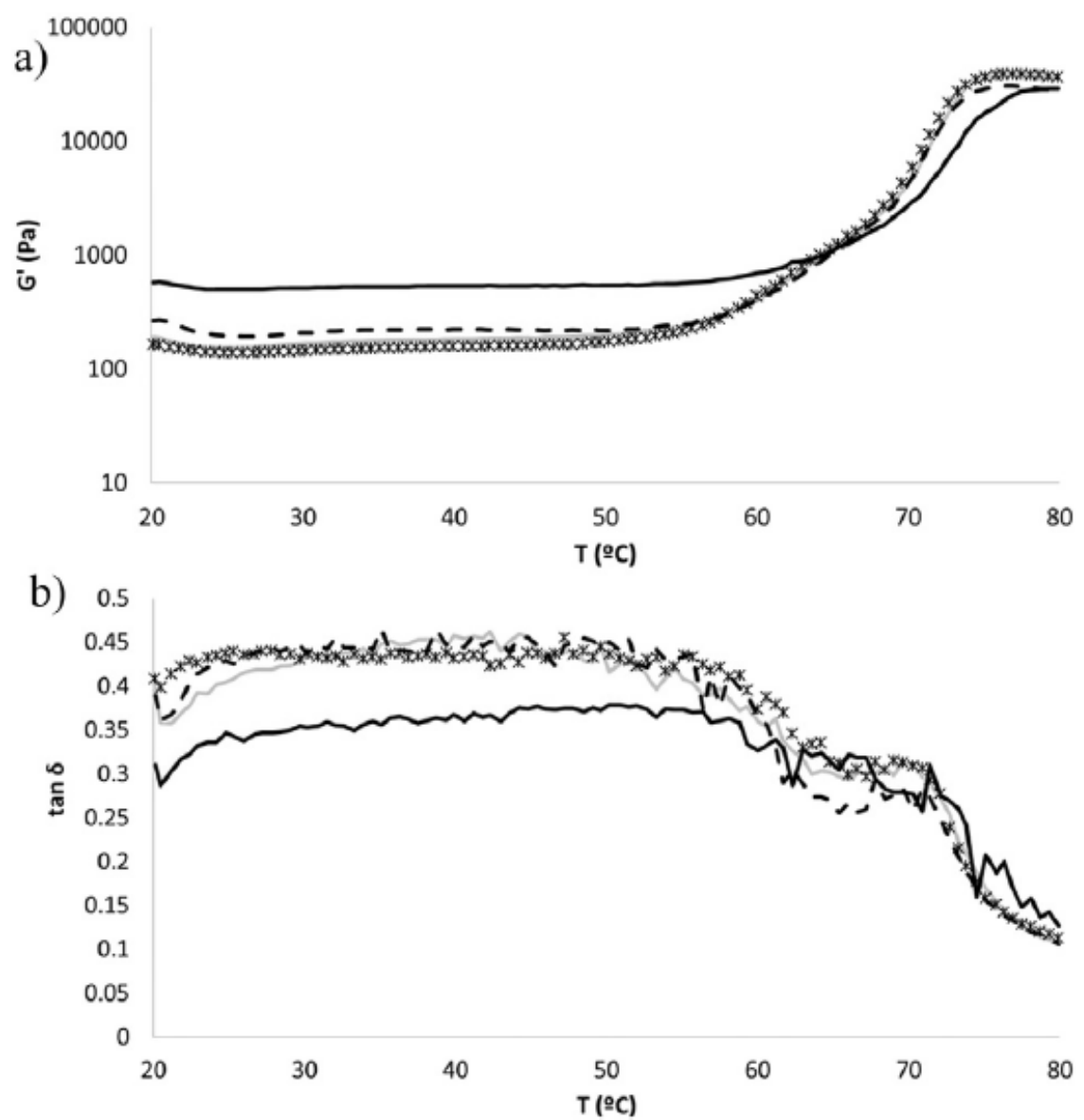

Fig. 3. G' (a) and $\tan \delta(\mathrm{b})$ as a function of temperature of batters with $15 \%$ wheat flour replacement by different extruded flours. Control (ж); flour 1(continuous grey line); flour 2 (discontinuous black line) and flour 3 (continuous black line). Velocity of change in temperature: $1^{\circ} \mathrm{C} / \mathrm{min}$.

\subsubsection{Mechanical spectra at $80 \mathrm{C}$}

The influence of extruded flours on the mechanical spectra obtained at $80 \mathrm{C}$ is shown in Fig. 4. In this figure it was observed an increase of both dynamic moduli as a consequence of the evolution from a soft gel at $20 \mathrm{C}$ (behaviour of the batter before coagulation) to a stronger gel (behaviour of the batter after coagulation). In this case, the effect of extruded flour on elastic moduli displayed an opposite trend compared to mechanical spectra at 20 C. However, the trend was not that clear regarding viscous moduli. Thereby, it was noticed that both in the case of 7.5 and $15 \%$ wheat flour replacement, both G0 and G00 of extruded flour containing batters were lower than that of control along the whole frequency range. Moreover, dynamic viscoelastic functions decreased parallely as the extrusion intensity increased. This opposite trend was also observed in the mechanical spectra at 15 and $60 \mathrm{C}$ studying the effect of incorporation of proteins to batters (Sanz et al., 2005b). Those authors attributed it to the effect of gluten delaying starch gelatinization. It is supposed that at this temperature, the differences in gelatinised starch content among extruded flour containing and control batters are not significant. 
However, severe extrusion treatments can even break the starch molecules (Martínez et al., 2014b), affecting the formation of the starch network that normally occurs either through granuleegranule interactions (early stage) or through amylose chain entanglements (later stage) (Champenois, Rao \& Walker, 1998). In addition, unfolded proteins, with enhanced exposure of hydrophobic groups (Sanz et al., 2005b), could yield unfavourable interactions with water in extruded flour containing batters. This explanation is also supported assessing the viscoelasticity (Table 1), where no significant differences were found, indicating again that changes could be attributed to the concentration phenomena of the already present rheological units, but in this case, conversely to mechanical spectra at $20 \mathrm{C}$, attributed to the unfolded proteins of extruded flours.

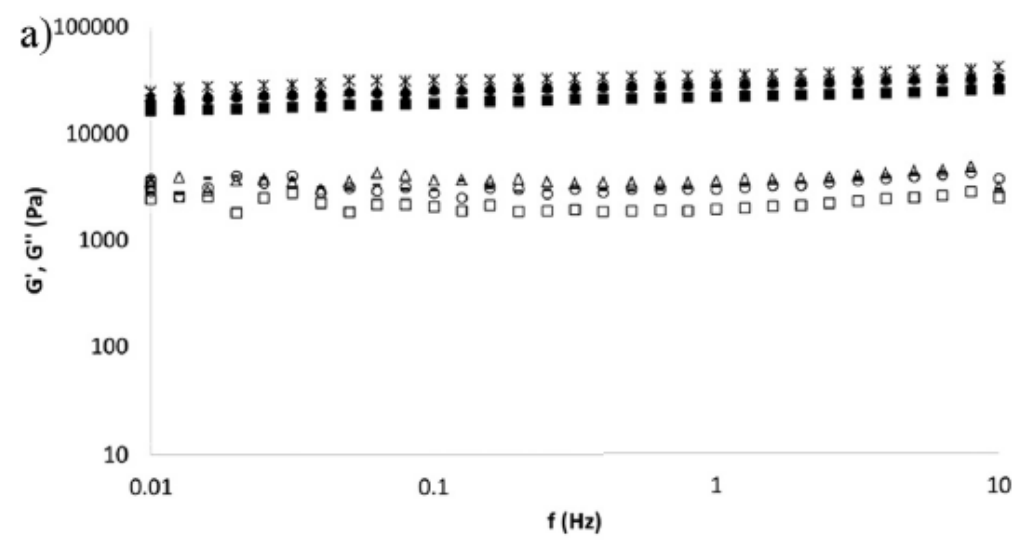

b) 100000

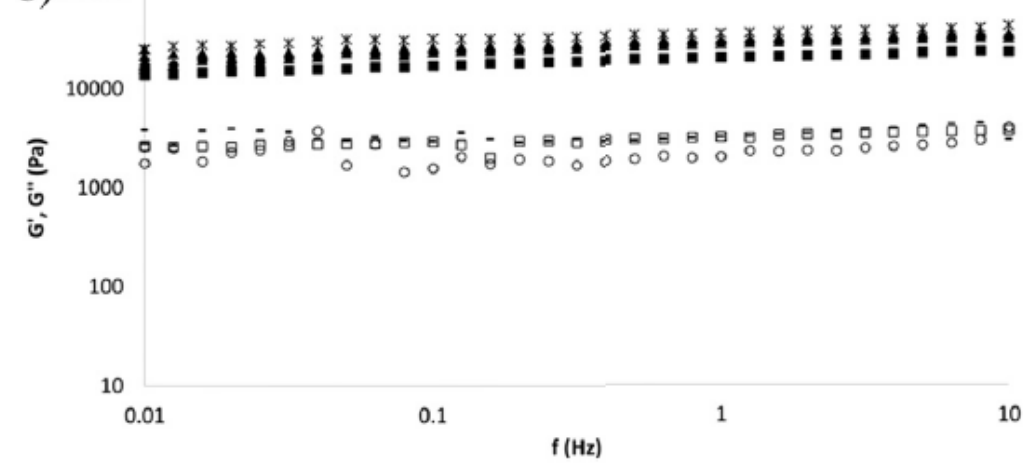

Fig. 4. Frequency sweep tests at $80^{\circ} \mathrm{C}$ of batters with $7.5 \%$ (a) and $15 \%$ (b) wheat flour replacement by different extruded flours. G' and G" are elicited by filled and unfilled symbols, respectively. Control (G' is represented by ж and G" by -); Flour 1 (triangle); Flour 2 (circle) and Flour 3 (square). Frequency: $1 \mathrm{~Hz}$..

\subsection{Thermal properties}

Changes in the thermal properties using differential scanning calorimetry (DSC) of the batter systems during cooking process are shown in Table 2 . All samples exhibited a single endothermic transition over the temperature range from 65 to $95 \mathrm{C}$ during the heating process, corresponding to amylopectin gelatinization. The extrusion treatment significantly modified the gelatinization temperatures of flour 3 containing batters. Gelatinization temperatures were progressively sifted to higher values when flours were 
treated under severe extrusion intensity (flour 3), but the temperature rangewas not affected. As commented earlier, higher gelatinization temperature would indicate more energy requirements to initiate gelatinization of the starch. This fact would suggest that extrusion is affecting the outer and more amorphous part of the granule and is progressing to the core of the granule till no crystalline structure is left for gelatinization (Martínez et al., 2014b). In addition, flour 3 batters showed lower enthalpy of amylopectin gelatinization, indicating a more amount of gelatinised starch already present in flour 3.

\begin{tabular}{|c|c|c|c|c|c|}
\hline \multirow[b]{2}{*}{ Extruded Flour } & \multicolumn{5}{|c|}{ Amylopectin gelatinization } \\
\hline & To $\left({ }^{\circ} \mathrm{C}\right)$ & $\mathrm{Tp}\left({ }^{\circ} \mathrm{C}\right)$ & $\mathrm{Tc}\left({ }^{\circ} \mathrm{C}\right)$ & Tp-To $\left({ }^{\circ} \mathrm{C}\right)$ & $\Delta \mathrm{H},(\mathrm{J} / \mathrm{g})$ \\
\hline Control & $67.24 \mathrm{a}$ & $73.37 \mathrm{a}$ & $89.66 a$ & $6.12 \mathrm{a}$ & $2.53 \mathrm{~b}$ \\
\hline 15\% Flour 1 & $67.95 \mathrm{a}$ & $74.105 a$ & $91.09 \mathrm{ab}$ & $6.10 \mathrm{a}$ & $2.39 \mathrm{~b}$ \\
\hline 15\% Flour 2 & $67.85 \mathrm{a}$ & $73.96 a$ & $91.15 \mathrm{ab}$ & $6.16 a$ & $2.23 \mathrm{ab}$ \\
\hline $15 \%$ Flour 3 & $70.27 b$ & $76.74 b$ & $93.68 b$ & $6.48 \mathrm{a}$ & $1.85 \mathrm{a}$ \\
\hline
\end{tabular}

To, gelatinization onset; Tp, peak temperature; Tc, conclusion temperature, Tp - To, gelatinization range, $\Delta \mathrm{H}$, enthalpy and $\mathrm{PHI}$, peak high index.

Numbers in sample codes are referred to extrusion intensity.

Values followed by different letters within each column indicate significant differences $(\mathrm{P} \leq 0.05)$.

\section{$\underline{4 . \text { Conclusions }}$}

Batter coatings enhance the flavour, texture and appearance of foods. One of the most crucial parameters is their viscosity and rheological properties. Replacement of native wheat flour by wheat flour subjected to different extrusion treatments caused an important increase of the apparent viscosity of the batters, especially when extruded flour was subjected to a severe treatment. Results obtained from small amplitude oscillatory shear rheology attributed those changes to the diminution of the water content as a consequence of the high water absorption capacity of gelatinised starch and of unfolded proteins of extruded flour. In addition, structural changes that took place during the cooking process of batters revealed a delay in the onset temperature for $\mathrm{GO}$ and tan $\mathrm{d}$ as well as higher gelatinization temperatures with the use of flour 3 . This would indicate an effect of extrusion on starch gelatinization and on gelation properties of gluten of wheat flours. In general, results suggested how a $15 \%$ of wheat flour replacement by wheat flour subjected to different extrusion treatments would offer batters with different viscosities and viscoelastic properties increasing the range of batters coatings available in the market.

\section{$\underline{\text { Acknowledgements }}$}

This study was financially supported by Junta de Castilla y Leon (VA054A12-2), Spain. The authors are grateful to Molendum Ingredients and Harinera Castellana for supplying flours. Mario M. Martínez would like to thank predoctoral fellowship from University of Valladolid. 


\section{$\underline{\text { References }}$}

Altunakar, B., Sahin, S., \& Sumnu, G. (2004). Functionality of batters containing different starch types for deep-fat frying of chicken nuggets. European Food Research and Technology, 218, 318e322.

Amboon, W., Tulyathan, V., \& Tattiyakul, J. (2012). Effect of hydroxypropyl methylcellulose on rheological properties, coating pickup, and oil content of rice flourbased batters. Food and Bioprocess Technology, 5, 601e608.

Baixauli, R., Sanz, T., Salvador, A., \& Fiszman, S. (2003). Effect of the addition of dextrin or dried egg on the rheological and textural properties of batters for fried foods. Food Hydrocolloids, 17, 305e310.

Calero, N., Mu noz, J., Cox, P., Heuer, A., \& Guerrero, A. (2013). Influence of chitosan concentration on the stability, microstructure and rheological properties of $\mathrm{O} /$ Wemulsions formulated with high-oleic sunflower oil and potato protein. Food Hydrocolloids, 30, 152e162.

Camire, M., Camire, A., \& Krumhar, K. (1990). Chemical and nutritional changes in foods during the extrusion. Critical Reviews in Food Science and Nutrition, 29, 35e57.

Champenois, Y., Rao, M. A., \& Walker, L. P. (1998). Influence of gluten on the viscoelastic properties of starch pastes and gels. Journal of the Science of Food and Agriculture, 78, 119e126.

Dolz, M., Gonzalez, F., Delegido, J., Hernandez, M. J., \& Pellicer, J. (2000). A timedependent expression for thixotropic areas. Application to aerosil 200 hydrogels. Journal of Pharmaceutical Sciences, 89, 790e797.

Doublier, J. L., Colonna, P., \& Mercier, C. (1986). Extrusion cooking and drum drying of wheat-starch. 2. Rheological characterization of starch pastes. Cereal Chemistry, 63, $240 \mathrm{e} 246$.

Ferry, J. D. (1980). Viscoelastic properties of polymers (3rd ed.). New York: John Wiley \& Sons Inc.

Fiszman, S. M., \& Salvador, A. (2003). Recent developments in coating batters. Trends in Food Science \& Technology, 14, 399e407.

Hagenimana, A., Ding, X., \& Fang, T. (2006). Evaluation of rice flour modified by extrusion cooking. Journal of Cereal Science, 43, 38e46.

Jacobs, H., \& Delcour, J. (1998). Hydrothermal modifications of granular starch, with retention of the granular structure: a review. Journal of Agricultural and Food Chemistry, 46, $2895 \mathrm{e} 2905$. 
Jeon, S., Lim, J., Inglett, G. E., \& Lee, S. (2013). Effect of enzymatic treatments on the rheological and oil-resisting properties of wheat flour-based frying batters. Journal of Food Engineering, 115, 215e219.

Letang, C., Piau, M., \& Verdier, C. (1999). Characterization of wheat flour-water dough. Part I. Rheometry and microstructure. Journal of Food Engineering, 41, 121e132.

Loewe, R. (1990). Ingredient selection for batter systems. In K. Kulp, \& R. Loewe (Eds.), Batters and breadings (pp. 11e28). St. Paul. Minnesota, USA: American Association of Cereal Chemists.

Martínez, M., Calvi $\sim$ no, A., Rosell, C., \& Gomez, M. (2014a). Effect of different extrusion treatments and particle size distribution on the physicochemical properties of rice flour. Food and Bioprocess Technology, 7, 2657e2665.

Martínez, M., Rosell, C., \& Gomez, M. (2014b). Modification of wheat flour functionality and digestibility through different extrusion conditions. Journal of Food Engineering, 143, 74e79.

Mohamed, S., Hamid, N., \& Hamid, M. (1998). Food components affecting the oil absorption and crispness of fried batter. Journal of the Science of Food and Agriculture, $78,39 \mathrm{e} 45$.

Olewnik, M., \& Kulp, K. (1993). Factors influencing wheat flour performance in batter systems. Cereal Chemistry, 75, 428e432.

Prakash, M., \& Rajalakshmi, D. (1999). Effect of steamed wheat flour on the sensory quality of batter coated products. Journal of Food Quality, 22, 523e533.

Purcell, S., Wang, Y.-J., \& Seo, H.-S. (2014a). Enzyme-modified starch as an oil delivery system for bake-only chicken nuggets. Journal of Food Science, 79, 802e809.

Purcell, S., Wang, Y.J., \& Seo, H.-S. (2014b). Application of oxidized starch in bake only chicken nuggets. Journal of Food Science, 79, 810e815.

Sanz, T., Fernandez, M., Salvador, A., Mu noz, J., \& Fiszman, S. (2005a). Thermogelation properties of methylcellulose (MC) and their effect on a batter formula. Food Hydrocolloids, 19, 141e147.

Sanz, T., Salvador, A., Velez, G., Mu noz, J., \& Fiszman, S. (2005b). Influence of ingredients on the thermo-rheological behaviour of batters containing methylcellulose. Food Hydrocolloids, 19, 869e877.

Varela, P., \& Fiszman, S. (2011). Hydrocolloids in fried foods. A review. Food Hydrocolloids, 25, 1801e1812. 
Wen, L., Rodis, P., \& Wasserman, B. (1990). Starch fragmentation and protein insolubilization during twin-screw extrusion of corn meal. Cereal Chemistry, 67, $268 \mathrm{e} 275$.

Xue, J., \& Ngadi, M. (2006). Rheological properties of batter systems formulated using different flour combinations. Journal of Food Engineering, 77, 334e341.

Xue, J., \& Ngadi, M. (2007). Thermal properties of batter systems formulated by combinations of different flours. LWT Food Science and Technology, 40, 1459e1465.

Xue, J., \& Ngadi, M. (2009). Effects of methylcellulose, xanthan gum and carboxymethylcellulose on thermal properties of batter systems formulated with different flour combinations. Food Hydrocolloids, 23, $286 \mathrm{e} 295$. 


\section{CHAPTER 3.}

\section{Effect of extruded flours on final products: gluten containing and gluten-free breads}

Contents lists available at SciVerse ScienceDirect

Journal of Cereal Science

journal homepage: www.elsevier.com/locate/jcs

Effect of the addition of extruded wheat flours on dough rheology and bread quality

Mario Martínez, Bonastre Oliete, Manuel Gómez*

Área de Tecnología de los Alimentos, E.TS. Ingenierías Agrarias, Universidad de Valladolid, 34004 Palencia, Spain

\section{Journal of Food Quality}

Journal of Food Quality ISSN 1745-4557

\section{INFLUENCE OF THE ADDITION OF EXTRUDED FLOURS ON RICE BREAD QUALITY}

MARIO M. MARTÍNEZ, BONASTRE OLIETE, LAURA ROMÁN and MANUEL GÓMEZ

Food Technology Area, E.T.S. Ingenierías Agrarias, Valladolid University, Avd. Madrid 44, Palencia 34071, Spain 


\subsection{Effect of the addition of extruded wheat flours on dough rheology and bread quality}

Journal of Cereal Science 57 (2013) 424-429

Contents lists available at SciVerse ScienceDirect

Journal of Cereal Science

journal homepage: www.elsevier.com/locate/jcs

Effect of the addition of extruded wheat flours on dough rheology and bread quality

Mario Martínez, Bonastre Oliete, Manuel Gómez*

Área de Tecnología de los Alimentos, E.T.S. Ingenierías Agrarias, Universidad de Valladolid, 34004 Palencia, Spain

\section{Introduction}

One of the main interests of the bakery industry is to improve bread output during the bread making process (obtaining a greater quantity of bread from the same quantity of flour). Such an increase in production would enable manufacturers to maximize benefits or to reduce the retail price and be more competitive. One way to achieve this objective is to increase the amount of water included into the formula, but avoiding any modification of bread quality and preventing water loss during baking. Doughs with excess water are difficult to handle; it thus becomes necessary to modify the recipe or processing conditions. Increasing the water absorption capacity of doughs is the easiest way to obtain high-water content and highyield breads (Puhr and D'Appolonia, 1992).

The water absorption capacity of dough depends mainly on the flour composition, and increases with increasing protein, pentosane and damaged starch content. The association between the quantity of damaged starch and the water absorption capacity of flour has been established (Dexter et al., 1994). Studies have also been performed with pregelatinized starches, which show a similar behaviour to damaged starch because the starch granules break down during this process. Based on these findings, Miller et al. (2008) investigated the possibility of increasing bread output through the addition of certain pregelatinized (hydroxypropylated and cross-linked) wheat starches, with good results. The addition of heat-moisture treated maize starch has also been studied, although in this case, the breads obtained were of low quality (Miyazaki and Morita, 2005). Another possible way to increase output during bread-making consists of the addition of hydrocolloids, due to their high water absorption capacity; however, hydrocolloids produce major alterations in other characteristics of breads and doughs (Rosell et al., 2001). 
It is known that the changes that take place in flours during hydrothermal treatment depend on the initial water content of the product, the temperature reached and the time and type of treatment: heated rolls, atomization or extrusion (Chiu and Solarek, 2009). Extrusion produces gelatinization of starch and increased damaged starch content, together with a reduction in lipid oxidation due to enzyme inactivation, an increase in soluble fibre and a reduction in thermolabile vitamins, antinutritional factors and microbial load (Camire et al., 1990). Extrusion also causes higher levels of mechanical damage in starch than traditional cooking methods (Wolf, 2010). Extruded wheat flours may therefore be an interesting alternative to pregelatinized starch and hydrocolloids to increase bread output in the bakery manufacturing process. Furthermore, it is not necessary to label these kinds of flour as additives but as wheat flours, which will facilitate clear labelling, a tendency currently favoured in the food industry (Sloan, 2011).

Few studies have investigated the use of extruded flours in bread-making and they are limited to the addition of these flours into non-wheat doughs or into doughs with a high content of nonwheat flours such as maize (Curic et al., 2009), barley (Gill et al., 2002) or rice (Sanchez et al., 2008) flours in order to make up for gluten deficiency. Therefore, the aim of this work was to evaluate the effect of substituting $5 \%$ wheat flour by extruded wheat flours with different time-temperature extrusion treatments. In each case, we determined the effect of this addition on dough mixing, handling and fermentation evolution and on the final quality of the bread (volume, weight, height/width ratio, texture and colour).

\section{Materials and methods}

\subsection{Materials}

Wheat flour (14.48\% moisture, $0.58 \%$ ash, $11.78 \%$ protein) was supplied by Harinera Castellana. Extrusion was performed by Harinera Los Pisones (Zamora, Spain). An industrial Buhler Basf single-screw extruder (Buhler S.A., Uzwil, Switzerland) was used for the extrusion process. Five kinds of extrusion treatments were studied. In treatment 1, flour was extruded with $4 \%$ water added in the system and the maximum temperature of the extruder was $60 \mathrm{C}$; in treatments 2, 3 and 4, flour was extruded at a maximum extruder temperature of $110 \mathrm{C}$ and with $4 \%, 10 \%$ and $16 \%$ water added in the system, respectively; and in treatment 5 , flour was extruded with $9 \%$ water added in the system and a maximum extruder temperature of $140 \mathrm{C}$. The extrusion conditions were fixed to ensure correct flow behaviour of the dough into the extruder. The extruded product was milled with compression drums and sieved through a 200-mm sieve. The product obtained from the sieve was used. Wheat flour composition was determined using AACC Methods (AACC, 2000): moisture, method 44-15A; ash, method 08-01; and protein, method 46-08. Saf-Instant yeast (Lesaffre, Lille, France) was used as the leavening agent. Salt from the local supermarket and tap water were used in the bread-making analysis. Analytical quality ascorbic acid (Panreac Quimica S.A.U., Barcelona, Spain) was used. 


\subsection{Methods}

\subsubsection{Dough rheology and gas production}

Extruded flours were added at $5 \mathrm{~g}$ per $95 \mathrm{~g}$ flour (5\% extruded flour) obtaining flours A, B, C, D and E when extruded flour added was from treatments 1, 2, 3, 4 and 5 respectively. Control dough without the addition of extruded flour was also analysed. The pasting properties of flours were analysed using the standard method with a Rapid Visco Analyser (RVA-4) (Perten Instruments Australia, Macquarie Park, Australia) (method 6102.01, AACC, 2000), controlled by Thermocline for Windows software (Perten Instruments Australia, Macquarie Park, Australia). Analyses were performed in duplicate.

Water absorption and the mixing behaviour of flours were studied using the doughLAB equipment (Perten Instruments Australia, Macquarie Park, Australia). Dough was developed in the mixing bowl at $30 \mathrm{C}$, by the rotary action of two sigma-arm mixing blades at $63 \mathrm{rpm}$ and its resistance to kneading was obtained as a torque value. Data obtained from the doughLAB were analysed using doughMAP software (Perten Instruments Australia, Macquarie Park, Australia). The following mixing-profile values were measured: 1) absorption, defined as the amount of water required to reach a flour consistency of $500 \mathrm{FU}$ with $14 \%$ moisture; 2) development time, defined as the time to reach peak resistance; and 3) stability, defined as the difference between the time required to reach peak resistance and the time required to fall below peak resistance. The analyses were performed in duplicate.

Alveograph measurements were made with an Alveograph MA 82 (Chopin, Tripette et Renaud, Villeneuve La Garenne, France) using the standard AACC Approved Method 54-30 (AACC, 2000). The alveogram characteristics were automatically recorded by the Alveolink-NG computer software program developed by Chopin S. A. (Chopin, Tripette et Renaud, Villeneuve La Garenne, France). The characteristics recordedweremaximumover-pressure $(\mathrm{P})$ needed to blow the dough bubble (an indicator of dough tenacity or resistance to extension), the average abscissa (L) at bubble rupture (an indicator of dough extensibility), the deformation energy (W) (an indicator of dough strength), and the curve configuration ratio or balance (P/L). A second alveogram was performed by adding a quantity of water equal to the absorption capacity obtained on DoughLab analysis. The two alveograms were performed in duplicate.

The rheofermentometer test (Chopin, Tripette and Renaud, Villeneuve La Garenne, France) was used to study dough height according to fermentation time and gas release following the method described by Czuchajowska and Pomeranz (1993).

\subsubsection{Bread making}

A straight dough method was used for bread preparation. The following ingredients

(g/100 g flour basis) were used: water (calculated to obtain a doughLab absorption value 
of $500 \mathrm{FU})$, instant dry yeast $(1 \mathrm{~g} / 100 \mathrm{~g})$, ascorbic acid $(0.01 \mathrm{~g} / 100 \mathrm{~g})$ and salt $(1.8 \mathrm{~g} / 100$ g). Water temperature was calculated to achieve a dough temperature of $23 \mathrm{C}$. Wheat flour was replaced with extruded wheat flours to a proportion of $5 \mathrm{~g}$ per $100 \mathrm{~g}$ flour. Control bread with no extruded flour was also prepared. After mixing all the ingredients for 15 min using a double-arm kneader AB-20 (Salva, Lezo, Spain), the bread dough was divided into $300 \mathrm{~g}$ portions, hand-rounded, mechanically moulded, and proofed for 90 min at $30 \mathrm{C}$ and $75 \% \mathrm{RH}$. The breads were baked in an electric oven for $30 \mathrm{~min}$ at 200 C. After baking, the loaves were left to cool for $20 \mathrm{~min}$, and then weighed. They were then placed in polyethylene bags and stored at $20 \mathrm{C}$ until analysis. All the samples were prepared in duplicate.

\subsubsection{Bread quality}

Weight loss was calculated by weighing the breads $1 \mathrm{~h}$ after baking. Bread volumewas determined using a laser sensor with the BVM-L 370 volume analyser (Perten Instruments, Hägersten, Sweden). A digital calliper was used to measure height/weight ratio. Measurements were made in triplicate.

Crumb texture was determined with a TA-XT2 texture analyser (Stable Microsystems, Surrey, UK) fitted with the "Texture Expert" software. A 25-mm diameter cylindrical aluminium probewas used in a "Texture Profile Analysis" (TPA) double compression test to penetrate to $50 \%$ of the sample depth at a test speed of $2 \mathrm{~mm} / \mathrm{s}$ and with a $30 \mathrm{~s}$ delay between first and second compressions. Firmness $(\mathrm{N})$, cohesiveness, springiness, resilience and chewiness were calculated from the TPA graph (Gómez et al., 2007). Texture analyses were performed $18 \mathrm{~h}$ after baking on slices with a thickness of $30 \mathrm{~mm}$. Analyses were performed on two slices from two breads $(2 \times 2)$ from each type of preparation, taking the average of the 4 measurements made.

Colour was measured using a Minolta spectrophotometer CN-508i (Minolta, Co.LTD, Tokio, Japan). Results were expressed in the CIE L*a*b* colour space and were obtained using the D65 standard illuminant, and the 2standard observer. Colour determinations were made 4 - 5 times on each piece of bread (two breads from each type of elaboration): crumb and crust colour was checked at four different points on each piece of bread and each point was measured five times.

\subsubsection{Electron microscope photomicrographs}

Dough photomicrographs were taken with a Quanta 200FEG (Hillsboro, Oregon, USA) environmental scanning electron microscope (ESEM) fitted with a backscattered electron detector (BSED). 


\subsubsection{Statistical analysis}

Analysis of variance (ANOVA) was used to analyse the effect of the addition of extruded flour. Fisher's least significant difference (LSD) test was used to describe means with $95 \%$ confidence.

\section{Results and discussion}

\subsection{Dough rheology and gas production}

Fig. 1 shows the RVA curves from the extruded flours. Observing the differences in behaviour compared to the control, it can be seen that extrusion intensity increases both with temperature and, at a constant temperature, with increasing water content. Increasing the extrusion intensity leads to a decrease in dough viscosity during the heatingecooling cycle. This effect has already been observed by other authors, who attributed the decrease to early starch gelatinization (Doublier et al., 1986; Hagenimana et al., 2006; Mercier and Feillet, 1975); the decrease in viscosity would therefore indicate the proportion of gelatinized starch. It can thus be shown that flours that have undergone the most intense extrusion treatments have the highest quantity of gelatinized starch.

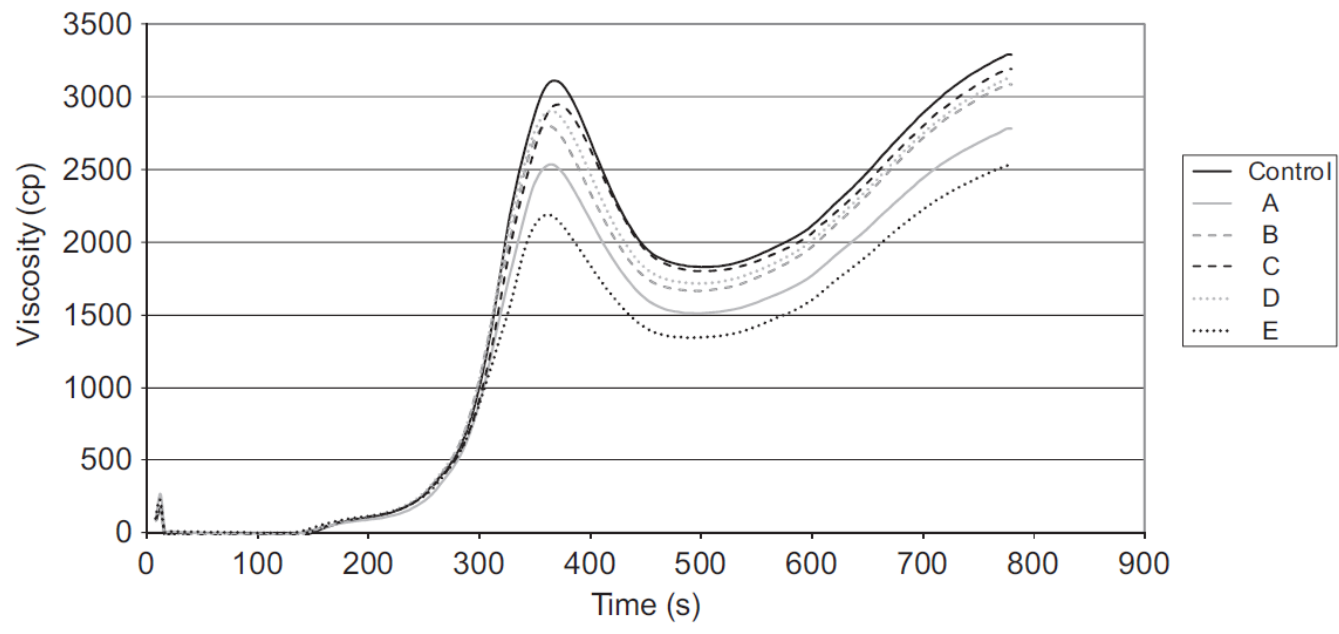

Fig. 1. Pasting properties curves of wheat flour, after the addition of extruded flours, measured using a Rapid Visco Analyzer. Control: wheat flour 14.48\% moisture, 0.58\% ash, $11.78 \%$ protein; Flour A: extruded with $60 \mathrm{C}$ maximum extruder temperature and 4\% water; Flours B, C and D: extruded with 110 C maximum extruder temperature and $4 \%, 10 \%$ and $16 \%$ water respectively. Extruded flours were added at $5 \mathrm{~g} / 100 \mathrm{~g}$ flour.

In the analysis of flour behaviour during mixing (Table 1), dough water absorption capacity was found to increase after the addition of extruded flour, and this increase was greater the more intense the extrusion intensity, reaching an increase compared to thecontrol value up to $7 \%$ in doughs prepared with flour that had undergone the most intense treatment (flour E). This finding is explained by the greater damage to the starch granules and greater starch gelatinization as the extrusion conditions (temperature and 
water content) increase (Mercier and Feillet, 1975). There were no significant differences in dough development time in any case. However, dough stability tended to decrease with increasing extrusion intensity, although significant differences were only observed between the control dough and the doughs prepared with the three flours that had undergone the most intense extrusion treatments. It is known that farinograph stability depends on the characteristics of the protein network, and thus on protein quality (Konopka et al., 2004; Zhu and Khan, 2001). The reduction in stability may therefore be related to the degradation of the gluten matrix occurring during the extrusion process, due to the increase in temperature, as high-temperature treatments will modify the characteristics of the components of the gluten matrix ( $\mathrm{Li}$ and Lee, 1996; Singh and MacRitchie, 2004).

Gaines et al. (2006) stated that alveographic assay was one of the best methods for measuring dough strength, which has been correlated with bread volume (Janssen et al., 1996). The results of the alveographic assay of doughs made with extruded flours are shown in Table 1. Itmay be seen that the addition of extruded flours decreases dough extensibility in all cases, and that there was an increase in dough tenacity, though this was only significant after the most intense extrusion treatments. The two effects offset each other on the area of the alveograph curve, meaning that no significant differences were observed in the overall strength values. The $\mathrm{P} / \mathrm{L}$ ratio or balance did increase when extruded flour was added, although the change was only significant with flours C and D. The variations in the alveogram characteristics were principally related to two factors: gluten matrix degradation and starch modification, both of which are effects of the extrusion treatment. Gluten matrix degradation increases with treatment intensity. This was confirmed by Gómez et al. (2011) when they found significant correlations between the alveogram parameters and the zeleny index, an indicator of protein quality. Starch modification during the extrusion process leads to an increase in dough consistency due to the increase in the quantity of damaged starch and its higher water absorption capacity (Preston et al.,1987), as had already been observed in the DoughLab analysis. In fact, when dough water content was modified on the basis of the DoughLab analysis, unifying dough consistency, a significant effect on dough tenacity was only observed with the dough prepared with flour E, which had the highest extrusion temperature and thus the most extensive modification of the gluten matrix. The decrease in dough extensibility was much lower than that observed with doughs with constant water content, and it was only significant for flours B and D. In this analysis we observed that the decrease in dough strength became more noticeable with increasing intensity of the extrusion treatment, as the decrease in length of the curve (extensibility) was not compensated by the increase in height of the curve (tenacity). The increase in the $\mathrm{P} / \mathrm{L}$ balance therefore also occurs when extruded flours are added, except in the case of flour $\mathrm{E}$ as a result of the decrease in tenacity. Fig. 2 shows the curves obtained by the rheofermentometer. It may be seen that the addition of extruded flours increases gas production (Fig. 2a) during fermentation. This increase is more noticeable when using flours that have undergone a milder 
extrusion treatment, and leads to an increase in dough expansion. The doughs did not fall during the assay, except doughs prepared with flour E, which developed a small break at $2 \mathrm{~h}$ (Fig. 2b). The increase in gas production may be related to the higher proportion of damaged starch, which is more accessible to enzymatic hydrolysis and to the generation of sugars (Potus et al., 1994). 
Table 1. DoughLab and alveographic properties of dough after the addition of extruded flours

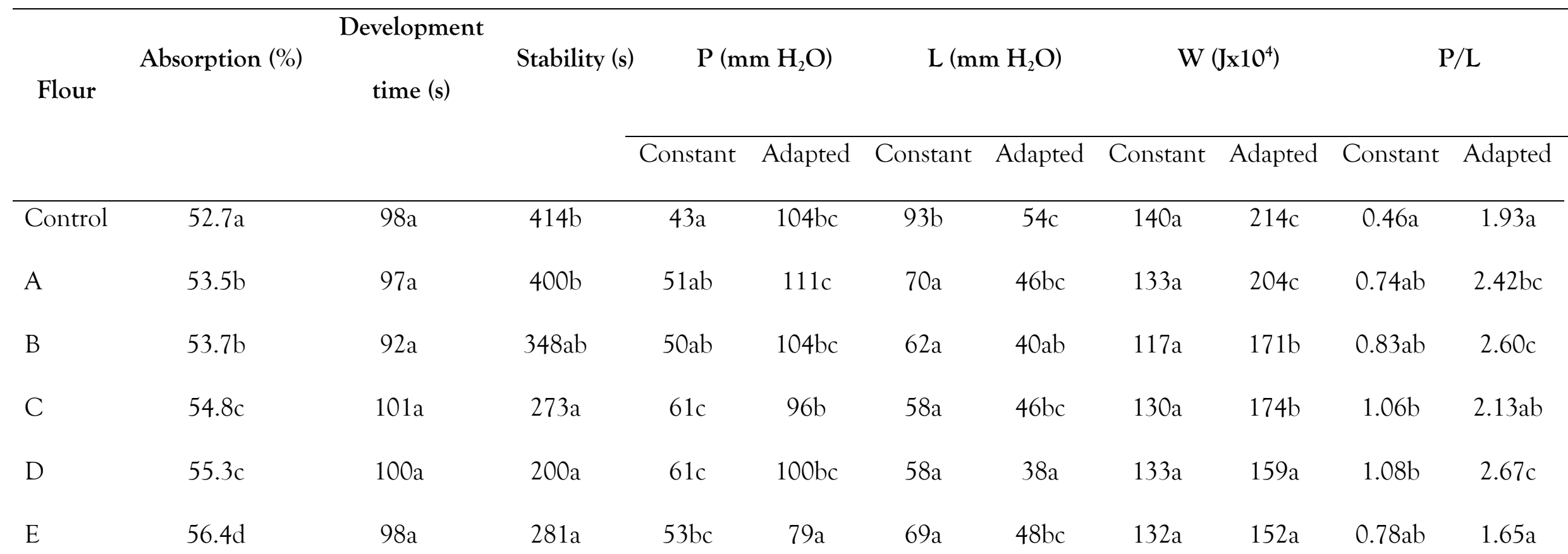

Control: wheat flour $14.48 \%$ moisture, $0.58 \%$ ash, $11.78 \%$ protein; Flour A: extruded with $60^{\circ} \mathrm{C}$ maximum extruder temperature and $4 \%$ water; Flours B, C and D: extruded with $110^{\circ} \mathrm{C}$ maximum extruder temperature and $4 \%, 10 \%$ and $16 \%$ water respectively. Extruded flours were added at $5 \mathrm{~g} / 100 \mathrm{~g}$ flour.

Values are means of two replicates

Different letters in the same parameter indicate significant differences $(\mathrm{P}<0.05)$

P: tenacity or maximum overpressure in the alveograph; L: extensibility or abscissa at rupture in the alveogram; W: strength or deformation energy of dough; P/L: balance or curve configuration ratio. 
It is noticeable that the flours with the most intense treatments reduced gas production compared to those with the mildest treatments, though it should be taken into account that high temperature treatments also reduce enzyme activity and hence decrease starch hydrolysis. The lower resistance to excess fermentation observed in flour E may be related to the effect of the treatment on gluten quality due to protein denaturation, as it is known that gluten proteins affect gas retention (Gan et al., 1995). This finding coincides with what was observed on the alveograph curves. Furthermore, photomicrographs of the doughs (Fig. 3) showed that whilst the control dough (3a) shows a close structure with large starch granules within a compact mass of small starch granules united by a protein matrix, the doughs prepared with flour E (3b) show an open and less compact structure, with a smaller number of starch granules, as the granules lose their structure during the extrusion process.

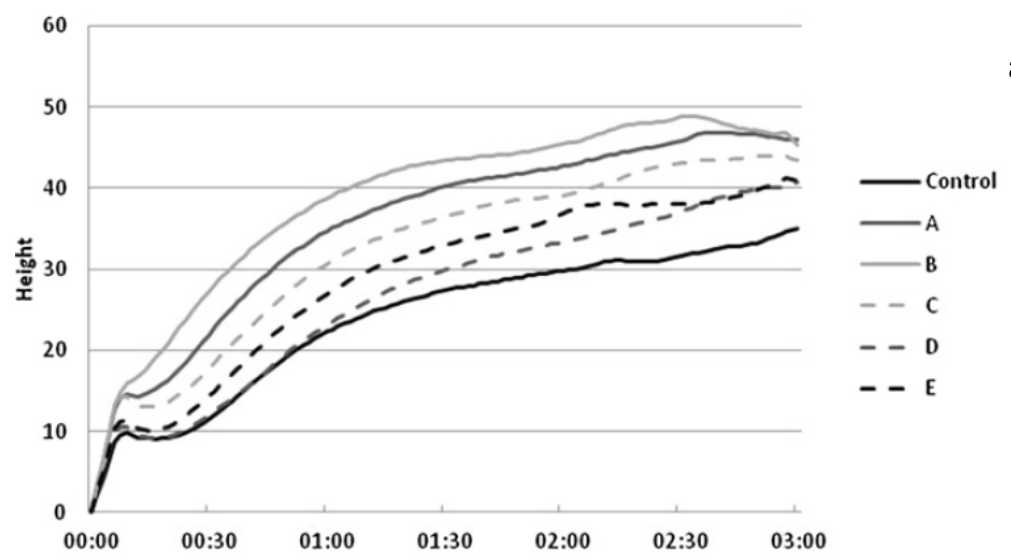

a) Gas production

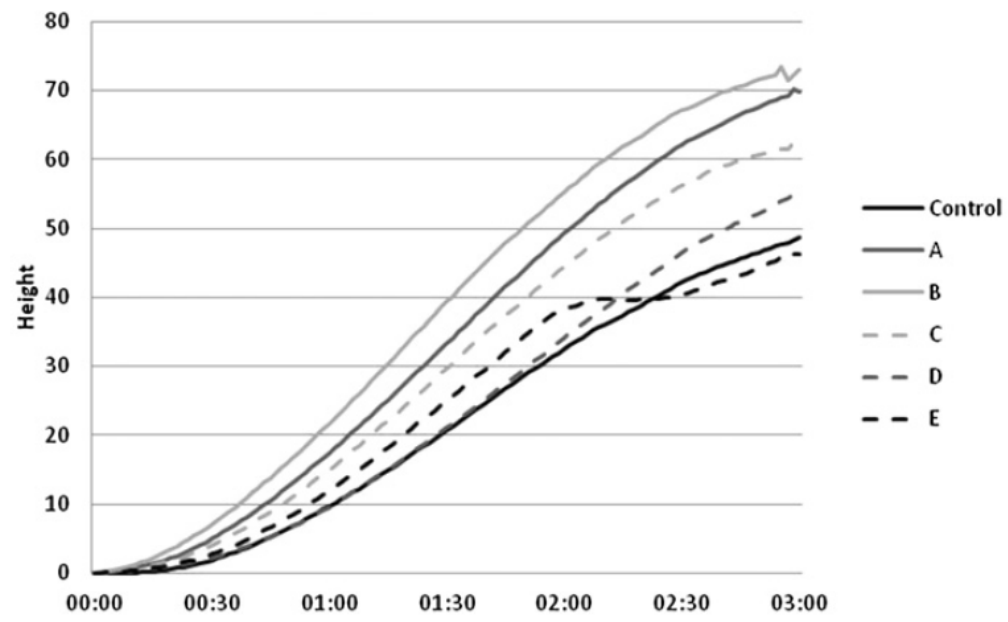

b) Dough development

Fig. 2. Rheofermentograph properties of dough after the addition of extruded flours. a) Gas production, b) Dough development. Control: wheat flour 14.48\% moisture, $0.58 \%$ ash, $11.78 \%$ protein; Flour A: extruded with 60C maximum extruder temperature and 4\% water; Flours B, C and D: extruded with 110C maximum extruder temperature and $4 \%, 10 \%$ and $16 \%$ water respectively. Extruded flours were added at 5 $\mathrm{g} / 100 \mathrm{~g}$ flour. The mean results from two replicates of each type of dough were used to define the graph. 


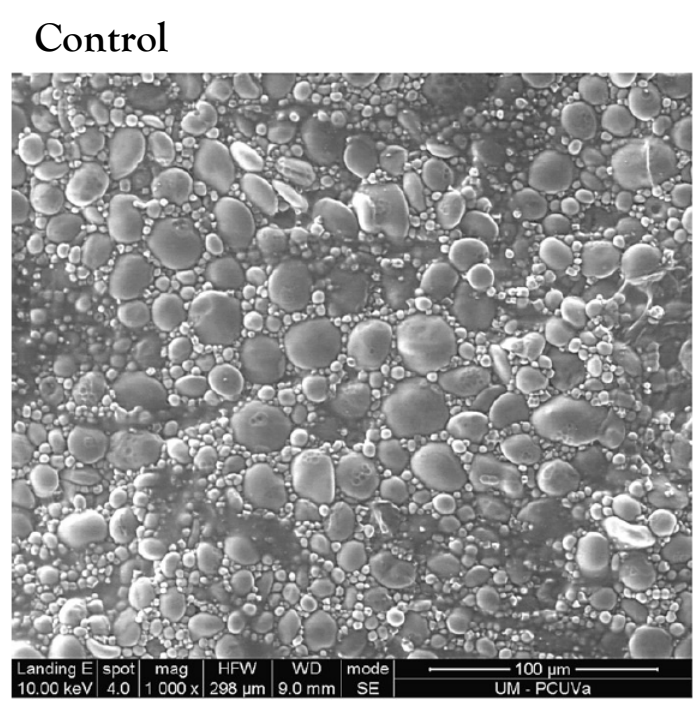

\section{$5 \mathrm{~g} / 100 \mathrm{~g}$ of extruded flour $\mathrm{E}\left(110^{\circ} \mathrm{C}\right.$ maximum extruded temperature and}

$16 \%$ water) dough

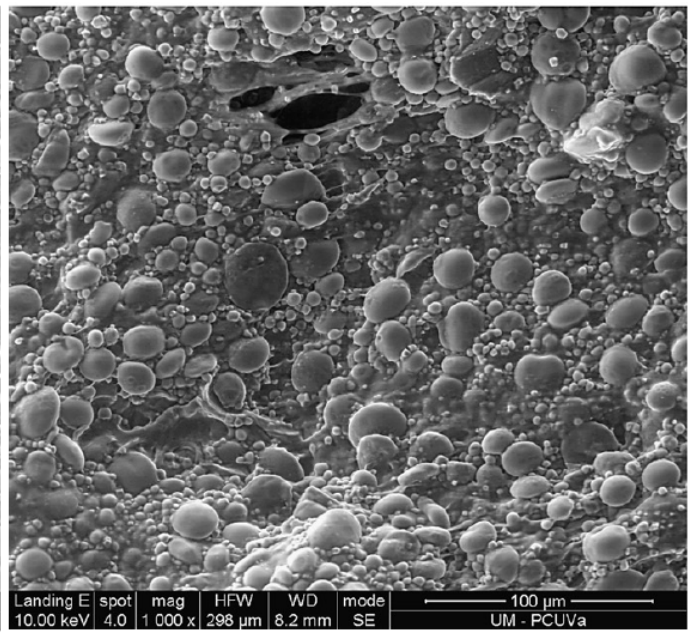

Fig. 3. Photomicrographs of doughs. a) Control, b) $5 \mathrm{~g} / 100 \mathrm{~g}$ of extruded flour E (110 C maximum extruder temperature and $16 \%$ water) dough

\subsection{Bread properties}

With regard to the bread characteristics, the quantity of extruded wheat flour added did not lead to significant differences in volume, specific volume or height/width ratio (Table 2). A lowerweight after baking, indicating greater water loss was only observed in breads made with flour B. The differences observed in dough development during fermentation thus did not lead to noticeable differences in the final product, probably because dough expansion (due to gas expansion and the final phases of gas production by yeasts during baking) led to there being no change in the final volume. This result coincides with the findings reported by Miller et al. (2008) who studied the effect of adding different pregelatinized starch percentages (1e2\%) to the formula. The addition of extruded flours may therefore be an alternative to the addition of pregelatinized starch. Nor were there any significant differences in firmness or chewiness. The absence of any difference in bread firmness has also been demonstrated in studies that correlated this parameter with bread volume (Axford et al., 1968; Gómez et al., 2008). The differences in the other textural parameters were minimal (Table 2). The highest cohesiveness and resilience values were observed in breads with flour $\mathrm{B}$, indicating the best resistance to deformation and instantaneous elasticity. Higher springiness values were observed in breads made with flour E compared to control bread. 
Table 2: Bread properties and texture after the addition of extruded flours

\begin{tabular}{|c|c|c|c|c|c|c|c|c|c|}
\hline Flour & $\begin{array}{l}\text { Volume } \\
(\mathrm{cm} 3)\end{array}$ & $\begin{array}{c}\text { Weight } \\
\text { (g) }\end{array}$ & $\begin{array}{l}\text { Specific } \\
\text { volume } \\
(\mathrm{cm} 3 / \mathrm{g})\end{array}$ & Height/Width & Firmness $(\mathbf{N})$ & Cohesiveness & Springiness & Resilience & Chewiness $(\mathrm{N})$ \\
\hline Control & $386 a$ & $128 b$ & $3.02 \mathrm{a}$ & $0.66 a$ & $15.86 \mathrm{a}$ & $0.47 a$ & $0.83 a$ & $0.19 a$ & $6.25 a$ \\
\hline B & $404 a$ & $122 \mathrm{a}$ & $3.31 \mathrm{a}$ & $0.72 \mathrm{a}$ & $14.51 \mathrm{a}$ & $0.53 b$ & $0.86 \mathrm{ab}$ & $0.28 b$ & $6.75 a$ \\
\hline $\mathrm{C}$ & $390 \mathrm{a}$ & $128 b$ & $3.06 \mathrm{a}$ & $0.77 \mathrm{a}$ & $13.71 \mathrm{a}$ & $0.50 \mathrm{ab}$ & $0.88 \mathrm{ab}$ & $0.23 \mathrm{ab}$ & $6.01 \mathrm{a}$ \\
\hline $\mathrm{D}$ & $397 \mathrm{a}$ & $126 b$ & $3.14 \mathrm{a}$ & $0.67 \mathrm{a}$ & $14.71 \mathrm{a}$ & $0.48 \mathrm{a}$ & $0.86 \mathrm{ab}$ & $0.22 \mathrm{a}$ & $6.13 a$ \\
\hline
\end{tabular}

Control: wheat flour $14.48 \%$ moisture, $0.58 \%$ ash, $11.78 \%$ protein; Flour A: extruded with $60^{\circ} \mathrm{C}$ maximum extruder temperature and $4 \%$ water; Flours B, C and D: extruded with $110^{\circ} \mathrm{C}$ maximum extruder temperature and $4 \%, 10 \%$ and $16 \%$ water respectively. Extruded flours were added at $5 \mathrm{~g} / 100 \mathrm{~g}$ flour.

Values of bread properties are means of four replicates ( 2 breads $\times 2$ elaborations) and values of texture are means of 8 replicates ( 2 slices $\times 2$ breads $\times 2$ elaborations)

Different letters in the same parameter indicate significant differences $(P<0.05)$ 
Finally, bread colour showed no clear trends (Table 3). With regard to crumb colour, only the bread prepared with flour E showed a lower $b^{*}$ value compared to control bread, whereas no significant differences were observed in the other breads or other parameters. In general, crumb colour is related to the flour colour, as the temperatures in the interior of the piece do not reach $100 \mathrm{C}$. In contrast, this temperature is greatly exceeded in the crust and crust colour is therefore the result of a Maillard reaction and sugar caramelization due to the presence of reducing sugars and amino acids. Analysis of crust colour revealed that the crust of bread prepared with flour A was paler than the others, and that of bread prepared with flour $E$ was significantly redder or more yellowish, probably due to the higher quantity of sugars and amino acids produced by the intense thermal treatment. Breads made with flours B and C also showed significantly higher $\mathrm{b}^{*}$ values than the control bread.

Table 3: Crust and crumb colour characteristics of bread after the addition of extruded flours

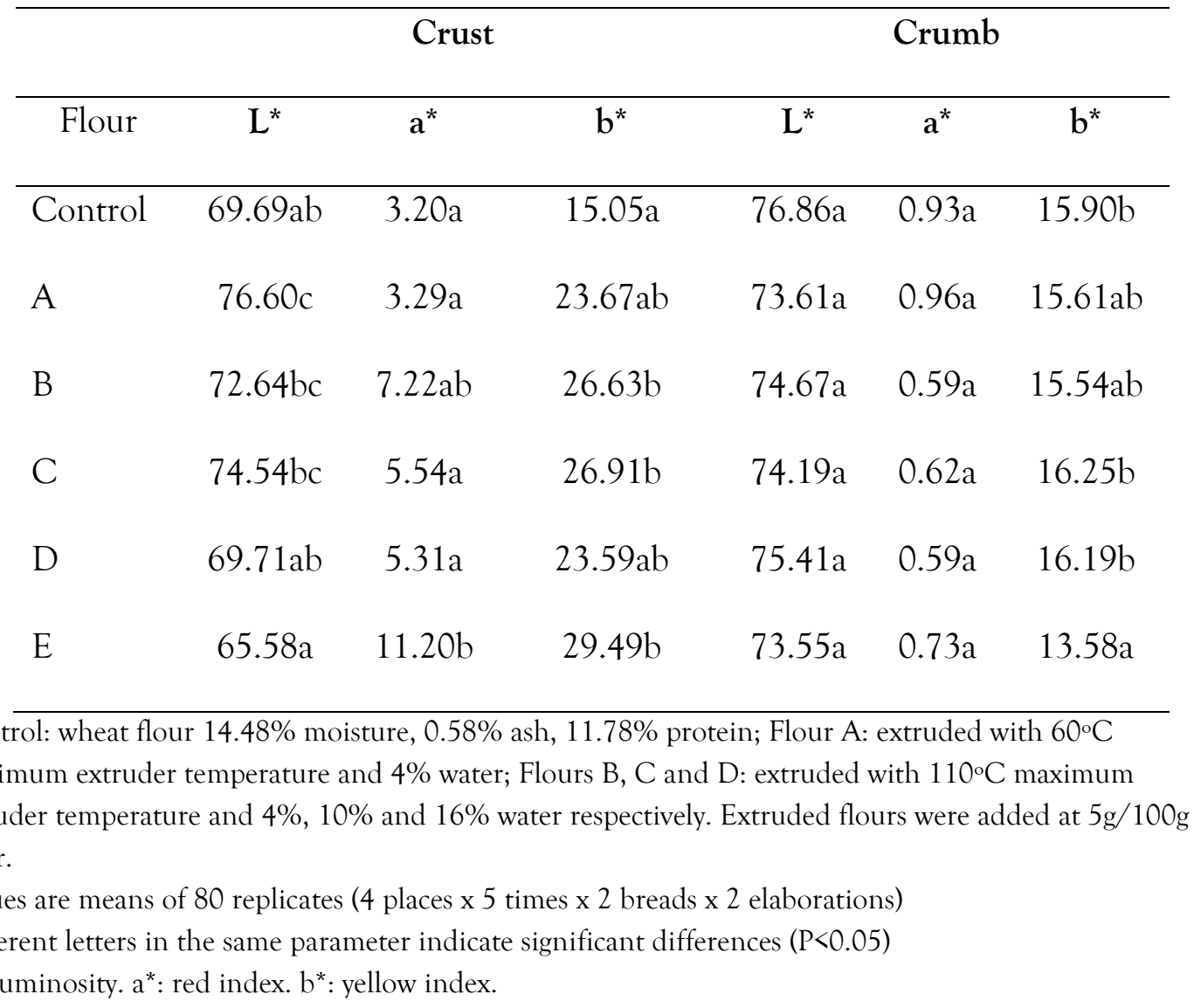

\section{Conclusion}

The results obtained demonstrate that the addition of $5 \%$ extruded wheat flour allows the quantity of water in the formulation to be increased; the more intense the extrusion treatment, the greater the increase in the quantity of water that can be added. This will 
increase bread output. The doughs obtained show adequate behaviour during mixing, handling and fermentation, with no detriment to bread quality. In the future it would be advisable to establish the limits of bread output with the addition of increasing quantities of extruded flour and to determine if this effect is present in other kinds of bakery products.

\section{$\underline{\text { Acknowledgements }}$}

This study was supported financially by Junta de Castilla y León (VA054A12-2), Spain. he authors are also grateful to Harinera Los Pisones for supplying the raw materials. 


\section{$\underline{\text { References }}$}

AACC, 2000. Approved Methods of the American Association of Cereal Chemists, Methods 44-15A (Moisture), 08-01(Ash), 46-08 (Protein), 54-30(Alveographic Analysis), 61e02.01 (Rapid Visco Analysis), tenth ed. American Association of Cereal Chemists, St. Paul, MN.

Axford, D.W.E., Colwell, K.H., Cornford, S.J., Elton, G.A.H., 1968. Effect of loaf specific volume on rate and extent of staling in bread. Journal of the Science of Food and Agriculture 19, 95e101.

Camire, M.E., Camire,A., Krumhar, K.,1990. Chemical and nutritional changes in foods during extrusion. Critical Reviews in Food Science and Nutrition 29, 35e57.

Chiu, C., Solarek, D., 2009. Modification of starch. In: BeMiller, J., Whistler, R. (Eds.), Starch. Chemistry and Technology. Academic Press, New York, pp. 629e656.

Curic, D., Novotni, D., Bauman, I., Kricka, T., Dugum, J., 2009. Optimization of extrusion cooking of cornmeal as raw material for bakery products. Journal of Food Process Engineering 32, 294e317.

Czuchajowska, Z., Pomeranz, Y., 1993. Gas formation and gas retention. I. The system and methodology. Cereal Foods World 38, 499e503.

Dexter, J.E., Preston, K.R., Martin, D.G., Gander, E.J., 1994. The effects of proteincontent and starch damage on the physical dough properties and breadmaking quality of Canadian durum-wheat. Journal of Cereal Science 20, 139e 151.

Doublier, J., Colonna, P., Mercier, C., 1986. Extrusion cooking and drum drying of wheat-starch. 2. Rheological characterization of starch pastes. Cereal Chemistry 63, $40 \mathrm{e} 246$.

Gaines, C.S., Reid, J.F., Vander Kant, C., Morris, C.F., 2006. Comparison of methods for gluten strength assessment. Cereal Chemistry 83, $284 \mathrm{e} 286$.

Gan, Z., Ellis, P.R., Schofield, J.D., 1995. Gas cell stabilization and gas retention in wheat bread dough. Journal of Cereal Science 21, $215 \mathrm{e} 230$.

Gill, S., Vasanthan, T., Ooraikul, B., Rossnagel, B., 2002. Wheat bread quality as influenced by the substitution of waxy and regular barley flours in their native and extruded forms. Journal of Cereal Science 36, $219 \mathrm{e} 237$.

Gómez, M., Oliete, B., Pando, V., Ronda, F., Caballero, P.A., 2008. Effect of fermentation conditions on bread staling kinetics. European Food Research and Technology 226, 1379e1387. 
Gómez, M., Ronda, F., Caballero, P.A., Blanco, C.A., Rosell, C.M., 2007. Functionality of different hydrocolloids on the quality and shelf-life of yellow layer cakes. Food Hydrocolloids 21, 167e173.

Gómez, M., Ruiz-Paris, E., Oliete, B., 2011. Influence of wheat milling on low hydration bread quality developed by sheeting rolls. Food Science and Technology International 17, $257 \mathrm{e} 265$.

Hagenimana, A., Ding, X., Fang, T., 2006. Evaluation of rice flour modified by extrusion cooking. Journal of Cereal Science 43, 38e46.

Janssen, A.M., vanVliet, T., Vereijken, J.M., 1996. Fundamental and empirical rheological behaviour of wheat flour doughs and comparison with bread making performance. Journal of Cereal Science 23, 43e54.

Konopka, I., Fornal, L., Abramczyk, D., Rothkaehl, J., Rotkiewicz, D., 2004. Statistical evaluation of different technological and rheological tests of Polish wheat varieties for bread volume prediction. International Journal of Food Science and Technology 39, $11 \mathrm{e} 20$.

Li, M., Lee, T., 1996. Effect of extrusion temperature on solubility and molecular weight distribution of wheat flour proteins. Journal of Agricultural and Food Chemistry 44, $763 \mathrm{e} 768$.

Mercier, C., Feillet, P., 1975. Modification of carbohydrate components by extrusion cooking of cereal products. Cereal Chemistry 63, $283 \mathrm{e} 297$.

Miller, R.A., Maningat, C.C., Hoseney, R.C., 2008. Modified wheat starches increase bread yield. Cereal Chemistry 85, 713e715.

Miyazaki, M., Morita, N., 2005. Effect of heat-moisture treated maize starch on the properties of dough and bread. Food Research International 38, 369e376.

Potus, J., Poiffait, A., Drapron, R., 1994. Influence of dough-making conditions on the concentration of individual sugars and their utilization during fermentation. Cereal Chemistry 71, 505e508.

Preston, K.R., Kilborn, R.H., Dexter, J.E., 1987. Effects of starch damage and waterabsorption on the alveograph properties of Canadian hard red spring wheats. Canadian Institute of Food Science and Technology Journal 20, 75e80.

Puhr, D.P., D’Appolonia, B.L., 1992. Effect of baking absorption on bread yield, crumb moisture, and crumb water activity. Cereal Chemistry 69, 582e586.

Rosell, C.M., Rojas, J.A., de Barber, C.B., 2001. Influence of hydrocolloids on dough rheology and bread quality. Food Hydrocolloids 15, 75e81. 
Sanchez, H.D., Gonzalez, R.J., Osella, C.A., Torres, R.L., de la Torre, M.A.G., 2008. Elaboration of bread without gluten from extruded rice flours. Ciencia y Tecnología Alimentaria 6, 109e116.

Singh, H., MacRitchie, F., 2004. Changes in proteins induced by heating gluten dispersions at high temperature. Journal of Cereal Science 39, $297 \mathrm{e} 301$.

Sloan, E., 2011. Food expo highlights clean labels \& functional foods. Food Technology $65,48 \mathrm{e} 51$.

Wolf, B., 2010. Polysaccharide functionality through extrusion processing. Current Opinion in Colloid \& Interface Science 15, $50 \mathrm{e} 54$.

Zhu, J., Khan, K., 2001. Effects of genotype and environment on glutenin polymers and breadmaking quality. Cereal Chemistry 78, 125e130. 


\subsection{Influence of the addition of extruded flours on rice bread quality}

\section{Journal of Food Quality}

Journal of Food Quality ISSN 1745-4557

\section{INFLUENCE OF THE ADDITION OF EXTRUDED FLOURS ON RICE BREAD QUALITY}

MARIO M. MARTÍNEZ, BONASTRE OLIETE, LAURA ROMÁN and MANUEL GÓMEZ'

Food Technology Area, E.T.S. Ingenierías Agrarias, Valladolid University, Avd. Madrid 44, Palencia 34071, Spain

\section{$\underline{1 . \text { Introduction }}$}

Gluten-free breads are characterized by their deficient quality and high price compared with traditional breads. This has led to increased interest in developing high quality gluten-free products in recent years (Cureton \& Fasano, 2009), with the consequent increase in the volume of research and the number of scientific publications on this subject.

Most research studies into the development of gluten-free products have focussed on the substitution of wheat flours by mixtures of gluten-free cereals, starches, proteins and hydrocolloids (Schober, 2009), and on the enzymatic improvement of these formulations (Rosell, 2009). However, less information is available on the use of physical treatments to modify the functional properties of flours used in gluten-free products, and these methods have been less widely employed. Hydrothermal treatments stand out as being among the most effective physical treatments.

If starch, the major component of flour, is subjected to a high-temperature treatment with enough moisture it can be gelatinized, increasing the swelling capacity of the granule, decreasing crystallinity and sometimes causing break-up of the granules (Atwell et al., 1988). Hoover \& Vasanthan (1994) also demonstrated that starch undergoing thermal treatment at $100^{\circ} \mathrm{C}$ presents a high gelatinization temperature and high resistance to acid hydrolysis due to realignment of the starch chains, although these changes varied depending on the kind of starch used.

Pregelatinized rice flour has been widely used as the principal ingredient in many kinds of foods (rice cakes, infant foods, instant rice pudding) due to its thickener properties. It is known that uses of pregelatinized rice flour are determined by its physicochemical and functional properties, which differ depending on the variety of rice and the processing method employed (Hsieh \& Luh, 1991; Lu, et al., 1994). These hydrothermal treatments may be performed in various ways, such as drying a paste by atomization or heated drums; 
but one of the most versatile alternatives is extrusion. Extrusion is a treatment which applies heat and mechanical strain to a flour-water mixture. The main interest of the extrusion of flours and starches is to modify their functional properties, which will vary according to the extrusion conditions applied (Curic, et al., 2009).

When flours are extruded, changes take place in starch which modify the rheological behaviour of dough, similar to the changes that occur when dough is subjected to coolingheating cycles (Hagenimana et al., 2006). However, extrusion causes more intense changes to the starch than traditional cooking methods, as it damages a larger number of starch granules and modifies the cold thickening capacity (Wolf, 2010). This treatment may even rupture amylopectin molecules (Mercier \& Feillet, 1975). Colonna et al. (1984) demonstrated that extruded wheat starches contain amylose and amylopectin chains with a lower molecular weight than those obtained by treatment in heated drums. This effect, due to the shear force applied to the starch, is translated into an increase in the solubility and a decrease in the cold thickening capacity (Doublier, et al., 1986).

These functional modifications of flour after extrusion could also lead to changes in the baking properties. However, this has not been extensively researched in gluten-free breads.

Defloor et al. (1991) found that a mixture of extruded starches and emulsifying agents improved the quality of breads prepared with a mixture of tapioca and soya and a high level of hydration (145\%).

Sanchez, et al. (2008) observed that the addition of extruded rice flour improved bread volume and crumb structure, but this effect was more noticeable when the waxy varieties of rice were used. However those authors used high percentages of extruded flour $(15 \%$ and 30\%) and modified the quantity of water in the formula according to the penetrometer dough consistency values; those variations led to an increase in dough hydration by more than $30 \%$ in the majority of cases. It is also important to note that those authors used over $80 \%$ starch in the formula.

The effect of the substitution of $10 \%$ of the rice flour by extruded non-acidified and acidified rice flour has also been tested (Clerici \& El-Dash, 2006) (Clerici, et al., 2009). However, those authors did not use hydrocolloids in their bread-making process and the specific volume of their breads was excessively low in all cases.

In summary, some studies do exist on the use of extruded flours in gluten-free breads, but research needs to be extended to include formulae with the addition of hydrocolloids, with hydration percentages below $90 \%$, and with rice flour as the main ingredient.

The particle size of the rice flour is also known to have an effect on gluten-free breadmaking (Araki, et al., 2009; Nishita \& Bean, 1982; Ylimaki, et al., 1988), but there have 
been no studies to determine the effect of the particle size of extruded rice flour on the functional characteristics of gluten-free breads.

In this study of constant consistency gluten-free bread making we have determined the effect of substituting $10 \%$ of non-extruded rice flour by extruded rice flour produced using three different extrusion intensities and with two different particle sizes. We analysed the viscous behaviour of flours in a heating-cooling cycle, dough rheology, dough development and gas production during fermentation, the differences in the microstructure of the flours and doughs, and the texture properties and specific volume of the breads.

\section{Materials and methods}

\subsection{Materials}

The rice flour used in this study was provided by Harinera Los Pisones (Zamora, Spain). Rice flour was extruded using an industrial Buhler Basf single-screw extruder (Buhler S.A., Uzwil, Switzerland). Three kinds of flour were used. Flour 1 was extruded with the addition of $2 \%$ moisture with a maximum temperature at the end of the extruder of $110^{\circ} \mathrm{C}$. Flour 2 was extruded with the addition of $15 \%$ moisture and a maximum temperature of $110^{\circ} \mathrm{C}$. For flour 3, $10 \%$ moisture was added and the maximum temperature in the extruder was $140^{\circ} \mathrm{C}$. The resulting products were ground by compression rollers and sieved to obtain flours with two different particle sizes, fine and coarse. Fine flours (f) were obtained by sieving through a 132 micron screen, and coarse flours (c) were retained between a 132 micron sieve and a 200 micron sieve. Depending on the thermal treatment and the particle size, extruded rice flours were referred to by a number $(1,2,3)$ and a letter $(f, c)$. Non-extruded rice flour was use as the control. Due to the fact that the chemical composition of coarse and fine flour could be changed by shieving the flour into fractions, chemical composition is attached (table 1).

Saf-Instant yeast (Lesaffre, Lille, France), dry refined salt (Esco European Salt Company, Niedersachsen, Germany), local tap water, white sugar (Acor, Valladolid, Spain), refined sunflower oil (Coosur, Vilches, Spain) and hydroxypropylmethylcellulose (HPMC) Methocel K4M Food grade (Dow Wolf Celullosics, Bitterfeld, Germany) were also used in the bread-making.

\subsection{Methods}

\subsubsection{Flour characterisation}

The viscous behaviour of flours during the heating-cooling cycle was measured with the Rapid Visco Analizer (RVA) (Newport Scientific, Warriewood, Australia), following AACC method 61.02.01 (AACC, 2012). The microstructure of the flours was analysed with an environmental scanning electron microscope (ESEM) (FEI, Quanta 200FEG, 
Oregon, USA) with integrated x-ray microanalysis using an EDAX Genesis XM2i, which enables wet samples to be analysed at ambient pressure without superficial metallization.

Table 1: Chemical composition of different types of flour of non-extruded flour with $10 \%$ substituted extruded flour.

\begin{tabular}{cccc}
\hline Flours & Damage Starch (\%) & Protein (\%) & Moisture (\%) \\
\hline Flour 3f & $29,81 \pm 2.50$ & $7,85 \pm 1.24$ & $9,56 \pm 0.40$ \\
Flour 3c & $36,57 \pm 0.28$ & $8,42 \pm 1.50$ & $10,23 \pm 0.65$ \\
Flour 2f & $19,78 \pm 2.60$ & $8,25 \pm 1.30$ & $13,96 \pm 2.10$ \\
Flour 2c & $30,29 \pm 4.22$ & $8,11 \pm 1.11$ & $14,04 \pm 1.74$ \\
Flour 1f & $11,09 \pm 2.91$ & $8,74 \pm 0.98$ & $10,72 \pm 3.65$ \\
Flour 1c & $10,88 \pm 1.64$ & $8,04 \pm 1.01$ & $11,2 \pm 2.64$ \\
Control & $5,75 \pm 0.97$ & $7,81 \pm 0.99$ & $13,45 \pm 3.05$ \\
\hline
\end{tabular}

\subsubsection{Dough rheology, gas production and dough microstructure.}

The rheological behaviour of dough at constant moisture was studied using a Thermo Scientific Haake RheoStress 1 controlled strain rheometer (Thermo Fisher Scientific, Schwerte, Germany) and a Phoenix II P1-C25P water bath which controlled the analysis temperature (set at $\left.25^{\circ} \mathrm{C}\right)$. The rheometer was equipped with parallel-plate geometry $(60$ $\mathrm{mm}$ diameter titanium serrated plate-PP60 Ti) with $3 \mathrm{~mm}$ gap. After adjustment of the 3 $\mathrm{mm}$ gap, the excess batter was removed and vaseline oil (Panreac, Panreac Química SA, Castellar del Vallés, Spain) was applied to cover the exposed sample surfaces. Dough was rested for 300 seconds before measuring. Samples were analysed in duplicate and without yeast. First, a strain sweep test was performed at $25^{\circ} \mathrm{C}$ with a strain range of $0.1-100 \mathrm{~Pa}$ and a constant frequency of $1 \mathrm{~Hz}$ to identify the linear viscoelastic region. On the basis of the results obtained, a strain value included into the linear viscoelastic region was used in a frequency sweep test at $25^{\circ} \mathrm{C}$ with a frequency range of $100-0.1 \mathrm{~Hz}$. Values of the complex modulus $\left(\mathrm{G}^{*}[\mathrm{~Pa}]\right)$, elastic modulus $\left(\mathrm{G}^{\prime}[\mathrm{Pa}]\right)$, viscous modulus $\left(\mathrm{G}^{\prime}[\mathrm{Pa}]\right)$ and tangent $\delta\left(G^{\prime} / G^{\prime}\right)$ were obtained for different frequency values $(\omega[\mathrm{Hz}])$ (Dobraszczyk \& Morgenstern, 2003).

A rheofermentometer (Chopin, Tripette and Renaud, France) was used to analyse dough height, gas production and gas liberation related to the fermentation time following the method described by Czuchajowska \& Pomeranz, (1993). However, the authors adapted 
the method for gluten-free dough. Only $200 \mathrm{~g}$ of dough were placed into the rheofermentometer container, the $2 \mathrm{~kg}$ weight indicated by the method was removed, $3 \%$ yeast was added to the formula, and fermentation in the rheofermentometer was performed at $30^{\circ} \mathrm{C}$.

Dough microstructure was studied with an ESEM microscope (FEI, Quanta 200FEG, Oregon, USA). The doughs did not contain yeast to avoid alterations in image visualization.

\subsubsection{Bread making}

The following ingredients ( $\mathrm{g} / 100 \mathrm{~g}$ flour) were used in the bread making: Saf-Instant yeast $(3 \mathrm{~g} / 100 \mathrm{~g})$, salt $(1.8 \mathrm{~g} / 100 \mathrm{~g})$, refined sunflower oil $(6 \mathrm{~g} / 100 \mathrm{~g})$, HPMC $(2 \mathrm{~g} / 100 \mathrm{~g})$ and white sugar $(5 \mathrm{~g} / 100 \mathrm{~g})$. The quantity of water in the doughs made with extruded flour was regulated in each sample to obtain a $G^{*}$ value equal to the $G^{*}$ value of the control dough.

The water temperature in all the tests was between $20^{\circ} \mathrm{C}$ and $22^{\circ} \mathrm{C}$. Rice flour was substituted by extruded rice flour at a rate of $10 \mathrm{~g} / 100 \mathrm{~g}$. Control breads containing no extruded rice flour were also prepared. After mixing all the ingredients for 8 minutes in a Kitchen Aid 5KPM50 mixer (Kitchen Aid, Michigan, USA), $250 \mathrm{~g}$ of the bread dough were placed in model 151090 aluminium pans measuring $108 \mathrm{~mm}$ by $232 \mathrm{~mm}$ (ALU. Schale, Wiklarn, Germany). Fermentation was performed at $30^{\circ} \mathrm{C}$ and $75 \% \mathrm{RH}$ for 90 minutes in an FC-K proofer (Salva, Lezo, Spain). After fermentation, doughs were baked in an electric modular oven (Salva, Lezo, Spain) for 40 minutes at $190^{\circ} \mathrm{C}$. The loaves were removed from the moulds after a 60 -minute cooling period and were weighted. The measurements on the breads were performed 24 hours after baking, except for the texture parameters which were measured at 1, 24 and 72 hours after baking. The loaves were introduced into polyethylene plastic bags and stored at $20^{\circ} \mathrm{C}$ until analysis. All the elaborations were performed twice.

\subsubsection{Bread characteristics}

Bread volume was determined using a laser sensor with the BVM-L 370 volume analyser (Perten Instruments, Hägersten, Sweden). The volume measurements were performed in duplicate on two loaves from each elaboration. The specific volume was calculated as the ratio of bread volume to its mass.

Crumb texture was measured with a TA-XT2 texture analyzer (Stable Microsystems, Surrey, UK) fitted with the "Texture Expert" software. A 25-mm diameter cylindrical aluminium probe was used in a "Texture Profile Analysis" (TPA) double compression test to penetrate to $50 \%$ of the sample depth at test speed of $2 \mathrm{~mm} / \mathrm{s}$ and with a 30 second delay between first and second compressions. Hardness $(\mathrm{N})$, cohesiveness and springiness were calculated from the TPA graph (Gómez et al., 2007). Texture analyses were performed on $30 \mathrm{~mm}$ thick slices at 1, 24 and 72 hours after baking. Analyses were 
performed on two slices from two loaves $(2 \times 2)$ from each type of elaboration, taking the average of the 4 measurements made.

\subsubsection{Statistical analysis}

All data were presented as mean values and analysed using an analysis of unidirectional parametric variance (ANOVA) using Fisher's least significant difference (LSD) $(p<0.05)$. The analyses were performed using the Statgraphics Centurion XVI statistical package (StatPoint Technologies Inc, Warrenton, USA). Additionally, in order to plot the hardness values over time, an analysis of variance was also performed taking into account time as a factor for repeated measures using Fisher's least significant difference $(p<0.05)$. The Statistica 6 software (Statsoft Inc, Tulsa, USA) was used for this analysis.

\section{$\underline{\text { 3. Results and Discussion }}$}

\subsection{Electron microscopy of flours}

Figure 1 shows the microstructure of the flours used in this study. It may be observed that the particles of non-extruded rice flour (a) was formed by compound starch granules connected by a compact protein structure. In contrast, in the extruded rice flour with the most intense treatment (d), the starch granules lose their integrity and a paste is formed in which the different components cannot be distinguished in the resultant particles. In the extruded flours with low-intensity hydrothermal treatment, intermediate structures are observed. Whilst swollen starch granules, which represent a phase prior to gelatinization, are observed in flour 1 (b), fusion of the different components is observed in flour 2 (c). 

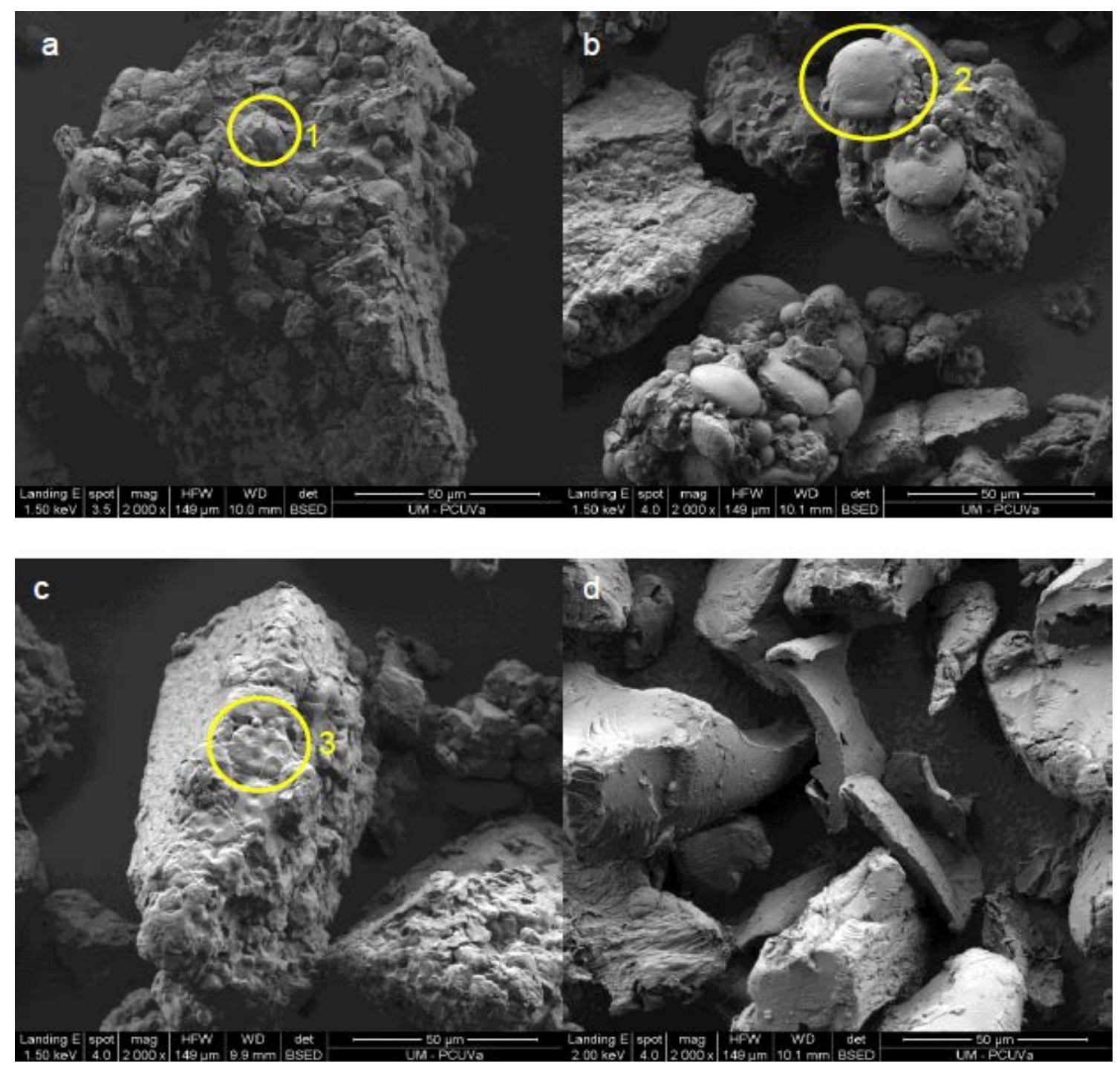

FIG. 1. Photomicrographs from the environmental scanning electron microscope $($ esem $)(\times 2000)$ study of the control flour and flours extruded with different intensities of treatment. Analysis made in triplicate with subsequent selection of the most representative photomicrographs (a) control flour (nonextruded), (b) extruded flour 1f, (c) extruded flour 2f, (d) extruded flour 3f. (1) compound starch granule, (2) swollen starch granule, (3) gelatinized starch granules.

Our observations coincide with those reported by Yeh et al. (1999) and by Chao-Chi Chuang \& Yeh (2003), who studied the morphological changes of rice starch during heating extrusion. Yeh et al. (1999) showed that non-extruded rice flour had a powderlike appearance and that starch granules swelled as they advanced through the cold zone of the extruder but without losing the powder-like appearance. When the rice flour reached the heating zone of the extruder, the starch granules started to melt and formed a continuous matrix. However, those authors obtained their samples from intermediate zones of the extruder and without milling. Our samples were obtained at the end of the extrusion treatment after drying, milling and sieving. Chao-Chi Chuang \& Yeh (2003) 
showed that starch gelatinization increased with increases in the temperature and duration of treatment.

\subsection{Viscous behaviour of flours during a heating-cooling cycle.}

The RVA parameters for non-extruded rice flour and for $10 \%$ substituted extruded flours are shown in Table 2. It can be seen that the more intense the extrusion treatment, the lower the values of pasting viscosity (PV), breakdown (BR), trough (TR), setback (ST) and final viscosity (FV). No significant differences were observed in relation to particle size. Dough viscosity decreased throughout the heating-cooling cycle as the treatment intensity increased. However, no significant differences were observed between the milder treatments (1 and 2). It is known that changes in the physicochemical properties of starch during extrusion develop as a result of morphological changes of the starch granules and the degree of gelatinization (Camire et al., 1990; Yeh \& Li, 1996). It is also known that dough viscosity depends mainly on the degree of gelatinization of the starch granules and the degree of rupture of the molecular chains (El-Dash et al., 1983). Previous studies related high PV values to a high quantity of non-gelatinized starch, whereas low PV values indicated a proportion of gelatinized starch which is attributable to the variation in the degree of depolymerization and the molecular tangle resulting from the processing conditions (Barres et al., 1990; McPherson et al., 2000). The decrease in PV, BR and TR observed when the intensity of treatment increased, previously observed by Hagenimana et al. (2006), could indicate degradation and gelatinization of the starch. High values of these parameters in the non-extruded rice flour would be related to the presence of nongelatinized starch. These modifications in the starches and in the flour particles have been studied on the photomicrographs, and the flours undergoing the most intense treatment (flours 3) contained the highest quantity of gelatinized starch. 
Table 2: Viscous behaviour in a heating-cooling cycle of non-extruded flour with $10 \%$ substituted extruded flour.

\begin{tabular}{cccccc}
\hline Flours & PV $(\mathrm{cp})$ & BR $(\mathrm{cp})$ & TR $(\mathrm{cp})$ & ST $(\mathrm{cp})$ & FV $(\mathrm{cp})$ \\
\hline Flour 3f & $3793 \mathrm{a} \pm 94$ & $1296 \mathrm{a} \pm 2$ & $2496 \mathrm{a} \pm 93$ & $2510 \mathrm{~b} \pm 6$ & $5006 \mathrm{a} \pm 98$ \\
Flour 3c & $3913 \mathrm{a} \pm 46$ & $1224 \mathrm{a} \pm 182$ & $2688 \mathrm{ab} \pm 135$ & $2306 \mathrm{a} \pm 106$ & $4994 \mathrm{a} \pm 29$ \\
Flour 2f & $4596 \mathrm{~b} \pm 64$ & $1759 \mathrm{bc} \pm 19$ & $2837 \mathrm{~b} \pm 84$ & $2773 \mathrm{~cd} \pm 17$ & $5610 \mathrm{~b} \pm 67$ \\
Flour 2c & $4571 \mathrm{~b} \pm 16$ & $1690 \mathrm{bc} \pm 160$ & $2881 \mathrm{~b} \pm 176$ & $2656 \mathrm{bc} \pm 121$ & $5537 \mathrm{~b} \pm 56$ \\
Flour 1f & $4444 \mathrm{~b} \pm 77$ & $1663 \mathrm{~b} \pm 35$ & $2781 \mathrm{ab} \pm 42$ & $2777 \mathrm{~cd} \pm 26$ & $5558 \mathrm{~b} \pm 16$ \\
Flour 1c & $4682 \mathrm{~b} \pm 244$ & $1706 \mathrm{bc} \pm 11$ & $2975 b c \pm 234$ & $2706 \mathrm{c} \pm 6$ & $5681 \mathrm{~b} \pm 228$ \\
Control & $5175 \mathrm{c} \pm 142$ & $1947 \mathrm{c} \pm 192$ & $3228 \mathrm{c} \pm 49$ & $2925 \mathrm{~d} \pm 62$ & $6153 \mathrm{c} \pm 12$ \\
\hline
\end{tabular}

The fall in FV and ST values in the extruded flours has already been observed by Doublier et al. (1986) and by Mercier \& Feillet (1975). These values indicate the degree of retrogradation that occurrs after heating. When the hot gels are cooled, the increase of viscosity depends on the tendency of starch to reassociate. The extruded rice flours that had undergone the milder treatments showed higher FV values than the same flours extruded with more intense treatments.

Although it seems that starch gelatinization is the main factor responsible for changes in the RVA curve, other authors have also observed modifications in the amylose/amylopectin ratio during the extrusion treatments of corn flour (Chinnaswamy \& Hannah, 1990) and wheat flour (Colonna et al., 1984). Those authors state that fragmentation of amylose and amylopectin chains takes place during extrusion, and that this is more intense in the amylopectin chains; this will therefore modify the behaviour of the flours during the heating-cooling cycle.

\subsection{Dough rheology and gas production}

\subsubsection{Dynamic rheology of dough.}

Figures 2 and 3 show the rheological properties of gluten-free doughs at constant moisture. There was a clear tendency to an increase in $G^{\prime}, G^{\prime \prime}$ and $G^{*}$, and a decrease in $\operatorname{tag} \delta$ when extruded rice flours were added to the formula. The most marked effect was 
observed after the addition of flours 2 and 3; flour 2 was associated with the highest G' and $G^{*}$ values and the lowest tag $\delta$ values. Particle size, on the other hand, produced no clear differences. Thus, when increasing the intensity of the extrusion process, doughs became more consistent and elastic, and this effect was most noticeable with flour 2. G' values were higher than G" values in all cases and over the whole frequency range, which indicated behaviour to be more elastic than viscous.
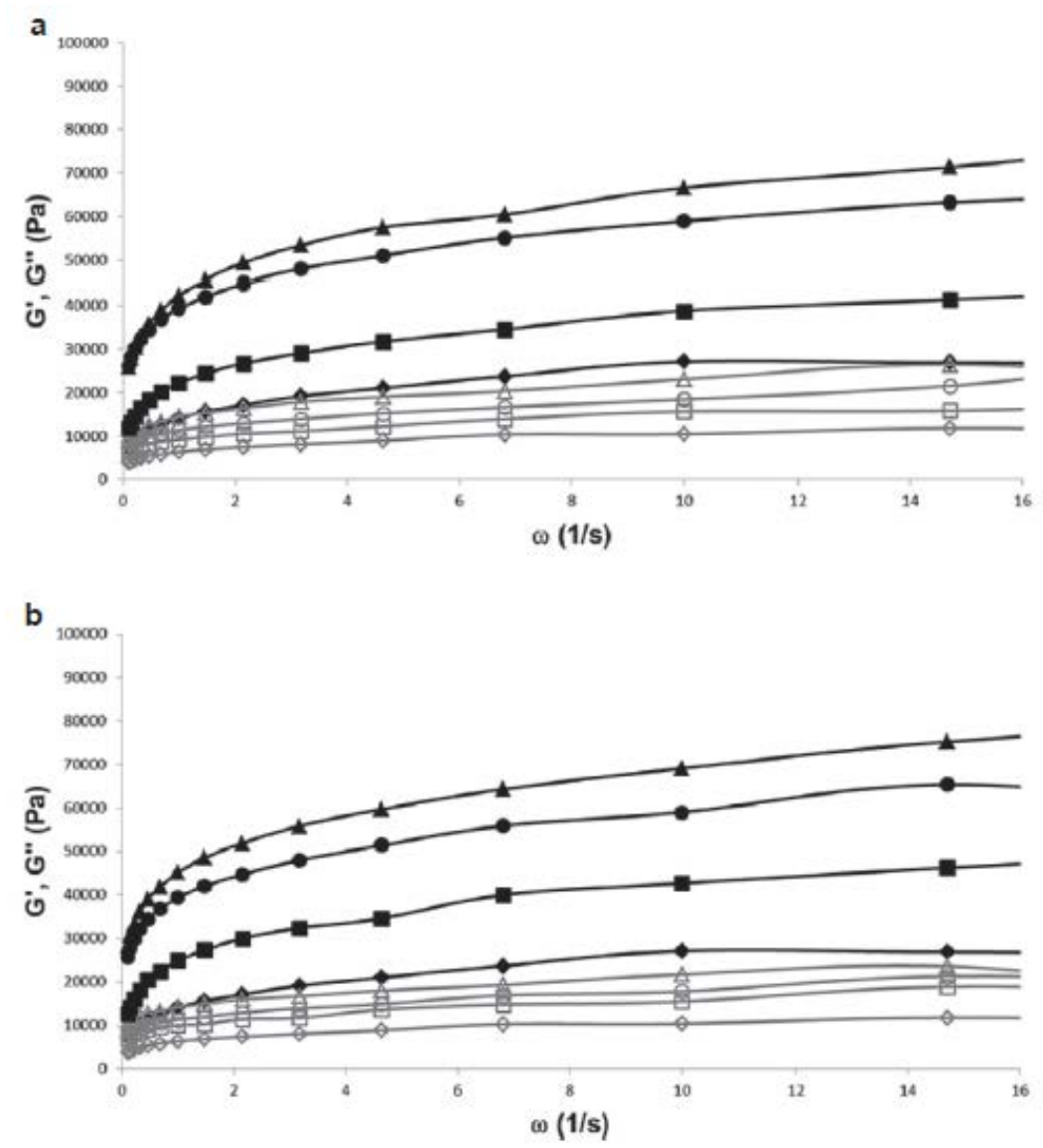

FIG. 2. Mechanical spectrum of doughs. $G^{\prime}$ and $G^{\prime \prime}$ values according to oscillation frequency $(\omega)$ in fine flours (a) and coarse flours (b). $G^{\prime}$ values are represented by filled symbols and $G^{\prime \prime}$ values are represented by unfilled symbols. Control (diamond), flour 1 (square), flour 2 (triangle), flour 3 (circle).

Chao-Chi-Chuang \& Yeh (2002), studying the extrusion process, and Kim et al. (2009), using the steam cooking method, observed that the moisture content in hydrothermal treatments was the key to the variation in G', G' and tag $\delta$ values. In particular, ChaoChi-Chuang \& Yeh (2002) detected higher G' and G" values in the treatments with lower moisture; our observations did not coincide with their findings, though it should be recognized that those authors subjected the flours to higher moisture contents (45\%-55\%) than were employed in our study, with lower extrusion temperatures $\left(20^{\circ} \mathrm{C}-100^{\circ} \mathrm{C}\right)$ and they used waxy varieties of rice. However, those authors did observe that an increase in the mechanical energy applied during extrusion produced an increase in G' and G" values and a fall in $\tan \delta$ values. It is already known that an increase in the consumption 
of mechanical energy usually leads to extruded samples with a higher degree of cooking (González et al., 2000). In our case, the flours with lower viscosity values in the RVA curves, and thus a higher degree of cooking, were those that obtained the highest G',G" and $\mathrm{G}^{*}$ values.

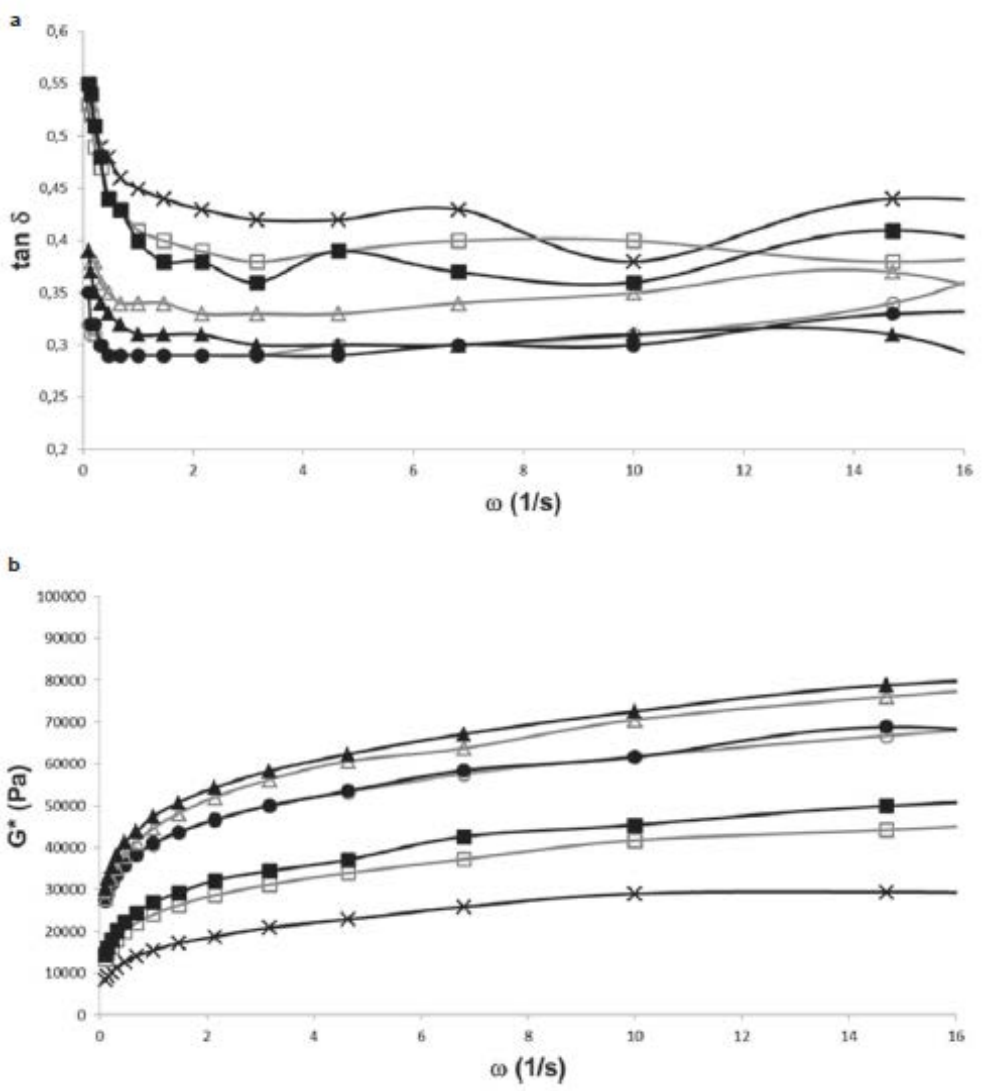

FIG. 3. Mechanical spectrum of dough. $\tan \delta$ (a) and $G^{*}(b)$ according to oscillation frequency $(\omega)$. Extruded fine flours are represented by unfilled symbols and extruded coarse flours by filled symbols. Control (cross), flour 1f (unfilled square), flour $2 \mathrm{f}$ (unfilled triangle), $3 \mathrm{f}$ (unfilled circle), 1c (filled square), 2c (filled triangle), 3c (filled circle).

These changes in rheology may be related to changes in the starch during the extrusion treatment, as Shim \& Mulvaney (1999) found that the balance between the intact starch granules and gelatinized or damaged ones affected $G^{\prime}$ values. It has already been shown that extruded flours contain a higher quantity of pregelatinized starch than non-extruded flours and, according to Slade \& Levine (1994), this greater degree of gelatinization increases the water absorption capacity of doughs. These rheological changes may also be related to the internal structure of the dough, which may be seen in Figure 4. In the two doughs studied (control dough and dough with flour 3c), the structure is composed of large flour particles covered by small simple starch granules, compacted by a matrix formed of water, hydrocolloids and dissolved substances. However, in the case of dough with flour $3 \mathrm{c}$, there was a smaller quantity of simple starch granules, which is consistent with what was observed in the microstructure of the extruded flours (the starch granules 
had lost their integrity). The starch granules observed correspond to starch granules from the non-extruded flour. It could therefore be thought that extruded flour is mixed with the network formed by water and hydrocolloids, and this will modify the viscoelastic properties of dough.

Additionally, an increase in the quantity of damaged starch granules was observed in the flour 3c sample compared with the control, as can be seen in Figures 1 and 4 (starch granules with small holes and breaks) and in table 1 .

The amount of water needed in bread-making at constant consistency $\left(G^{*}=15500 \pm 101550 \%\right)$ is shown in Table 3. The addition of extruded flours increased the quantity of water required to obtain doughs with constant consistency, and thus they can increase the bread yield. This increase was greater in doughs prepared with flours 2 and 3 (the more intense extrusion treatments) than doughs prepared with flour 1 . This finding may be explained by a higher degree of damage caused to the starch granules and to the greater degree of gelatinization in the extrusion process with more intense processing conditions (temperature and moisture) (Mercier and Feillet, 1975). However no clear difference was observed between the doughs made with flours 2 and 3 or with flours with different particle sizes.

Table 3: Specific volume, texture properties and percentage hydration of breads made at constant consistency.

\begin{tabular}{cccccc}
\hline Flour & $\begin{array}{c}\text { Specific volume } \\
(\mathrm{m} 3 / \mathbf{k g})\end{array}$ & Hardness $(\mathrm{N})$ & Springiness & Cohesiveness & \% Hydration \\
\hline Flour 3f & $2.807 \mathrm{a} \pm 0.121$ & $22.018 \mathrm{e} \pm 1,155$ & $0.689 \mathrm{a} \pm 0,030$ & $0.244 \mathrm{a} \pm 0,001$ & $76.67 \mathrm{~d} \pm 0,01$ \\
Flour 3c & $2.813 \mathrm{a} \pm 0.192$ & $21.370 \mathrm{e} \pm 0,588$ & $0.738 \mathrm{a} \pm 0,045$ & $0.314 \mathrm{a} \pm 0,102$ & $74.55 \mathrm{c} \pm 0,31$ \\
Flour 2f & $2.987 \mathrm{a} \pm 0.171$ & $13.675 \mathrm{~d} \pm 0,583$ & $0.706 \mathrm{a} \pm 0,015$ & $0.271 \mathrm{a} \pm 0,005$ & $74.86 \mathrm{c} \pm 0,08$ \\
Flour 2c & $3.637 \mathrm{~b} \pm 0.259$ & $6.430 \mathrm{c} \pm 1,649$ & $0.635 \mathrm{a} \pm 0,070$ & $0.307 \mathrm{a} \pm 0,061$ & $78.92 \mathrm{c} \pm 0,23$ \\
Flour 1f & $3.041 \mathrm{a} \pm 0.311$ & $4.153 \mathrm{~b} \pm 0,181$ & $0.615 \mathrm{a} \pm 0,007$ & $0.286 \mathrm{a} \pm 0,003$ & $72.98 \mathrm{~b} \pm 0,01$ \\
Flour 1c & $4.597 \mathrm{c} \pm 0.121$ & $2.431 \mathrm{~b} \pm 0,378$ & $0.590 \mathrm{a} \pm 0,125$ & $0.297 \mathrm{a} \pm 0,013$ & $73.36 \mathrm{~b} \pm 0,33$ \\
Control & $4.802 \mathrm{c} \pm 0.044$ & $1.723 \mathrm{a} \pm 0,693$ & $0.656 \mathrm{a} \pm 0,067$ & $0.348 \mathrm{a} \pm 0,018$ & $70.00 \mathrm{a} \pm 1,17$ \\
\hline
\end{tabular}

Values with different letters in the same parameter are significantly different $(p<0.05)$.

Data shown are the means of two repetitions for each kind of simple

\subsubsection{Dough height development and gas production.}

The curves of dough height development during fermentation at constant consistency are shown in Figure 5. Regarding gas production, no significant differences were seen in any case (data not shown). Greater height development was observed in doughs made with non-extruded flours than in doughs with extruded flours, but the differences only became evident after a certain duration of fermentation (around minute 90). The poor dough height development over the whole fermentation process when using flour 1f, was noticeable. The differences between the other extruded flours were minimal but doughs 
made with flour 3 were somewhat more stable if over-fermentation occurred. Greatest height development was obtained in doughs made with flours $1 \mathrm{c}$ and $2 \mathrm{c}$, although overfermentation had a negative effect in both cases. Doughs with flour 3 showed a higher stability than the other doughs, and higher $G^{\prime}$ and $G^{*}$ values and lower $\tan \delta$ values; they are thus more consistent and elastic doughs. This could be related to starch gelatinization and damage during the extrusion treatment (Shim \& Mulvaney, 1999), as these changes increase the water absorption capacity of dough, as indicated previously (Slade \& Levine, 1994).
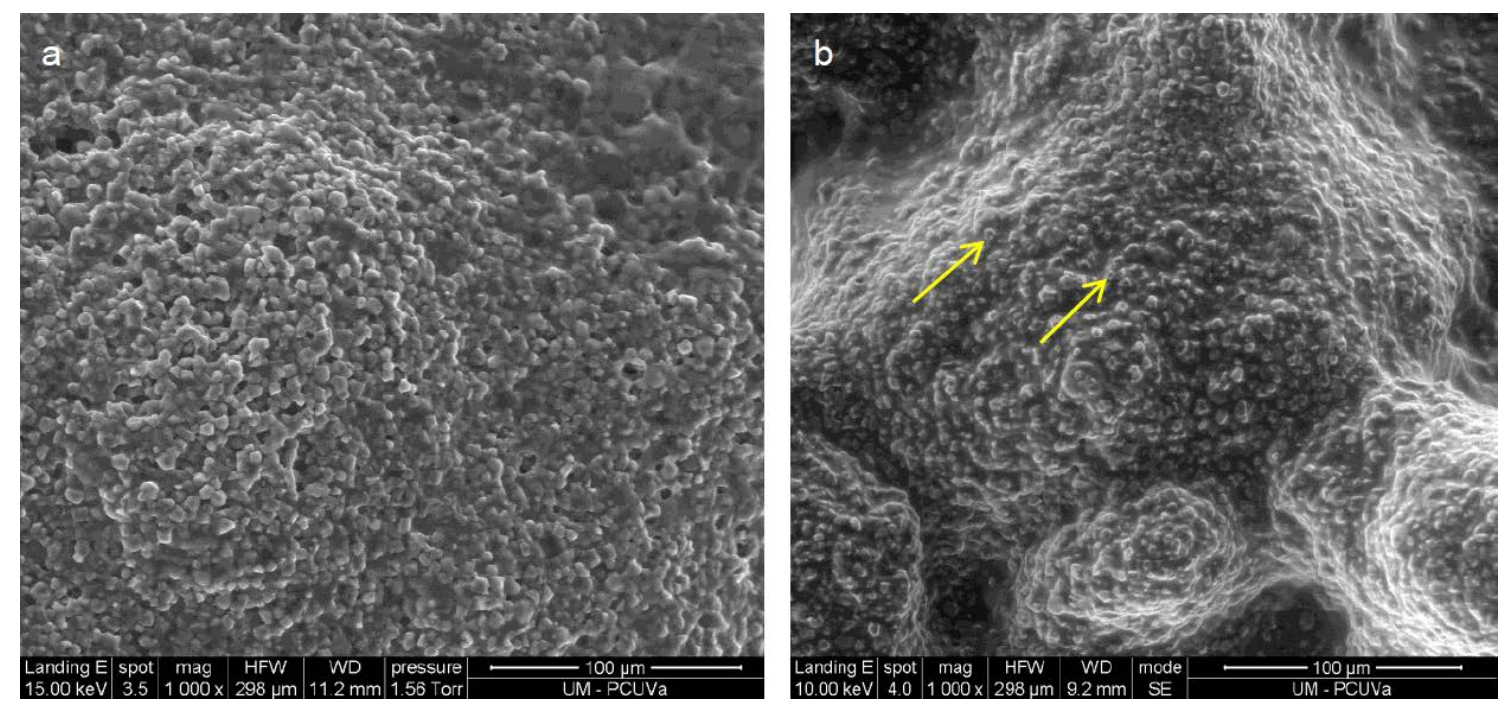

FIG. 4. Photomicrographs of the scanning electronic microscope $(\mathrm{sem})(\times 1,000)$ of doughs prepared with nonextruded flour with $10 \%$ substitution by extruded flour. Analysis performed in triplicate with subsequent selection of the most representative photomicrographs (a) control, (b) dough made with flour 3c. Arrows indicate damaged starch granules.

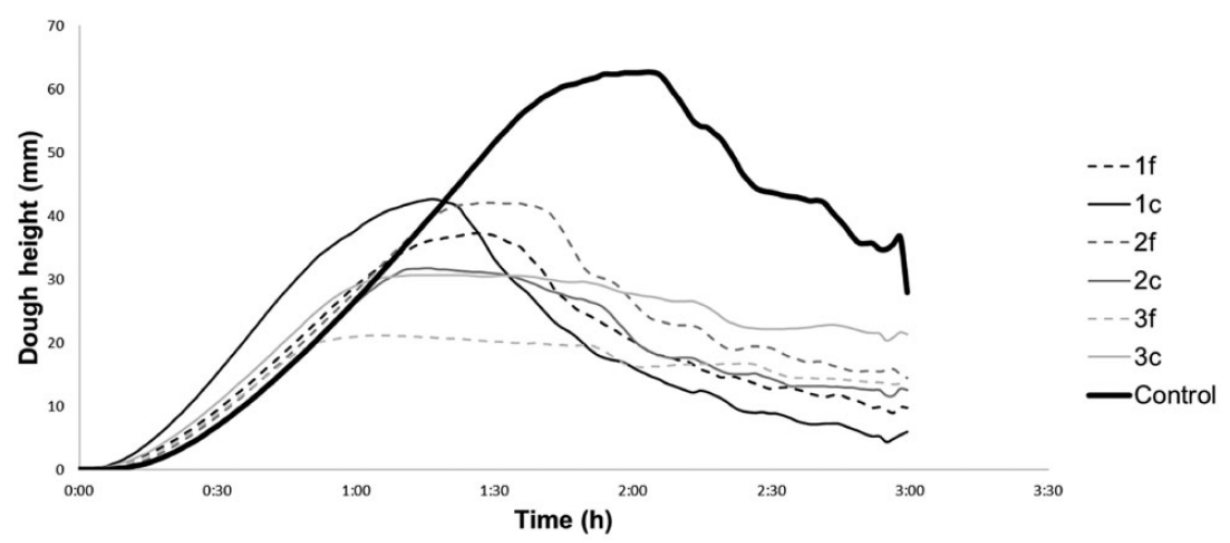

FIG. 5. Dough height during fermentation

Changes in the dough height development during fermentation can be also related to the internal structure of the dough (Figure 4). The dough prepared with flour 3c, which was the dough with the highest stability in the case of excess fermentation, had the lowest 
quantity of simple starch granules. This is consistent with the results observed in the microstructure of extruded flours, which showed a loss of integrity of the starch granules. It can therefore be assumed that extruded flours form a mixture with the network produced by the water and hydrocolloid, modifying dough height development during fermentation.

\subsection{Bread properties}

\subsubsection{Specific volume and weight lost}

Table 3 shows the specific volume of breads made at constant consistency. A decrease in the specific volume was observed when extruded flours were added to the formula, except after the addition of flour $1 \mathrm{c}$, which produced a specific volume equal to that of the control. Only the breads prepared with flours $1 \mathrm{c}$ and $2 \mathrm{c}$ stood out, showing higher specific volumes than the other extruded flours.

Table 3: Specific volume, texture properties and percentage hydration of breads made at constant consistency.

\begin{tabular}{|c|c|c|c|c|c|}
\hline Flour & $\begin{array}{c}\text { Specific volume } \\
(\mathrm{m} 3 / \mathrm{kg})\end{array}$ & Hardness (N) & Springiness & Cohesiveness & $\%$ Hydration \\
\hline Flour $3 \mathrm{f}$ & $2.807 \mathrm{a} \pm 0.121$ & $22.018 \mathrm{e} \pm 1,155$ & $0.689 a \pm 0,030$ & $0.244 a \pm 0,001$ & $76.67 \mathrm{~d} \pm 0,01$ \\
\hline Flour 3c & $2.813 a \pm 0.192$ & $21.370 \mathrm{e} \pm 0,588$ & $0.738 a \pm 0,045$ & $0.314 a \pm 0,102$ & $74.55 c \pm 0,31$ \\
\hline Flour $2 \mathrm{f}$ & $2.987 \mathrm{a} \pm 0.171$ & $13.675 \mathrm{~d} \pm 0,583$ & $0.706 a \pm 0,015$ & $0.271 \mathrm{a} \pm 0,005$ & $74.86 c \pm 0,08$ \\
\hline Flour 2c & $3.637 b \pm 0.259$ & $6.430 c \pm 1,649$ & $0.635 a \pm 0,070$ & $0.307 a \pm 0,061$ & $78.92 c \pm 0,23$ \\
\hline Flour 1f & $3.041 \mathrm{a} \pm 0.311$ & $4.153 b \pm 0,181$ & $0.615 a \pm 0,007$ & $0.286 a \pm 0,003$ & $72.98 b \pm 0,01$ \\
\hline Flour 1c & $4.597 c \pm 0.121$ & $2.431 b \pm 0,378$ & $0.590 a \pm 0,125$ & $0.297 a \pm 0,013$ & $73.36 b \pm 0,33$ \\
\hline Control & $4.802 c \pm 0.044$ & $1.723 a \pm 0,693$ & $0.656 a \pm 0,067$ & $0.348 a \pm 0,018$ & $70.00 \mathrm{a} \pm 1,17$ \\
\hline
\end{tabular}

Values with different letters in the same parameter are significantly different $(p<0.05)$.

Data shown are the means of two repetitions for each kind of simple

No differences in weight loss were observed in the doughs during baking (data not shown).

In previous studies it has been found that both acidified (Clerici et al., 2009) and nonacidified (Clerici and El-Dash, 2006) extruded rice flours could improve the specific volume of gluten-free breads, depending on the extrusion conditions. However, those authors did not use hydrocolloids in the formula, and the specific volume values obtained were much lower than in our case. This result could indicate some kind of interaction between the hydrocolloids and the extruded flours or their components. Sanchez et al. (2008) made bread with extruded waxy rice flours and also observed an increase in the specific volume of breads when using the extruded flours with the highest intensity extrusion treatments. It is important to note the difference in the moisture values between the bread obtained by those authors as they prepared bread at constant 
consistency using a penetrometer. In contrast to our study, those authors used a high percentage of starch in the formula and considered that the increase in volume was related to the increase in the quantity of soluble solids, as those components increased the consistency of the aqueous phase, improving the viscoelastic characteristics of doughs.

Defloor et al. (1991) also found that the addition of extruded starch improved the volume of breads prepared with a mixture of tapioca and soya flour. It is important to note that these authors used high levels of hydration (145\%), and their doughs were therefore less consistent than ours. In their case, extruded starches increased the consistency of very soft doughs (in contrast to our study, in which we used more consistent doughs with lower hydration) and made it possible to increase bread volume.

Gallagher et al. (2003), on the other hand, observed that an increase in dough hydration increased bread volume. In our study we also found that the level of hydration could alter the effect of including certain components that increase dough consistency, such as extruded flours and coarser flours, which have a high amount of damaged starch that could contribute greatly to increase dough hydration, as can be seen in table 1 and in figure 1 and 4 .. In excessively soft doughs, a certain increase in consistency could therefore be useful, though this can have a negative effect in more consistent doughs with lower hydration. Nevertheless, this factor alone cannot explain the changes observed, as breads with a constant consistency were also found to have a different specific volume.

\subsubsection{Texture analysis}

The texture parameters of bread at constant consistency are presented in Table 3.

A tendency to increased hardness was observed as the extrusion intensity of the flours increased. Higher hardness values were also found when using fine flours compared to coarse ones, although significant differences were only detected with loaves elaborated using flours 2.

No significant differences were found in the springiness or cohesiveness of loaves made with extruded flours compared to control loaves. As in our study, Clerici \& El-Dash (2006) reported higher hardness values in breads made with extruded flours. Maleki et al. (1980) and Morad \& Wakeil (1976) found that starch retrogradation was strongly influenced by the moisture content of the product. As it is shown in table 1, coarser flours have higher damaged starch content, which is able to absorb a higher amount of water than the native starch, thus Tthe reduction of starch retrogradation through increased moisture content would therefore produce softer breads. It is also known that bread hardness correlates with bread volume (Gómez et al., 2011), and thus the explanation of the differences in hardness could be related to differences in the specific volume. 
The changes in hardness over time are shown in Figure 6. Loaves made with the control flour and with flours $1 \mathrm{f}$ and $2 \mathrm{f}$ showed the fastest rates of hardening. Loaves made with flours $1 \mathrm{c}$ and $2 \mathrm{c}$ showed the lowest hardness values and their hardening curves had a low gradient. Loaves made with flours 3 had the highest hardness values up to 24 hours, but the values subsequently remained almost constant or even fell, indicating a decrease in the rate of staling.

Changes in crumb properties associated with staling include an increase in starch crystallinity and crumb hardness and a decrease in aroma, soluble starch and crumb hydration capacity (D'Appolonia \& Morad, 1981). Rogers et al. (1988) stated that the main cause of bread staling is starch retrogradation, which increases with increased moisture content of breads. As gluten-free breads have a high moisture content, starch retrogradation may progress faster during storage than in gluten breads. Extruded flours have a higher water-retention capacity than non-extruded flours and they could thus delay water migration from the crumb to the crust, decreasing the rate of staling. Besides, regarding this aspect, the higher amount of damaged starch of coarse flours (Figure 1), could also delay water migration from the crumb to the crust, decreasing the rate of staling. Furthermore, the extrusion process may even break the amylopectin chains (Mercier and Feillet, 1975) and Colonna et al. (1984) demonstrated that extruded wheat starches contain amylose and amylopectin chains with lower molecular weights than drum-dryer starches; this could be another factor that decreases retrogradation and the rate of staling of bread.

\section{Conclusion}

The use of extruded flours in the elaboration of gluten-free bread offers an interesting alternative approach to improve gluten-free breads. We found that the addition of extruded flours subjected to high intensity extrusion treatments produced doughs with a higher elastic modulus and consistency, and that it was necessary to add larger volumes of water to achieve constant consistency. The bakery yield is therefore increased. However, the development of doughs prepared with extruded flours was lower, but these doughs showed higher stability to over-fermentation. In general, the addition of extruded flours reduced the specific volume of breads and increased hardness, but these effects were minimized by using the coarse flour fractions, which also reduced the rate of staling. Future studies should look in detail at the effect of these extruded flours on the acceptability of breads and their influence in breads with higher levels of hydration.

\section{$\underline{\text { Acknowledgements }}$}

This study was supported financially by Junta de Castilla y León (VA054A12-2), Spain. The authors are also grateful to Harinera Los Pisones (Zamora, Spain) for supplying the rice flours. 


\section{$\underline{\text { References }}$}

AACC. 2012. Approved methods of the American Association of Cereal Chemists, method 61-02.01 (RVA) (11th ed.). St. Paul, Minnesota: American Association of Cereal Chemists.

ARAKI, E., IKEDA, T., ASHIDA, K., TAKATA, K., YAMAKA, M., and IIDA, S. 2009. Effects of rice flour properties on specific loaf volume of one-loaf bread made from rice flour with wheat vital gluten. Food Sci Technol, 15, 439-448.

ATWELL, W., HOOD, L., LINEBACK, D., VARRIANOMARSTON, E., and ZOBEL, H. 1988. The terminology and methodology associated and basic starch phenomena. Cereal Foods World, 33, 306-308, 310-311.

BARRES, C., VERGES, B., TAYEB, J., and DELLA VALLE, G. 1990. Transformation of wheat flour by extrusion cooking. Influence of screw configuration and operating conditions. Cereal Chem, 67, 427-433.

CAMIRE, M., CAMIRE, A., and KRUMHAR, K. 1990. Chemical and nutritional changes in foods during extrusion. Crit Rev Food Sci Nutr, 29, 35-57.

CHAO-CHI CHUANG, G., and YEH, A. 2003. Effect of screw profile on residence time distribution and starch gelatinization of rice flour during single screw extrusion cooking. J Food Eng, 63, 21-31.

CHAO-CHI-CHUANG, G., and YEH, A. 2002. Effects of product temperature and moisture content on viscoelastic properties of glutinous rice extrudate. Cereal Chem, 79, $36-40$.

CHINNASWAMY, R., and HANNAH, M. 1990. Macromolecular and functional properties of native and extruded corn starch. Cereal Chem, 67, 490-499.

CLERICI, M., and EL-DASH, A. 2006. Extruder rice flour as a gluten substitute in the production of rice bread. Arch Latinoam Nutr, 56, 288-294.

CLERICI, M., ARIOLDI, C., and EL-DASH, A. 2009. Production of acidic extruder rice flour and its influence on the qualities of gluten free bread. Food Sci Technol, 42, 618. 623.

COlONNA, P., DOUbliER, J., MELCION, J., MONREDON, F., and MERCIER, C. 1984. Extrusion cooking and drum drying of wheat starch. I. Physical and macromolecular modifications. Cereal Chem, 61, 538-543.

CURETON, P., and FASANO, A. 2009. The increasing incidence of celiac disease and the range of gluten-free products in the marketplace . In Gluten-Free Food Science and Technology (E. Gallagher ed.) pp. 1-15. Dublin, Ireland: Wiley-Blackwell. 
CURIC, D., NOVOTNI, D., BAUMAN, I., KRICKA, T., and DUGUM, J. 2009. Optimization of extrusion cooking of cornmeal as raw material for bakery products. J Food Process Eng, 32, 294-317.

CZUCHAJOWSKA, Z., and POMERANZ, Y. 1993. Gas-formation and gas retention 1. The system and methodology. Cereal Foods World, 38, 499-503.

D'APPOLONIA, L., and MORAD, M. 1981. Bread staling. Cereal Chem, 58, 186-190.

DEFLOOR, I., DE GEEST, C., SCHELLEKENS, M., MARTENS, A., and DELCOUR, J. 1991. Emulsifiers and/or extruded starch in the productions of breads from cassava. Cereal Chem, 68, 323-327.

DOBRASZCZYK, B., and MORGENSTERN, M. 2003. Rheology and the breadmaking process. J Cereal Sci, 38, 229-245.

DOUBliER, J., COLONNA, P., and MERCIER, C. 1986. Extrusion cooking and drum drying of wheat-starch 2. Rheological characterization of starch pastes. Cereal Chem, 63, 240-246.

EL-DASH, A., GONZALES, R., and CIOL, M. 1983. Response surface methodology in the control of thermoplastic extrusion of starch. J Food Eng, 2, 129-152.

CURETON, P., and FASANO, A. 2009. The increasing incidence of celiac disease and the range of gluten-free products in the marketplace. In Gluten-Free Food Science and Technology (E. Gallagher ed.) pp. 1-15. Dublin, Ireland: Wiley-Blackwell.

GAllagher, E., GORMLEY, T., and ARENDT, E. 2003. Crust and crumb characteristics of gluten free breads. J Food Eng, 56, 153-161.

GÓMEZ, M., JIMÉNEZ, S., RUIZ, E., and OLIETE, B. 2011. Effect of extruded wheat bran on dough rheology and bread quality. Food Sci Technol, 44, 2231-2237.

GONZÁlEZ, R. J., TORRES, R. L., and AÑÓN, M. C. 2000. Comparison of rice and corn cooking characteristics. Polish J Food, 50, 29-54.

HAGENIMANA, A., DING, X., and FANG, T. 2006. Evaluation of rice flour modified by extrusion cooking. J Cereal Sci, 43, 38-46.

HOOVER, R., and VASANTHAN, T. 1994. Effect of heat-moisture treatment on the structure and physicochemical properties of cereal, legume and tuber starches. Carbohydr Res, 252, 33-53.

HSIEH, F., and LUH, B. 1991. Rice snack foods. In Rice volume II: Utilization (B. Luh ed.) pp. 225-249. Nueva York. EEUU: Van Nostrand Reinhold. 
KIM, D., BAE, I., INGLETT, G., and LEE, S. 2009. Effect of hydrothermal treatment on the physicochemical, rheological and oil-resistant properties of rice flour. J Texture Stud, 40, 192-207.

LU, S., CHEN, C., and LII, C. 1994. Gel-chromatography fractionation and thermal characterization of rice starch affected by hydrothermal treatment. Cereal Chem, 73, 511.

MALEKI, M., HOSENEY, R., and MATTERN, P. 1980. Effects of loaf volume, moisture content, and protein quality on the softness and staling of bread. Cereal Chem, 57, 138140 .

MCPHERSON, A., BAILEY, T., and JANE, J. 2000. Extrusion of cross-linked hydroxypropylated corn starches I. Pasting properties. Cereal Chem, 77, 320-325.

MERCIER, C., and FEILLET, P. 1975. Modification of carbohydrate components by extrusion-cooking of cereal products. Cereal Chem, 63, 283-297.

MORAD, M., and WAKEIL, F. 1976. Effect of wheat starch, protein and moisture content on staling of bread. Getreide, Mehl und Brot, 30, 106-107.

NISHITA, K., and BEAN, M. 1982. Grinding methods: Their impact in rice flour properties. Cereal Chem, 59, 46-49.

ROGERS, D., ZELEZNAK, K., and LAI, C. H. 1988. Effect of native lipids, shortening and bread moisture on bread firming. Cereal Chem, 65, 398-401.

ROSELL, C. 2009. Enzymatic Manipulation of Gluten-Free Breads. In Gluten-Free Food Science and Technology (E. Gallagher ed.) pp. 83-98. Dublin, Ireland: Wiley-Blackwell.

SANCHEZ, H., GONZALEZ, R., OSELlA, C., TORRES, R., and DE LA TORRE, M. 2008. Elaboration of bread without gluten from extruded rice flour. Cienc Tecnol Aliment, 6, 109-116.

SCHOBER, T. 2009. Manufacture of gluten-free specialty breads and confectionery products. In Gluten-Free Food Science and Technology (E. Gallagher ed.) pp. 130-180. Dublin, Irlanda: Wiley-Blackwell.

SHIM, J., and MULVANEY, S. 1999. Effect of cooking temperature and stirring speed on rheological properties end microstructure of corn starch and oat flour gels. Cereal Foods World, 44, 349-356.

SLADE, L., and LEVINE, H. 1994. Structure-function relationships of cookie and cracker ingredients. In The Science of Cookie and Cracker Production (H. Faridi, ed.) pp. 23-241. Nueva York: Chapman and Hall. 
WOLF, B. 2010. Polysaccharide functionality through extrusion processing. Curr Opin Colloid Interface Sci, 15, 50-54.

YEH, A., and LI, J. 1996. A continuous measurement of swelling of rice starch during heating. J Cereal Sci, 23, 277-283.

YEH, A., WU, T., and JAW, Y. 1999. Starch transitions and their influence on flow pattern during single-screw extrusion cooking of rice flour. Food Bioprod Process, 77, 47 54.

YLIMAKI, G., HAWARYSH, Z., HARDIN, R., and THOMSON, A. 1988. Application of response surface methodology to the development of rice flour yeast breads: objective measurements. J Food Sci, 53, 1800-1805. 


\subsection{Texture development in gluten-free breads: effect of different enzymes and extruded flour}

\section{TEXTURE DEVELOPMENT IN GLUTEN-FREE BREADS: EFFECT OF DIFFERENT ENZYMES AND EXTRUDED FLOUR}

MARIO M. MARTÍNEZ, PABLO MARCOS and MANUEL GÓMEZ'

Food Technology Area, E.T.S. Ingenierlas Agrarias, Valladolid University, Ed. La Yutera, Avd. Madrid 44, 34004 Palencia, Spain

\section{$\underline{\text { 1. Introduction }}$}

In recent years, there has been increasing interest in the development of high-quality gluten-free products and this has led to an increase in the volume of research and in the number of scientific publications on this subject. Gluten-free breads are characterized by a deficient quality and high cost compared to traditional bread, leading to a low turnover of products and hence the need to obtain breads with a long shelf life. The staling of baked products is usually defined as an increase in crumb firmness and a loss of product freshness. The retrogradation of starch, a major component of flour, plays an important role in these changes. In the case of gluten-free bread and, in particular, when rice flour is used, these staling phenomena may be augmented because retrogradation has been found to be greater with rice starch than with wheat starch (Baker and Rayas-Duarte 1998). It has also been observed that rice bread is drier and crumblier than wheat bread and that it shows greater retrogradation during storage than wheat bread (Kadan et al. 2001).

Although there are fewer studies of staling and of its prevention with gluten-free breads than with wheat bread, the interest in this subject has increased in recent years. Ziobro et al. (2012) observed that the staling of breads made with potato and corn starch can be reduced during the first $48 \mathrm{~h}$ by the addition of modified starches such as hydroxypropyl distarch phosphate. Purhagen et al. (2012) showed that the addition of emulsifiers could decrease bread hardening over the first $3 \mathrm{~d}$. That finding coincides with the observations of Nunes et al. (2009) after the addition of sodium stearoyl lactylate (SSL) and monoglycerides, but not with other emulsifiers, such as lecithin or diacetyl tartaric acid ester of mono- and diglycerides. The addition of gums with a highwater-holding capacity, such as oat $\beta$-glucan (Hager et al. 2011), xanthan gum (Sciarini et al. 2010a) or small quantities of high-pressure treated sorghum (Vallons et al. 2010) or oat (Huettner et al. 2010), may also reduce bread hardening. In breads made with different types of starch, the addition of protein sources, such as soya flour (Sciarini et al. 2010b) or gluten (Every et al. 1998), also increases shelf life. Witczak et al. (2010) studied the effect of adding maltodextrins and reported that low-dextrose-equivalent maltodextrins produced poorer 
bread whereas high-dextrose-equivalent maltodextrins improved volume and reduced hardening and amylopectin recrystallization enthalpy.

Physically modified flours, such as extruded flours, are being used more every time in bread making due to the particularities they show. Extruded flours have a lower retrogradation and a higher water retention capacity than native flours (Camire et al. 1990). These flours have been used in the manufacture of gluten-free bread improving volume and texture (Clerici and El-Dash 2006; Sanchez et al. 2008; Clerici et al. 2009). However, there are a few studies about the influence of extruded flour on the development of the bread texture. Enzymes are widely used in the manufacture of wheat bread. They enable various chemical additives to be substituted because they catalyze certain reactions and they are considered to be a good alternative to additives as "clean label compounds." Furthermore, the protein structure of enzymes is denaturalized during baking and the enzymes are therefore not active in the final product. The use of enzymes in gluten-free bread making is not so widespread and studies are now focusing on increasing bread volume through the addition of transglutaminase, glucose oxidase (Rosell 2009) or protease (Hamada et al. 2013). The use of enzymes to delay hardening in gluten-free breads has not been extensively investigated and only Gujral et al. (2003) observed that the use of mid-stability amylases and cyclodextrin glycosyltransferase can help minimize bread hardening by reducing the retrogradation capacity of amylopectin during storage.

The modeling of texture development in gluten-free breads has been already studied. The Avrami model has been used to investigate starch retrogradation phenomena (Zhang and Jackson 1992) and the development of bread hardness (Armero and Collar 1998), although, with short storages times, some authors have found better correlations using a linear model (Jekle and Becker 2012). Gomez et al. (2008) proposed simple models with two variables to study the development of different texture parameters over time. They observed that the most suitable models were different for white breads and whole-grain breads. In cakes, in which the gluten matrix is not developed, the modeling of texture parameters also differs from the models used for wheat bread (Gomez et al. 2010); thus, the most suitable model for gluten-free breads may also be different.

Most of the studies performed on the staling of gluten-free bread are based on firmness and they have not taken other parameters, such as cohesiveness or springiness, into account. In addition, those studies looked at firmness on specific days or differences between those days and the initial firmness. In the present study, we have investigated the development of the different texture parameters of gluten-free breads over time by using a number of simple mathematical models. We have also looked at the possibility of reducing the changes through the use of enzymes and extruded flour. 


\section{Materials and methods}

\subsection{Materials}

The rice flours used in this study were supplied by Harinera Los Pisones (Zamora, Spain). oth the raw and the extruded flour used in the study were obtained from the fraction between the 132 and $200 \mu \mathrm{m}$ sifts. Extruded rice flour was prepared using an industrial single-screw extruder (Buhler S.A., Uzwil, Switzerland) with 10\% of additional humidity and with a maximum flour temperature of $140 \mathrm{C}$ in the final section of the extruder. The product obtained was then milled in a compression-roller flour mill and sieved. Four commercial enzymes were used: a protease (Grindamyl PR59), a glycolipase (Powerbake 4070), an amylase (Max-Life P15) and a G-4 amylase (Powersoft 7001), all supplied by Danisco, Copenhagen, Denmark. The other ingredients used in the bread making included Saf-Instant yeast (Lesaffre, Lille, France) as the leavening agent, refined dry salt (Esco European Salt Company, Niedersachsen, Germany), tap water, white sugar (Acor, Valladolid, Spain), refined sunflower oil (Coosur, Vilches, Spain) and Methocel K4M Food-grade hydroxymethylcellulose (Dow Wolf Celullosics, Bitterfeld, Germany).

\subsection{Methods}

\subsubsection{Bread Making}

A straight-dough process was employed, prepared using a Kitchen-Aid Professional mixer (KPM5, KitchenAid, St. Joseph, MI) with a dough hook (K45DH). The following ingredients (as \% on flour basis) were used in all formulas: water (80\%), sunflower oil $(6 \%)$, sucrose $(5 \%)$, salt $(1.8 \%)$, instant yeast $(3 \%)$ and hydroxypropyl methylcellulose (2\%). Instant yeast was first rehydrated in half the amount of water. The dough was kneaded for 8 min using a dough hook at speed 2. The doughs were molded into aluminium pans of $232 \times 108 \times 43.5 \mathrm{~mm}$, placing $300 \mathrm{~g}$ into each pan, and were then proofed for $90 \mathrm{~min}$ in a chamber at $30 \mathrm{C}$ and $70 \%$ relative humidity. After proofing, the breads were baked in an electric oven for $40 \mathrm{~min}$ at 190C; they were then demolded, cooled for $60 \mathrm{~min}$ at room temperature andpacked into sealed polyethylene bags to prevent dehydration. Two batches per manufacture were made with five loaves per batch. The enzymes PROT, LIP, AMYL and G-4AMYL were added at dosages selected according to the supplier's recommendations: $0.3,0.08,0.4$ and $0.9 \mathrm{~g} / 1,000 \mathrm{~g}$ of flour, respectively. When extruded flour was used, $100 \mathrm{~g} / 1,000 \mathrm{~g}$ of untreated flour was substituted by extruded rice flour. Enzymes and extruded rice flour were added according to the experimental 25 factorial design shown in Table 1. Each additive was tested at two levels: 0 (absence) and 1 (presence). Before the tests, the flour and enzymes (when added) were mixed for 1 h using a Rotary Mixer MR 2 L (Chopin, Tripette et Renaud, France). 
Table $1.2^{5}$ Factorial design for sampling

\begin{tabular}{|c|c|c|c|c|c|}
\hline \multirow{2}{*}{ Sample $n^{\circ}$} & \multicolumn{5}{|l|}{ Factors $^{\mathrm{a}}$} \\
\hline & A & $B$ & $\mathrm{C}$ & $\mathrm{D}$ & $E$ \\
\hline 1 & 1 & 1 & 0 & 0 & 0 \\
\hline 2 & 1 & 0 & 0 & 0 & 0 \\
\hline 3 & 1 & 1 & 1 & 0 & 0 \\
\hline 4 & 0 & 1 & 1 & 0 & 0 \\
\hline 5 & 0 & 0 & 0 & 0 & 0 \\
\hline 6 & 1 & 1 & 1 & 0 & 1 \\
\hline 7 & 1 & 0 & 0 & 0 & 1 \\
\hline 8 & 0 & 1 & 1 & 1 & 1 \\
\hline 9 & 1 & 1 & 1 & 1 & 0 \\
\hline 10 & 1 & 0 & 1 & 1 & 1 \\
\hline 11 & 1 & 1 & 0 & 1 & 1 \\
\hline 12 & 1 & 1 & 0 & 0 & 1 \\
\hline 13 & 0 & 1 & 1 & 1 & 0 \\
\hline 14 & 0 & 0 & 0 & 1 & 0 \\
\hline 15 & 1 & 1 & 1 & 1 & 1 \\
\hline 16 & 0 & 0 & 1 & 0 & 1 \\
\hline 17 & 1 & 0 & 1 & 1 & 0 \\
\hline 18 & 0 & 0 & 1 & 0 & 0 \\
\hline 19 & 0 & 1 & 0 & 1 & 0 \\
\hline 20 & 1 & 0 & 1 & 0 & 1 \\
\hline 21 & 0 & 1 & 0 & 1 & 1 \\
\hline 22 & 0 & 0 & 0 & 0 & 1 \\
\hline 23 & 1 & 0 & 0 & 1 & 0 \\
\hline 24 & 1 & 1 & 0 & 1 & 0 \\
\hline 25 & 1 & 0 & 0 & 1 & 1 \\
\hline 26 & 1 & 0 & 1 & 0 & 0 \\
\hline 27 & 0 & 0 & 1 & 1 & 0 \\
\hline 28 & 0 & 0 & 1 & 1 & 1 \\
\hline 29 & 0 & 1 & 1 & 0 & 1 \\
\hline 30 & 0 & 1 & 0 & 0 & 1 \\
\hline 31 & 0 & 0 & 0 & 1 & 1 \\
\hline 32 & 0 & 1 & 0 & 0 & 0 \\
\hline
\end{tabular}

aLevels $(0,1)$ of factors (A to E): $\mathrm{A}=$ Lipase (LIP): none (0), $0.08 \mathrm{~g} / 1000 \mathrm{~g}$ flour (1); B = Protease (PROT): none (0), $0.3 \mathrm{~g} / 1000 \mathrm{~g}$ flour (1); C = G-4 amylase (G-4AMYL): none (0), $0.9 \mathrm{~g} / 1000 \mathrm{~g}$ flour (1); $\mathrm{D}=$ Amylase (AMYL): none (0), $0.4 \mathrm{~g} / 1000 \mathrm{~g}$ flour (1); E = Extruded flour (EXT): none (0), $100 \mathrm{~g} / 1000 \mathrm{~g}$ flour (1).

\subsubsection{Bread Characteristics.}

After cooling for $1 \mathrm{~h}$, baked breads were weighed and loaf volume was measured using a laser sensor with the BVM-L 370 volume analyzer (TexVol Instruments, Viken, Sweden). Bread density was calculated dividing bread weight by bread volume.Measurements were 
run in triplicate. Crumb texture was determined by a Texture Analyzer TA-XT2i (Stable Microsystems, Surrey, U.K.) running the "Texture Expert" software and equipped with a 25-mm-diameter cylindrical aluminum probe. Slices with a thickness of $3 \mathrm{~cm}$ were compressed to $50 \%$ of their original height in a "Texture Profile Analysis" (TPA) double compression test at a test speed of $1 \mathrm{~mm} / \mathrm{s}$, with a $30 \mathrm{~s}$ delay between first and second compressions. Primary parameters (firmness, cohesiveness, springiness and resilience) and chewiness (a secondary mechanical characteristic) were calculated from the TPA graph. Measurements were made on two central slices from two breads made with each dough on days 0 ( 2 h after baking), 3, 6, 9 and 12 .

\subsubsection{Statistical Analysis}

Changes in each texture parameter were adjusted to different curvilinear models for each combination of factors studied. Mean values of the coefficients of determination for each model are shown in Table 1. After selecting the most suitable models for each texture parameter, we determined the "a" and " $b$ " values that defined each test.

Data were analyzed using analysis of variance. Fisher's least significant difference test was used to describe means with $95 \%$ confidence. The analyses were performed using the Statgraphics Plus V5.1 statistical software (Statpoint Technologies, Warrenton, VA).

\section{$\underline{\text { 3. Results and discussion }}$}

\subsection{Modeling of Texture Parameters}

Table 2 shows the means of the correlation coefficients (r2) obtained when the trends of the different texture parameters over time in each test were adjusted to different simple curvilinear models. The means of the correlation coefficients obtained when adjusting to a second-degree polynomial equation are also included. Firmness is the most extensively studied texture parameter in research into staling in both wheat and gluten-free breads. In the case of wheat bread, the Avrami equation has been used in several studies to model the development of firmness because of its relationship with starch retrogradation phenomena (Armero and Collar 1998; Collar and Bollain 2005). High r2 values were obtained in those cases, although it is important to take into account that curves with only 5 or 7 points were adjusted to equations more complex that those applied in the present study. In our study, the highest mean correlation coefficient corresponded to the polynomial equation. This would appear to be a logical result as this is an equation with three variables, unlike the other equations with only two variables. Furthermore, the interpretation of the values obtained in the polynomial equation can be more complex than with other equations (except for the "a" parameter, which is equivalent to the initial value of the curve). The linear model is easier to interpret and the correlation coefficient is not significantly different from the coefficient of the polynomial equation. Some authors have stated that the development of bread firmness adequately fitted the linear model over the initial days of storage, although there was subsequently a fall in the rate of 
increase of firmness (Rasmussen and Hansen 2001). In previous studies on bread (Gomez et al. 2008) and sponge cakes (Gomez et al. 2010), this model was proposed to study firmness development because of the high correlation coefficients that were obtained. In the present study, the mean correlation coefficients in the linear model were lower than those obtained in the study of wheat bread but higher than those obtained for sponge cakes. In the case of the linear model, the "a" parameter corresponds to the initial value of the variable studied and the " $b$ " parameter indicates the rate of change of the variable.

Table 2. Mean of $\mathrm{R}^{2}$ values of the different curvilinear models used to describe the

\begin{tabular}{|c|c|c|c|c|c|}
\hline Model & Firmness $(\mathrm{N})$ & Cohesiveness & Resilience & Springiness & Chewiness (N) \\
\hline Linear $y=a+b * x$ & $87.55 \pm 10,34 \mathrm{ab}$ & $55.16 \pm 8,34 f$ & $51.24 \pm 8,90 \mathrm{e}$ & $58.94 \pm 12,91 \mathrm{e}$ & $23,08 \pm 19,20 \mathrm{gh}$ \\
\hline Multiplicative $y=a^{*} \mathrm{xb}$ & $79.76 \pm 16,17 \mathrm{bc}$ & $92.23 \pm 6,20 \mathrm{bc}$ & $90.39 \pm 6,85 c$ & $88.83 \pm 8,93 b$ & $47,77 \pm 25,13 \mathrm{de}$ \\
\hline $\begin{array}{l}\text { Square root-x } \\
y=a+b^{*} x^{1 / 2}\end{array}$ & $83.08 \pm 10,88 b$ & $80.28 \pm 5,14 \mathrm{e}$ & $77.49 \pm 5,97 \mathrm{~d}$ & $80.82 \pm 8,33 d$ & $39,07 \pm 24,25 \mathrm{ef}$ \\
\hline $\begin{array}{l}\text { Square root-y } \\
y=\left(a+b^{*} x\right)^{2}\end{array}$ & $87.54 \pm 10,63 \mathrm{ab}$ & $55.66 \pm 9,33 f$ & $50.71 \pm 10,10 \mathrm{e}$ & $58.82 \pm 13,75 \mathrm{e}$ & $19,67 \pm 18,84$ ghi \\
\hline $\begin{array}{l}\text { Exponential } \\
y=\exp \left(a+b^{*} x\right)\end{array}$ & $86.54 \pm 11,10 \mathrm{ab}$ & $56.11 \pm 10,75 f$ & $49.95 \pm 11,76 \mathrm{e}$ & $58.52 \pm 14,71 \mathrm{e}$ & $16,47 \pm 17,96 \mathrm{hi}$ \\
\hline $\begin{array}{l}\text { Logarithmic- } x \\
y=a+b * \ln (x)\end{array}$ & $69.99 \pm 17,00 \mathrm{de}$ & $93.51 \pm 4,04 \mathrm{abc}$ & $92.54 \pm 3,47 b c$ & $91.36 \pm 6,48 \mathrm{ab}$ & $59,63 \pm 25,81 b c$ \\
\hline $\begin{array}{l}\text { Double reciprocal } \\
\mathrm{y}=1 /(\mathrm{a}+\mathrm{b} / \mathrm{x})\end{array}$ & $73.80 \pm 21,92 \mathrm{~cd}$ & $89.81 \pm 10,54 \mathrm{~cd}$ & $90.22 \pm 10,37 \mathrm{c}$ & $87.76 \pm 11,38 b c$ & $49,98 \pm 22,31 \mathrm{~cd}$ \\
\hline S-curve $y=\exp (a+b / x)$ & $63.89 \pm 21,47 \mathrm{e}$ & $94.51 \pm 8,75 \mathrm{ab}$ & $95.54 \pm 7,57 \mathrm{ab}$ & $91.79 \pm 8,56 \mathrm{ab}$ & $62,45 \pm 22,94 b$ \\
\hline $\begin{array}{l}\text { Reciprocal-y } \\
y=1 /\left(a+b^{*} x\right)\end{array}$ & $81.28 \pm 14,31 \mathrm{bc}$ & $56.50 \pm 14,73 \mathrm{f}$ & $47.52 \pm 16,26 \mathrm{e}$ & $57.56 \pm 17,00 \mathrm{e}$ & $15,24 \pm 24,16 \mathrm{hi}$ \\
\hline $\begin{array}{l}\text { Reciprocal-x } \\
y=a+b / x\end{array}$ & $52.24 \pm 20,69 f$ & $97.19 \pm 6,66 \mathrm{a}$ & $98.07 \pm 5,39 a$ & $94.79 \pm 6,25 a$ & $72,95 \pm 24,16 a$ \\
\hline $\begin{array}{l}\text { Square of } X \\
y=a+b^{*} x^{2}\end{array}$ & $80.27 \pm 17,34 b c$ & $30.55 \pm 8,18 \mathrm{~g}$ & $27.18 \pm 8,32 f$ & $35.72 \pm 14,39 f$ & $12,83 \pm 14,26 \mathrm{i}$ \\
\hline $\begin{array}{l}2 \text { nd order } \\
\text { polynomial } \\
\text { regression } \\
\mathrm{y}=\mathrm{a}+\mathrm{b}^{*} \mathrm{x}^{+} \mathrm{c}^{*} \mathrm{x}^{2}\end{array}$ & $91.18 \pm 11,34 \mathrm{a}$ & $85.60 \pm 9,09 \mathrm{~d}$ & $82.05 \pm 13,43 \mathrm{~d}$ & $82.88 \pm 7,66 \mathrm{~cd}$ & $79,07 \pm 14,43 a$ \\
\hline
\end{tabular}

relationship between different texture parameters and the storage time in rice breads.

Different letters in the same column mean significantly different $(\mathrm{p}<0.05)$

In bold, the models selected for the data analysis.

With regard to cohesiveness, resilience and springiness, the model with the highest mean correlation coefficients was the reciprocal-x model, followed by the S-curve model. With the reciprocal-x model, these correlations exceeded 97\% for cohesiveness and resilience 
and $94 \%$ for springiness. In previous studies on the changes in these parameters in wheat bread, Collar and Bollain (2005) proposed the multiplicative model to study the development of cohesiveness and resilience, but Gomez et al. (2008) proposed the logarithmic-x model for cohesiveness, the reciprocal-x model for resilience and the square root-x model for springiness. In our study, the multiplicative andlogarithmic-x models also obtained good correlation coefficients for cohesiveness and resilience, and thus the changes in these parameters in gluten-free breads did not differ greatly from those observed in wheat breads. However, the reciprocal-x model showed significantly higher values than the other models and, compared with the S-curve model, the reciprocal-x is easier to interpret, and was thus the model chosen. In our study, the changes in the texture parameters were characterized by an abrupt fall in the initial values and stabilization of the values after the second day of measurement. In contrast to other models, such as the linear model, the "a" parameter did not indicate the initial value but rather the value at which the studied parameter was going to stabilize over time; it thus indicated the change. In all cases, we analyzed the initial value obtained from the mathematical model and the "a" parameter as the indicator of change.

In the case of chewiness, the correlation values were very low in the curvilinear models. The reason for the low correlation observed in the present study is the abrupt fall in chewiness observed in the initial stages of the experiment, followed by a slow recovery after the second day of measurement. The behavior thus seemed to fit better to a seconddegree polynomial model, and this was the reason for the inclusion of this model in the study. The mean correlation coefficient with the second-degree polynomial model for chewiness was over $80 \%$, noticeably higher than with the other models. In this case, the "a" value indicated the initial value of the parameter, while $b / 2 c$ defined the time to reach the minimum value, and $a-(b 2 / 2 c)+(b 2 / 4 c)$ defined the minimum value of the slope.

It is important to note that although the models used to describe the changes in the texture parameters of gluten-free breads are similar to those of gluten-containing breads, the values obtained were very different. The firmness values of gluten-free breads were lower than those obtained for gluten-containing breads in the study by Gomez et al. (2008), both initially and during the course of the study; this could be considered as a positive finding. In the case of cohesiveness, resilience and springiness, the values obtained for gluten-free breads were lower than those obtained for wheat breads in the study by Gomez et al. (2008), both initially and after a few days of storage, and the changes in these parameters progressed more rapidly in the case of wheat breads. Low values of these parameters should be considered as a negative characteristic and one of the most important defects of gluten-free breads (Matos and Rosell 2012). These values do not show an adequate fit to the proposed models for firmness and their development is therefore not closely related to starch retrogradation phenomena. However, these changes may be related to the redistribution of the internal water, which hydrates the 
gluten, the structural matrix that gives cohesion to the dough in the case of wheat gluten (Hathorn et al. 2008), or hydrocolloids in the case of gluten-free breads (Matos and Rosell 2012).

\subsection{Effect of Enzymes and Extruded}

\subsubsection{Flour on Texture}

The effects of the addition of the different enzymes and extruded flour on the texture variables are shown individually for each product in Table 3. The lipase and the extrudedflour positively affected bread volume, whereas the protease had a negative effect and the amylases showed no significant effect. Lipases are capable of acting as emulsifiers by hydrolysing the lipids in dough, and Nunes et al. (2009) have already reported that the emulsification of certain substances, such as the monoglycerides, lecithin or SSL, increases the volume of gluten-free breads. This effect may be related to an increased capacity of dough to incorporate air or to stabilization of the bubbles formed in the dough and the prevention of coalescence phenomena (Sahi and Alava 2003). In our study, the effect of adding extruded flour was similar to the effect reported in other studies using extruded rice flours, whether acidified (Clerici et al. 2009), nonacidified (Clerici and El-Dash 2006) or waxy (Sanchez et al. 2008). Defloor et al. (1991) also observed that the addition of extruded starches improved the volume of breads made with a mixture of tapioca and soya flours. These effects may be attributed to the partial gelatinization of starch during the extrusion process and to the increased consistency of the dough; these changes improve gas retention. The negative effect of proteases on volume may be explained by the effect of these enzymes on the rheology of gluten-free doughs, as they reduce dough viscosity (Renzetti and Arendt 2009) and, therefore, the capacity of the dough to retain the gas generated during fermentation. 
Table 3. Significant individual effects of design factors on bread quality and staling kinetics parameters of rice breads

\begin{tabular}{|c|c|c|c|c|c|c|c|c|c|c|c|c|}
\hline & \multicolumn{4}{|c|}{ LIP } & \multicolumn{2}{|c|}{ PROT } & \multicolumn{2}{|c|}{ G-4AMYL } & \multicolumn{2}{|c|}{ AMYL } & \multicolumn{2}{|c|}{ EXT } \\
\hline & Media & SE & 0 & 1 & 0 & 1 & 0 & 1 & 0 & 1 & 0 & 1 \\
\hline Volume & 973.4 & 15.2 & 930.5 & $1016.3^{* *}$ & 1009.7 & $937.1^{* *}$ & & & & & 915.7 & $1031.1^{* * *}$ \\
\hline Weight & 244.4 & 0.8 & 245.7 & $243.0^{*}$ & 242.7 & $246.1^{* *}$ & & & & & 246.1 & $242.7^{*}$ \\
\hline Density & 0.254 & 0.004 & 0.266 & $0.242^{* *}$ & 0.244 & $0.264^{* *}$ & & & & & 0.270 & $0.238^{* * *}$ \\
\hline Initial hardness (a) & 1.87 & 0.12 & 2.23 & $1.50 * * *$ & & & 2.20 & $1.53^{* *}$ & 2.17 & $1.56^{* *}$ & 2.38 & $1.35^{* * *}$ \\
\hline Hardness development (b) & 0.272 & 0.026 & 0.351 & $0.193^{* * *}$ & & & & & & & 0.368 & $0.176^{* * *}$ \\
\hline Initial cohesiveness & 0.434 & 0.014 & & & & & & & & & & \\
\hline $\begin{array}{l}\text { Cohesiveness development } \\
\text { (a) }\end{array}$ & 0.156 & 0.004 & & & 0.161 & $0.150^{*}$ & & & & & 0.148 & $0.164^{* *}$ \\
\hline Initial resilience & 0.239 & 0.012 & & & & & & & 0.256 & $0.221^{*}$ & & \\
\hline Resilience development (a) & 0.067 & 0.002 & & & & & & & & & 0.064 & $0.070^{*}$ \\
\hline Initial springiness & 0.737 & 0.023 & & & 0.701 & $0.774^{*}$ & & & & & & \\
\hline Springiness development (a) & 0.415 & 0.010 & & & & & 0.432 & $0.397^{*}$ & 0.440 & $0.390^{* *}$ & 0.446 & $0.383^{* * *}$ \\
\hline Initial chewiness (a) & 0,543 & 0,047 & 0,645 & $0,440 * * *$ & & & & & 0,629 & $0,456^{*}$ & 0,653 & $0,433^{* * *}$ \\
\hline Chewiness development $1^{a}$ & 6,53 & 0,528 & & & & & & & & & & \\
\hline Chewiness development $2^{\mathrm{b}}$ & 0,190 & 0,023 & & & & & & & 0,230 & $0,149^{*}$ & 0,258 & $0,122^{* *}$ \\
\hline
\end{tabular}

${ }^{a}$ Time to reach the minimum value

${ }^{\mathrm{b}}$ Minimum value

Levels $(0,1)$ of factors (A to E): A = Lipase (LIP): none (0), $0.08 \mathrm{~g} / 1000 \mathrm{~g}$ flour (1); B = Protease (PROT): none (0), $0.3 \mathrm{~g} / 1000 \mathrm{~g}$ flour (1); C = G-4 amylase (G-4AMYL): none (0), $0.9 \mathrm{~g} / 1000 \mathrm{~g}$ flour (1); D = Amylase (AMYL): none (0), $0.4 \mathrm{~g} / 1000 \mathrm{~g}$ flour (1); E = Extruded flour (EXT): none (0), $100 \mathrm{~g} / 1000 \mathrm{~g}$ flour (1).

${ }^{*} \mathrm{p}<0.05 ;{ }^{* *} \mathrm{p}<0.01 ;{ }^{* * *} \mathrm{p}<0.001$ 
We also observed that a higher bread volume was associated with a lower weight after baking. This fact can beexplained by the increased surface area of the loaves and the consequent increase in the area for moisture exchange with the exterior. In Table 3, an inverse correlation can be observed between bread volume and bread weight $(r=0.55)$. As expected, there is a high inverse correlation between volume and density $(r=0.985)$.

Firmness is the most extensively studied parameter in texture research. We observed a decrease in the initial firmness of breads with the lipase, with both amylases and with the extruded flour. However, only lipase and extruded flour were significantly associated with a reduced hardening during storage. The most intense effect on initial firmness and firmness development was observed with the addition of extruded flour, with a $43 \%$ decrease in initial firmness and a $52 \%$ decrease in firmness development. The effect of the addition of lipase and extruded flour may be related to the increase in the volume observed after the addition of these two products. An inverse correlation was found between volume and initial firmness $(r=0.670)$, which would seem logical, but we also detected an inverse correlation between volume and firmness development $(r=0.774)$, which was somehow higher than the correlation with initial firmness. These values are higher when the firmness parameters are correlated with the density of the loaves. The correlation between firmness development and volume or density has already been demonstrated in other studies on wheat bread (Axford et al. 1968; Gomez et al. 2008), although the correlation coefficients with wheat bread were higher with initial firmness than with firmness development, and were higher than those obtained in our study. However, Gomez et al. (2010) performed a study of sponge cakes - a product made with flour but which, like rice bread, does not show development of the gluten matrix - and found correlations with similar values. In that case, however, in contrast to gluten-free bread, the correlation coefficients were higher with initial firmness than with firmness development. Those authors also included layer cakes in the same study and found that volume and density showed significant correlations with firmness development but not with initial firmness. Initial firmness and firmness development can therefore be partly explained by differences in the volume or density of the loaves, but this is by no means the only factor. The addition of amylases reduces initial firmness but does not have any significant effect on the volume or density of the loaves. In gluten-free breads, contradictory effects have been observed after the addition of amylases. Although no differences in the initial firmness or in firmness development compared to controls were detected in some studies (Sciarini et al. 2012), other authors have reported a reduction in initial firmness, although with a firmness development very similar to the control product (Gujral et al. 2003). In that latter study, with similar results to those found in our study, the authorsused an amylase with intermediate stability, as we did, and the enzymatic activity could therefore have continued during the early stages of baking, when starch also starts to gelatinize and becomes more accessible to the action of enzymes. Some authors have stated that the low-molecular weight dextrins produced in this hydrolysis may interfere with the retrogradation phenomena of amylopectin (Lin and Lineback 1990; 
Defloor and Delcour 1999; Rojas et al. 2001; Leon et al. 2002) and, therefore, alter bread hardening. However, in the present study it would appear that increased amylose retrogradation was the main factor responsible for the initial firmness. The effect of the lipases, apart from their influence on volume, may be related to the generation of emulsified substances and the interaction between those substances and starch, reducing retrogradation phenomena through the formation of an amylose-lipid complex, as has already been observed after the addition of lipases to wheat breads (Leon et al. 2002; Purhagen et al. 2011). Emulsifiers have been used to reduce hardening in gluten-free breads in a number of studies (Nunes et al. 2009; Purhagen et al. 2012). As it has been mentioned, extruded flour breads present a higher volume, which can be negatively correlated either with initial firmness of the breads or their development. Furthermore, during flour extrusion at high temperatures and with sufficient humidity, starch undergoes partial gelatinization (Camire et al. 1990) and the molecules of amylopectin can be fragmented (Mason 2009). These phenomena can also have an influence on staling of breads.

As already mentioned, the low values of cohesiveness, resilience and springiness compared with typical wheat breads are one of the main problems of gluten-free breads (Matos and Rosell 2012). Cohesiveness characterizes the degree to which a material can be deformed before breaking, reflecting the internal cohesion of the material. Breads with high cohesiveness values are desirable as they allow a bolus to be formed during mastication instead of breaking up. Low cohesiveness values indicate an increased susceptibility of breads to break up or crumble (Onyango et al. 2011). Low springiness values are also indicative of greater bread fragility, leading to crumbling during slicing (McCarthy et al. 2005). Table 4 shows the high correlation between the initial cohesiveness and resilience values $(r=0.972)$ and between their development indices $(r=$ 0.908); in contrast to firmness, the initial cohesiveness and resilience values did not correlate with bread volume or density. However, a correlation was found between the development index and bread weight. The factors studied did not generally show any effect on the initial cohesiveness and resilience, except the addition of amylase, which had a negative effect as it reduced the initial resilience. In the case of the development of these parameters, the extruded flour reduced the fall in the values of cohesiveness and resilience, and thus it had a positive effect, whereas the protease increased the fall in cohesiveness and thus had a negative effect. The enzymes that affected firmness development, which is related to starch retrogradation (Leon et al. 2002), did not show any effect on cohesiveness or resilience development, and therefore this development may not be related to starch retrogradation. In contrast, there was a correlation with bread humidity, and both the extruded flour, which has high water retention capacity (Hagenimana et al. 2006), and the proteases, which reduce water retention capacity (Primo-Martin et al. 2006), had a detectable effect. It can therefore be assumed that the fall in cohesiveness and resilience are related to the water redistribution phenomena within the bread structure, as previously suggested by Hathorn et al. (2008); to minimize 
this, it would be necessary to resort to additives with a high water retention capacity, such as certain hydrocolloids (Matos and Rosell 2012).

The initial values of springiness showed a degree of correlation with the volume and density of the breads, and with the initial values of cohesiveness and resilience, as may be seen in Table 4. Only the addition of the protease showed a significant effect on springiness, producing an increase in the value. However, springiness development showed a higher correlation with bread volume, initial firmness and firmness development. We may therefore assume that springiness development can be partially explained by starch retrogradation phenomena, as occurred with firmness. However, the higher the volume and the lower the firmness of breads, the lower the value of springiness stabilization over time. Both kinds of amylase and the extruded flour, which reduced the initial firmness of breads, were also found to reduce the values of springiness stabilization. The values of initial chewiness, in particular the lowest ones, showed a high correlation with initial firmness, and thus with bread volume and density. This result would appear logical as chewiness is calculated from firmness (Chewiness $=$ Firmness * Cohesiveness * Springiness). The amylase and the extruded flour, which had a significant effect on bread firmness, showed a significant effect on the minimum chewiness values during storage, and lipase, extruded flour and amylase produced a significant decrease in initial chewiness. The changes in chewiness, as already commented for firmness, can therefore be explained, at least partially, by starch retrogradation phenomena.

Table 5 shows the interactions of combinations of two of the factors studied. In general, only a few interactions are observed; the most evident were those that occurred between the amylases and the extruded flour. It is important to note that the extruded flour presented high levels of damaged starch (Yeh et al. 1999; Chao-Chi-Chuang and Yeh 2002), which is therefore accessible to enzyme action (Tipples 1969). 
Table 4. Coefficients of correlation of the linear relationship between weight, density and texture parameters of rice breads

\begin{tabular}{|c|c|c|c|c|c|c|c|c|c|c|c|c|c|}
\hline & Weight & Density & $\begin{array}{c}\text { Initial } \\
\text { hardness } \\
\text { (a) }\end{array}$ & $\begin{array}{c}\text { Hardness } \\
\text { development } \\
\text { (b) }\end{array}$ & $\begin{array}{c}\text { Initial } \\
\text { cohesiveness }\end{array}$ & $\begin{array}{c}\text { Cohesiveness } \\
\text { development } \\
\text { (a) }\end{array}$ & $\begin{array}{c}\text { Initial } \\
\text { resilience }\end{array}$ & $\begin{array}{c}\text { Resilience } \\
\text { development } \\
\text { (a) }\end{array}$ & $\begin{array}{c}\text { Initial } \\
\text { springiness }\end{array}$ & $\begin{array}{l}\text { Springiness } \\
\text { development } \\
\text { (a) }\end{array}$ & $\begin{array}{l}\text { Initial } \\
\text { chewiness } \\
\text { (a) }\end{array}$ & $\begin{array}{c}\text { Chewiness } \\
\text { development } \\
1^{\mathrm{a}}\end{array}$ & $\begin{array}{c}\text { Chewiness } \\
\text { development } \\
2^{\mathrm{b}}\end{array}$ \\
\hline Volume & $-0.550^{* *}$ & $-0.985^{* * *}$ & $-0.670^{* * *}$ & $-0.774^{* * *}$ & & $0.411^{*}$ & & & $-0.422^{*}$ & $-0.635^{* * *}$ & $-0.662^{* * *}$ & & $-0,369^{* * *}$ \\
\hline Weight & & $0.641^{* * *}$ & & $0.597^{* * *}$ & & $-0.494^{* *}$ & & $-0.475^{* *}$ & & $0.477^{* *}$ & $0.389^{*}$ & & $0,359^{*}$ \\
\hline Density & & & $0.677^{* * *}$ & $0.819^{* * *}$ & & $-0.422^{*}$ & & & $0.422^{*}$ & $0.688^{* * *}$ & $0.677^{* * *}$ & & $0,663^{* * *}$ \\
\hline Initial hardness (a) & & & & $0.696^{* * *}$ & & & & & & $0.757^{* * *}$ & $0.741^{* * *}$ & $-0,397^{*}$ & $0,818^{* * *}$ \\
\hline $\begin{array}{l}\text { Hardness } \\
\text { development (b) }\end{array}$ & & & & & & $-0.471^{* *}$ & & $-0.401^{*}$ & & $0.699^{* * *}$ & $0.659^{* * *}$ & & $0,789^{* * *}$ \\
\hline Initial cohesiveness & & & & & & & $0.972^{* * *}$ & & $0.463^{* *}$ & & & & \\
\hline $\begin{array}{l}\text { Cohesiveness } \\
\text { development (a) }\end{array}$ & & & & & & & & $0.908^{* * *}$ & & & & & \\
\hline Initial resilience & & & & & & & & & $0.504^{* *}$ & & & & \\
\hline $\begin{array}{l}\text { Resilience } \\
\text { development (a) }\end{array}$ & & & & & & & & & & & & & \\
\hline Initial springiness & & & & & & & & & & $0.511^{* *}$ & & & \\
\hline $\begin{array}{l}\text { Springiness evolution } \\
\text { (a) }\end{array}$ & & & & & & & & & & & $0.646^{* * *}$ & & $0,799^{* * *}$ \\
\hline Initial chewiness (a) & & & & & & & & & & & & & $0,704^{* * *}$ \\
\hline $\begin{array}{l}\text { Chewiness } \\
\text { development } 1^{\text {a }}\end{array}$ & & & & & & & & & & & & & \\
\hline
\end{tabular}

${ }^{a}$ Time to reach the minimum value

${ }^{\mathrm{b}}$ Minimum value

${ }^{*} \mathrm{p}<0.05 ;{ }^{* *} \mathrm{p}<0.01 ;{ }^{* * *} \mathrm{p}<0.001$ 
Table 5. Significant second-order interactive effects of design factors on bread quality and staling kinetics parameters of rice breads

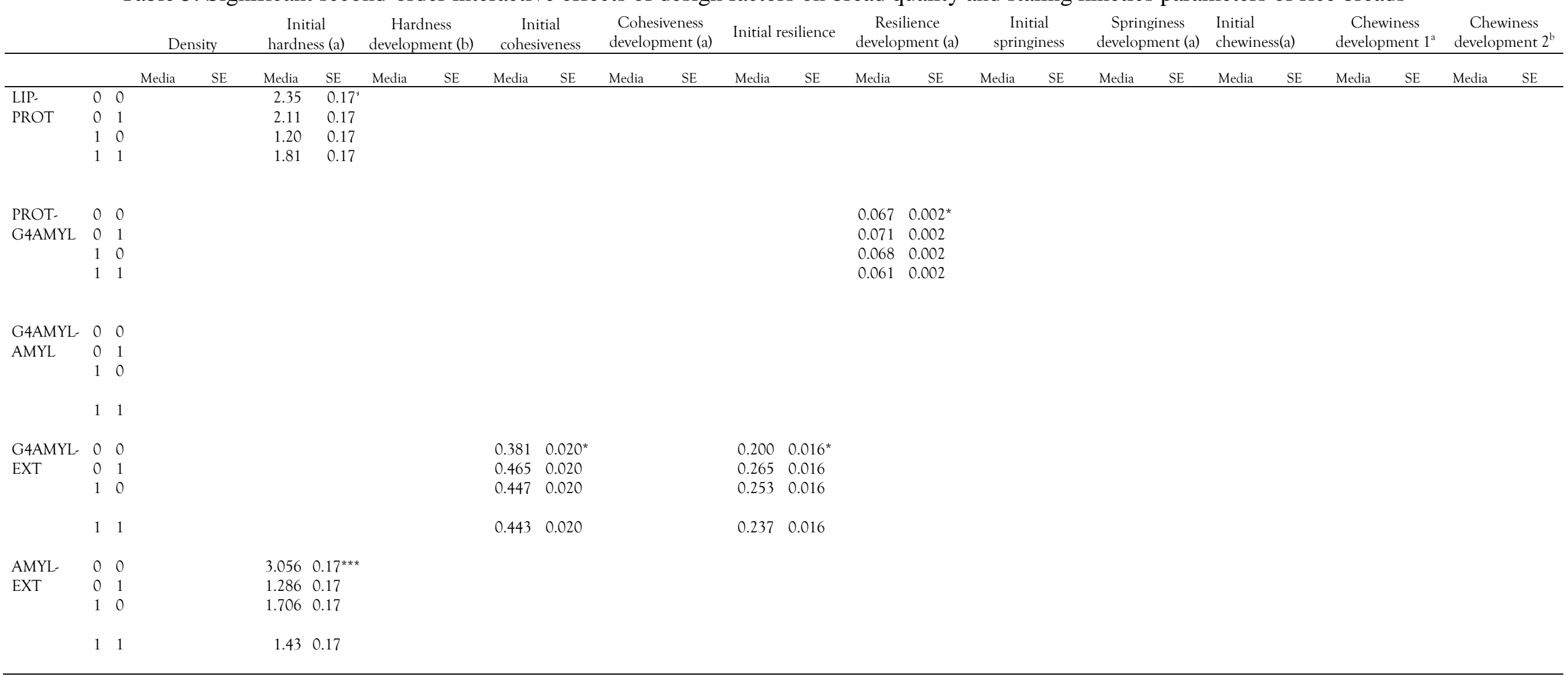

${ }^{a}$ Time to reach the minimum value

${ }^{\mathrm{b}}$ Minimum value

Levels $(0,1)$ of factors (A to E): A = Lipase (LIP): none (0), $0.08 \mathrm{~g} / 1000 \mathrm{~g}$ flour (1); B = Protease (PROT): none (0), $0.3 \mathrm{~g} / 1000 \mathrm{~g}$ flour (1); C = G-4 amylase (G-4AMYL): none (0),

$0.9 \mathrm{~g} / 1000 \mathrm{~g}$ flour (1); $\mathrm{D}=$ Amylase (AMYL): none (0), $0.4 \mathrm{~g} / 1000 \mathrm{~g}$ flour (1); $\mathrm{E}=$ Extruded flour (EXT): none (0), $100 \mathrm{~g} / 1000 \mathrm{~g}$ flour (1).

${ }^{*} \mathrm{p}<0.05 ;{ }^{* *} \mathrm{p}<0.01 ;{ }^{* * *} \mathrm{p}<0.001$

\section{Mario Martínez Martínez}

Extruded flours: Applications and new functionality 


\section{Conclusion}

The model of the texture parameters has enabled us to study the influence of different factors on the staling of gluten-free breads. The addition of lipases and extruded flour can improve the quality of rice breads by increasing the volume, reducing initial firmness and delaying hardening. Extruded flour can also minimize the loss of cohesiveness and resilience of these breads. However, the degrees of cohesiveness and resilience of rice breads are still very low in comparison with those of wheat breads and are not related to other texture parameters, such as firmness. Further studies are therefore required to establish methods to increase these values.

\section{$\underline{\text { Acknowledgments }}$}

This study was supported financially by Junta de Castilla y León (VA054A12-2), Spain. The authors are also grateful to Harinera Los Pisones in Zamora, Spain, for supplying the rice flours and to Dupont Nutrition and Biosciences Ibérica for supplying the enzymes.

\section{$\underline{\text { References }}$}

ARMERO, E. and COLLAR, C. 1998. Crumb firming kinetics of wheat breads with antistaling additives. J. Cereal Sci. 28, 165-174.

AXFORD, D.W.E., COLWELl, K.H., CORNFORD, S.J. and ELTON, G.A.H. 1968. Effect of loaf specific volume on rate and extent of staling in bread. J. Sci. Food Agric. 19, 95-101.

BAKER, L.A. and RAYAS-DUARTE, P. 1998. Retrogradation of amaranth starch at different storage temperatures and the effects of salt and sugars. Cereal Chem 75, 308314.

CAMIRE, M., CAMIRE, A. and KRUMHAR, K. 1990. Chemical and nutritional changes in foods during extrusion. Crit. Rev. Food Sci. Nutr. 29, 35-57.

CHAO-CHI-CHUANG, G. and YEH, A. 2002. Effects of product temperature and moisture content on viscoelastic properties of glutinous rice extrudate. Cereal Chem. 79, $36-40$.

ClERICI, M., ARIOLDI, C. and EL-DASH, A. 2009. Production of acidic extruder rice flour and its influence on the qualities of gluten free bread. LWT-Food Sci. Technol. 42, $618-623$.

CLERICI, M. and EL-DASH, A. 2006. Extruder rice flour as a gluten substitute in the production of rice bread. Arch. Latinoam. Nutr. 56, 288-294. 
COLLAR, C. and BOLLAIN, C. 2005. Impact of microbial transglutaminase on the staling behaviour of enzyme-supplemented pan breads. Eur. Food Res. Technol. 221, 298-304.

DEFlOOR, I., DE GEEST, C., SCHELlEKENS, M., MARTENS, A. and DELCOUR, J. 1991. Emulsifiers and/or extruded starch in the productions of breads from cassava. Cereal Chem. 68, 323-327.

DEFLOOR, I. and DELCOUR, J.A. 1999. Impact of malto dextrins and antistaling enzymes on the differential scanning calorimetry staling endotherm of wheat flour-water doughs. J. Agric. Food Chem. 47, 737-741.

EVERY, D., GERRARD, J.A., GILPIN, M.J., ROSS, M. and NEWBERRY, M.P. 1998. Staling in starch bread: The effect of gluten additions on specific loaf volume and firming rate. Starch-Starke 50, 443-446.

GOMEZ, M., Oliete, B., PANDO, V., RONDA, F. and CABAllERO, P.A. 2008. Effect of fermentation conditions on bread staling kinetics. Eur. Food Res. Technol. 226, 1379-1387.

GOMEZ, M., RUIZ-PARIS, E., OLIETE, B. and PANDO, V. 2010. Modeling of texture evolution of cakes during storage. J. Texture Stud. 41, 17-33.

GUJRAL, H.S., HAROS, M. and ROSELL, C.M. 2003. Starch hydrolyzing enzymes for retarding the staling of rice bread. Cereal Chem. 80, 750-754.

HAGENIMANA, A., DING, X. and FANG, T. 2006. Evaluation of rice flour modified by extrusion cooking. J. Cereal Sci. 43, 38-46.

HAGER, A.S., RYAN, L.A.M., SCHWAB, C., GAENZLE, M.G., O’DOHERTY, J.V. and ARENDT, E.K. 2011. Influence of the soluble fibres inulin and oat beta-glucan on quality of dough and bread. Eur. Food Res. Technol. 232, 405-413.

HAMADA, S., SUZUKI, K., AOKI, N. and SUZUKI, Y. 2013. Improvements in the qualities of gluten-free bread after using a protease obtained from Aspergillus oryzae. J. Cereal Sci. 57, 91-97.

HATHORN, C.S., BISWAS, M.A., GICHUHI, P.N. and BOWELL-BENJAMIN, A.C. 2008. Comparison of chemical, physical, micro-structural, and microbial properties of breads supplemented with sweet potato flour and high gluten dough enhancers. LWTFood Sci. Technol. 41, 803-815.

HUETTNER, E.K., DAL BELLO, F. and ARENDT, E.K. 2010. Fundamental study on the effect of hydrostatic pressure treatment on the bread-making performance of oat flour. Eur. Food Res. Technol. 230, 827-835. 
JEKLE, M. and BECKER, T. 2012. Effects of acidification, sodium chloride, and moisture levels on wheat dough: II. Modeling of bread texture and staling kinetics. Food Biophys 7, 200-208.

KADAN, R.S., ROBINSON, M.G., THIBODEUX, D.P. and PEPPERMAN, A.B. 2001. Texture and other physiochemical properties of whole rice bread. J. Food Sci. 66, 940944.

LEON, A.E., DURAN, E. and DE BARBER, C.B. 2002. Utilization of enzyme mixtures to retard bread crumb firming. J. Agric. Food Chem. 50, 1416-1419.

LIN,W. and LINEBACK, D.R. 1990. Changes in carbohydrate fractions in enzymesupplemented bread and the potential relationship to staling. Starch 42, 385-394.

MASON,W.R. 2009. Starch use in foods. In Starch Chemistry and Technology (J. BeMiller and R. Wristler, eds.) pp. 745-795, Academic Press, Oxford, U.K.

MATOS, M.E. and ROSELL, C.M. 2012. Relationship between instrumental parameters and sensory characteristics in gluten free breads. Eur. Food Res. Technol. 235, 107-117.

MCCARTHY, D.F., GALlAGUER, E., GORMLEY, T.R., SCHOBER, T.J. and ARENDT, E.K. 2005. Application of response surface methodology in the development of gluten free bread. Cereal Chem. 82, 609-615.

NUNES, M.B., MOORE, M.M., RYAN, L.A.M. and ARENDT, E.K. 2009. Impact of emulsifiers on the quality and rheological properties of gluten-free breads and batters. Eur. Food Res. Technol. 228, 633-642.

ONYANGO, C., MUtUNGI, C., UNBEHEND, G. and LINDHAUER, M.G. 2011. Modification of gluten free sorghum batter and bread using maize, potato, cassava or rice starch. LWT-Food Sci. Technol. 44, 681-686.

PRIMO-MARTIN, C., DE PIJPEKAMP, A.V., VAN VLIET, T., DE JONGH, H.H.J., PLIJTER, J.J. and HAMER, R.J. 2006. The role of the gluten network in the crispness of bread crust. J. Cereal Sci. 43, 342-352.

PURHAGEN, J.K., SJOO, M.E. and ELIASSON, A.C. 2011. Starch affecting anti-staling agents and their function in freestanding and pan-baked bread. Food Hydrocolloid 25, $1656-1666$.

PURHAGEN, J.K., SJOO, M.E. and ELIASSON, A.C. 2012. The anti-staling effect of pre-gelatinized flour and emulsifier in gluten-free bread. Eur. Food Res. Technol. 235, 265-276.

RASMUSSEN, P.H. and HANSEN, A. 2001. Staling of wheat bread stored in modified atmosphere. LWT-Food Sci. Technol. 34, 487-491. 
RENZETTI, S. and ARENDT, E.K. 2009. Effects of oxidase and protease treatments on the breadmaking functionality of a range of gluten-free flours. Eur. Food Res. Technol. $229,307-317$.

ROJAS, J.A., ROSELl, C.M. and BENEDITO DE BARBER, C. 2001. Role of maltodextrins in the staling of starch gels. Eur. Food Res. Technol. 212, 364-368.

ROSELL, C.M. 2009. Enzymatic manipulation of gluten-free breads. In Gluten-Free Food Science and Technology (E. Gallagher, ed.) pp. 83-98,Wiley-Blackwell, Chichester, U.K.

SAHI, S. and ALAVA, J. 2003. Functionality of emulsifiers in sponge cake production. J. Sci. Food Agric. 83, 1419-1429.

SCIARINI, L.S., RIBOTTA, P.D., LEON, A.E. and PEREZ, G.T. 2010a. Effect of hydrocolloids on gluten-free batter properties and bread quality. Int. J. Food Sci. Technol. 45, 2306-2312.

SCIARINI, L.S., RIBOTTA, P.D., LEON, A.E. and PEREZ, G.T. 2010b. Influence of gluten-free flours and their mixtures on batter properties and bread quality. Food Bioprocess. Technol. 3, 577-585.

SCIARINI, L.S., RIBOTTA, P.D., LEON, A.E. and PEREZ, G.T. 2012. Incorporation of several additives into gluten free breads: Effect on dough properties and bread quality. J. Food Eng. 111, 590-597.

TIPPLES, H. 1969. The relation of starch damage to the baking performance of flour. Bakers Digest 43, 28-32.

SANCHEZ, H., GONZALEZ, R., OSELlA, C., TORRES, R. and DE LA TORRE, M. 2008. Elaboration of bread without gluten from extruded rice flour. Cienc. Tecnol. Aliment. 6, 109-116.

VALLONS, K.J.R., RYAN, L.A.M., KOEHLER, P. and ARENDT, E.K. 2010. High pressure-treated sorghum flour as a functional ingredient in the production of sorghum bread. Eur. Food Res. Technol. 231, 711-717.

WITCZAK, M., KORUS, J., ZIOBRO, R. and JUSZCZAK, L. 2010. The effects of maltodextrins on gluten-free dough and quality of bread. J. Food Eng. 96, 258-265.

YEH, A., WU, T. and JAW, Y. 1999. Starch transitions and their influence on flow pattern during single-screw extrusion cooking of rice flour. Food Bioprod. Process. 77, $47-54$.

ZHANG,W. and JACKSON, D.S. 1992. Retrogradation behaviour of wheat-starch gels with differing molecular profiles. J. Food Sci. 57, 1428-1432. 
ZIOBRO, R., KORUS, J., WITCZAK, M. and JUSZCZAK, L. 2012. Influence of modified starches on properties of gluten-free dough and bread. Part II: Quality and staling of gluten-free bread. Food Hydrocolloid 29, 68-74. 


\title{
CHAPTER 4
}

\section{Taking advantage of the high chemical reactivity of extruded flours towards enzyme catalysis}

Food Chemistry 167 (2015) 447-453

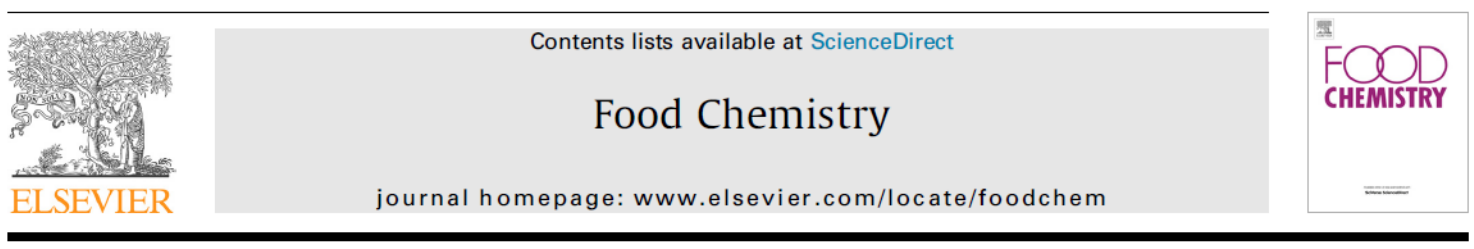

Physicochemical modification of native and extruded wheat flours by enzymatic amylolysis

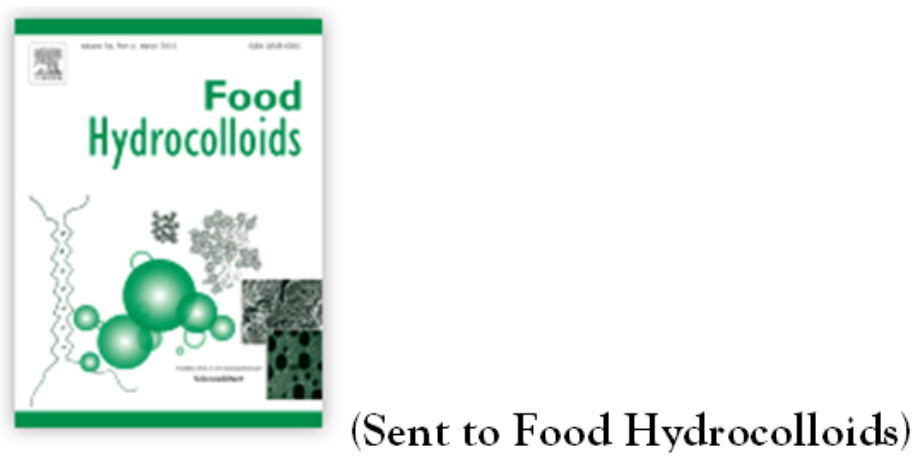

Synergistic maltogenic $\alpha$-amylase and branching treatment to produce enzyme-resistant molecular and supramolecular structures in extruded matrices

\author{
Mario M. Martínez ${ }^{1 *}$, Joana Pico ${ }^{2}$, Manuel Gómez ${ }^{1}$ \\ ${ }^{1}$ Food Technology Area, College of Agricultural Engineering, University of Valladolid, 34004, Palencia, Spain




\subsection{Physicochemical modification of native and extruded wheat flours by enzymatic amylolysis}

Food Chemistry 167 (2015) 447-453

\section{Introduction}

Native starches and flours are widely used as raw materials, due to their particular polymeric characteristics, which make them suitable for numerous food applications. However, the new demands of the food industry quality requirements of foodstuff are forcing manufacturers of starchy ingredients to find new functionalities. Starch modification by enzymatic hydrolysis could be an alternative way to control the functionality making the label cleaner unlike the chemically modified starches or syrups control the functionality and physicochemical properties of starches and flours (Chiu \& Solarek, 2009).

Starch hydrolysis generates products with different dextrose equivalents (DE), depending on the time of incubation and the amount and type of enzyme being used. Two major hydrolysis products are maltodextrins that consist of partly hydrolysed starch chains with a DE below 30, and glucose and maltose syrups with a DE above 40 that contain mono-, di-, and some higher saccharides (Baks, Kappen, Janssen, \& Boom, 2008). Maltodextrins are nonsweet, cold water soluble, and have water-holding characteristics. They can be used as carrier or bulk agents, texture providers, spray-drying aids for the production of flavour enhancers, fat replacers, film formers, freeze-control agents to prevent crystallisation, or to supply nutritional value (Ba, Blecker, Danthine, Tine, Destain, \& Thonart, 2013). Meanwhile, glucose and maltose syrups are employed in a variety of foods like soda water, sweets, baked products, ice-creams, sauces, baby food, conserves, and tined food.

Amylases, together with amyloglucosidases, are the enzymes most commonly used in starch hydrolysis. Alpha-amylase is an endoamylase that cleaves the $\alpha-1,4$ glycosidic bonds of the amylose or amylopectin chain at internal positions (endo) to yield products (oligosaccharides with varying lengths and branched oligosaccharides called limit dextrins) 
with an $\alpha$-configuration. Meanwhile, amyloglucosidase catalyses the hydrolysis of both $\alpha$ 1,4 and $\alpha-1,6$ glycosidic bonds at the branching point to release $\beta$-D-glucose residues of the polymer substrate (van der Maarel, van der Veen, Uitdehaag, Leemhuis, \& Dijkhuizen, 2002). Because of these different mechanisms of amylolysis, selection of the type and amount of enzyme is important, since it will determine the physicochemical properties of the final flour or starch.

Native starch granules are semi-crystalline and resistant to enzyme hydrolysis. Native granular starch is hydrolysed very slowly by both amylases and amyloglucosidase, but disruption of the starch granular structure (gelatinisation) could enhance its chemical reactivity towards hydrolytic enzymes (Uthumporn, Shariffa, \& Karim, 2012). Extrusion cooking is a hydrothermal treatment of high temperature and short duration, during which flours or starches are subjected to high temperatures and mechanical shearing at relatively low levels of moisture content (Camire, Camire, \& Krumhar, 1990). By means of extrusion, it is possible to gelatinise the starch present in cereal flour (Martínez, Calviño, Rosell \& Gómez, 2014). Several authors have used extruders to gelatinise native starch and hydrolyse it enzymatically (Govindasamy, Campanella, \& Oates, 1997a, 1997b; Lee \& Kim, 1990; Vasanthan, Yeung, \& Hoover, 2001).

The vast majority of the studies about hydrolysis of cereal-based products focus on starch modification whereas; flour modification has been scarcely investigated. Vasanthan, et al., (2001) studied the dextrinisation of barley flours with alpha-amylase by extrusion. Flours are fine, powdery materials obtained by grinding and sifting the starch-containing plant organelles. Components often found in flours include starch, non-starch polysaccharide, sugar, protein, lipid, and inorganic materials. Thereby, the interactions between starch and non-starch components of flour during hydrothermal and enzymatic treatments are possibly different from that of starch. Commercial wheat flour is produced by milling of wheat kernels, whereas wheat starch is generally obtained by gluten agglomeration. Such a treatment involves four major issues to consider: raw materials, products, cost and operability (Maningat, Seib, Bassi, Woo \& Lasater, 2009). Moreover, water consumption and effluent disposal demand careful operation of the plant (Maningat, Seib, Bassi, Woo $\&$ Lasater, 2009). Therefore the lower cost and environmental impact of subjecting wheat flour instead wheat starch to enzymatic hydrolysis could made flour modifications a better alternative for industrial processes.Vasanthan, et al., (2001) studied the dextrinisation of barley flours with alpha-amylase by extrusion.

Despite the particular physicochemical characteristics of extruded flours and their high susceptibility to enzymatic hydrolysis, the properties of their hydrolysed products have never been studied, nor have they been compared with hydrolysed products of native flours. The objective of the present study was to investigate the effect of a potential feasible industrial enzymatic hydrolysis (by alpha-amylase, amyloglucosidase, or a blend of both) extrusion on microstructure, oligosaccharide composition, crystallinity, pasting, 
colour, and hydration properties of native and extruded wheat flours. hydrolysed by alpha-amylase, amyloglucosidase, or a blend of both.

\section{Materials and methods}

\subsection{Materials}

Native wheat flour $(11.73 \%$ and $11.20 \% \mathrm{w} / \mathrm{w}$ of moisture and protein contents, respectively) was supplied by Harinera Castellana (Medina del Campo, Valladolid, Spain). Extruded modified wheat flour was provided by Harinera Los Pisones (Zamora, Spain), which performed the extrusion treatment using a Bühler Basf single screw extruder (Bühler S.A., Uzwil, Switzerland). The extrusion conditions were carried out based on preliminary experiences in order to ensure the starch gelatinization. The length-todiameter (L/D) ratio for the extruder was 20:1. Wheat flour was extruded at a maximum barrel temperature of $160^{\circ} \mathrm{C}$ and a feed moisture content of $50 \mathrm{~L} / \mathrm{h}$, with a feed rate of $500 \mathrm{~kg} / \mathrm{h}$ and with a screw speed of $340 \mathrm{rpm}$. The extruded product was dried by convection air till it reached $11.2 \%$ of moisture. Then it was ground with a compression roller to a particle size below 200 microns.

The amyloglucosidase from Aspergillus niger AMILASETM AG 300L (300 AGU/mL) and the fungal alpha-amylase Fungamil ${ }^{\circledR}$ 800L from Aspergullus oryzae (800 FAU/g) were gently provided by Novozymes (Bagsvaerd, Denmark).

\subsection{Methods}

\subsubsection{Flour hydrolysis}

The quantity of enzymes was based on previous experiments, where the minimum amount of enzyme to produce changes in the viscosity of starch slurries was selected. Amylase and amyloglucosidase flour slurries with a $0.2 \% \mathrm{w} / \mathrm{w}$ of enzyme (flour basis) were made by dissolving $0.1 \mathrm{~g}( \pm 0.001)$ of amylase or amyloglucosidase solution $(20 \% \mathrm{w} / \mathrm{w}$ of enzyme) respectively into $40 \mathrm{~mL}( \pm 0.01)$ of distilled water. In the case of using both enzymes simultaneously, $0.05 \mathrm{~g}( \pm 0.001)$ of each enzyme was dissolved. The quantity of flour was also selected based on preliminary tests, in order to achieve suspensions easily dryable. Then, $10 \mathrm{~g}$ of flour were added to the enzyme solution previously prepared and mixed to achieve a homogenous paste. These pastes were covered by plastic film to avoid drying of the sample and then incubated at $50^{\circ} \mathrm{C}$ for 2 hours. With the aim of bringing to an end the enzymatic activity, the pastes were heated at $105^{\circ} \mathrm{C}$ for 4 hours. Afterwards, they were rested in a desiccator at room temperature for 3 minutes, before being milled in a Moulinex super junior s (Groupe Seb Iberica, S.A, Barcelona) for 20 seconds. Flours were stored in airtight plastic containers at $4^{\circ} \mathrm{C}$ until analysis. Thereby, the whole process of flour hydrolysis was performed considering the feasibility of further potential industrial processes in the food industry. 


\subsubsection{Environmental scanning electron microscopy (ESEM)}

Flour photomicrographs were taken with a Quanta 200FEI (Hillsboro, Oregon, USA) ESEM. Photomicrographs were taken in beam deceleration mode (BDM) at $1.5 \mathrm{KeV}$ in high vacuum mode with a backscattered electron detector (BSED).

\subsubsection{Oligosaccharide content of flours by High Performance Anion Exchange Chromatography} with Pulsed Amperometric Detection (HPAEC-PAD)

The aim of the HPAEC-PAD analysis was to determine the content of oligosaccharides in the extruded and non-extruded enzymatically treated flours. D-(+)-Glucose, maltose monohydrate, maltotetraose, and maltopentaose (Neat, Sigma-Aldrich, Steinheim, Germany), isomaltose (98\%, Sigma-Aldrich, Steinheim, Germany), and maltotriose hydrate (95\%, Sigma-Aldrich, Steinheim, Germany) were the standards employed to analyse these compounds in the flours studied.

Sample treatment consisted of solid-liquid extraction with MilliQ deionised water (Millipore, Molsheim, France) without derivatisation. Then, $0.5 \mathrm{~g}( \pm 0.09)$ of the ground sample were weighed in a falcon tube, $15 \mathrm{~mL}$ of water were added, and the mixture was shaken for 5 minutes at $430 \mathrm{rpm}$ in a shaker. Then, $2 \mathrm{~mL}$ of Carrez II reagent [potassium hexacyanoferrate (II) trihydrate, Panreac, Barcelona, Spain] were added and the mixture was shaken again for 5 minutes at $430 \mathrm{rpm}$. The mixture was centrifuged for 20 minutes at $12,000 \mathrm{rpm}$ and $20^{\circ} \mathrm{C}$ and immediately after, to avoid re-suspension of the precipitate, the supernatant was transferred to a flask. A second extraction was needed; therefore, another $15 \mathrm{~mL}$ of water were added to the solid phase obtained from the centrifugation, the mixture was again shaken for 5 minutes at $430 \mathrm{rpm}$ and centrifuged for 20 minutes at $12,000 \mathrm{rpm}$ and $20^{\circ} \mathrm{C}$. Afterwards, the supernatant was transferred to the flask containing the first extract. After making up to the volume with water, a suitable dilution was filtered with $0.45 \mu \mathrm{m}$ nylon filters into the vial and then injected.

HPAEC-PAD analyses were carried out on a Metrohm system (Herisau, Switzerland) consisting of an 850 Professional IC with an isocratic pump, an automatic 858 Professional Sample Processor with ultrafiltration, an 872 extension module to provide another pump and the possibility of making gradients, and an IC Amperometric Detector working as a pulsed amperometric detector (PAD) with a gold electrode as the working electrode and a palladium electrode as the reference electrode. MagICnet software (Metrohm, Herisau, Switzerland) was used to analyse the chromatograms.

Separation was achieved on a Hamilton RCX-30 column and a Metrosep RP2 Guard precolumn from Metrohm (Herisau, Switzerland), with the same stationary phase as the column. Column and precolumn were thermostated at $30^{\circ} \mathrm{C}$ and the PAD at $35^{\circ} \mathrm{C}$. The flow rate was $1.0 \mathrm{~mL} / \mathrm{min}$ constantly and the volume injection was $20 \mu \mathrm{L}$. A binary gradient solvent system was used as mobile phase, consisting of (A) $50 \mathrm{mM} \mathrm{NaOH}$ (Panreac, Barcelona, Spain) and (B) a mixture of $500 \mathrm{mM} \mathrm{NaAcO}$ (Panreac, Barcelona, 
Spain) and $50 \mathrm{mM} \mathrm{NaOH}$. The gradient was as follows: initial conditions of $95 \% \mathrm{~A}$, then down linearly from the start to 15 minutes until $80 \% \mathrm{~A}$, held from 15 to 25 minutes at $80 \% \mathrm{~A}$, then returned to the initial conditions, rising linearly from 25 to 28 minutes to 95\% A and finally, held at 95\% A for 10 minutes. The total run was 38 minutes. The potentials and time periods for the pulsed amperometric detector were: $\mathrm{E} 1,+100 \mathrm{mV}(\mathrm{t} 1$ $=300 \mathrm{~ms}) ; \mathrm{E} 2,+550 \mathrm{mV}(\mathrm{t} 2=50 \mathrm{~ms})$; and E3, $-100 \mathrm{mV}(\mathrm{t} 3=200 \mathrm{~ms})$. Measurements were made in duplicate.

\subsubsection{Flour crystallinity by X-ray diffraction}

Crystallinity of samples was determined using a Bruker D8 Discover A25 X-ray diffractometer (Bruker AXS, Rheinfelden, Germany) equipped with a copper tube operating at $40 \mathrm{kV}$ and $40 \mathrm{~mA}$, producing CuKa radiation of $0.154 \mathrm{~nm}$ wavelength. Diffractograms were obtained by scanning from 5 to $40^{\circ}$ ( 2 theta), at the rate of $1.2 \% \mathrm{~min}$, a step size of $0.02^{\circ}$, a divergence slit width variable (DS) of $5 \mathrm{~mm}$, and a scatter slit width (SS) of $2.92^{\circ}$.

\subsubsection{Pasting properties}

Pasting properties of the normal and extruded enzymatically treated flours were determined using a Rapid Visco Analyser (Model RVA-4C, Newport Scientific Pty. Ltd., Warriewood, Australia). The flour slurry was prepared by dispersing $3.5 \mathrm{~g}( \pm 0.1)$ of the flour in $25 \mathrm{~g}( \pm 0.1)$ of distilled water. The slurry was then poured into an aluminium canister and stirred manually using a plastic paddle for 20 seconds before being poured into the RVA machine. The heating and cooling cycles were programmed following general pasting method 61.02.01 (AACC, 2012). The test was run in duplicate.

\subsubsection{Gel hydration properties}

Water absorption index (WAI) or swelling capacity and water solubility index (WSI) of different rice flour fractions were determined following the method of Toyokawa, Rubenthaler, Powers, \& Schanus (1989), with slight modification, as reported Rosell, Yokoyama, \& Shoemaker (2011). Briefly, the flour $(50.0 \pm 0.1 \mathrm{mg})$ sample was dispersed in $1.0 \mathrm{~mL}$ of distilled water in an eppendorf tube using a wire rod and cooked at $90^{\circ} \mathrm{C}$ for 10 minutes in a water bath. The cooked paste was cooled in an ice water bath for 10 minutes, and then centrifuged at $3000 \times \mathrm{g}$ at $4^{\circ} \mathrm{C}$ for 10 minutes. The supernatant was decanted into an evaporating dish and the dry solids were recovered by evaporating the supernatant at $105^{\circ} \mathrm{C}$ till constant weight. Four replicates were made for each sample. Residues (Wr) and dried supernatants (Ws) were weighed and WAI, WSI, and swelling power (SP) were calculated as follows:

WAI $(g / g)=W r / W i$

WSI $(\mathrm{g} / 100 \mathrm{~g})=(\mathrm{Ws} / \mathrm{Wi}) \times 100$ 
$\mathrm{SP}(\mathrm{g} / \mathrm{g})=\mathrm{Wr} /(\mathrm{Wi}-\mathrm{Ws})$

where $\mathrm{Wi}$ is the sample weight $(\mathrm{g}, \mathrm{db})$. Values are expressed as the average of three four replicates.

\subsubsection{Colour determination of flours}

Colour was measured using a Minolta CN-508i spectrophotometer (Minolta, Co. Ltd. Tokyo, Japan) with the D65 standard illuminant and the $2^{\circ}$ standard observer. The results are expressed in the CIE L*a* $b^{*}$ colour space. Colour determinations were made five times at two different points on each sample of flour.

\subsection{Statistical analysis}

Multiple analysis of variance was used to determine the individual effects of the type of enzyme and flour. Fisher's least significant difference (LSD) was used to describe means with 95\% confidence intervals. Statistical analysis was performed with Statgraphics Centurion XVI software (Statpoint Technologies, Inc., Warrenton, VA, USA).

\section{$\underline{3 \text { Results and discussion }}$}

\subsection{Photomicrographs of flours}

With the objective to observe the effect of extrusion on the susceptibility of flour particles to enzymatic hydrolysis by amylase and amyloglucosidase, the microstructure was analysed using ESEM (Figure 1). Native and extruded wheat flour particles not treated with enzymes (Figure 1a and Figure 1d) had a polygonal shape and small superficial irregularities. The fact that significant differences were scarcely observed between them would suggest that the drying process used to halt the enzymatic activity also produced partial gelatinisation of starch granules. However, there were some non-gelatinised starch granules in the native flour, whereas they were not found in the extruded flour, where all starch granules were completely melted during the extrusion treatment. Thus, the drying process did not prevent significant differences between native and extruded samples. Thus the observed differences cannot be explained only by the drying process but also by the extrusion process. 

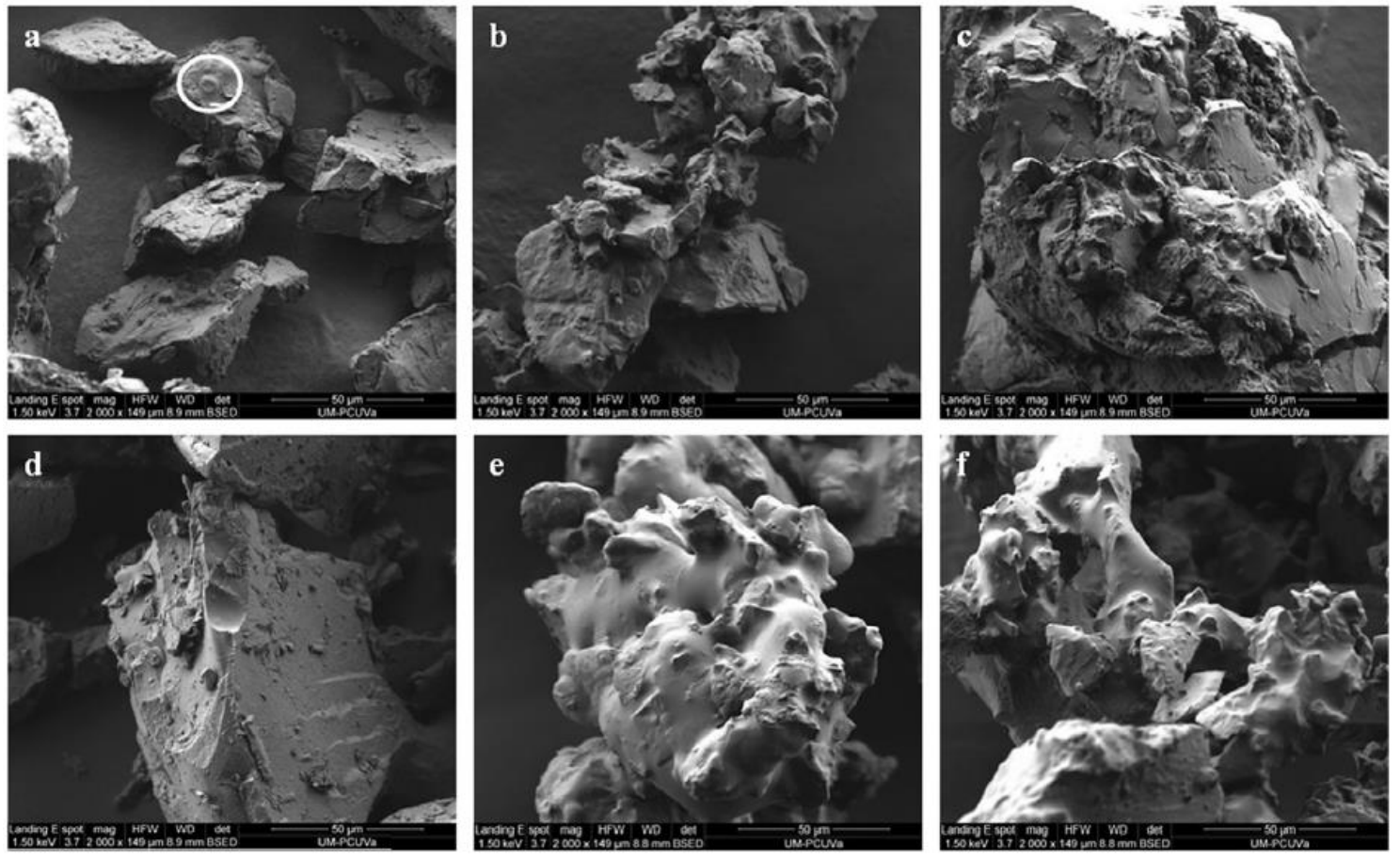

Fig. 1. Scanning electron micrographs (2000x magnification) of native and extruded flours. Native wheat flour without enzyme treatment (a), native wheat flour treated with amylase (b), native wheat flour treated with amyloglucosidase (c), extruded wheat flour without enzyme treatment (d), extruded wheat flour treated with amylase (e), and extruded wheat flour treated with amyloglucosidase (f). The white circle indicates nongelatinised starch granules.

Native flour particles treated by amylase (Figure 1b) appeared disaggregated, disrupted, and pasted to each other, which could be explained by the leaching of some of the amylose, which acted as a gluing material (Dura, Błaszczak \& Rosell, 2014). Meanwhile, extruded flour particles (Figure 1e) showed a more amassed structure, with a melting component joining the granules. Chain fragmentation of polymers such as amylose during the extrusion (Chinnaswamy \& Hannah, 1990) and the enzymatic processes could lead to leaching of amylose, resulting in greater abundance of gel in the extruded samples.

Native flour particles treated by amyloglucosidase (Figure 1c) showed only a superficial corrosion promoted by the enzyme, whereas extruded wheat flour (Figure 1f) was much easier to hydrolase and the particles ended up almost completely disrupted, with a melting component joining the granules. Therefore, a higher susceptibility of extruded wheat flour to enzymatic hydrolysis was observed. Uthumporn, et al. (2012) has already reported that starch molecules compacted inside the starch granules simply cannot be readily accessed by enzymes. Thus, starch gelatinisation during extrusion enhances the chemical reactivity of flour particles towards hydrolytic enzymes. 


\subsection{Oligosaccharide content of flours}

The oligosaccharide content of native and extruded wheat flours was analysed by HPAECPAD in order to evaluate the susceptibility of native and extruded wheat flours to enzymatic hydrolysis (Figure 2). Maltotetraose and maltopentaose were not present in any flour, or were under the limits of detection. We observed a three-fold increase of maltose and maltotriose contents with amylase treatment compared with extruded flours. Glucose content increased with the use of amyloglucosidase, especially in extruded wheat flours (six times higher than its native counterpart).

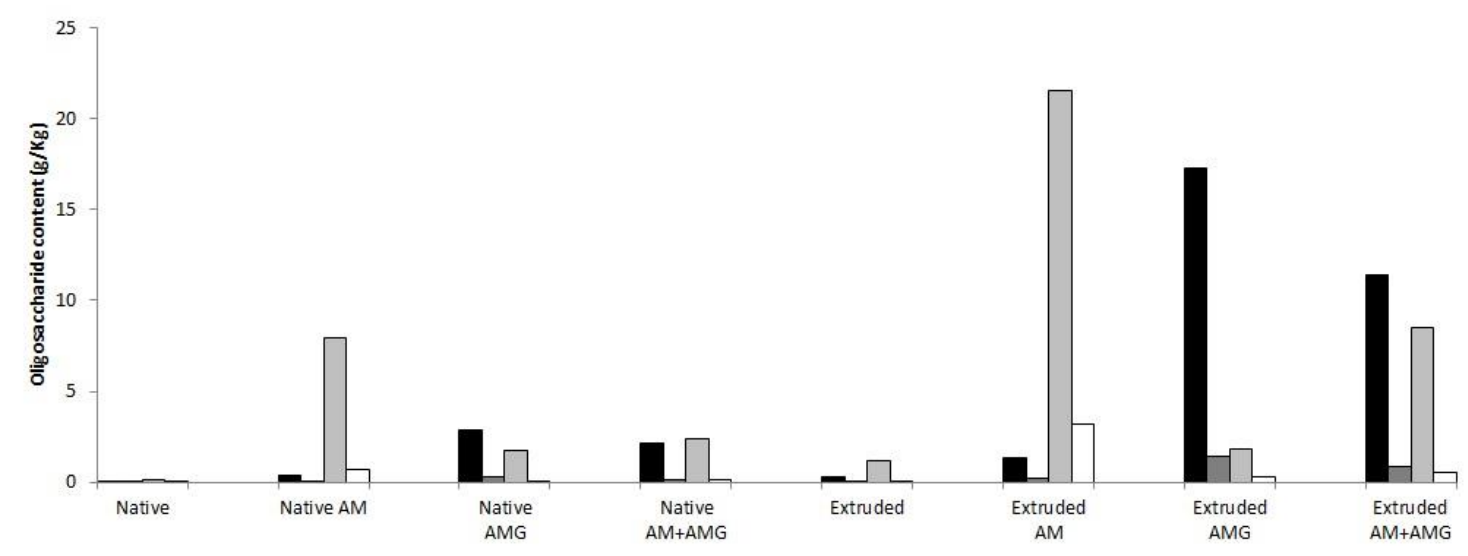

Fig. 2. Oligosaccharide content $(\mathrm{g} / \mathrm{kg})$ of enzymatically treated native and extruded flours, measured by High Performance Anion Exchange Chromatography with Pulsed Amperometric Detection (HPAECPAD). Glucose (black column), isomaltose (dark grey column), maltose (clear grey column), and maltotreose (white column). AM, amylase; AMG, amyloglucosidase.

Vasanthan, et al. (2001) treated barley flours by simultaneous extrusion and hydrolysis and achieved a $25.5 \%$ of DP2 (oligosaccharides with a degree of polymerisation of 2). Nevertheless, they used $4 \%$ amylase (based on dry weight of flour). In our study, flours with $79.9 \%$ maltose were achieved with the use of only $0.2 \%$ amylase, and flours with $90.9 \%$ glucose were achieved with the use of only $0.2 \%$ amyloglucosidase. The starch gelatinisation achieved with the severe extrusion conditions used in our study could have increased the susceptibility of extruded flours to enzymatic hydrolysis, as Martínez et al. (2014) observed in rice flour, and therefore greater production of these oligosaccharides. As was also shown in the previous section, starch gelatinisation during extrusion enhanced the chemical reactivity of flour particles towards hydrolytic enzymes. Meanwhile, the combination of amylase and amyloglucosidase gave rise to flours with a high content of both glucose and maltose, which exceeded the amounts achieved with the use of those enzymes separately. No synergy between amylase and amyloglucosidase was found; only an additive effect was observed. 


\subsection{X-ray diffractometry (XRD)}

The crystalline structures of enzymatically hydrolysed native and extruded wheat starches were observed using XRD. The diffractograms are shown in Figure 3. Less pronounced crystalline peaks were observed in all samples, indicating that the extrusion and especially the drying processes disrupted the native crystalline structures and produced a highly amorphous structure, as has already been reported by several authors (Rumruaytum, Borompichaichartkul, \& Kongpensook, 2014; Van der Veen, Veelaert, Van der Goot, \& Boom, 2006). All samples showed V-type crystalline peaks at $2 \theta$ of around 13 and 20 (Figure 3). The V-type crystalline structure originated from single helical amylose, such as amylose-lipid complexes (Lopez-Rubio, Flanagan, Gilbert, \& Gidley, 2008), which could have been created during the drying process at the end of the treatment, since no V-type crystal growth has been reported in wheat starch subjected to annealing conditions (Biliaderis, 2009). The different shapes of the diffractograms could be due to the different mechanisms of actuation of the enzymes used. Nevertheless, when extruded flours were subjected to enzymatic hydrolysis, a B-type crystalline peak at $2 \theta$ of around $21^{\circ}$ was produced. The voids of this peak can accommodate numerous water molecules (Perez, Baldwin \& Gallant, 2009). The more amassed structure seen in enzymatically hydrolysed extruded flours (Figure 1), which was attributed to the leaching of amylose during the extrusion, could have produced this B-type crystalline peak, which was even more intense with the use of amyloglucosidase. 

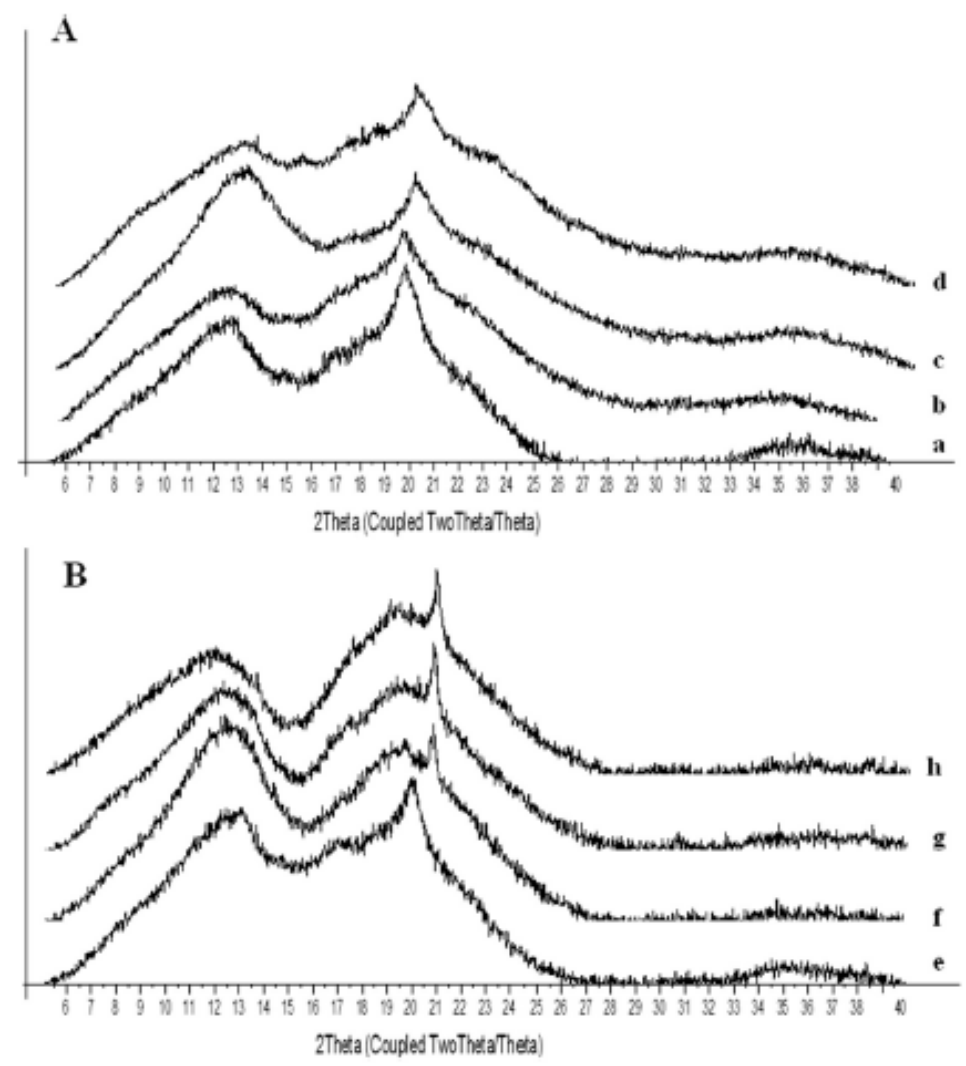

Fig. 3. X-ray diffractograms of native (A) and extruded (B) wheat flours. Native wheat flour without enzyme treatment (a), native wheat flour treated with amylase (b), native wheat flour treated with amyloglucosidase (c), and native wheat flour treated with amylase and amyloglucosidase (d). Extruded wheat flour without enzyme treatment (e), native wheat flour treated with amylase (f), native wheat flour treated with amyloglucosidase $(\mathrm{g})$, and native wheat flour treated with amylase and amyloglucosidase (h).

\subsection{Pasting characteristics}

The effect of the enzymatic and extrusion treatments on the pasting properties of wheat fours is shown in Figure 4. The low viscosities reached during heating and cooling in all samples indicate that both extrusion (Martínez et al., 2014) and drying processes (Rumruaytum, et al., 2014) gelatinised the starch. However, lower values of viscosity were found for extruded wheat flours, which is consistent with previous studies where the lower peak viscosity, the higher the amount of gelatinised and damaged starch (Barres, Verges, Tayeb, \& Della Valle, 1990). 

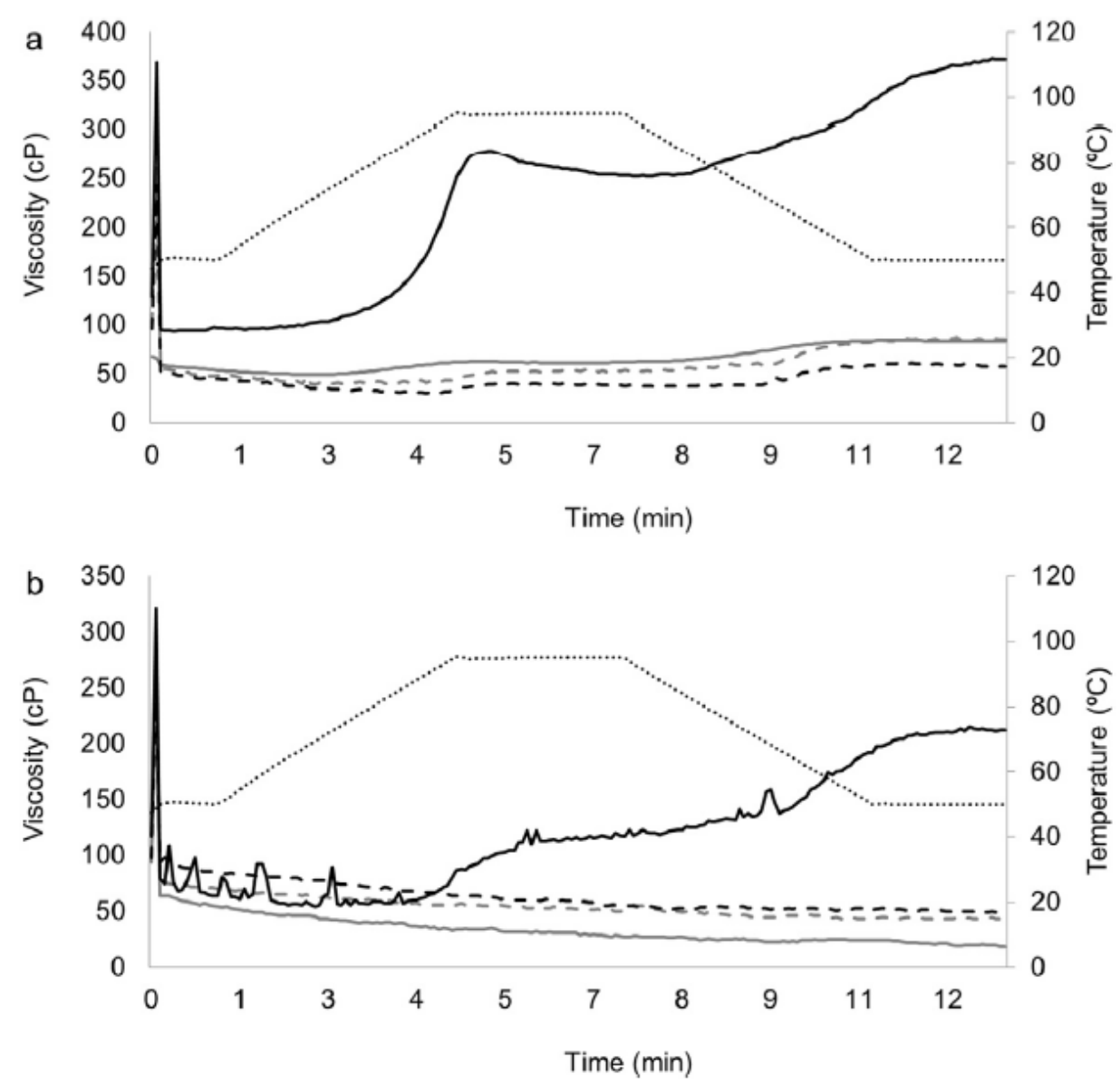

Fig. 4. Effect of extrusion and enzymatic treatments on the pasting properties of native (a) and extruded (b) wheat flours. Flour without enzyme treatment (black line), flour treated with amylase (discontinuous black line), flour treated with amyloglucosidase (dark grey line), and flour treated with amylase and amyloglucosidase (discontinuous dark grey line). Temperature profile (discontinuous points).

Considering the effect of the enzymes, native flour treated by amyloglucosidase displayed a higher viscosity than the rest of the enzymatically treated native flours, whereas extruded flour treated by amyloglucosidase showed a lower viscosity than the rest of the enzymatically treated extruded flours. The opposite effects indicate a strong effect of the type of flour (extruded or non-extruded) on its susceptibility to enzymatic hydrolysis by amyloglucosidases, as shown in the micrographs of Figure 1. The reduction in the final viscosity observed for extruded wheat flours could be related to the loss of the ability of the amylose chain to retrograde during cooling, due to its fragmentation during extrusion, an effect that agrees with previous results of Doublier, Colonna, \& Mercier (1986). At the same time, this amylose fragmentation made it more susceptible to attack by enzymes, thereby yielding greater oligosaccharide production.

\subsection{Gel hydration and colour properties}

The individual effects of the type of enzyme and the type of flour (native or extruded) on gel hydration and colour properties of enzymatically treated wheat flours are shown in 
Table 1. Native flours displayed higher WAI and SP than extruded flours; however, no significant differences were found in WSI between them. Doublier, et al., (1986) already reported a lower SP for extruded wheat starch compared with drum-dried wheat starch, which was attributed to the compact structure of particles achieved during extrusion that could diminish water accessibility. No significant differences were found in WAI and WSI among the different enzymatic treatments. Nevertheless, flours treated by a combination of amylase and amyloglucosidase showed lower values of SP, which could be related to the higher disruption of flour particles, as a consequence of the different mechanisms of actuation of amylase and amyloglucosidase.

Table 1: Effects of the type of enzyme and flour on hydration and colour properties

Enzyme

Flour

\begin{tabular}{|c|c|c|c|c|c|c|c|}
\hline & \multicolumn{4}{|c|}{$\mathrm{AM}$ and } & \multirow[b]{2}{*}{ Amylase } & \multirow[b]{2}{*}{ Native } & \multirow[b]{2}{*}{ Extruded } \\
\hline & Media & SE & AMG & Amyloglucosidase & & & \\
\hline WAI (g/g) & 4.14 & 1.51 & $3.64 a$ & $4.46 a$ & $4.30 \mathrm{a}$ & $5.42 \mathrm{~b}$ & $2.85 \mathrm{a}$ \\
\hline \multicolumn{8}{|l|}{ WSI (g/100 } \\
\hline g) & 4149 & 78 & $4140 \mathrm{a}$ & $4121 \mathrm{a}$ & $4185 a$ & $4104 a$ & $4194 a$ \\
\hline $\mathrm{SP}(\mathrm{g} / \mathrm{g})$ & 6.30 & 1.01 & $5.68 \mathrm{a}$ & $6.83 b$ & $6.39 b$ & $7.05 \mathrm{~b}$ & $5.54 \mathrm{a}$ \\
\hline $\mathrm{OAC}(\mathrm{g} / \mathrm{g})$ & 1.78 & 0.11 & $1.74 \mathrm{a}$ & $1.83 \mathrm{a}$ & $1.77 \mathrm{a}$ & $1.76 \mathrm{a}$ & $1.80 \mathrm{a}$ \\
\hline $\mathrm{L}^{*}$ & 73.60 & 5.77 & $70.32 \mathrm{a}$ & $70.81 \mathrm{a}$ & $79.68 b$ & $70.86 a$ & $76.35 b$ \\
\hline Hue & 1.25 & 0.09 & $1.23 b$ & $1.19 \mathrm{a}$ & $1.35 \mathrm{c}$ & $1.23 \mathrm{a}$ & $1.28 b$ \\
\hline Chroma & 22.25 & 3.74 & $25.06 c$ & $23.41 \mathrm{~b}$ & $18.29 \mathrm{a}$ & $24.34 b$ & $20.16 \mathrm{a}$ \\
\hline
\end{tabular}

Values followed by different letters within each parameter for each factor (enzyme and flour) indicate significant differences.

WAI, water absortion index, WSI, water solubility index, SP, swelling power, OAC, oil absortion capacity, $\mathrm{L}^{*}$, luminosity, SE, Standard deviation, AM, Amylase, AMG, Amyloglucosidase

Regarding colour properties, hydrolysed native flours showed lower luminosity, lower hue, and higher chroma, indicating that after hydrolysis, these flours were darker, more reddish, and had greater colour intensity than extruded flours. The Maillard reaction takes place when reducing sugars such as glucose, amino acids, especially lysine, and proteins are heated together (Camire, et al., 1990), whereas caramelisation is a term for describing a complex group of reactions that occur due to direct heating of carbohydrates, particularly reducing sugars (Pathare, Opara, \& Al-Said, 2013). These reactions produce high molecular weight coloured compounds, principally hydroxymethylfurfural and melanoidins (Cho \& Peterson, 2010; Purlis, 2010). Severe extrusion conditions can lead to a decrease in lysine content (Camire, et al., 1990). The more reactive the amino acid, the lower the production of hydroxymethylfurfural and melanoidins. Thus, extruded flours are clearer than native flours.

Meanwhile, flours submitted to enzymatic hydrolysis by amyloglucosidase and a combination of amylase and amyloglucosidase showed a dark, reddish, and intense colour. As shown in a previous section of this study and as reported by van der Maarel, et 
al. (2002), amyloglucosidase releases $\beta$-D-glucose residues. Glucose, besides being one of the main reactants that participate in Maillard and caramelisation thermal reactions that occur high-temperature processes such as baking, drying, and frying (Pathare, et al., 2013), is more reactive than other disaccharides such as maltose (Ameur, Mathieu, Lalanne, Trystram, \& Birlouez-Aragon, 2007), producing darker flours.

\section{$\underline{4 \text { Conclusions }}$}

The new demands of the food industry quality requirements demanded by the food industry are forcing manufacturers of starchy ingredients to develop flours with different functionalities, such as higher sweetness and higher content of natural sugars making the label cleaner than chemically modified starches. This study showed changes in the microstructure, oligosaccharide profile, crystalline order, pasting, colour, and gel hydration properties of wheat flours subjected to extrusion and enzymatic treatment by $\alpha$ amylase, amyloglucosidase, or a combination of both. The results suggest that starch gelatinisation of flour by extrusion increases its susceptibility to enzymatic hydrolysis, thereby achieving flours with a greater content of glucose and maltose, substrates for fermentative microflora and the main reactants that participate in Maillard and caramelisation thermal reactions. In general, enzymatic hydrolysis of extruded wheat flours offers an interesting way to achieve flours with different functionalities, which could be of interest for different applications in the food industry, on which later works should deep.

\section{$\underline{\text { Acknowledgements }}$}

This study was financially supported by Junta de Castilla y León (VA054A12-2), Spain. The authors are grateful to Harinera Los Pisones, Harinera Castellana, and Novozymes for supplying flours and enzymes. 


\section{$\underline{\text { References }}$}

AACC. (2012). Approved methods of the American Association of Cereal Chemists, (11th ed.). St. Paul: American Association of Cereal Chemists.

Ameur, L., Mathieu, O., Lalanne, V., Trystram, G., \& Birlouez-Aragon, I. (2007). Comparison of the effects of sucrose and hexose on furfural formation and browning in cookies baked at different temperatures. Food Chemistry, 101(4), 1407-1416.

Ba, K., Blecker, C., Danthine, S., Tine, E., Destain, J., \& Thonart, P. (2013). Physicochemical characterization of dextrins prepared with amylases from sorghum malt. Starch-Starke, 65(11-12), 962-968.

Baks, T., Kappen, F., Janssen, A., \& Boom, R. (2008). Towards an optimal process for gelatinisation and hydrolysis of highly concentrated starch-water mixtures with alphaamylase from B. licheniformis. Journal of Cereal Science, 47(2), 214-225.

Barres, C., Verges, B., Tayeb, J., \& Della Valle, G. (1990). Transformation of wheat flour by extrusion cooking. Influence of screw configuration and operating conditions. Cereal Chemistry 67, 427-433.

Biliaderis, C. G. (2009). Structural transitions and related physical properties of starch. In J. BeMiller \& R. Whistler (Eds.), Starch. Chemistry and Technology, (pp. 293-375). New York. USA: Academic Press.

Camire , M. E., Camire , A., \& Krumhar, K. (1990). Chemical and nutritional changes in foods during extrusion. Critical Reviews in Food Science and Nutrition, 29, 35-57.

Chinnaswamy, R., \& Hannah, M. A. (1990). Macromolecular and functional properties of native and extruded corn starch. Cereal Chemistry, 67, 490-499.

Chiu, C., \& Solarek, D. (2009). Modification of starch. In J. BeMiller \& R. Whistler (Eds.), Starch. Chemistry and Technology, (pp. 629-656). New York. USA: Academic Press.

Cho, I., \& Peterson, D. (2010). Chemistry of Bread Aroma: A Review. Food Science and Biotechnology, 19(3), 575-582.

Doublier, J. L., Colonna, P., \& Mercier, C. (1986). Extrusion cooking and drum drying of wheat-starch. 2. Rheological characterization of starch pastes. Cereal Chemistry, 63, 240-246.

Dura, A., Błaszczak, W., \& Rosell, C.M. (2014). Functionality of porous starch obtained by amylase or amyloglucosidase treatments. Carbohydrate Polymers, 101, 837-845.

Govindasamy, S., Campanella, O., \& Oates, C. (1997a). Enzymatic hydrolysis of sago starch in a twin-screw extruder. Journal of Food Engineering, 32(4), 403-426. 
Govindasamy, S., Campanella, O., \& Oates, C. (1997b). The single screw extruder as a bioreactor for sago starch hydrolysis. Food Chemistry, 60(1), 1-11.

Lee, Y., \& Kim, K. (1990). Gelatinization and liquefaction of starch with a heat-stable alpha-amylase. Journal of Food Science, 55(5), 1365-1366.

Lopez-Rubio, A., Flanagan, B., Gilbert, E., \& Gidley, M. (2008). A novel approach for calculating starch crystallinity and its correlation with double helix content: A combined XRD and NMR study. Biopolymers, 89(9), 761-768.

Maningat, C. C., Seib, P. A., Bassi, S. D., Woo, K. S. \& Lasater, G. D. (2009). Wheat starch: Production, Properties, Modification and uses. in: BeMiller, J., Whistler, R. (Eds.), Starch. Chemistry and Technology. Academic Press, New York. USA., pp. 441- 510.

Martínez, M. M., Calviño, A., Rosell, C. M., \& Gómez, M. (2014). Effect of different extrusion treatments and particle size distribution on the physicochemical properties of rice flour. Food and Bioprocess Technology, DOI: 10.1007/s11947-014-1252-7.

Pathare, P., Opara, U., \& Al-Said, F. (2013). Colour Measurement and Analysis in Fresh and Processed Foods: A Review. Food and Bioprocess Technology, 6(1), 36-60.

Perez, S., Baldwin, P. M., \& Gallant, D. J. (2009). Structural features of starch granules I. In J. BeMiller, \& R. Whistler (Eds.), Starch: Chemistry and technology. (pp 149-188). New York. USA: Academic Press.

Purlis, E. (2010). Browning development in bakery products - A review. Journal of Food Engineering, 99(3), 239-249.

Rosell, C., Yokoyama, W., \& Shoemaker, C. (2011). Rheology of different hydrocolloidsrice starch blends. Effect of successive heating-cooling cycles. Carbohydrate Polymers, 84(1), 373-382.

Rumruaytum, P., Borompichaichartkul, C., \& Kongpensook, V. (2014). Effect of drying involving fluidisation in superheated steam on physicochemical and antioxidant properties of Thai native rice cultivars. Journal of Food Engineering, 123, 143-147.

Toyokawa, H., Rubenthaler, G., Powers, J., \& Schanus, E. (1989). Japanese noodle qualities .1. Flour components. Cereal Chemistry, 66(5), 382-386.

Uthumporn, U., Shariffa, Y., \& Karim, A. (2012). Hydrolysis of Native and Heat-Treated Starches at Sub-Gelatinization Temperature Using Granular Starch Hydrolyzing Enzyme. Applied Biochemistry and Biotechnology, 166(5), 1167-1182.

van der Maarel, M., van der Veen, B., Uitdehaag, J., Leemhuis, H., \& Dijkhuizen, L. (2002). Properties and applications of starch-converting enzymes of the alpha-amylase family. Journal of Biotechnology, 94(2), 137-155. 
Van der Veen, M., Veelaert, S., Van der Goot, A., \& Boom, R. (2006). Starch hydrolysis under low water conditions: A conceptual process design. Journal of Food Engineering, 75(2), 178-186.

Vasanthan, T., Yeung, J., \& Hoover, R. (2001). Dextrinization of starch in barley flours with thermostable alpha-amylase by extrusion cooking. Starch-Starke, 53(12), 616-622. 


\title{
7.2. Synergistic maltogenic $\alpha$-amylase and branching treatment to produce enzyme-resistant molecular and supramolecular structures in extruded matrices
}

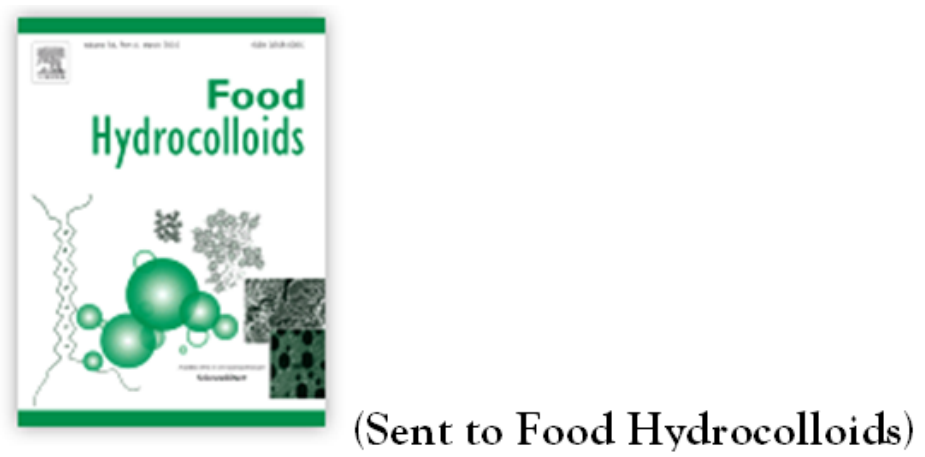

Synergistic maltogenic o-amylase and branching treatment to produce enzyme-resistant molecular and supramolecular structures in extruded matrices

\author{
Mario M. Martínez ${ }^{1 *}$, Joana Pico ${ }^{2}$, Manuel Gómez ${ }^{1}$ \\ ${ }^{1}$ Food Technology Area, College of Agricultural Engineering, University of Valladolid, 34004, Palencia, Spain \\ ${ }^{2}$ I.U.Cinquima. Analytical Chemistry Group, University of Valladolid, Valladolid, Spain.
}

\section{Introduction}

Maize (Zea mays L.) is the main produced cereal followed by paddy rice and wheat (FAOSTAT, 2013). Its ready availability at relatively low and steady prices, its storability from season to season, its ease of transportation and handling, and its high starch content (Eckhoff \& Watson, 2009) has made maize kernels be processed into a wide variety of commercial products. Grit and meal maize are mainly used in the production of snacks and breakfast cereals, whereas maize flour or starch are mostly used in blends with wheat flours in bakery products or as a thickening agent in many dishes such as soups, sauces, infant products and gravies among others (Román, Martínez, Rosell \& Gómez, 2015).

Extrusion is a high-temperature-short-time (HTST) physical treatment during which ingredients are subjected to high temperatures and mechanical shearing at relatively low levels of moisture content. Extrusion allows starch gelatinization, denaturation of protein, microbial reduction, enzyme (in)activation and colour changes, the extent of which are dependent on the conditions of the extrusion (Camire, Camire \& Krumhar, 1990; Martínez, Calviño, Rosell \& Gómez, 2014a; Martínez, Rosell \& Gómez, 2014b). Extrusion is also responsible for changing the extent of molecular associations between components, e.g. the amylose-lipid complex (Hagenimana, Ding \& Fang, 2006). However, from a nutritional perspective, the improvement in the functionality achieved by 
extrusion also can give rise to a decline in the digestibility of starch and flour (Martínez et al., 2014a, b). In some snack and breakfast cereal productions, the maize-containing product is extruded with the aim of mixing, cooking, forming and shearing the ingredients in one continuous process (Berrios, Ascheri \& Losso, 2013). Meanwhile, the maize-based ingredients (maize flour or starch) can be extruded to gelatinize, melt and fragment their starch in order to adapt its rheological and hydration properties to the emerging needs imposed by the new food trends (Gómez \& Martínez, 2015).

Generally, molecular ( $\alpha, 1-4$ and $\alpha, 1-6$ glycosidic bonds), supramolecular (starch ordered structures such as crystallites and double helices), and granular structures of starch, are disrupted by thermal (barrel temperature), humidity (plasticizer content) and energy input (screw speed, feeding rate, die size and screw configuration) during the intense shear regime reached during extrusion cooking (Zhang et al., 2015). This disruption led to increasing the accessibility of digestive enzymes to starch polymers (Zhang et al., 2015) and to increasing the number of simple sugars, easily digested, in extruded products (Martínez, Pico \& Gómez, 2015). This fast digestion may contribute to general chronic diseases in people such as type II diabetes, obesity, and cardiovascular disease (Lovegrove et al., 2015; Zeng et al., 2015).

Enzymatic methods are emerging as alternative clean technologies to provide more environment and consumer safe solutions for starch modification. In addition, enzymeassisted catalysis can be more specifically controlled and it operates under very mild conditions, thus reducing the risk for producing harmful or unwanted by-products (Butler, van der Maarel \& Steeneken, 2004). Several authors have studied different strategies based on the catalytic mechanism of branching enzyme (B) and maltogenic $\alpha$ amylase (MA) in order to slow down the digestion of starches or flours through: (i) increasing the ratio of short chains (degree of polymerisation, DP<13) to longer chains (DP>13) of amylopectin (Ao et al., 2007; Zhang, Sofyan, \& Hamaker, 2008); (ii) increasing the relative amounts of $\alpha, 1-6$ linkages giving smaller chains and a higher branching fraction (Backer \& Saniez, 2005; Shin, Simsek, Reuhs \& Yao, 2008); (iii) increasing the content of prebiotic isomaltooligosacharides, such as isomaltose, panose and isomaltotriose (Ao et al., 2007). B mainly acts on $\alpha, 1-4$ glycosidic linkages to produce branched $\alpha$-glucans by intra- or inter-molecular $\alpha, 1-6$ glucosidic transfer (Okada, Kitahana, Yoshikawa, Sugimoto \& Sugimoto, 1984; Roussel et al., 2013) alongside cyclization of amylose and amylopectin (Takata, Takaha, Okada, Takagi \& Imanaka, 1996). Meanwhile, MA cleaves $\alpha, 1-4$ glycosidic bonds of starch, generating maltose, and also exhibits high transglycosylation activity via formation of various glycosidic linkages such as $\alpha, 1-6$ linkages producing branched oligosaccharides from liquefied starch (Kim \& Park 2002; Park et al., 2000). In this way, several authors have reported a partial shortening of the branch chains of amylopectin and an increase of $\alpha-1,6$ linkages in maize starch (Ao et al., 2007; Li et al., 2014), rice starch (Lee et al., 2008) and tapioca starch (Le et al., 2009) treated with B and a combined B/MA treatment, which in turn, reduced the 
starch digestion rate in all cases. Added to that, Ao et al. (2007) reported an increase of the isomaltooligosacharadide content with the use of B and MA. These strategies have given rise also to several patent applications of branching enzymes with a view to creating branched glucans with slower digestion rate (Dermaux, Peptitjean \& Wills 2007; Fuertes, Roturier \& Petitjean, 2005; van der Maarel, Binnema, Semeijn \& Buwalda 2007). All author previously mentioned, studied the effects of the enzymatic treatments on native samples after boiling in a water bath or autoclaving. Nevertheless, the effect of these enzymatic treatments on the structure of extruded matrices has never been studied. In this regard, taking into account the high starch disruption reached during extrusion, it is expected a high chemical reactivity towards B and MA catalysis.

Our approach was to manipulate extruded maize flours in order to create resistant molecular and supramolecular structures that attenuate the starch digestion properties. In this way, the aim of the present study was to investigate the effect of $\mathrm{B}$ and a combined B/MA treatment on the formation of molecular (amylopectin fine structure, amylose fraction and linear and branched oligosaccharides content) and supramolecular (shortand long-range molecular order) structures in maize extruded flours and their native counterparts. Added to that, the effect of two solvents of different extractability towards sugars (water and ethanol) employed during the last step of the enzymatic treatment was also studied.

\section{$\underline{2 \text { Materials and methods }}$}

\subsection{Materials}

Native maize flours (11.95 g/100 g moisture; $7.6 \mathrm{~g} / 100 \mathrm{~g}$ protein) were supplied by Molendum Ingredients (Zamora, Spain). Extrusion of maize flour was carried out by Molendum Ingredients in a single screw extruder Bühler Basf (Bühler S.A., Uzwil, Switzerland). The length to diameter (L/D) ratio for the extruder was 20:1. The extrusion conditions were carried out based on preliminary experiments in order to ensure starch gelatinization (not detected gelatinization endotherm). Maize flour was extruded at a maximum barrel temperature of $160^{\circ} \mathrm{C}$ with further water addition of $12 \%$, a feed rate of $500 \mathrm{~kg} / \mathrm{h}$ and a screw speed of $453 \mathrm{rpm}$. Extruded product $(7.1 \mathrm{~g} / 100 \mathrm{~g}$ protein) was dried by convection air up to $9.32 \%$ of moisture content and then milled with a compression roller till particle size was lower than 200 microns. The extruded flour resulted after milling had a mean particle size of $99.37 \mu \mathrm{m}$.

Branching enzyme EC 2.4.1.18 (Branchzyme®; declared activity: $5000 \mathrm{BEU} / \mathrm{g}$ product) and maltogenic $\alpha$-amylase EC 3.2.1.133 (Amylase ${ }^{\mathrm{TM}}$ AG $300 \mathrm{~L}$; declared activity: 10000 MANU/g product), both from Bacillus subtilis, were gently provided by Novozymes (Bagsvaerd, Denmark). Isoamylase EC 3.2.1.68 from Pseudomonas sp (declared activity: $11,100,000 \mathrm{U} / \mathrm{mL}$ ) was purchased from Sigma-Aldrich (Steinheim, Germany). All other chemical reagents were of analytical grade. 


\subsection{Methods}

\subsubsection{Combined enzymatic treatment}

Preliminary assays were carried out for optimizing enzymatic reactions (flour quantity and $\mathrm{pH})$. Native or extruded maize flours $(6.0 \mathrm{~g})$ were suspended in $30 \mathrm{~mL}$ of sodium acetate buffer (0.01M, pH 5.0). Prior to the next step (incubation), native maize flour suspensions were either heated at $95^{\circ} \mathrm{C}$ for $30 \mathrm{~min}$ or incubated without being cooked previously. The aim was to compare the hydrolysis kinetics of the enzymatic treatment in native $(N)$, cooked (C) and extruded (E) matrices. The incubation was carried out with $300 \mathrm{U}$ of B/g flour (B) and a combination of $300 \mathrm{U}$ of $\mathrm{B}$ and $7 \mathrm{U}$ of $\mathrm{MA} / \mathrm{g}$ flour (BMA). The incubation was performed at $55^{\circ} \mathrm{C}$ for $2.5 \mathrm{~h}$ in a water bath. Then, $60 \mathrm{~mL}$ of either distilled water or a $96 \%$ ethanol solution were added prior homogenization with an UltraTurrax homogenizer IKA-T25 (IKA works, Wilmington, USA) during $1 \mathrm{~min}$ at $13,000 \mathrm{rpm}$. Subsequently, samples were centrifuged for $10 \mathrm{~min}$ at $4000 \times \mathrm{g}$. Flours were washed again and centrifuged at the same conditions as before. Supernatants were collected together and boiled in a water bath for $10 \mathrm{~min}$ to halt the enzymatic activity before the analysis of the hydrolysis kinetics (total carbohydrate content and iodine binding values) in a range of times from $10 \mathrm{~min}$ to $2.5 \mathrm{~h}$ (see section 2.2.2). Sediments were dried at $45^{\circ} \mathrm{C}$ for $48 \mathrm{~h}$ and milled for $20 \mathrm{~s}$ into powder in a Moulinex super junior $\mathrm{S}$ (Groupe Seb Iberica, S.A, Barcelona, Spain). Flours with the longest incubation time $(2.5 \mathrm{~h})$ were stored in airtight plastic containers perfectly sealed at $4^{\circ} \mathrm{C}$ for further analysis. All treatments were made in duplicate in order to have two repetitions for further analysis.

\subsubsection{Hydrolysis kinetics of supernatants during the enzymatic treatment}

Hydrolysis kinetics was characterised measuring both the total carbohydrate content, through the phenol-sulphuric acid method (Dubois, Gilles, Hamilton, Rebers, \& Smith, 1956), and the iodine binding values, according to the method described by Dura, Blaszczak and Rosell (2014), of the supernatants during the enzymatic treatment (of the two replicates).

\subsubsection{Residual enzymatic activity of enzymatically treated flours}

The residual enzymatic activity of treated flours was determined by analysing the amylolitic effect of B and MA with a modified DNS (dinitrosalicylic acid) test (Bernfel, 1955). $100 \mathrm{mg}$ of sample was dispersed in distilled water, from which $100 \mu \mathrm{L}$ were added to a dispersion of $2 \mathrm{~mL}$ of $5 \%$ maize amylopectin (Sigma-Aldrich, Steinheim, Germany) in a $50 \mathrm{mM}$ sodium acetate buffer $\mathrm{pH} 5.8$ with $5 \mathrm{ppm}$ calcium chloride. The mixture was then incubated at $55^{\circ} \mathrm{C}$ for $10 \mathrm{~min}$. The hydrolysis reaction was stopped by the addition of $2 \mathrm{~mL}$ of DNS solution and boiled for $5 \mathrm{~min}$. Subsequently the dispersion was cooled in an ice-bath to room temperature. Then, $1 \mathrm{~mL}$ of the cooled dispersion was diluted with $5 \mathrm{~mL}$ of distilled water and centrifuged at $13,000 \mathrm{rpm}$ for $15 \mathrm{~min}$. The clear supernatant 
was measured at $540 \mathrm{~nm}$. The absorption was measured against a blank, which was treated as described above but without the incubation step.

\subsubsection{Amylose content of enzymatically treated flours}

The amylose content of flour samples was determined by the Megazyme amylose assay kit (Megazyme, Bray, Ireland) using the Concanavalin A precipitation procedure (Gibson, Solah \& McCleary, 1997). The analysis was made in triplicate.

2.2.5. Sugar content of enzymatically treated flours by High Performance Anion Exchange Chromatography with Pulsed Amperometric Detection (HPAEC-PAD).

The aim of the HPAEC-PAD analysis was to determine the content of the most common oligo- and isomaltooligosacharides in the treated flours. The oligosaccharides D-(+)Glucose and maltose monohydrate (Neat, Sigma-Aldrich, Steinheim, Germany) and the isomaltooligosacharides isomaltose, D-panose and isomaltotriose (98\%, Sigma-Aldrich, Steinheim, Germany), were the standards employed to analyse these compounds. The sample treatment and the HPAEC-PAD analyses were carried according to the method described by Pico, Martínez, Martín and Gómez (2015). The analysis was made in duplicate.

\subsubsection{Thermal properties of enzymatically treated flours}

Analyses were performed in a differential scanning calorimeter Q-20 (TA instruments, Crawley, UK) equipped with a refrigerated cooling system (RCS 40). Prior to sample measurements, the calibration for enthalpy and temperature was completed using indium (Tonset $=155.74^{\circ} \mathrm{C}$ and $\left.\Delta \mathrm{H}=28.69 \mathrm{~J} / \mathrm{g}\right)$. High volume DSC pans $(100 \mathrm{~mL})(\mathrm{TA}$ Instruments) were employed. An empty pan was used as reference and dry nitrogen at a flow rate of $50 \mathrm{~mL} / \mathrm{min}$, was used as the purge gas. Flour $(6 \mathrm{mg})$ was loaded into the aluminium pan and distilled water $(20 \mu \mathrm{L})$ was added with the help of a micro syringe. Samples were hermetically sealed and allowed to stand for $30 \mathrm{~min}$ at room temperature before heating in the DSC oven. The calorimeter scan conditions were set as follows: samples were kept at $40{ }^{\circ} \mathrm{C}$ for $2 \mathrm{~min}$, heated from 40 to $110{ }^{\circ} \mathrm{C}$ at $10{ }^{\circ} \mathrm{C} / \mathrm{min}$. Onset temperature (To), peak temperature $(\mathrm{Tp})$, gelatinization temperature range $(\mathrm{Tp}-\mathrm{To})$, as well as the enthalpy of starch gelatinization $(\Delta \mathrm{Hg})$ (expressed as $\mathrm{mJ} / \mathrm{mg}$ of sample) were determined. All samples were run in triplicate.

\subsubsection{Crystallinity of enzymatically treated flours (X-ray diffraction)}

Crystallinity of samples was determined using a Bruker D8 Discover A25 X-ray diffractometer (Bruker AXS, Rheinfelden, Germany) equipped with a copper tube operating at $40 \mathrm{kV}$ and $40 \mathrm{~mA}$, producing CuKa radiation of $0.154 \mathrm{~nm}$ wavelength. Diffractograms were obtained by scanning from $5^{\circ}$ to $40^{\circ}$ ( 2 theta), at a rate of $1.2 \% \mathrm{~min}$, a step size of $0.02^{\circ}$, a divergence slit width variable (DS) of $5 \mathrm{~mm}$, and a scatter slit width (SS) of $2.92^{\circ}$. All samples were run in duplicate. 
2.2.8 Assessment of the glycosidic bonds of enzymatically treated flours through Proton Nuclear Magnetic Resonance Spectroscopy $\left({ }^{1} \mathrm{H}-\mathrm{NMR}\right)$

Dry flour (20mg) was dissolved in $1 \mathrm{~mL} \mathrm{D2O}$, heated for $30 \mathrm{~min}$ at $100^{\circ} \mathrm{C}$ followed by a freeze-drying. The dried and deuterated sample $(6 \mathrm{mg})$ was re-dissolved in $1 \mathrm{~mL} \mathrm{D2O}$ and heated for $30 \mathrm{~min}$ at $100^{\circ} \mathrm{C}$ under continuous stirring. The NMR-samples were always prepared immediately before measurements and never cooled below $70^{\circ} \mathrm{C}$, in order to prevent retrogradation prior to analysis.

1H-NMR spectra were recorded with a spectrometer (mod. RMN 500 DD2, Agilent, Santa Clara, USA) operating at $500.25 \mathrm{MHz}$. Spectra (16 scans) were accumulated at $80^{\circ} \mathrm{C}$ from 1 to $7 \mathrm{ppm}$. The chemical shifts were obtained by comparing the results obtained by Gidley (1985) and expressed in ppm by reference to internal acetone ( $\delta 2.05$ for $1 \mathrm{H}$ ). In addition, chemical shifts were also endorsed by the multiplicity of the proton bounded to the $\mathrm{C} 1$ of the different situations. NMR spectra were processed using MestreNova V 10.0 software (Mestrelab Research, Escondido, USA). The ratio of $\alpha, 1-4$ to $\alpha, 1-6$ glycosidic bonds was determined from integration of the anomeric resonance at 5.4 and $5.0 \mathrm{ppm}$, respectively. The analysis was made in duplicate.

2.2.9 Chain length distributions (CLDs) of enzymatically treated flours by Matrix-Assisted Laser Desorption/Ionization-Time of Fight mass spectrometry (MALDI-TOF MS)

Debranching of starch fractions of flours was performed using pseudomonas isoamylase according to the method of Vilaplana and Gilbert (2010) with slight modifications. The flour fractions $(70.0 \mathrm{mg}$ ) were dispersed with $9.5 \mathrm{~mL}$ of sodium acetate buffer $(0.01 \mathrm{M}, \mathrm{pH}$ 3.5 ) and heated in a boiling water bath for $10 \mathrm{~min}$ with gentle stirring. The dispersion was cooled to room temperature and incubated in a water bath at $38^{\circ} \mathrm{C}$ for $3 \mathrm{~h}$ after adding $80 \mu \mathrm{L}$ of the enzyme solution $(77700 \mathrm{U} / \mathrm{mL})$. The enzyme was deactivated by immersion of the solution in boiling water for $10 \mathrm{~min}$. The debranched fractions were immediately frozen, to avoid retrogradation of the debranched chains, until subsequent freeze-drying.

The enzyme-modified flours were suspended in 1:1 acetonitrile:water by vortexing and diluted with water to a final concentration of $4.6 \mathrm{mg} / \mathrm{mL}$. A solution of 2,5dihydroxybenzoic acid in 1:1 acetonitrile:water $(30.8 \mathrm{mg} / \mathrm{mL})$ was prepared as the matrix. The matrix solution $(2 \mu \mathrm{L})$ was combined with the diluted analyte suspension $(2 \mu \mathrm{L})$ and this solution $(2 \mu \mathrm{L})$ was added to the target and air-dried. MALDI-TOF MS was performed using a Bruker Daltonics autoflex speed instrument (Bruker AXS, Rheinfelden, Germany). Positive-ion mode spectra were recorded using the linear mode. A $340 \mathrm{~nm}$ laser was used and mass spectra were typically accumulated from 6,000 laser shots. Spectra were acquired over a $200 \mathrm{~m} / \mathrm{z}$ range (from $200 \mathrm{Da}$ to 50,000 Da, with matrix suppression up to $200 \mathrm{Da}$ ). The accelerating voltage was $19 \mathrm{kV}$. The analysis was made in duplicate.

\subsubsection{Statistical analysis}


Differences between the parameters for the flours were studied by analysis of variance (one-way ANOVA). Fisher's least significant difference (LSD) was used to describe means with 95\% confidence intervals. The statistical analysis was performed with Statgraphics Centurion XVI software (Statpoint Technologies, Inc., Warrenton, USA).

\section{$\underline{3 \text { Results and discussion }}$}

\subsection{Susceptibility of maize flours to the enzyme catalysis}

The susceptibility of maize flours (native, boiled and extruded) to the enzyme catalysis was assessed by analysing the carbohydrate content (expressed in glucose units) of the supernatants obtained after centrifugation (Fig. 1). As commented, B produces branched $\alpha$-glucans and cyclic amylose and amylopectin (Okada et al., 1984; Takata et al., 1996). Their high branching and relatively low molecular size make them highly soluble in water, as compared to normal starch, giving a highly stable clear solution (Takata et al., 1996). Thereby, the susceptibility of maize flours to be hydrolysed by these enzymes could be analysed by measuring the leached carbohydrates. Added to that, MA removes successive maltose residues from the non-reducing ends of the chains, therefore giving an additional amount of soluble sugars, as it was endorsed by the presence of a light higher content of leached carbohydrates of BMA samples. The carbohydrate leaching over time in all samples followed a first order kinetic equation, similar to the curves reported by Li et al., (2014), treating maize starch with B, and by Miao et al., (2014, 2015), treating maize starch with a combination of $\mathrm{B}$ and $\beta$-amylase. This slowing of rate as the reaction proceeds, typical from first order kinetics, is a natural consequence of both, the declining substrate concentration as starch is converted to products, and by the enzyme inhibition of the hydrolysis product (Miao et al., 2014). Regarding the solvent, it was also observed a higher carbohydrate concentration in water supernatants than in the ethanol ones, except for native sample treated with BMA, where significant differences were not detected. This could be due to the higher extractability of oligosaccharides with water (Pico et al., 2015), giving rise to higher leached carbohydrates in water curves. In this way, water could be a better solvent with a view to getting a better insight the degree of hydrolysis as the reaction proceeds. Results also showed a low susceptibility of native maize flours to the enzyme catalysis, which was increased when flours were previously boiled, due to likely to the starch gelatinization. Nevertheless, extruded flours displayed even higher susceptibility than boiled counterparts. This could be due to the high molecular disruption reached during extrusion, increasing the chemical reactivity towards these enzymes (Martínez et al., 2015). In this way, extruded flours could be a suitable raw material for yielding high branching and cyclization effects of $\mathrm{B}$ as well as increasing the amylolitic and transglycosylation effects of MA. 


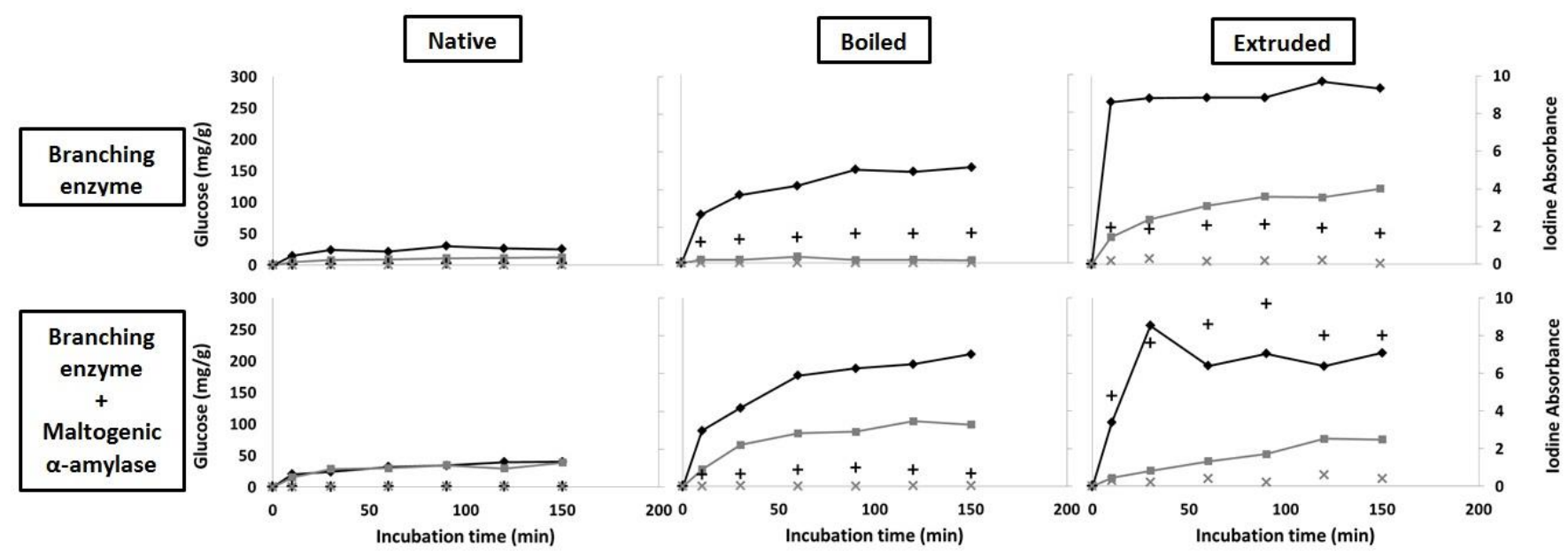

Figure 1. Susceptibility of native, boiled and extruded maize flours towards enzyme catalysis. The carbohydrate content of supernatants is depicted with continuous black line and continuous grey line for samples washed with water and ethanol respectively. The iodine binding values of supernatants are depicted with black $(+)$ and grey $(\mathrm{x})$ for samples washed with water and ethanol respectively.

In order to get better information about the carbohydrates leaching, long chain oligosaccharides of the supernatant were also evaluated by iodine complex formation of the helical conformation of chains with at least 6 glucose residues in one helix turn (Bates, French \& Rundle, 1943; Gidley \& Bulpin, 1987) (Fig. 1). As in the total carbohydrate release curves, higher iodine binding values were found when washing with water than with ethanol, except for native sample treated with BMA. This occurrence could be explained by the scenario observed by Barret, Barret and Khan (1998), who reported that the iodine complex formation is most favoured in pure water and decreases as the proportion of no aqueous solvent is increased. Results showed that the supernatants of native maize flours did not present high iodine binding values, whereas supernatants of boiled flours displayed high binding value, due to likely to starch gelatinization. It is pointed out the high iodine binding values observed in extruded flours, indicating a higher leaching of long chain oligosaccharides. This occurrence could be related to the changes produced during extrusion, such as starch gelatinization and fragmentation (Chinnaswamy \& Hannah, 1990; Martínez et al., 2015). In addition, extruded maize flours were especially susceptible to the BMA catalysis, where the combined effect of $\mathrm{B}$ and MA increased the amount of long chain oligosaccharides leached.

Taking into account the susceptibility of the different flours to the enzyme catalysis, boiled sampled were discarded for further studies and only the effect of the enzymatic treatments on the molecular and supramolecular structures of native and extruded flours were studied and compared. It is noteworthy that the residual enzymatic activity of any of enzymatically treated flours was similar and low, with maximum values of absorbance of 
0.048 (data not shown), thus it was expected a high stability of maize flours to be later further analysed.

\subsection{Amylose (long linear fraction) and oligosaccharide (short linear fraction) content of enzymatically treated flours}

The amylose percent of enzymatically treated maize flours was analysed, since amylose is susceptible to retrograde and can contribute to the formation of resistant starch (Zhang, Ao \& Hamaker, 2008). Results are shown in Fig. 2a. Extrusion itself produced a reduction of the amylose percent compared to the native counterparts. This change in the amylose/amylopectin ratio could be attributed to both chains fragmentation, which is more intense in the amylose fraction (Chinnaswamy \& Hannah, 1990). Regarding the enzymatic treatments, neither B nor BMA enzymatic treatments significantly modified the amylose content on native maize flours, due to the low accessibility of enzymes to the starch granules, as observed in the previous section. Nevertheless, both of the enzymatic treatments produced a similar significant increase in the amylose percent (long linear fraction) on extruded maize flours. Generally, molecular, crystalline, and granular structure of starches from nanometer to micrometer length scales are disrupted by the intense thermo-mechanical energy input of an extruder. This is expected to create an amorphous structure and increase the accessibility of starch molecules for the enzymes (Zhang et al., 2015) and therefore making noticeable the effects of the enzymes on the amylose percent content. However, this is not in accordance with the results reported by Li et al. (2014), who reported a reduction in the amylose content during the branching enzyme treatment, attributed to the cleavage of the long linear chains of maize starch, which were simultaneously transferred to produce the new branched glucans. In this regard, it is noteworthy that, long linear amylose chains could have been involved in the formation of different amylose-amylose, lipid-amylose and ethanol-amylose complexes during extrusion, as it will be later shown in section 3.4. This highly ordered structures are resistant to the enzyme catalysis (Robyt, 2009). Therefore, amylopectin chains would have been the preferable substrate to be cleaved, decreasing the amount of amylopectin and therefore increasing the amylose fraction. 

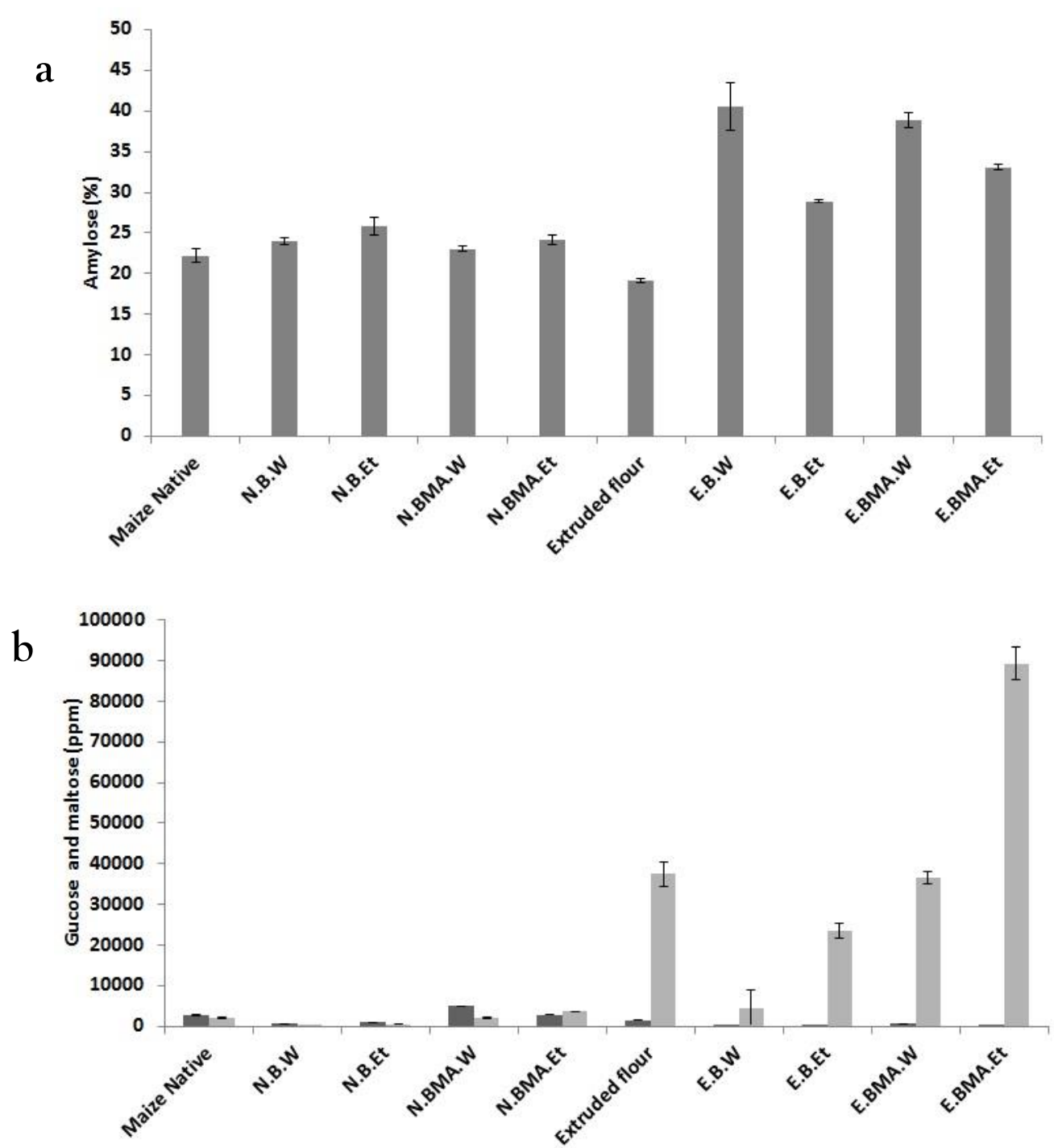

Figure 2. Effect of branching enzyme (B) and a combination of branching enzyme and maltogenic $\alpha$ amylase enzymatic (BMA) treatments on the amylose percent (a) and the glucose (dark grey bar) and maltose (clear grey bar) content (b) and of native $(\mathrm{N})$ and extruded $(\mathrm{E})$ maize flours washed with either water (W) or ethanol (Et).

The content of the most abundant oligosaccharides (glucose and maltose) was also assessed (Fig. 2b). Glucose content of all samples was barely affected by the extrusion and the enzymatic treatments. However, extrusion itself produced a significant increase of the maltose content, as it was observed by Martínez et al. (2015), which was attributed to the chain fragmentation reached during extrusion (Chinnaswamy \& Hannah, 1990). Maltose content was reduced in samples treated with $B$, which could be due to its intra- or intermolecular $\alpha, 1-6$ glucosidic transfer, using maltose as substrate. Nevertheless, samples treated with a combination of B and MA displayed higher values of maltose, which can be explained by the removal of successive maltose residues from the non-reducing ends of the starch chains catalysed by the enzyme MA (Kim \& Park 2002; Park et al., 2000). At this point, it is important to mention the importance of the proper selection of the 
ethanol-water solution. A final wash with water removed more maltose and kept more amylose fraction than a final wash with ethanol, result of the higher extractability of oligosaccharides with water (Pico et al., 2015). This gave rise to samples with less maltose and more amylose fraction in samples washed with water.

\subsection{Branched oligosaccharide content (Isomaltooligosacharides) of enzymatically treated flours}

Isomaltooligosaccharides (IMOs) consist mainly of oligomers of isomaltose, panose and isomaltotriose connected by non-digestible $\alpha, 1-6$ glycosidic linkages. IMOs were found to be effective at increasing the numbers of bifidobacteria and lactate and improving the intestinal microflora (Rastall \& Gibson, 2002). Therefore, they are categorized as prebiotic (Rycroft, Jones, Gibson \& Rastall, 2001). The IMO content of extruded and native treated wheat flours was assessed and the computed results are shown in Fig. 3. Panose was not present in native and extruded maize flours without enzymatic treatment, whereas isomaltotriose was only present in non-treated native flour. Nevertheless, native and extruded enzymatically treated flours displayed a high content of isomaltose which was strongly decreased by the effect of the B and BMA enzymatic treatments. This could be related with the higher extractability of isomaltose with any of the solvents used in the wash step during the enzymatic treatments, since isomaltose is formed by only two Dglucose molecules. On the other hand, the combined BMA treatment produced an increase in the panose and isomaltotriose content in native flours and especially in the panose content of extruded maize flours. These results were in accordance with those shown by Ao et al. (2007), which reported an increase in the IMO content with a combined B and MA treatment on autoclaved maize starch. This could be explained by the transglycosylation capacity of MA (Kang, Kim, Kim \& Park, 1997), which transfers glucose units and forms $\alpha, 1-6$ linkages. However, as in the case of the short and long linear polysaccharide fraction, the solvent used had a strong effect, in such a way ethanol helped to keep higher the IMO content in native and extruded maize samples. Defloor, Vandenreyken, Grobet, and Delcour, (1998) and Bouchard, Hofland, and Witkamp (2007) observed a decrease in solubility of oligosaccharides and polysaccharides with increasing ethanol concentrations and for any given ethanol concentration, the higher the DP the lower its solubility. Also, according to the results, it is observed a higher preferential extraction for linear $\alpha, 1-4$ bonded than for $\alpha, 1-6$ bonded oligosaccharides into the aqueous ethanol phase. Therefore, one must consider the compromise between removing glucose and maltose (easily digested sugars) and keeping IMOs (categorized as prebiotic) and long linear amylose (susceptible to retrograde) choosing the suitable aqueous-ethanol solution. 


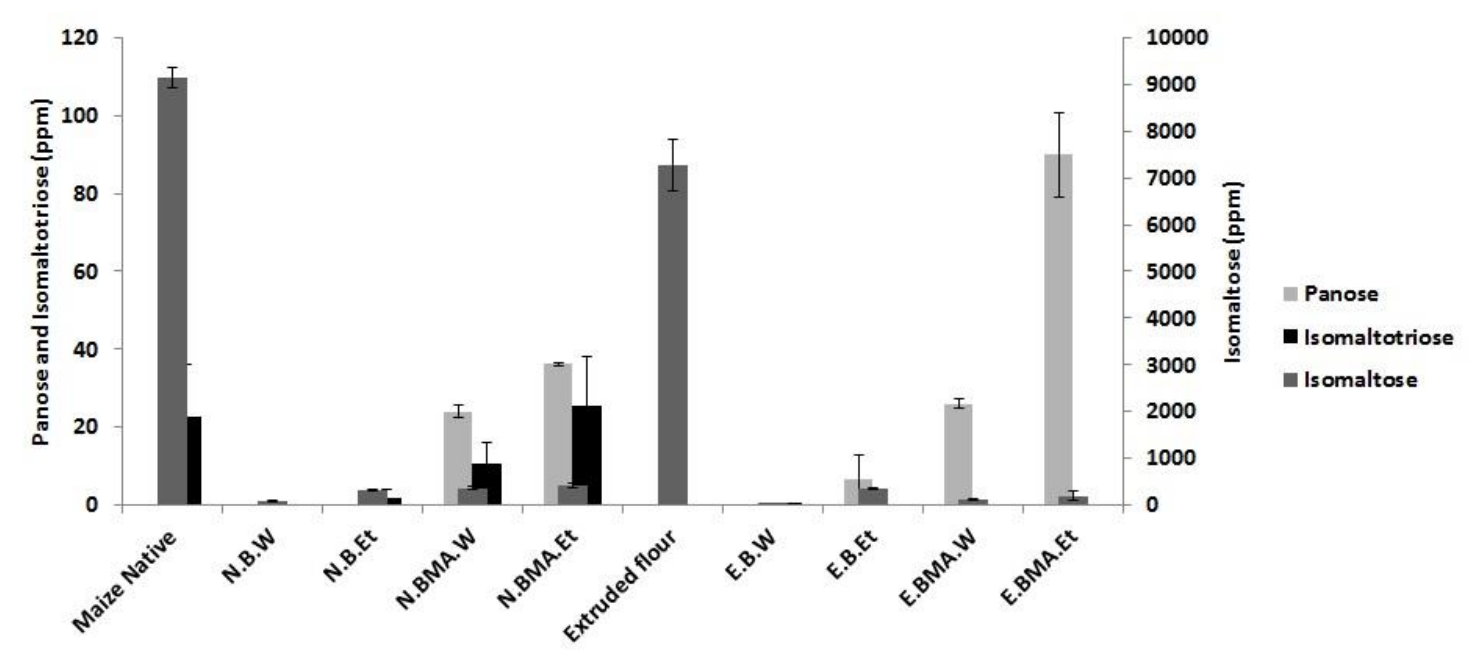

Figure 3. Effect of branching enzyme (B) and a combination of branching enzyme and maltogenic $\alpha$ amylase enzymatic (BMA) treatments on the isomaltooligosacharide content of native $(N)$ and extruded (E) maize flours washed with either water (W) or ethanol (Et).

\subsection{Supramolecular structures: short and long-range molecular order}

The effect of the enzymatic treatments on the formation of resistant supramolecular structures of native and extruded maize flours was assessed by differential scanning calorimetry (DSC) and X-ray diffraction. In the range of temperature tested, native flours exhibited one endothermic peak, corresponding to the melting of ordered chain domains of amylopectin (table 1). The enzymatic treatments did not have a significant influence on the enthalpy and only slightly increased the onset temperature. However, a narrowing in the gelatinization range was observed especially in samples treated with the combined BMA treatment. With regard to the extruded samples, the extrusion conditions applied were severe enough to complete starch gelatinization in such a way extruded flour did not display any endothermal peak. Nevertheless, the effect of the enzymatic treatments caused the apparition of an endothermal peak in extruded samples washed with water, with lower onset, peak and conclusion temperatures and with a much narrower gelatinization range than those peaks observed in native flours. This apparition of a gelatinization enthalpy of enzymatically treated extruded samples could imply a net increase in the level of short-range molecular order, i.e. a conformational ordering (double helices) of amylose and may also involve short-range ordering of amylopectin side chains (Biliaderis, 2009). In addition, the fact that this peak was only observed in samples washed with water, with higher content of long linear chains of amylose, could indicate that the conformational ordering of amylose was the main reason. These effects, typical from annealing (Biliaderis, 2009), could have been produced during the enzymatic treatment, since samples were held in excess of water at temperatures above the $\mathrm{Tg}$ (glass transition) and below the equilibrium Tm (melting temperature) of the crystallites of amylopectin. 
Table 1. Effect of branching enzyme (B) and a combination of branching enzyme and maltogenic $\alpha$-amylase (BMA) treatments on the amylopectin gelatinization of native $(\mathrm{N})$ and extruded (E) maize flours washed with either water (W) or ethanol (Et).

\begin{tabular}{cccccc} 
Sample & $\begin{array}{c}\text { Enthalpy } \\
(\mathbf{J} / \mathbf{g})\end{array}$ & To $\left({ }^{\circ} \mathrm{C}\right)$ & Tp $\left({ }^{\circ} \mathbf{C}\right)$ & Tc $\left({ }^{\circ} \mathbf{C}\right)$ & $\begin{array}{c}\text { Tc-To } \\
\left({ }^{\circ} \mathbf{C}\right)\end{array}$ \\
\hline Maize Native & $8,58 \mathrm{~b}$ & $68,03 \mathrm{~b}$ & $74,16 \mathrm{~cd}$ & $90,95 \mathrm{~cd}$ & $22,91 \mathrm{~d}$ \\
N.B.W & $8,25 \mathrm{~b}$ & $69,29 \mathrm{~cd}$ & $73,62 \mathrm{c}$ & $86,71 \mathrm{~b}$ & $17,42 \mathrm{c}$ \\
N.B.Et & $13,30 \mathrm{c}$ & $69,46 \mathrm{~cd}$ & $74,56 \mathrm{~cd}$ & $92,76 \mathrm{~d}$ & $23,3 \mathrm{~d}$ \\
N.BMA.W & $10,43 \mathrm{~b}$ & $69,82 \mathrm{~d}$ & $73,82 \mathrm{~cd}$ & $86,24 \mathrm{~b}$ & $16,41 \mathrm{bc}$ \\
N.BMA.Et & $10,14 \mathrm{~b}$ & $70,45 \mathrm{~d}$ & $74,97 \mathrm{~d}$ & $87,31 \mathrm{bc}$ & $16,86 \mathrm{bc}$ \\
& & & & & \\
Extruded flour & $\mathrm{nd}$ & $\mathrm{nd}$ & $\mathrm{nd}$ & $\mathrm{Nd}$ & $\mathrm{nd}$ \\
E.B.W & $2,12 \mathrm{a}$ & $63,42 \mathrm{a}$ & $67,15 \mathrm{a}$ & $76,06 \mathrm{a}$ & $12,64 \mathrm{ab}$ \\
E.B.Et & $\mathrm{nd}$ & $\mathrm{nd}$ & $\mathrm{nd}$ & $\mathrm{Nd}$ & $\mathrm{nd}$ \\
E.BMA.W & $1,87 \mathrm{a}$ & $64,08 \mathrm{a}$ & $67,96 \mathrm{a}$ & $76,05 \mathrm{a}$ & $11,98 \mathrm{a}$ \\
E.BMA.Et & $0,19 \mathrm{a}$ & $68,08 \mathrm{bc}$ & $70,09 \mathrm{~b}$ & $76,83 \mathrm{a}$ & $8,75 \mathrm{a}$ \\
\hline
\end{tabular}

n.d.: Not detected.

To, gelatinization onset; $\mathrm{Tp}$, peak temperature; $\mathrm{Tc}$, conclusion temperature, $\mathrm{Tp}-\mathrm{To}$, gelatinization range, $\Delta \mathrm{H}$, enthalpy,

$(p<0.05)$. Values followed by equal letters within each parameter indicate no significant differences.

Long-range molecular order (crystallinity) of native and extruded enzymatically treated flours is shown in Fig. 4. Native samples exhibited a typical A-type pattern (main peaks at $2 \theta$ of around $14.9^{\circ}, 17.0^{\circ}, 17.9^{\circ}$, and $23.0^{\circ}$ ), which was barely affected by the enzymatic treatments both washing samples with ethanol and with water (Fig. 4a). Meanwhile, extruded samples showed less pronounced A-type crystalline peaks (Fig. 4b), indicating that the extrusion disrupted the native crystalline structures (A-type crystalline structures) and produced a highly amorphous structure (Martínez et al., 2015). Extrusion also increased the intensity of the peaks at $2 \theta$ of around $13^{\circ}$ and $20^{\circ}$, corresponding to the $\mathrm{V}$ type crystalline structures originated from single helical amylose (Lopez-Rubio, Flanagan, Gilbert \& Gidley, 2008). Moreover, these peaks were more pronounced when treating extruded maize flour with B and BMA. Regarding the solvent, peaks from treated extruded samples washed with ethanol were sharper and with a shift in the $\mathrm{d}$-spacing compared to those from extruded samples washed with water. This could indicate that: 1 ) all enzymatic treatments increased the amylose (or long chain)-lipid complexes; 2) and that in samples washed with ethanol, amylose (or long chain)-ethanol complexes could have been also formed, which could in turn explain the shift of the $\mathrm{d}$-spacing $\mathrm{V}$-type peaks between water and ethanol washed-treated extruded flours (Ao et al., 2007). 

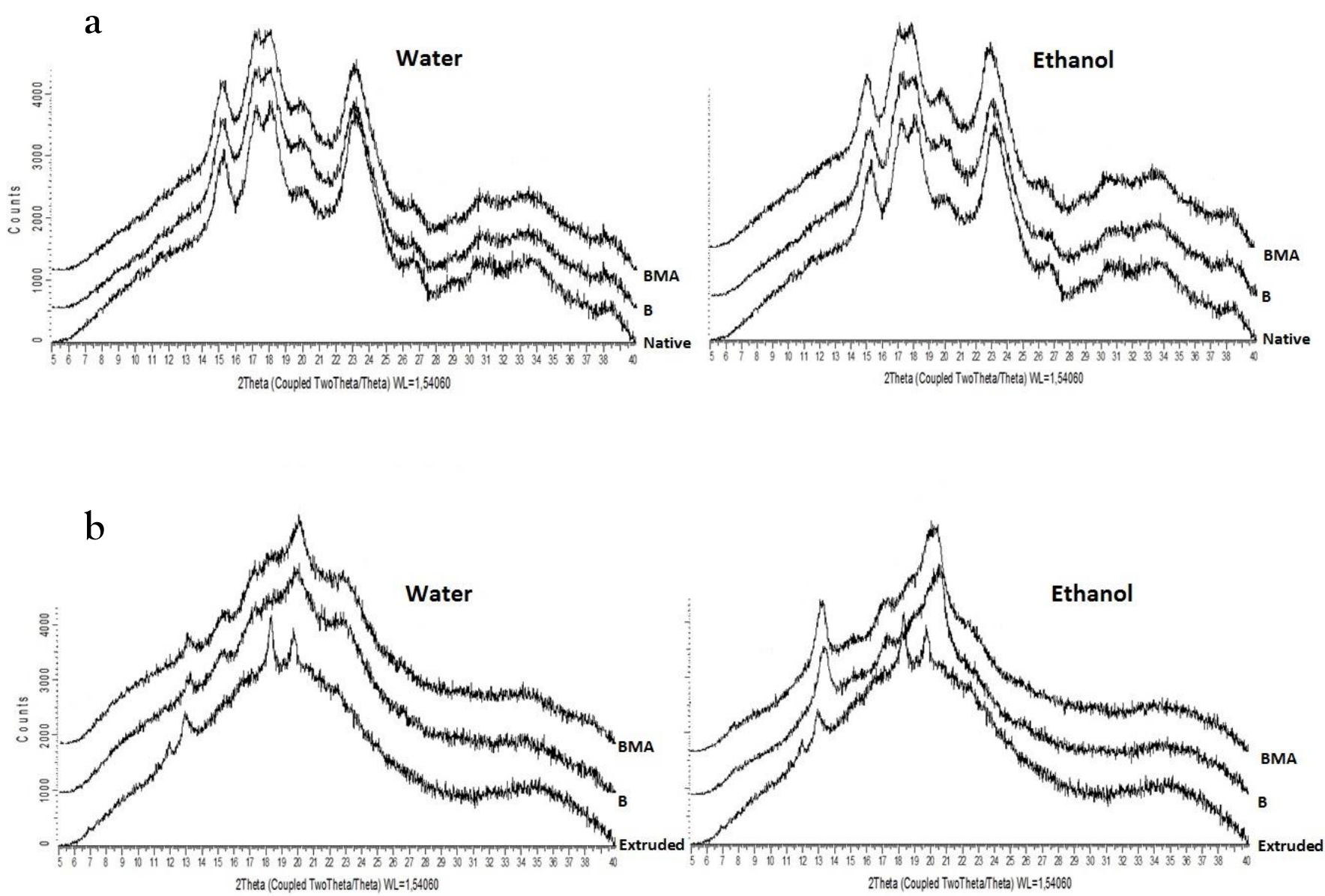

Fig. 4. X-ray diffractograms of native (a) and extruded (b) maize flours treated with branching enzyme (B) and the combination of branching enzyme and maltogenic $\alpha$-amylase enzymatic (BMA).

\subsection{Amylopectin fine structure: glycosidic bonds and chain length distributions}

Even though amylose is the fraction which contributes to the formation of resistant starch, amylopectin is the starch molecule associated with slowly digestible starch (Zhang, Ao \& Hamaker, 2008). To further characterize the structural properties of the amylopectin of enzymatically modified maize flours, the resonance of the anomeric protons involved in $\alpha, 1-4$ and $\alpha-1-6$ glycosidic bonds as well as those present in $\alpha$ anomeric reducing ends was assessed using 1H-NMR spectroscopy. Fig. 5 shows partial $1 H-N M R$ spectra of the enzymatically and non-treated native and extruded maize flours. The intensity of the doublet at a chemical shift around $5.4 \mathrm{ppm}$ is assigned to $\alpha, 1-4$ linked units (Gidley, 1985). Extruded itself decreased the intensity of this peak, whereas the enzymatic treatments produced an increased in the intensity of the peak both in native and extruded flours, without appreciating a clear effect considering the enzyme and the solvent. This occurrence was in accordance with the presence of the amylose fraction, already discussed in section 3.2. The second chemical shift to mention is that around $5.25 \mathrm{ppm}$, assigned to $\alpha$-anomeric reducing ends (Gidley, 1985). A clear higher intense in 
the peak in native and extruded maize flour BMA treated was observed, indicating that the combination of $\mathrm{B}$ and MA increased the $\alpha$-anomeric reducing ends, probably as a consequence of the generation of maltose (reducing sugar) by MA (Kim \& Park 2002; Park et al., 2000). However, that peak was only appreciable in samples washed with water. It is highlighted that this is not in agreement with the previous results obtained, since reducing sugars, such as maltose, had higher extractability in water and were less abundant in samples washed with water. Nevertheless, 1H-NMR does not distinguish between oligosaccharides and amylopectin (Gidley, 1985), thus this could also indicate a higher number of outer chains in amylopectin. The third peak highlighted is that at a chemical shift around 4.98ppm, assigned to $\alpha, 1-6$ linked units. In this case, a high peak was observed in samples treated with a combination of B and MA washed with both water and ethanol, followed by samples treated with B washed with ethanol. These results could be related with the IMO content, and in particular with the content of panose and isomaltotriose, discussed in section 3.3. Nevertheless, again 1H-NMR does not distinguish between oligosaccharides and amylopectin, in such a way this signal could also be related to a high number of outer chains in amylopectin, which would also endorse the intensity assigned to the $\alpha$-anomeric reducing ends, previously described.

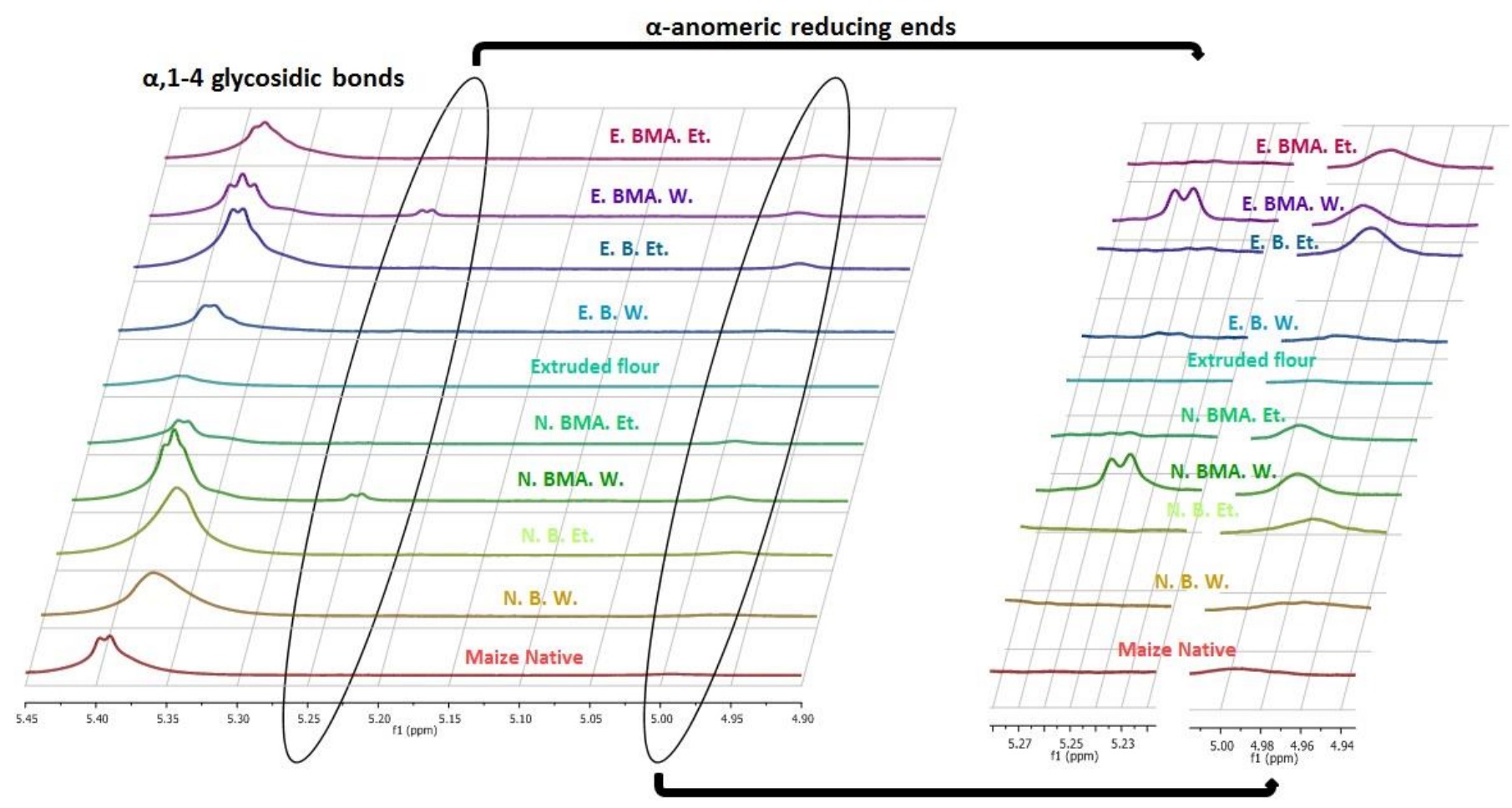

$\alpha, 1-6$ glycosidic bonds

Fig. 5. ${ }^{1} \mathrm{H}$ NMR spectra of native $(\mathrm{N})$ and extruded (E) maize flours treated with branching enzyme (B) and a combination of branching enzyme and maltogenic $\alpha$-amylase enzymatic (BMA) washed with either water or ethanol. Two small spectra on the right side represent an expansion of the chemical shifts corresponding to $\alpha$-anomeric reducing ends and $\alpha, 1-6$ glycosidic bonds. 
According to the NMR results, more branching points as well as more outer chains in amylopectin would have been created. However, still results did not provide accurate information about the chain length distribution of the outer clusters in amylopectin. Therefore, the chain length distribution of enzymatically treated native and extruded samples was analysed through mass spectrometry (Table 2). No significant differences were found in medium $(7<\mathrm{DP}<25)$ and long $(\mathrm{DP}>25)$ chain distribution among samples. Regarding the short chain fraction $(\mathrm{DP}<7)$, none of the enzymatic treatments influenced significantly the chain length distribution in native samples. However, extruded samples treated with a combination of $\mathrm{B}$ and MA and washed with water possessed the highest fraction of chains with lower degree of polymerization, followed by samples treated with $B$ and washed with ethanol. This effect could be attributed to the transfer capacity of B of one glycosyl group from many types of D-glucosyl donor substrates, preferably maltose, to suitable acceptor substrates, forming new outer chains, which would be later trimmed by the exo-hydrolytic action of MA (Ao et al., 2007). These results would be in agreement with those observed in the 1H-NMR spectra (Fig. 5), where more branching points and more $\alpha$-anomeric reducing ends in amylopectin were reported. This high ratio of amylopectin short chains to long chains has been related with slowly digestible starch (Zhang, et al., 2008).

Table 2. Chain length distribution analysis of native $(\mathrm{N})$ and extruded $(\mathrm{E})$ maize flours treated with branching enzyme (B) and a combination of branching enzyme and maltogenic $\alpha$-amylase enzymatic (BMA) washed with either water (W) or ethanol (Et).

DP, degree of polymerization

\begin{tabular}{lccc}
\multicolumn{1}{c}{ Sample } & DP $<7$ & $7<$ DP $<25$ & DP $>25$ \\
\hline Maize Native & $42.79 \mathrm{abcd}$ & $53.63 \mathrm{abc}$ & $3.58 \mathrm{ab}$ \\
N.B.W. & $46.98 \mathrm{bcde}$ & $51.08 \mathrm{abc}$ & $1.94 \mathrm{ab}$ \\
N.B.Et. & $32.99 \mathrm{abc}$ & $53.71 \mathrm{abc}$ & $13.30 \mathrm{ab}$ \\
N.BMA.W. & $25.59 \mathrm{ab}$ & $70.35 \mathrm{c}$ & $4.06 \mathrm{ab}$ \\
N.BMA.Et. & $23.75 \mathrm{a}$ & $62.84 \mathrm{bc}$ & $13.4 \mathrm{~b}$ \\
& & & \\
Extruded flour & $45.97 \mathrm{bcd}$ & $44.33 \mathrm{ab}$ & $9.70 \mathrm{ab}$ \\
E.B.W. & $50.32 \mathrm{cde}$ & $46.06 \mathrm{abc}$ & $3.61 \mathrm{ab}$ \\
E.B.Et. & $62.67 \mathrm{de}$ & $37.33 \mathrm{a}$ & $0.00 \mathrm{a}$ \\
E.BMA.W. & $68.92 \mathrm{e}$ & $29.30 \mathrm{a}$ & $1.78 \mathrm{ab}$ \\
E.BMA.Et. & $44.91 \mathrm{bcd}$ & $52.00 \mathrm{abc}$ & $3.08 \mathrm{ab}$ \\
\hline
\end{tabular}

$(p<0.05)$. Values followed by equal letters within each parameter indicate no significant differences.

\section{$\underline{4 .}$ Conclusions}

Extruded products and ingredients are gaining prominence. Nevertheless, the improvement in the functionality reached during extrusion brings about a decline in the digestion properties. In this study, extruded maize flours manifested a great susceptibility 
to be catalysed by branching enzyme (B) and maltogenic $\alpha$-amylase (MA) with the aim to attenuating their digestion properties. In this way, resistant molecular (isomaltooligosacharides, higher number of branching points and ratio of short chains to longer chains in amylopectin) and supramolecular (long linear amylose chains, conformational ordering of amylose or amylopectin side chains and amylose-lipid complexes) structures were created. These structures could be beneficial in terms of digestibility. Isomaltooligosacharides are categorized as prebiotic, resistant supramolecular structures contribute to the formation of resistant starch and high branched and trimmed amylopectin is the starch molecule associated with slowly digestible starch. Therefore, the combined enzymatic treatment proposed in this study could turn out very useful to manufacture extruded starches, flours or products with attenuate starch digestion properties. In any case, further studies to assess structure-digestion properties relationships of extruded flours are necessary. However, all results were constrained by the type of solvent used in the washing step. Thus, the selective modification of flour components should be approached according to the different solvent power of the ethanol-water solutions used during the enzymatic treatment.

\section{$\underline{\text { Acknowledgements }}$}

The authors are also grateful to Molendum Ingredients and Novozymes for supplying the flour and the enzymes, respectively. They also would like to thank Laura Pascual Velasco for the assistance for carrying out the enzymatic treatments in duplicate. Mario M. Martínez would like to thank predoctoral fellowship from Spanish Ministry of Education, Culture and Sport. 


\section{$\underline{\text { References }}$}

Ao, Z., Simsek, S., Zhang, G., Venkatachalam, M., Reuhs, B.L. \& Hamaker, B.R. (2007). Starch with a slow digestion property produced by altering its chain length, branch density, and crystalline structure. Journal of Agricultural and Food Chemistry, 55, 4540. 4547.

Backer, D. \& Saniez, M-H. (2005). Soluble highly branched glucose polymers and their method of production. US Patent 2005/0142167A1.

Barret, A.J., Barret, K.L. \& Khan, A. (1998). Effects of acetone, ethanol, isopropanol, and dimethyl sulfoxide on amylose-iodine complex. Journal of Macromolecular Science, Part A: Pure and Applied Chemistry, 35, 711-722.

Bates, F.L., French, D. \& Rundle, R.E. (1943). Amylose and amylopectin content of starches determined by their iodine complex formation. Journal of the American Chemical Society, 65, 142-148.

Bernfeld, P. (1955). Amylases, $\alpha$ and $\beta$-amylases. Methods in Enzymology, 1, 149-158.

Berrios, J.D.J., Ascheri, J.R., \& Losso, J.N. (2013). Extrusion processing of dry beans and pulses. In M. Siddiq \& M.A. Uebersax (Eds.), Dry Beans and Pulses. Production, Processing and Nutrition (pp. 185-203). Iowa, USA: Wiley Blackwell.

Biliaderis, C. (2009). Structural transitions and related physical properties of starch. In J. BeMiller, \& R. Whistler (Eds.), Starch. Chemistry and Technology (pp. 293-372). New York: Academic Press.

Bouchard, A., Hofland, G.W. \& Witkamp, G.J. (2007). Properties of sugar, polyol, and polysaccharide water-ethanol solutions. Journal of Chemical and Engineering Data, 52, 1838-1842.

Butler, D.P., van der Maarel, M.J.E.C. \& Steeneken, P.A.M. (2004). Starch-acting enzymes In A-C. Eliasson (Ed.), Starch in Food (pp. 128-155). Boca Raton, FL, USA: Woodhead Publishing.

Camire, M.E., Camire, A. \& Krumhar, K. (1990). Chemical and nutritional changes in foods during extrusion. Critical Reviews in Food Science and Nutrition, 29, 35-57.

Chinnaswamy, R. \& Hannah, M.A., (1990). Macromolecular and functional properties of native and extruded corn starch. Cereal Chemistry, 67, 490-499.

Defloor, I., Vandenreyken, V., Grobet, P.J. \& Delcour, J.A. (1998). Fractionation of maltodextrins by ethanol. Journal Chromatography A, 803, 103-109. 
Dermaux, L., Peptitjean, C., \& Wills, D. (2007). Soluble, highly branched glucose polymers for enteral and parenteral nutrition and for peritoneal dialysis. Patent WO2007099212.

Dubois, M., Gilles, K.A., Hamilton, J.K., Rebers, P.A., \& Smith, F. (1956). Colorimetric method for determination of sugars and related substances. Analytical Chemistry, 28, 350-356.

Dura, A., Blaszczak, W. \& Rosell, C.M. (2014). Functionality of porous starch obtained by amylase or amyloglucosidase treatments. Carbohydrate Polymers, 101, 515 837-845.

Eckhoff, S.R. \& Watson, S.A. (2009). Corn and sorghum starches production. In J. BeMiller \& R. Whistler (Eds.), Starch: Chemistry and Technology (pp. 373-439). New York: Academic Press.

FAOSTAT. (2013). Database of food and agricultural organization. Available from http://faostat3.fao.org/compare/E Accessed January 2015.

Fuertes, P., Roturier, J-M. \& Petitjean, C. (2005). Highly branched glucose polymers. Patent EP1548033.

Gibson, T. S., Solah, V. A. \& McCleary, B. V. (1997). A procedure to measure amylose in cereal starches and flours with Concanavalin A. Journal of Cereal Science, 25, 111-119.

Gidley, M. J. (1985). Quantification of the structural features of starch polysaccharides by N.M.R. spectroscopy. Carbohydrate Research, 139, 85-93.

Gidley, M.J. \& Bulpin, P.V. (1987). Crystallisation of malto-oligosaccharides as model of the crystalline forms of starch: Minimum chain-length requirement for the formation of double helices. Carbohydrate Research, 161, 291-300.

Gómez, M. \& Martínez, M.M. (In press). Changing flour functionality through physical treatments for the production of gluten-free baking goods. Journal of Cereal Science, DOI 10.1016/j.jcs.2015.07.009.

Hagenimana, A., Ding, X. \& Fang, T. (2006). Evaluation of rice flour modified by extrusion cooking. Journal of Cereal Science, 43, 38-46.

Kang, G.J., Kim, M.J., Kim, J.W. \& Park K.H. (1997). Immobilization of thermostable maltogenic amylase, from Bacillus stearothermophilus for continuous production of branched oligosaccharides. Journal of Agricultural and Food Chemistry, 45, 4168-4172.

Kim, J.W. and Park, K.M. (2002). Cooperative action of alpha-glucanotransferase and maltogenic amylase for an improved process of isomaltooligosaccharides (IMO) production. Journal of Agricultural and Food Chemistry, 50, 2812-2817. 
Le, Q-T., Lee, C-K., Kim, Y-W., Lee, S-J., Zhang, R., Withers, S.G., Yong-Ro Kim, Y-R., Auh, J-H. \& Park, K-H. (2009). Amylolytically-resistant tapioca starch modified by combined treatment of branching enzyme and maltogenic amylase. Carbohydrate Polymers, 75, 9-14.

Lee, C.K., Le, Q.T., Kim, Y.H., Shim, J.H., Lee, S.J., Park, J.H., Lee, K.P., Song, S.H., Auh, J.H., Lee, S.J. \& Park, K.H. (2008). Enzymatic synthesis and properties of highly branched rice starch amylose and amylopectin cluster. Journal of Agricultural and Food Chemistry, 56, 126-131.

Li, X., Miao, M., Jiang, H., Xue, J., Jiang, B., Zhang, T., Gao, Y. \& Jia Y. (2014). Partial branching enzyme treatment increases the low glycaemic property and $\alpha-1,6$ branching ratio of maize starch. Food Chemistry, 164, 502-509.

Lopez-Rubio, A., Flanagan, B., Gilbert, E. \& Gidley, M. (2008). A novel approach for calculating starch crystallinity and its correlation with double helix content: A combined XRD and NMR study. Biopolymers, 89, 761-768.

Lovegrove, A., Edwards, C.H., De Noni, I., Patel, H., El, S.N., Grassby, T., Zielke, C., Ulmius, M., Nilsson, L., Butterworth, P.J., Ellis, P.R. \& Shewry, P.R. (In press). Role of Polysaccharides in Food, Digestion and Health. Critical Reviews in Food Science and Nutrition, DOI:10.1080/10408398.2014.939263.

Martínez, M.M., Calviño, A., Rosell, C.M. \& Gómez, M., (2014a). Effect of different extrusion treatments and particle size distribution on the physicochemical properties of rice flour. Food and Bioprocess Technology, 7, 2657-2665.

Martínez, M.M., Pico, J. \& Gómez, M., (2015). Physicochemical modification of native and extruded wheat flours by enzymatic amylolysis. Food Chemistry, 167, 447-453.

Martínez, M.M., Rosell, C.M. \& Gómez, M. (2014b). Modification of wheat flour functionality and digestibility through different extrusion conditions. Journal of Food Engineering, 143, 74-79.

Miao, M., Li, R., Huang, C., Ye, Fan., Jiang, B. \& Zhang, T. (2015). Structural modification and characterisation of a sugary maize soluble starch particle after double enzyme treatment. Carbohydrate Polymers, 122, 101-107.

Miao, M., Xiong, S., Jiang, B., Jiang, H., Cui, S.W. \& Zhang, T. (2014). Dual-enzymatic modification of maize starch for increasing slow digestion property. Food Hydrocolloids, 38, 180-185.

Okada, S., Kitahata, S., Yoshikawa, S., Sugimoto, T. \& Sugimoto, K. (1984). Process for the production of branching enzyme, and a method for improving the qualities of food products therewith. Patent US4454161. 
Park, K.H., Kim, T.J., Cheong, T.K., Kim, J.W., Oh, B.H. \& Svensson, B. (2000) Structure, specificity and function of cyclomaltodextrinase, a multispecific enzyme of the $\alpha$-amylase family. Biochimica et Biophysica Acta (BBA), 1478, 165-185.

Pico, J., Martínez, M.M., Martín, M.T. \& Gomez, M. (2015). Quantification of sugars in wheat flours with an HPAEC-PAD method. Food Chemistry, 173, 674-681.

Rastall, R.A. \& Gibson, G.R. (2002). Prebiotic oligosaccharides evaluation of biological activities and potential future developments. In G.W. Tannock, (Ed.), Probiotics and Prebiotics: Where are we going (pp. 107-148). England: Caister Academic Press.

Robyt, J.F. (2009). Enzymes and their action on starch. In J. BeMiller \& R. Whistler (Eds.), Starch, Chemistry and Technology (pp. 237-292). New York: Academic Press.

Román, L., Martínez, M.M., Rosell, C.M. \& Gómez, M. (2015). Effect of microwave treatment on physicochemical properties of maize flour. Food and Bioprocess Technology, 8, 1330-1335.

Roussel, X., Lancelon-Pin, C., Viksø-Nielsen, A., Rolland-Sabaté, A., Grimaud, F., Potocki-Véronèse, G., Buléon, A., Putaux, J-L. \& D'Hulst, C. (2013). Characterization of substrate and product specificity of the purified recombinant glycogen branching enzyme of Rhodothermus obamensis. Biochimica et Biophysica Acta (BBA)-General Subjects, $1830,2167-2177$.

Rycroft, C. E., Jones, M. R., Gibson, G. R. \& Rastall, R. A. (2001). A comparative in vitro evaluation of the fermentation properties of prebiotic oligossacharide. Journal of Applied Microbiology, 5, 878-887.

Shin, J-E., Simsek, S., Reuhs, B. L. \& Yao, Y. (2008). Glucose release of water-soluble starch-related a-glucans by pancreatin and amyloglucosidase is affected by the abundance of a-1,6-glucosidic linkages. Journal of Agricultural and Food chemistry, 56, 10879-10886.

Takata, H., Takaha, T., Okada, S., Takagi, M. \& Imanaka, T. (1996). Cyclization reaction catalyzed by branching enzyme. Journal of Bacteriology, 178, 1600-1606.

van der Maarel, M.J.E.C., Binnema, D.J., Semeijn, C. \& Buwalda, P.L. (2007). Novel slowly digestible storage carbohydrate. Patent EP1943908.

Vilaplana, F. \& Gilbert, R.G (2010). Two-dimensional size/branch length distributions of a branched polymer. Macromolecules, 43, 7321-7329.

Zeng, F, Chen, F., Kong, F., Gao, Q., Aadil, R.M. \& Yu, S. (2015). Structure and digestibility of debranched and repeatedly crystallized waxy rice starch. Food Chemistry, $187,348-353$. 
Zhang, B., Dhital, S., Flanagan, B.M., Luckman, P., Halley, P.J. \& Gidley, M.J. (2015). Extrusion induced low-order starch matrices: Enzymic hydrolysis and structure. Carbohydrate Polymers, 134, 485-496.

Zhang, G., Ao, Z. \& Hamaker, B.R. (2008). Nutritional Property of Endosperm Starches from Maize Mutants: A Parabolic Relationship between Slowly Digestible Starch and Amylopectin Fine Structure. Journal of Agricultural and Food Chemistry, 56, 4686-4694.

Zhang, G., Sofyan, M. \& Hamaker, B.R. (2008). Slowly digestible state of starch: mechanism of slow digestion property of gelatinized maize starch. Journal of Agricultural and Food Chemistry, 56, 4695-4702. 


\section{DISCUSSION OF THE RESULTS AND FINAL REMARKS}




\section{Discussion of the results and final remarks}

The present doctoral thesis approaches the study of the structure, applications and new functionality of extruded flours. The main objective of this thesis was to develop cereal flours with different technologic and nutritional functionality through the application of extrusion and enzymes.

The first two objectives consisted on the study of the influence of the different extrusion conditions on the physicochemical and digestive properties of extruded gluten-containing (wheat) and gluten-free (rice) flours. Continuous innovation in foodstuff and their higher quality requirements force food industry to look for flours with new specific functionalities. The first two objectives of this thesis were to modify wheat flour functionality by using extrusion. This treatment significantly affected hydration, emulsifying, thermal and pasting properties of wheat flours besides their susceptibility to enzymatic hydrolysis and their amount of resistant starch. Thermal enthalpy decreased as the extrusion severity increased, indicating a higher amount of gelatinized starch. Hydration properties significantly increased, specifically 5-fold water binding capacity and 9-fold swelling compared with untreated wheat flour. These results can be attributed to the high water absorption capacity of gelatinized starch. This hydration ability leads to higher viscosity in cold solution, which might be very interesting for some food applications. Emulsifying capacity and the free sugar content increased in parallel with the extrusion severity. The susceptibility to enzymatic hydrolysis increased, which could indicate that these flours can be good raw materials for the starch conversion industry for the production of maltose or glucose. Nevertheless, this high susceptibility also affected negatively the starch digestion properties, decreasing the amount of resistant starch (RS) as the extrusion severity increased. Within the first two objectives, the study of the modification of the functional properties of rice flour by combining extrusion and size fractionation was also approached, since rice flour is an interesting alternative for developing gluten free products, but its features do not always meet the process requirements. Thus, different extrusion conditions (barrel temperature, feed moisture content and feed rate) were applied to vary the severity of the treatment on the flour constituents. Extrusion and mechanical fractionation of the rice flours modified their behaviour affecting hydration, thermal and pasting features, besides their susceptibility to enzymatic hydrolysis. Specifically, onset and peak temperature increased and gelatinization enthalpy decreased when increasing barrel temperature of the extrusion. Fine flours with stronger extrusion (high temperature barrel) showed the highest susceptibility to enzymatic hydrolysis. Overall, the combination of both physical treatments maybe an attractive alternative for obtaining clean label rice flours with modified features. The severity of the extrusion treatment was also accompanied by an increase in the amount of damage starch and free sugars content, the former contributing to the Maillard reaction, which can affect the luminosity of the flours. In general, results 
suggested that extrusion and fractionation can be an alternative to produce flours with different functional properties, which might be useful in gluten free bread-making.

In the third objective, the different physicochemical properties of extruded flours were exploited to study the effect of their incorporation in intermediate products during processing, such as pastes, gels and batters for coating. The first intermediate products to be studied were flour-marine hydrocolloids composed pastes and gels. Extruded and native wheat flours were combined with agars (Gracilaria and Gelidium) and carrageenans (k-carrageenan and i-carrageenan) to modify their paste and gel properties. Combinations of extruded flours with hydrocolloids produced an increase in the hydration properties (swelling volume and water holding and water binding capacities). All hydrocolloids (particularly i-carrageenan) also produced an increase in hydration properties after combination with native flours. With regard to the pasting properties of native flours combinations, all hydrocolloids produced an increase in peak viscosity (particularly Gelidium agar), but only agars decreased the onset temperature of gelatinization and increased breakdown, indicating a different mechanism of action. Agars would create bonds with solubilized/leached (primarily amylose) molecules, with a lower onset temperature of gelatinization, and no increase in amylose retrogradation in comparison with controls. Furthermore, the presence of agar could assist swelling of the granule, as indicated by the increase in PV and BR. On the other hand, carrageenans would create associations with gluten proteins and could not create bonds with solubilized/leached (primarily amylose) molecules, evidenced by the absence both of a decrease in the onset temperature of gelatinization and of final viscosity. In the presence of extruded flour, the incorporation of hydrocolloids increased the cold viscosity of flours in very different ways depending on the hydrocolloid. Added to that, both native and extruded flours exhibited higher G' and G" values and a lower $\tan \delta$ after the incorporation of carrageenans, which, together with the lower dependence on frequency, would produce stiffer and more stable pastes/gels. Based on gel properties, greatest hardness with native and extruded flours was achieved by the incorporation of carrageenans. In general, carrageenans, besides producing stiffer and more stable pastes, gave rise to harder and clearer gels compared to those made with agar, for both their combination with extruded and native wheat flours. Meanwhile, pastes made with combinations of extruded flours and agar showed higher thixotropy. In general, results suggested that carrageenans, besides producing stiffer and more stable pastes, give rise to harder and clearer gels compared to those made with agar, both for their combination with extruded and native wheat flours. Meanwhile, pastes made with combinations of extruded flours and agar could be a good option due to their greater thixotropy, which could be beneficial when making of sauces. 
The second intermediate product studied was batters for coating. One of the most crucial parameters of batter coatings is their viscosity and rheological properties. The effect of 7.5 and $15 \%$ of substitution of native wheat flour by wheat flour subjected to different extrusion conditions on the rheological and thermal properties of batters was investigated. The higher amount and severity of the extrusion process of extruded flours, the higher consistency coefficient and pseudoplasticity of batters. This indicates an important increase of the apparent viscosity of the batters for coating, especially when extruded flour is subjected to a severe treatment. Those changes were attributed to the diminution of the water content as a consequence of the high water absorption capacity of gelatinised starch and of unfolded proteins of extruded flour. With regard to the mechanical spectra, the dynamic moduli increased (at $20^{\circ} \mathrm{C}$ ) and decreased (at $80^{\circ} \mathrm{C}$ ) with the severity of the extrusion treatment of the extruded flour with $15 \%$ wheat flour replacement. In addition, structural changes that took place during the cooking process of batters revealed a delay in the onset temperature as well as higher gelatinization temperatures with the use of flour 3 (that subjected to the strongest extrusion conditions). These structural changes that take place during the cooking process of batters would indicate an effect of extrusion on starch gelatinization and on gelation properties of gluten of wheat flours. A $15 \%$ of wheat flour replacement by wheat flour subjected to different extrusion treatments would offer batters with different viscosities and viscoelastic properties increasing the range of batters coatings available in the market.

The fourth specific objective approaches the effect of the addition of extruded flour subjected to different extrusion conditions on gluten containing and gluten-free breads. In this way, the effect of extruded flours on dough rheology and bread quality was assessed. Extruded wheat flours, due to their increased water absorption capacity, constitute an opportunity to increase bread output in bakery production. However extrusion may modify dough and bread characteristics. The aim of the first study within this objective was to investigate the effect of the substitution of $5 \%$ of the wheat flour by extruded wheat flour (produced with different time-temperature extrusion treatments) on dough mixing, handling and fermentation behaviour and bread volume, shape, texture and colour. The RVA curves indicate that extrusion intensity increases with increasing temperature or water content. Water absorption capacity rises with increasing treatment intensity, but dough stability tends to decrease. Adding extruded flours decreases dough extensibility but increases tenacity and gas production. Differences in dough structure were observed on photomicrography, though there were no clear differences in bread quality. These results indicate that it is possible to obtain adequate dough and bread characteristics using dough with $5 \%$ extruded wheat flour. The addition of $5 \%$ extruded wheat flour allows the quantity of water in the formulation to be increased; the more intense the extrusion treatment, the greater the increase in the quantity of water that can be added. This will increase bread output. 
The effect of the addition of extruded gluten-free flours was also studied in the fourth objective. The extrusion may improve coeliac bread quality by modifying the functional properties of flour. This study investigates the influence of the substitution of $10 \%$ of rice flour by extruded rice flours (three intensities of treatment and two particle sizes) on the characteristics of gluten-free bread (specific volume and texture) at constant consistency. The microstructure and rheology of the doughs obtained and their behaviour during fermentation have also been analysed. The extruded flours increase dough consistency, and the effect is more noticeable with increasing intensities of treatment. The use of extruded flours requires the addition of a larger volume of water to obtain a constant consistency. The addition of extruded flour decreases dough development, producing a lower specific volume and greater bread hardness. This effect is minimized by increasing the particle size. The staling of bread from 24 to $72 \mathrm{~h}$ is less noticeable with a larger particle size. Therefore, the use of extruded flours in the elaboration of gluten-free bread offers an interesting alternative approach to improve gluten-free breads. The bakery yield is increased. However, their addition reduced the specific volume of breads and increased hardness, but these effects were minimized by using the coarse flour fractions, which also reduced the rate of staling. Moreover, due to the fact that one of the main problems with gluten-free breads is their texture and their rapid staling, the influence of different enzymes (one protease, one lipase and two amylases) and of extruded rice flour on ricebread texture and texture development was studied. For this purpose, the development of firmness, cohesiveness, resilience, springiness and chewiness was modelled and the parameters that define the initial values and the development of these characteristics were measured. The addition of lipase and extruded flour increased bread volume and reduced the initial firmness and hardening of breads. There was an early fall in cohesiveness and resilience, with minimum values reached a few days after elaboration. There were $99.9 \%$ significant correlations between bread density and firmness, springiness and chewiness development. The addition of lipases and extruded flour can improve the quality of rice breads by increasing the volume, reducing initial firmness and delaying hardening.

With the aim of exploiting the high susceptibility of extruded flours to the enzyme catalysis, the fifth objective consisted in the study of the enzymatic amylolysis with $\alpha$ amylase and glucoamylase in order to get flours with different functionality and high oligosaccharide content. The effect of two different enzymes, a-amylase and amyloglucosidase, and their combination on microstructure, oligosaccharide content, crystalline order, pasting, gel hydration, and colour properties of native and extruded wheat flours was investigated. Micrographs showed different mechanisms of actuation of the different enzymes on native and extruded flours, achieving greater than $300 \%$ and $500 \%$ increases of glucose and maltose contents, respectively, in extruded flours compared with their native counterparts. Thereby, these flours would be good substrates for fermentative microflora and the main reactants that participate in Maillard and caramelisation thermal reactions. Native flours displayed higher values of water absorption capacity and swelling power than extruded flours. Flours treated by a 
combination of amylase and amyloglucosidase showed low swelling power. Regarding colour, native flours were darker and more reddish than extruded flours, whereas flours treated by amyloglucosidase, and therefore had a higher glucose content, were darker and more reddish.

The last specific objective of this thesis consisted in attenuating the starch digestion properties of extruded matrices through creating resistant structures in the starch from those flours. As it was shown before, extruded flours had a great susceptibility to the enzymatic hydrolysis, which can be exploited to created flours rich in sugars. Nevertheless, from a nutritional point of view, that high susceptibility to the enzymatic hydrolysis can also increase the action of the pancreatic $\alpha$-amylase and therefore declining the digestion properties of those flours. From a nutritional perspective, extruded products and ingredients are characterised by a fast digestion rate. In this study, the effect of an enzymatic treatment with branching enzyme (B) and a combination of branching enzyme and maltogenic $\alpha$-amylase (BMA) on the formation of resistant molecular and supramolecular structures that attenuate the starch digestion properties of maize extruded flours was studied. Moreover, two solvents of different extractability towards sugars (water and ethanol) were employed during treatment. The total carbohydrate release during the enzymatic treatment suggested that extruded flours had a great susceptibility to be modified by the enzymes. The enzymatic treatment itself affected the formation of resistant supramolecular structures on extruded flours by increasing: 1) the long linear amylose chains susceptible to retrograde; 2) the level of short-range molecular order, typical from conformational ordering of amylose or amylopectin side chains; 3) and the amylose-lipid complexes. In particular, the combination of B and MA affected also the fine structure of amylopectin in extruded flours, increasing the number of branching points and the ratio of short chains to longer chains. In addition, the combined BMA treatment increased the amount of panose and isomaltotriose in extruded maize flours. Results therefore suggested the formation of resistant molecular (isomaltooligosacharides, higher number of branching points and ratio of short chains to longer chains in amylopectin) and supramolecular (long linear amylose chains, conformational ordering of amylose or amylopectin side chains and amylose-lipid complexes) structures. These structures could be beneficial in terms of digestibility, since isomaltooligosacharides are categorized as prebiotic, resistant supramolecular structures contribute to the formation of resistant starch and high branched and trimmed amylopectin is the starch molecule associated with slowly digestible starch. Therefore, the combined enzymatic treatment proposed could turn out very useful to manufacture extruded starches, flours or products with attenuate starch digestion properties. Nevertheless, all results were constrained by the type of solvent used in the washing step. In this regard, ethanol was more efficient in terms of keeping isomaltooligosacharides and forming amylose-ethanol complexes, whereas water removed maltose and kept higher the amount of long linear amylose chains and the ratio of short chains to longer chains in amylopectin of extruded flours. 


\section{CONCLUSIONS}




\section{Conclusions}

Down below, the most relevant conclusions obtained from results are described.

- Hydration, thermal, emulsifying and pasting properties of wheat flours besides their susceptibility to enzymatic hydrolysis can be modified by extrusion.

- Starch gelatinization increases with the extrusion severity, augmenting the hydration properties and the viscosity in cold solution of wheat flours, which could be interesting in food processes without availing heat.

- Extrusion also enhances the emulsifying capacity and increases the free sugars of wheat flours, making them suitable for some foodstuff.

- The susceptibility of wheat extruded flours to enzymatic hydrolysis increases, which could indicate that these flours can be good raw materials for the starch conversion industry for the production of maltose or glucose. Nevertheless, this high susceptibility also affected negatively the starch digestion properties, decreasing the amount of resistant starch (RS) as the extrusion severity increased.

- The hydration, thermal and pasting features, besides the susceptibility to enzymatic hydrolysis of rice flours were modified through extrusion and mechanical fraction. The severity of the extrusion treatment is accompanied by an increase in the amount of damage starch and free sugars content, the former contributing to the Maillard reaction, which can affect the luminosity of the flours.

- Hydration ability increases with the extrusion intensity, leading to higher viscosity in cold solution, which might be very interesting for some food applications.

- Fine flours with stronger extrusion shows the highest susceptibility to enzymatic hydrolysis and extrusion process increases that effect. Therefore, extrusion and fractionation can be an alternative to produce flours with different functional properties, which might be useful in gluten free bread-making.

- Agars create bonds with solubilized/leached (primarily amylose) molecules, with a lower onset temperature of gelatinization, and no increase in amylose retrogradation in comparison with controls. Furthermore, the presence of agar could assist swelling of the granule, as indicated by the increase in PV and BR. 
- The carrageenans create associations with gluten proteins and could not create bonds with solubilized/leached (primarily amylose) molecules, evidenced by the absence both of a decrease in the onset temperature of gelatinization and of final viscosity.

- Marked differences are also observed in flour viscosity without heating after the incorporation of distinct hydrocolloids in extruded flours.

- Carrageenans, besides producing stiffer and more stable pastes, give rise to harder and clearer gels compared to those made with agar, both for their combination with extruded and native wheat flours. Meanwhile, pastes made with combinations of extruded flours and agar showed higher thixotropy, which could be beneficial when making of sauces.

- Replacement of native wheat flour by wheat flour subjected to different extrusion treatments causes an important increase of the apparent viscosity of the batters for coating, especially when extruded flour is subjected to a severe treatment. Those changes were attributed to the diminution of the water content as a consequence of the high water absorption capacity of gelatinised starch and of unfolded proteins of extruded flour.

- A $15 \%$ of wheat flour replacement by wheat flour subjected to different extrusion treatments would offer batters with different viscosities and viscoelastic properties increasing the range of batters coatings available in the market.

- The addition of $5 \%$ extruded wheat flour allows the quantity of water in the formulation to be increased; the more intense the extrusion treatment, the greater the increase in the quantity of water that can be added. This will increase bread output. The doughs obtained show adequate behaviour during mixing, handling and fermentation, with no detriment to bread quality.

- The use of extruded flours in the elaboration of gluten-free bread offers an interesting alternative approach to improve gluten-free breads. The bakery yield is increased. However, the addition of extruded flours reduced the specific volume of breads and increased hardness, but these effects were minimized by using the coarse flour fractions, which also reduced the rate of staling.

- The addition of lipases and extruded flour can improve the quality of rice breads by increasing the volume, reducing initial firmness and delaying hardening. Extruded flour can also minimize the loss of cohesiveness and resilience of these 
breads. However, the degrees of cohesiveness and resilience of rice breads are still very low in comparison with those of wheat breads.

- Starch gelatinisation of flour by extrusion increases its susceptibility to enzymatic hydrolysis, thereby achieving flours with a greater content of glucose and maltose, substrates for fermentative microflora and the main reactants that participate in Maillard and caramelisation thermal reactions.

- Resistant molecular (isomaltooligosacharides, higher number of branching points and ratio of short chains to longer chains in amylopectin) and supramolecular (long linear amylose chains, conformational ordering of amylose or amylopectin side chains and amylose-lipid complexes) structures are created in extruded maize flours treated with branching enzyme and maltogenic $\alpha$-amylase. These structures could be beneficial in terms of digestibility, since isomaltooligosacharides are categorized as prebiotic, resistant supramolecular structures contribute to the formation of resistant starch and high branched and trimmed amylopectin is the starch molecule associated with slowly digestible starch. Therefore, the combined enzymatic treatment proposed could turn out very useful to manufacture extruded starches, flours or products with attenuate starch digestion properties.

- The creation of resistant structures to the digestion in extruded maize matrices is constrained by the type of solvent used in the washing step. Thus, the selective modification of flour components should be approached according to the different solvent power of the ethanol-water solutions used during the enzymatic treatment. 